Final Report

Submitted to the Pima County Regional Flood Control District

\title{
Evaluation of Flow and Sediment Models for the Rillito River
}

\author{
Jennifer G. Duan ${ }^{1}$ \\ Anu Acharya ${ }^{2}$ \\ Mary Yaeger ${ }^{2}$ \\ Shiyan Zhang ${ }^{2}$ \\ Monica Salguero ${ }^{2}$
}

Department of Civil Engineering and Engineering Mechanics

The University of Arizona

July 5th, 2008

\footnotetext{
${ }^{1}$ Assistant Professor, Department of Civil Engineering, the University of Arizona, 1209 E. $2^{\text {nd }}$ Street, Tucson, AZ 85721. Email: gduan@email.arizona.edu.

${ }^{2}$ Graduate Student, Department of Civil Engineering, the University of Arizona, same address.
} 


\section{Executive Summary}

Hydrodynamic and sediment transport models are useful engineering tools for predicting flood flow. Many models such as HEC-RAS, HEC-6, IALLUVIAL, SRH-1D were developed for perennial rivers, and may not be suitable to ephemeral rivers in arid and semi-arid regions. This report outlines a comparison study that examined the accuracy of those models by using the observed water surface and bed elevations of a flood event in the Rillito River at Tucson, Arizona. The results of IALLUVIAL2, HEC-RAS, HEC-6, and SRH-1D models were compared with field survey data. Results showed that IALLUVIAL2, which cannot compute bridge effects, predicted a flood stage hydrograph that best matched to the observed data, while HEC-RAS and HEC-6 models also yielded very close matches to the observed data. The SRH-1D model over estimated the peak stage by 1-2 ft. Therefore, IALLUVIAL2, HEC-RAS, and HEC-6 models are all applicable for predicting stage hydrographs.

As to the bed elevation changes, the HEC- 6 model yielded the best results of averaged bed elevation changes comparing to the observed data, while the results from the HEC-RAS model are slightly worse than that from the HEC-6 model. Both the SRH-1D and IALLUVIAL2 models significantly underestimate depositions, and tend to predict scour rather than the observed deposition for this event. These comparisons indicated that both the HEC-6 and HEC-RAS models are suitable for predicting bed elevation changes, however, the results are qualitative not quantitative. The overall RSME is close to $1.0 \mathrm{ft}$. None of the models are accurate for predicting bed elevation changes at the thalweg because these models were not designed for this purpose.

As to the total deposited or eroded sediment volume, none of the model's predictions are close to the observed 176,215 cubic yards of sedimentation. Both the HEC-6 and HEC-RAS models yielded a total deposited volume of about 37,000 cubic yard, far from the observed data. The other two models, IALLUVIAL2 and SRH-1D predicted less than $10 \%$ of the observed deposition and should not be used.

The HEC-6 model, up to now, is the best choice for predicting bed elevation changes and the total eroded/deposited sediment volumes. The HEC-RAS model predicted slightly worse results than the HEC-6 model, but much better results than the SRH-1D model and the IALLUVIAL2 model for sediment transport analysis. 


\section{List of Contents}

Executive Summary ............................................................................. 2

List of Contents ....................................................................... 3

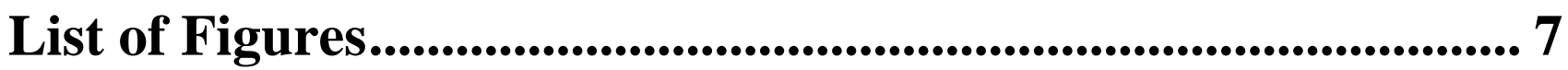

List of Tables ............................................................................. 12

1. Sediment Transport Models......................................................... 13

2. Study Site: The Rillito River ..................................................... 19

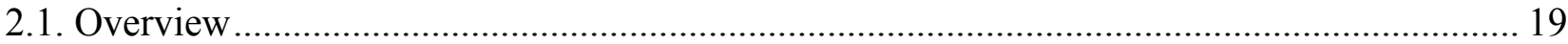

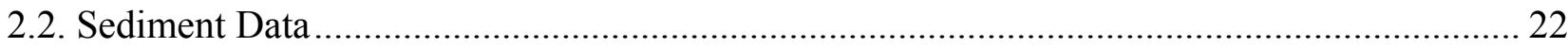

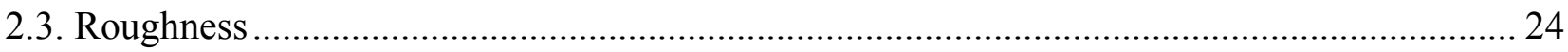

3. Model Parameterization......................................................... 31

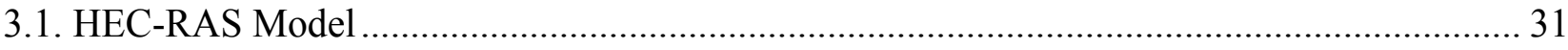

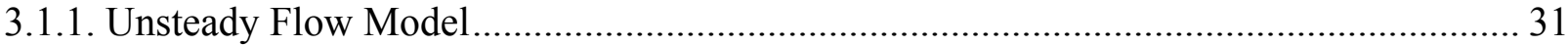

3.1.2. Quasi-unsteady Flow Model ........................................................................................ 32

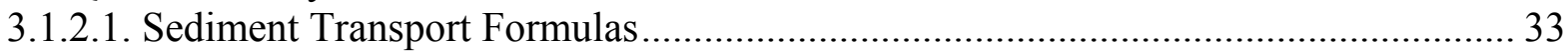

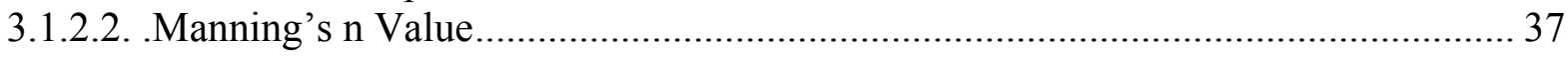

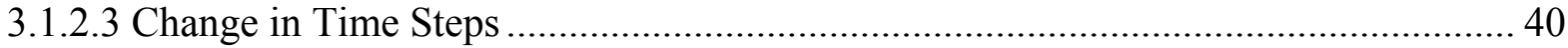

3.1.2.4. Steady vs Unsteady Flow Model ......................................................................... 42

3.1.2.5. Deposited/Eroded Sediment Volume.......................................................................... 43

3.1.2.6. Identification of Best-Performing Sediment Model .................................................. 45

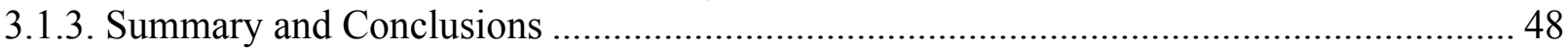

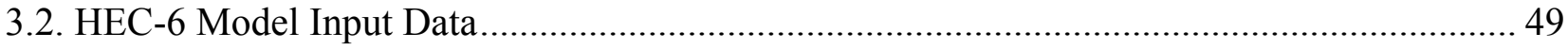

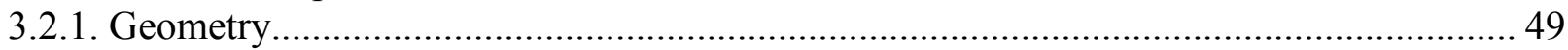

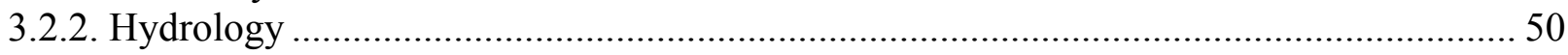

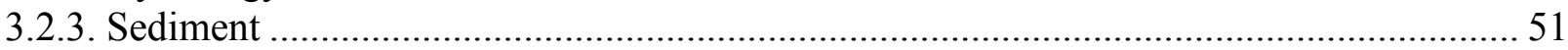

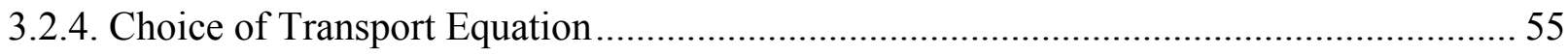

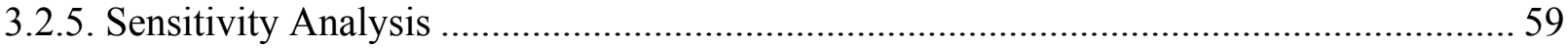

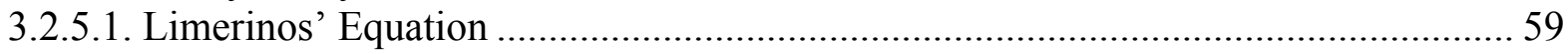

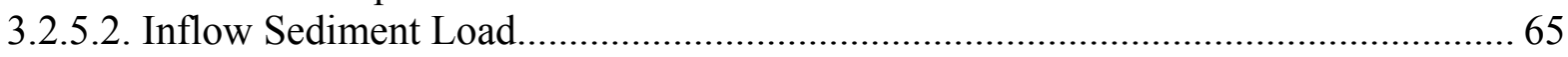

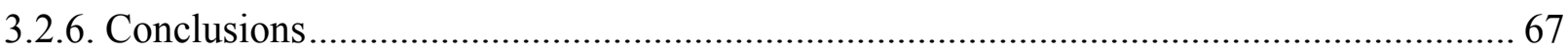

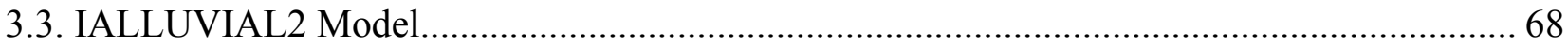

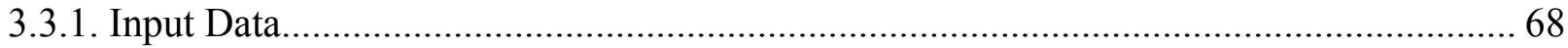

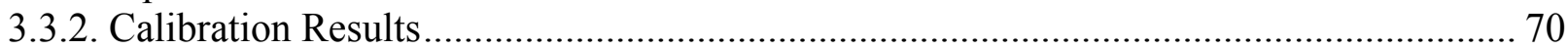

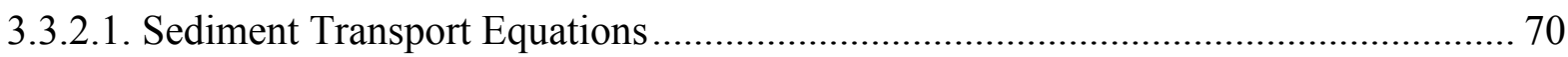

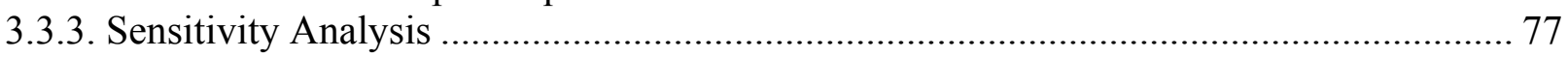

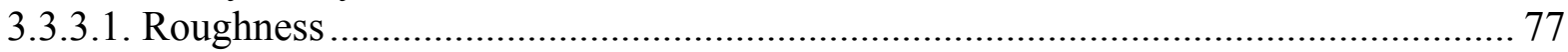

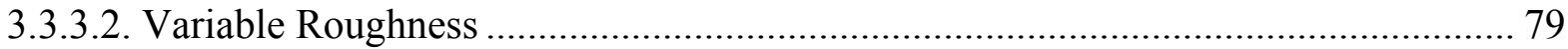

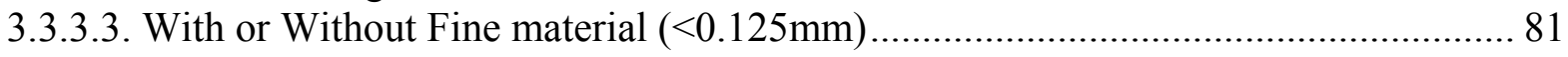

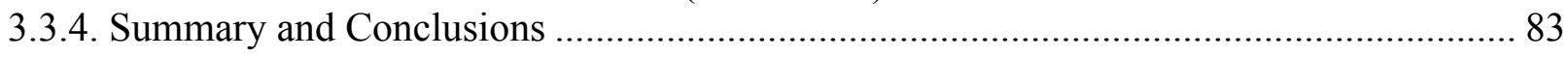




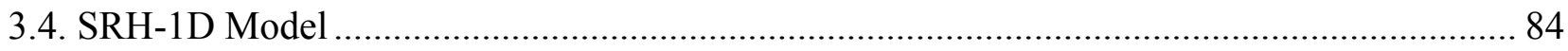

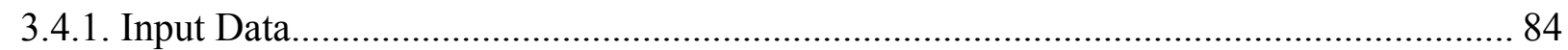

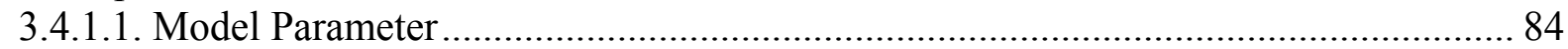

3.4.1.2. Upstream flow boundary condition ................................................................... 84

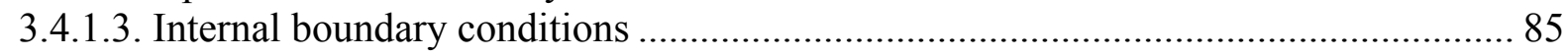

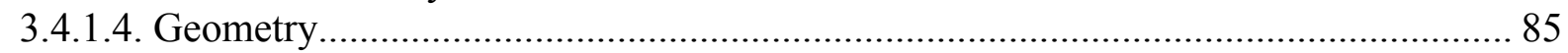

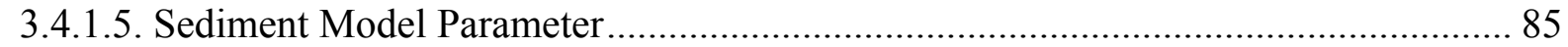

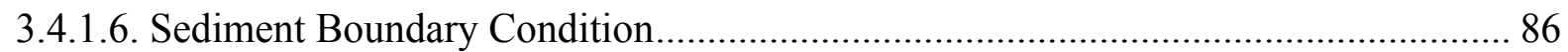

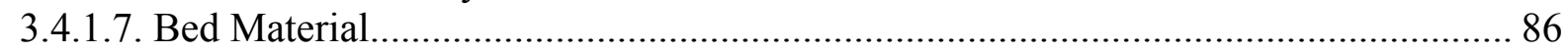

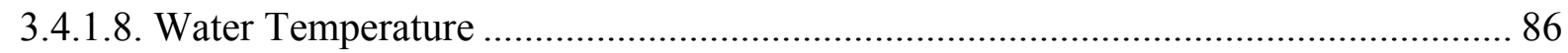

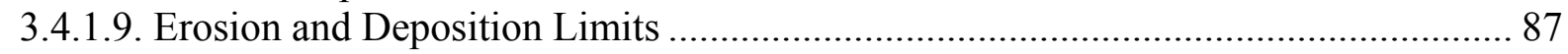

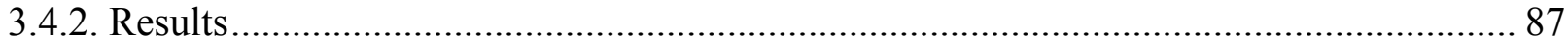

3.4.2.1. Sediment Transport Equations …………………................................................. 87

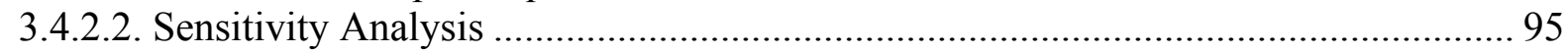

3.4.2.3 Identification of Best-Performing Sediment Model ................................................ 98

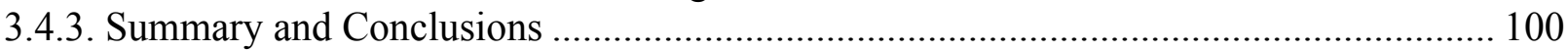

4. Model Comparison............................................................. 102

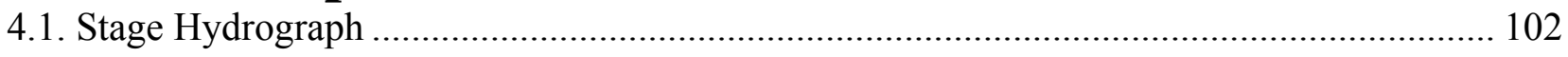

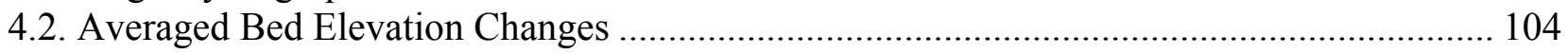

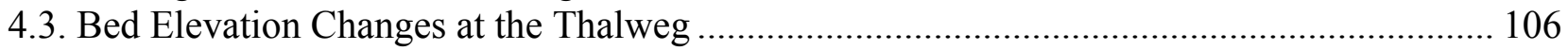

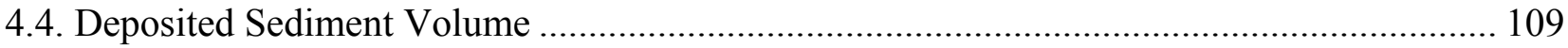

5. Changes of Channel Morphology and Vegetation .............. 111

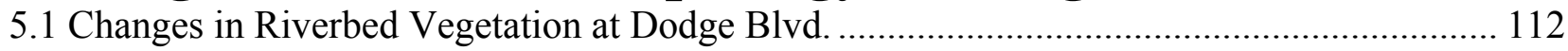

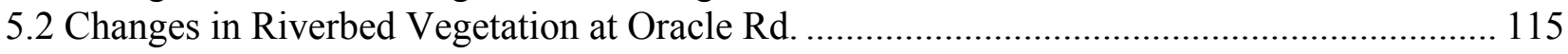

5.3 Changes in Riverbed Vegetation at La Cholla Blvd......................................................... 118

5.4 Changes in Riverbed Vegetation Between La Canada Dr. and La Cholla Blvd..................... 121

6. Conclusion ................................................................................. 125

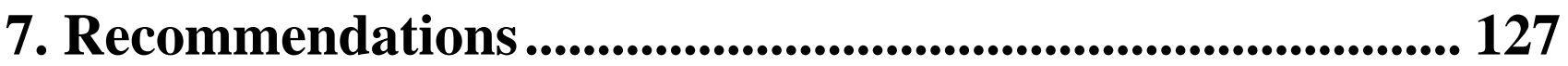

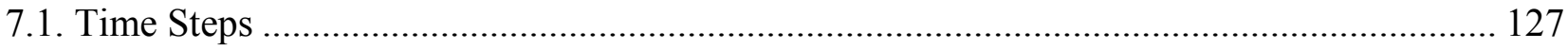

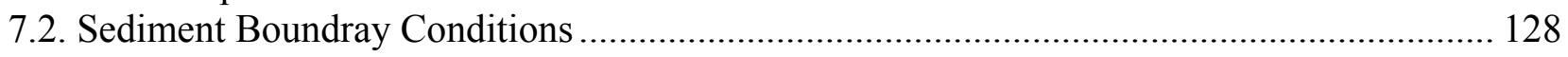

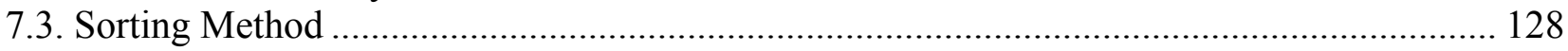

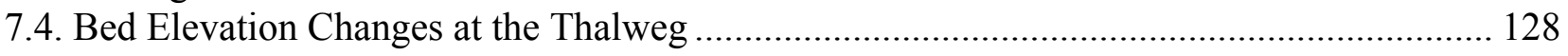

8. Acknowledgements .......................................................... 129

References.................................................................................. 130

Appendix A. HEC-RAS Model .............................................. 133

A.1. HEC-RAS Steady Flow Model - Flow Hydrodynamics ..................................................... 133

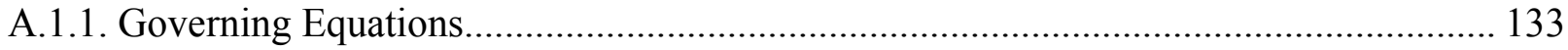

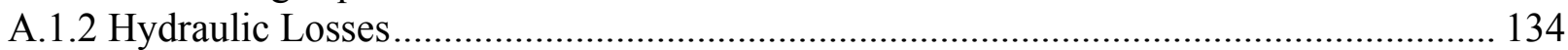

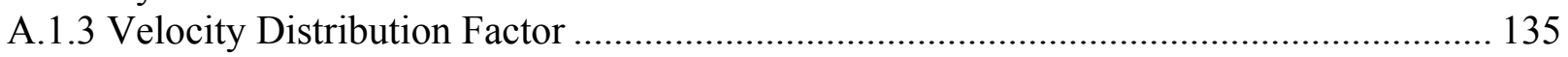

A.1.4 Critical Section Factor, Effective Depth and Effective Width....................................... 135 


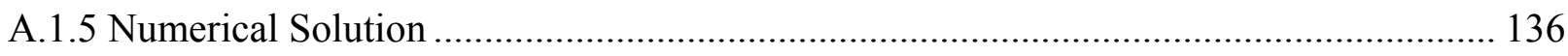

A.2 HEC-RAS Unsteady Flow Model - Flow Hydrodynamics..................................................... 136

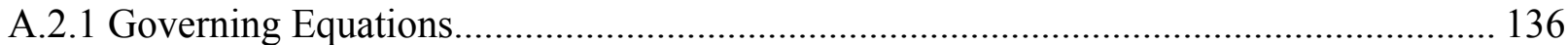

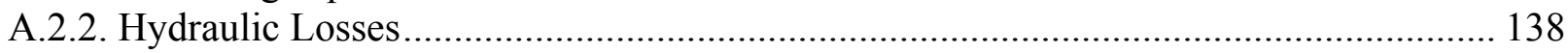

A.2.3. Velocity Distribution Factor ..................................................................................... 139

A.2.4. Critical Section Factor, Effective Depth and Effective Width...................................... 139

A.2.5. Numerical Solution ...................................................................................... 140

A.3. HEC-RAS Quasi-unsteady Flow Model - Sediment Transport............................................. 140

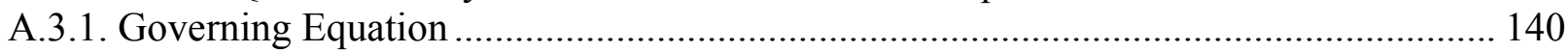

A.3.2. Selection of Fall Velocity Method .......................................................................... 141

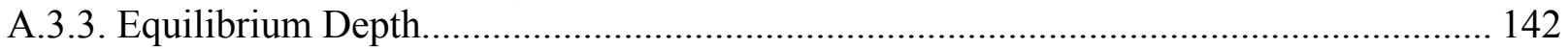

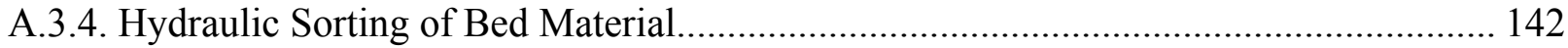

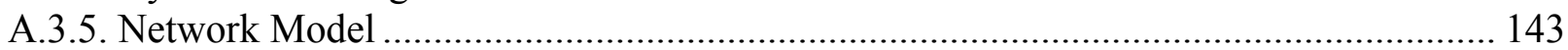

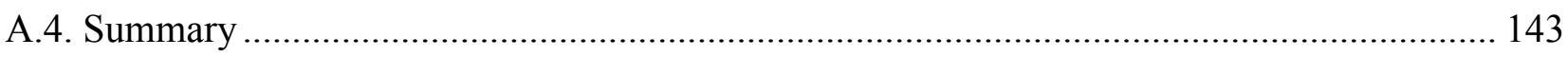

Appendix B. HEC-6 Model .................................................... 145

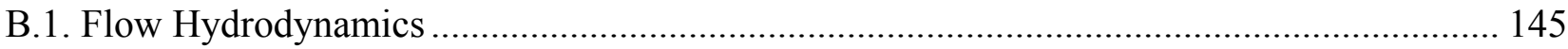

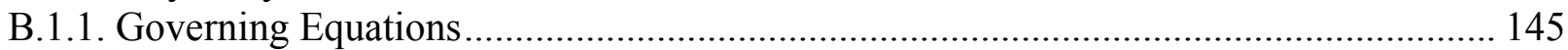

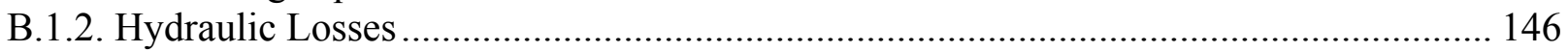

B.1.3. Velocity Distribution Factor.................................................................................... 147

B.1.4. Critical Section Factor, Effective Depth and Effective Width..................................... 148

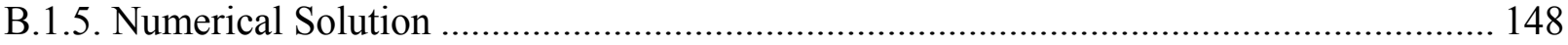

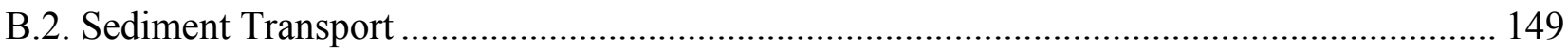

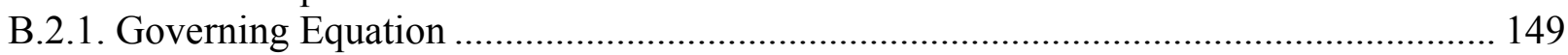

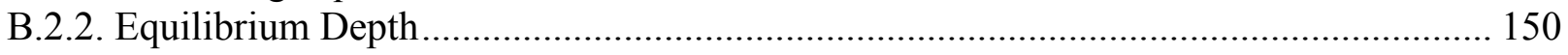

B.2.3. Hydraulic Sorting of Bed Material..................................................................... 150

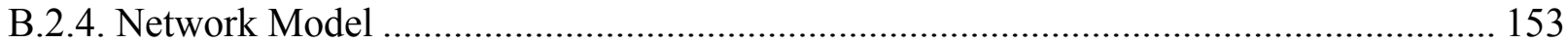

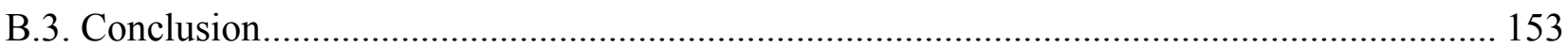

Appendix C. IALLUVIAL2 Model ....................................... 155

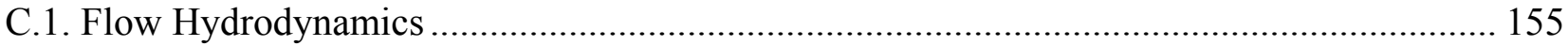

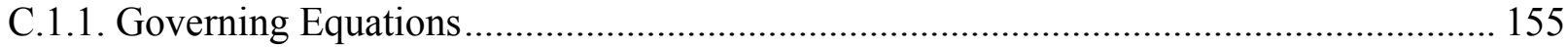

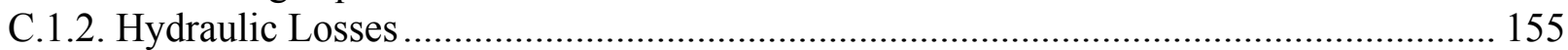

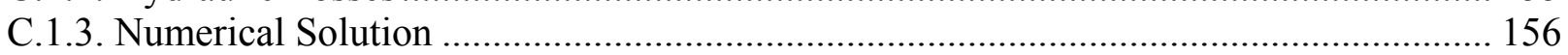

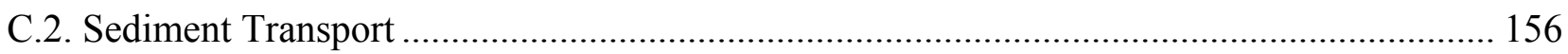

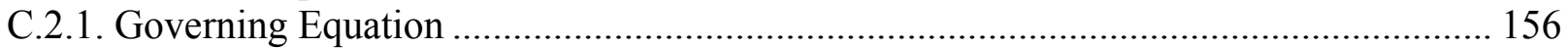

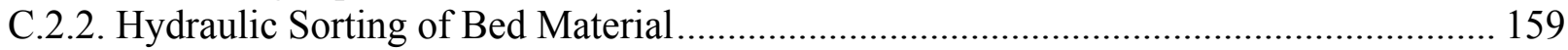

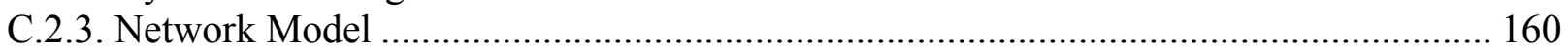

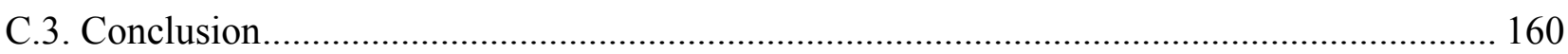

Appendix D. SRH-1D Model.................................................. 162

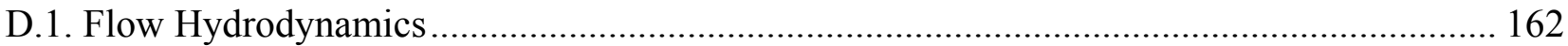

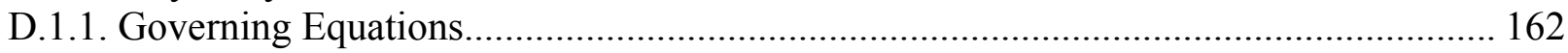

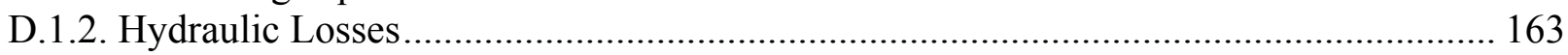

D.1.3. Velocity Distribution Factor ....................................................................................... 164 
D.1.4. Critical Section Factor, Effective Depth and Effective Width................................. 164

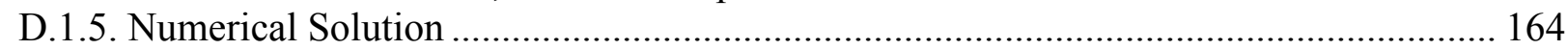

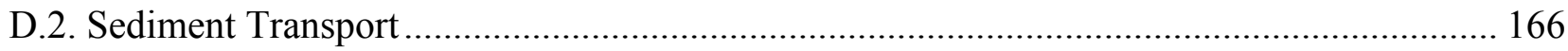

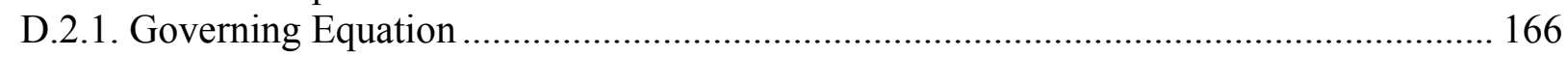

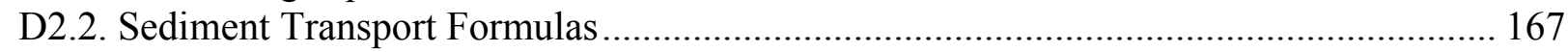

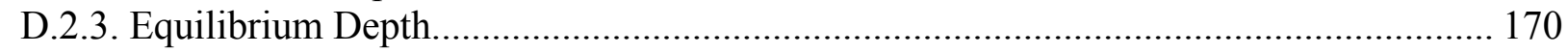

D.2.4. Hydraulic Sorting of Bed Material.......................................................................... 170

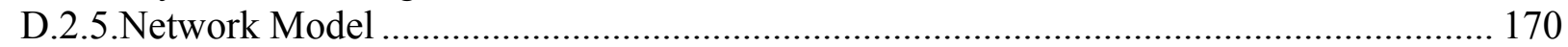

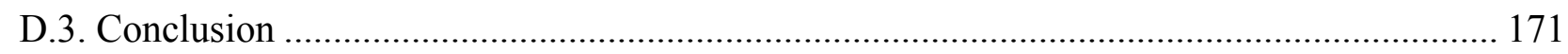

Appendix E: Bed Material Size Distributions ........................ 173

Appendix F. Locations of Cross Sections............................... 177

Appendix G. Changes in Cross Sections ................................. 178 


\section{List of Figures}

Figure 2. 1 Overview of the Rillito River and its Tributaries......................................................... 19

Figure 2. 2. Vegetation and sediment aggradation in the Rillito River ............................................ 19

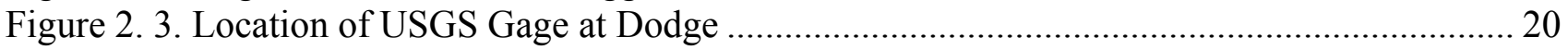

Figure 2. 4. Location of USGS Gage at La Cholla ..................................................................... 20

Figure 2. 5. Observed flow hydrograph at Dodge and La Cholla Gages........................................... 21

Figure 2. 6. Downstream boundary at the weir between I10 East and West bound bridges ............... 22

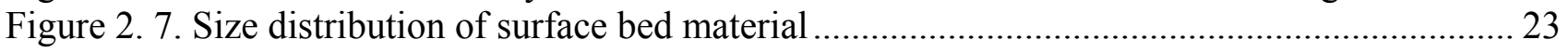

Figure 2. 8. Size distribution of substrate bed material .................................................................. 23

Figure 2. 9. Flow discharge versus flow depth at Dodge.............................................................. 24

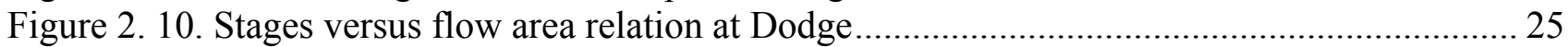

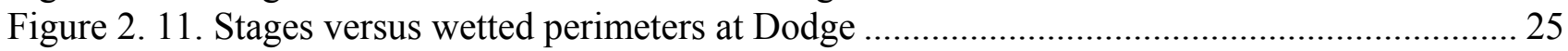

Figure 2. 12. Energy slope variation during the storm at Dodge ..................................................... 26

Figure 2. 13. Manning's roughness coefficient $\mathrm{n}$ varies with discharges at Dodge ........................... 27

Figure 2. 14. Manning's roughness coefficient $\mathrm{n}$ varies with discharges at La Cholla ....................... 27

Figure 2. 15. Roughness variation with discharge considering bed forms at Dodge.......................... 29

Figure 2. 16. Roughness variation with discharge considering bed forms at La Cholla .................... 30

Figure 3. 1. 1. HEC-RAS simulated stage hydrographs at La Cholla using different downstream

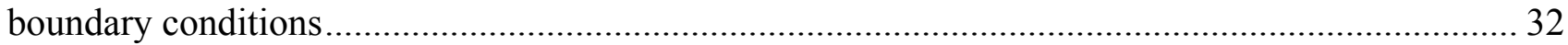

Figure 3. 1. 2. HEC-RAS simulated stage hydrographs at La Cholla using different sediment

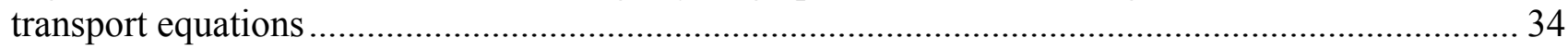

Figure 3. 1. 3. HEC-RAS simulated averaged bed elevation changes using different sediment

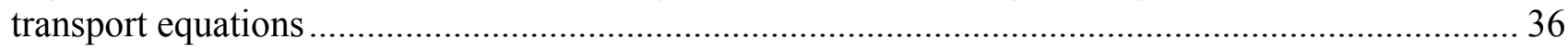

Figure 3. 1. 4. HEC-RAS simulated bed elevation changes at the thalweg using different sediment

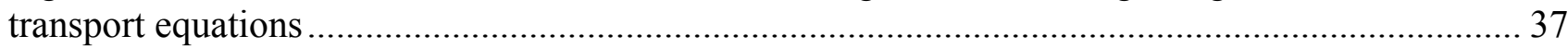

Figure 3. 1. 5. HEC-RAS simulated stage hydrographs at La Cholla using different Manning's $n$

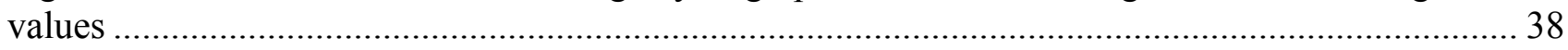

Figure 3. 1. 6. HEC-RAS simulated averaged bed elevation changes using different Manning's n

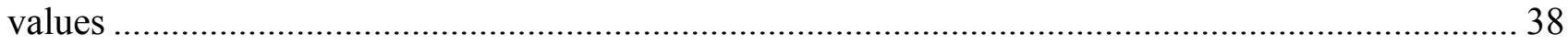

Figure 3. 1. 7. HEC-RAS simulated bed elevation changes at the thalweg using different Manning's

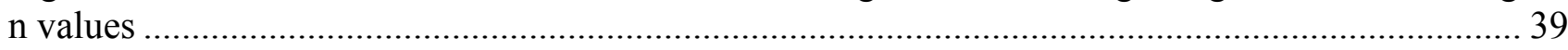

Figure 3. 1. 8. HEC-RAS simulated averaged bed elevation changes using different time steps ...... 41 Figure 3. 1. 9. HEC-RAS simulated bed elevation changes at the thalweg using different time steps

Figure 3. 1. 10. HEC-RAS simulated stage hydrographs at La Cholla using different flow models 43 Figure 3. 1. 11. HEC-RAS simulated cumulative volume change for different sediment transport equations

Figure 3. 1. 12. HEC-RAS simulated cross sectional volume change for different sediment equations

Figure 3. 1. 13. HEC-RAS best performed model for averaged bed elevation change ....................... 46

Figure 3. 1. 14. HEC-RAS best performed model of bed elevation changes at the thalweg.............. 47

Figure 3. 1. 15. HEC-RAS simulated volume changes between bridges for different sediment equations 
Figure 3. 2. 1. Schematic of a bridge cross section with piers ........................................................ 50

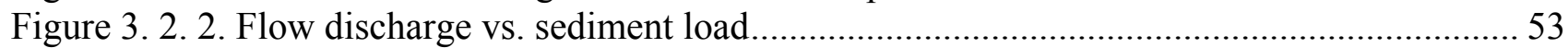

Figure 3. 2. 3. Movable bed material on the river bed............................................................... 54

Figure 3. 2. 4. HEC-6 simulated stage hydrographs at La Cholla using different sediment transport

equations (time step $=15$ min, Limerinos' equation was used) ……….............................................. 55

Figure 3. 2. 5. HEC-6 simulated cumulative volume change for different sediment transport

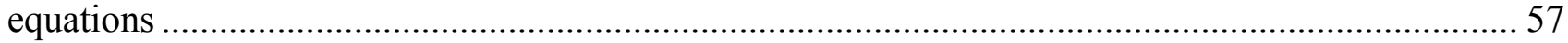

Figure 3. 2. 6. HEC-6 simulated deposited/eroded sediment volumes between bridges at $15 \mathrm{~min}$ time

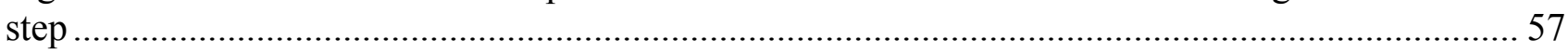

Figure 3. 2. 7. HEC-6 simulated change in channel volume (cu-yd) at 15 min time step.................. 58

Figure 3. 2. 8. HEC-6 simulated bed elevation changes comparing to observed averaged bed change

Figure 3. 2. 9. HEC-6 simulated bed elevation changes comparing to observed bed change at the

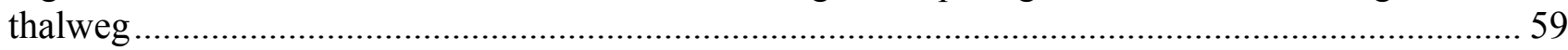

Figure 3. 2. 10. HEC-6 simulated stage hydrographs for sensitivity to the use of the Limerinos'

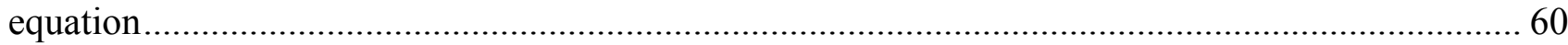

Figure 3. 2. 11. HEC-6 simulated deposited/eroded sediment volumes for sensitivity to the use of the

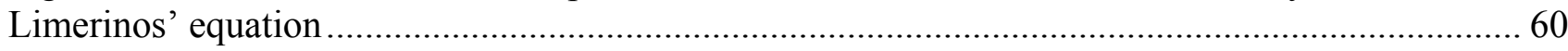

Figure 3. 2. 12. HEC-6 simulated average bed elevation change for sensitivity to the use of the

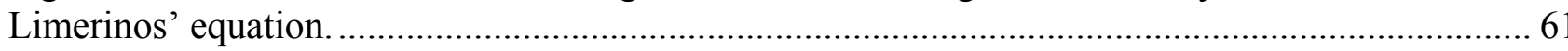

Figure 3. 2. 13. HEC-6 simulated elevation changes at the thalweg for sensitivity to the use of the

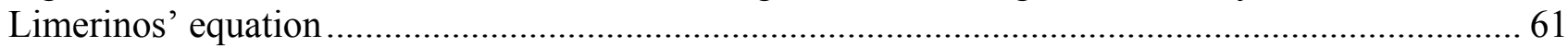

Figure 3. 2. 14. HEC-6 simulated average bed elevation change using different time steps ............ 62 Figure 3. 2. 15. HEC-6 sensitivity to different time steps compared to elevation change at the

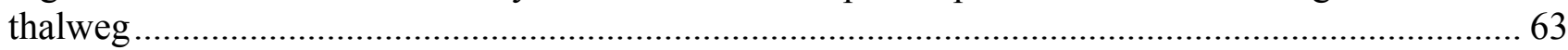

Figure 3. 2. 16. HEC-6 simulated stage hydrograph using different time steps ................................... 63

Figure 3. 2. 17. HEC-6 stage hydrograph using different Manning's coefficients.............................. 64

Figure 3. 2. 18. HEC-6 sensitivity to different Manning's $n$ values compared to average bed

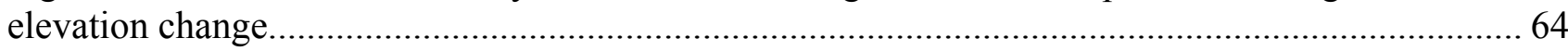

Figure 3. 2. 19. Sensitivity to different Manning's $n$ values compared to elevation change at the

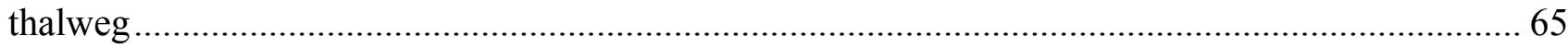

Figure 3. 2. 20. Sensitivity to inflowing sediment curve "Recirculation"...........................................6 66

Figure 3. 3. 1. IALLUVIAL2 simulated stage hydrographs at La Cholla ......................................... 73

Figure 3. 3. 2. IALLUVIAL2 simulated average change in bed elevation....................................... 74

Figure 3. 3. 3. IALLUVIAL2 simulated changes in thalweg elevation.............................................. 75

Figure 3. 3. 4. IALLUVIAL2 simulated deposited/eroded sediment volumes, per mile, between two

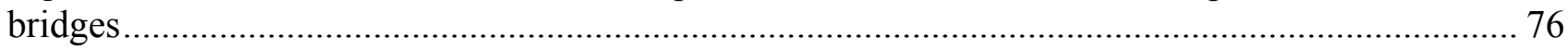

Figure 3. 3. 5. IALLUVIAL2 simulated deposited/eroded cumulative sediment volumes between

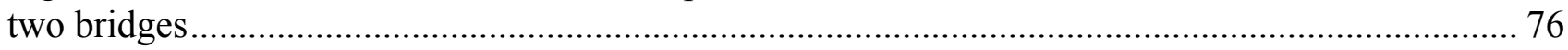

Figure 3. 3. 6. La Cholla Stage Results - Change in Manning's n................................................... 77 Figure 3. 3. 7. IALLUVIAL2 simulated averaged change in bed elevation with change in Manning's

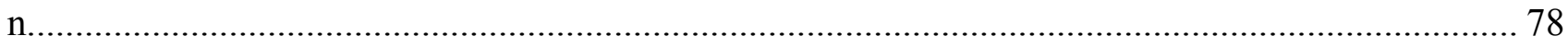
Figure 3. 3. 8. IALLUVIAL2 simulated average change in the thalweg with change in Manning's $n$ 78 
Figure 3. 3. 9. IALLUVIAL2 simulated averaged bed elevation changes using variable roughness 79 Figure 3. 3. 10. IALLUVIAL2 simulated averaged change in bed elevation using variable roughness

Figure 3. 3. 11. IALLUVIAL2 simulated changes at the thalweg using variable roughness ........... 80 Figure 3. 3. 12. IALLUVIAL2 simulated La Cholla stages with change in sediment distribution .... 81 Figure 3. 3. 13. IALLUVIAL2 simulated average change in bed elevation with change in sediment

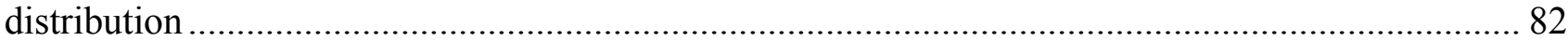

Figure 3. 3. 14. IALLUVIAL2 simulated change in the thalweg elevation with change in sediment

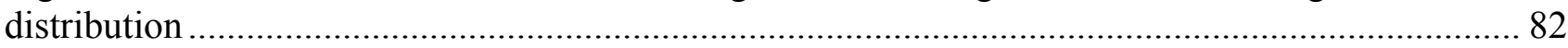
Figure 3. 4. 1. SRH-1D simulated stage hydrographs at La Cholla using Yang73, Engelund, Yang79 Equation 88

Figure 3. 4. 2. SRH-1D simulated stage hydrograph at La Cholla using AckersR, Laursen-Madden and Brownlie Equation .. 88

Figure 3. 4. 3. SRH-1D simulated averaged change in bed elevation using Yang73, Engelund and Yang79 Equation 90

Figure 3. 4. 4. SRH-1D simulated averaged change in bed elevation using Wu, AckersR, LaursenMadden and Brownlie Equation 90

Figure 3. 4. 5. SRH-1D simulated change in the thalweg elevation using Yang73, Engelund and Yang79 Equation 91 Figure 3. 4. 6. SRH-1D simulated change in the thalweg elevation using Wu, revised Ackers-White (1990), Laursen-Madden and Brownlie Equation 91 Figure 3. 4. 7. SRH-1D simulated deposited/eroded sediment volumes using different sediment transport equations

Figure 3. 4. 8. SRH-1D simulated stage hydrograph at La Cholla using different roughness factors 96 Figure 3. 4. 9. SRH-1D simulated change in bed elevation at the thalweg using different roughness factors. 97

Figure 3. 4. 10. SRH-1D Simulated change in averaged bed elevation by different roughness factors

Figure 3. 4. 11. SRH-1D best performing model for averaged stage hydrograph......................... 99

Figure 3. 4. 12. SRH-1D best performing model for averaged bed elevation change..................... 99

Figure 3. 4. 13. SRH-1D best performing model for change of bed elevation at the thalweg ........ 100 Figure 3. 4. 14. SRH-1D best performing model for simulated accumulated volume ................... 100

Figure 4. 1. Comparison of simulated stages at La Cholla by using different models ................... 103 Figure 4. 2. Comparison of simulated averaged bed elevation changes by using different models 106 Figure 4. 3. Comparison of simulated bed elevation changes at the thalweg by using different models 108

Figure 4. 4. Comparisons of simulated deposited sediment volume by using different models ...... 110

Figure 5. 1. 1. Rillito River at Dodge Blvd, 1998 ........................................................... 112

Figure 5. 1. 2. Rillito River at Dodge Blvd, 2002 ................................................................. 113

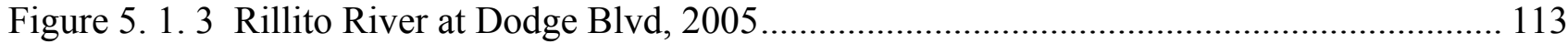

Figure 5. 1. 4. Rilltio River at Dodge Blvd, March 2006 ........................................................ 114

Figure 5. 1. 5. Rillito River at Dodge, March 2007 ............................................................. 114

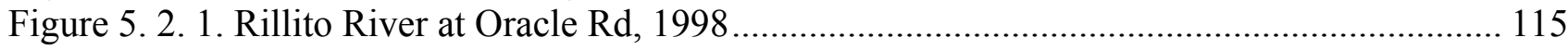

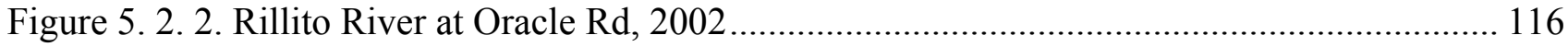




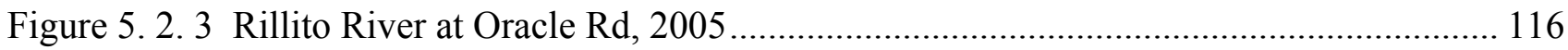

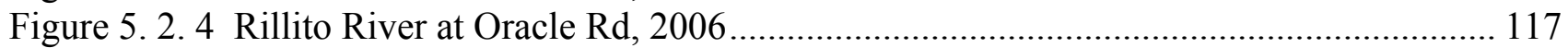

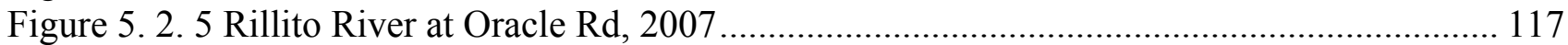

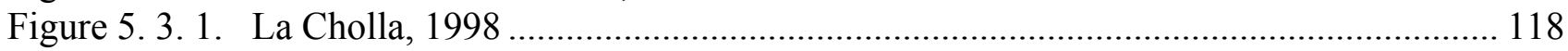

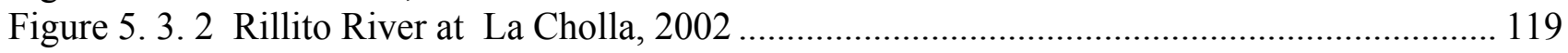

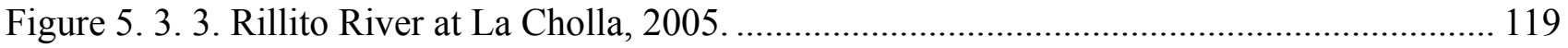

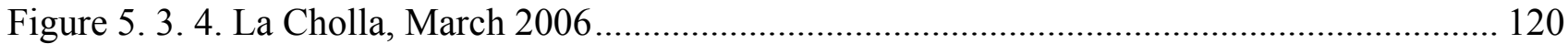

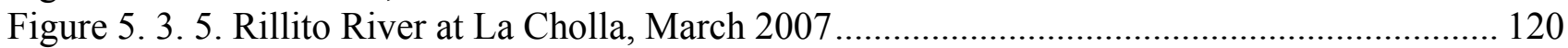

Figure 5. 4. 1. La Canada (right) and La Cholla (far left), 1998 ................................................ 121

Figure 5. 4. 2. La Canada (right) and La Cholla (far left), 2002 ................................................... 122

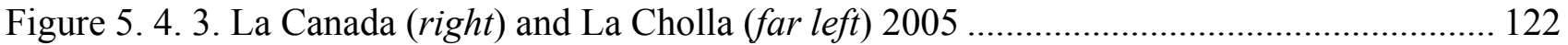

Figure 5. 4. 4. La Canada (right) and La Cholla (far left) March 2006 ........................................... 123

Figure 5. 4. 5. La Canada (right) and La Cholla (far left) April 2007 ............................................ 123

Figure G. 1. Changes of cross sections at River Mile 9.8 and 9.697 …..................................... 178

Figure G. 2. Changes of cross sections at River Mile 9.549 and 9.377 …….................................. 179

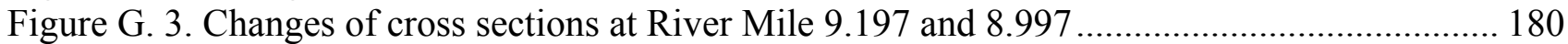

Figure G. 4 Changes of cross sections at River Mile 8.807 and 8.618 ……................................. 181

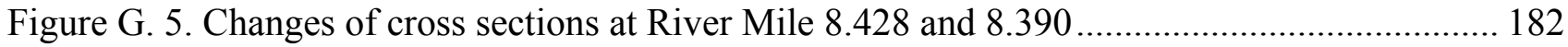

Figure G. 6. Changes of cross sections at River Mile 8.251 and 8.064 ........................................ 183

Figure G. 7. Changes of cross sections at River Mile 7.881 and 7.690 ……….............................. 184

Figure G. 8. Changes of cross sections at River Mile 7.511 and 7.361 ........................................ 185

Figure G. 9. Changes of cross sections at River Mile 7.282 and 7.092 ….................................... 186

Figure G. 10. Changes of cross sections at River Mile 6.912 and 6.837 ........................................ 187

Figure G. 11. Changes of cross sections at River Mile 6.717 and 6.528 …................................... 188

Figure G. 12. Changes of cross sections at River Mile 6.339 and 6.259 ....................................... 189

Figure G. 13. Changes of cross sections at River Mile 6.085 and 5.895 ....................................... 190

Figure G. 14. Changes of cross sections at River Mile 5.757 and 5.683 ....................................... 191

Figure G. 15. Changes of cross sections at River Mile 5.494 and 5.305 ......................................... 192

Figure G. 16. Changes of cross sections at River Mile 5.210 and 5.147 ....................................... 193

Figure G. 17. Changes of cross sections at River Mile 5.021 and 4.926 ...................................... 194

Figure G. 18. Changes of cross sections at River Mile 4.737 and 4.547 ........................................ 195

Figure G. 19. Changes of cross sections at River Mile 4.359 and 4.169 …................................. 196

Figure G. 20. Changes of cross sections at River Mile 4.112 and 4.074 ...................................... 197

Figure G. 21. Changes of cross sections at River Mile 3.885 and 3.695 ........................................ 198

Figure G. 22. Changes of cross sections at River Mile 3.507 and 3.317 ........................................ 199

Figure G. 23. Changes of cross sections at River Mile 3.128 and 3.033 ………………................ 200

Figure G. 24. Changes of cross sections at River Mile 2.964 and 2.874 ....................................... 201

Figure G. 25. Changes of cross sections at River Mile 2.686 and 2.496 ........................................ 202

Figure G. 26. Changes of cross sections at River Mile 2.307 and 2.118 …................................... 203

Figure G. 27. Changes of cross sections at River Mile 1.928 and 1.739 ....................................... 204

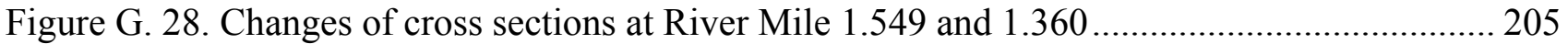

Figure G. 29. Changes of cross sections at River Mile 1.170 and 1.076 ........................................ 206

Figure G. 30. Changes of cross sections at River Mile 0.886 and 0.791 ......................................... 207

Figure G. 31. Changes of cross sections at River Mile 0.785 and 0.701 ......................................... 208 
Figure G. 32. Changes of cross sections at River Mile 0.679 and 0.649........ 


\section{List of Tables}

Table 1. 1. Comparison of Hydraulic Model in HEC-RAS 4.0 and HEC-6 ……............................... 13

Table 1. 2. Comparison of Hydraulic Models in IALLUVIAL 2 and SRH-1D ................................... 14

Table 1. 3. Comparison of Sediment Transport Model in HEC-RAS and HEC-6 ……...................... 15

Table 1. 4. Comparison of Sediment Transport Model in IALLUVIAL 2 and SRH-1D .................... 17

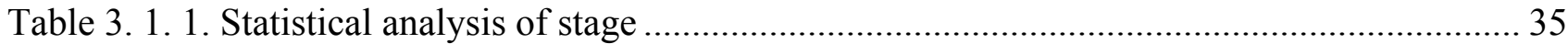

Table 3. 1. 2. Statistical analysis for average bed elevation change at the thalweg ............................ 36

Table 3. 1. 3. Statistical analysis for bed elevation change at the thalweg ..........................................36

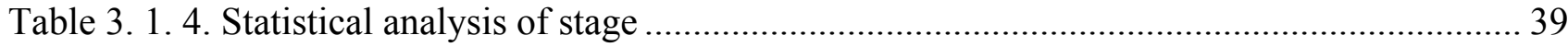

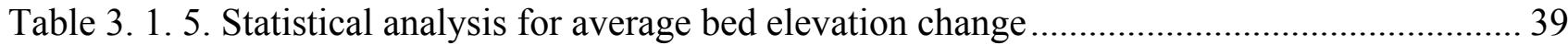

Table 3. 1. 6. Statistical analysis for bed elevation change at the thalweg ........................................ 40

Table 3. 1. 7. Statistical analysis for average bed elevation changes using different time steps........ 40

Table 3. 1. 8. Statistical analysis for the thalweg elevation change using different time steps ........... 40

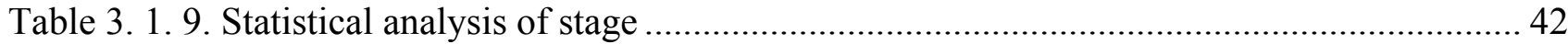

Table 3. 1. 10. Statistical analysis for depositied/eroded sediment volume per mile between the

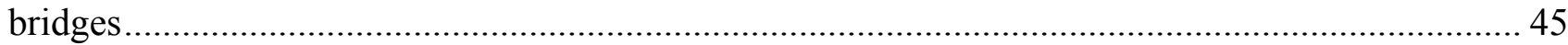

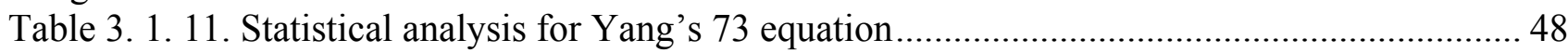

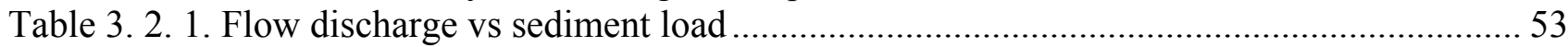

Table 3. 2. 2. Statistical analysis for the bed elevation change …………........................................ 56

Table 3. 2. 3. Statistical analysis for changes in volume between two consecutive bridge cross

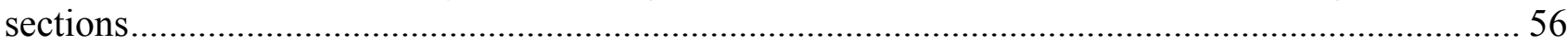

Table 3. 2. 4. Statistical Results for the Sensitivity to the Use of Limerinos' Equation. ........................ 62

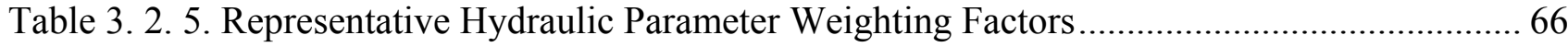

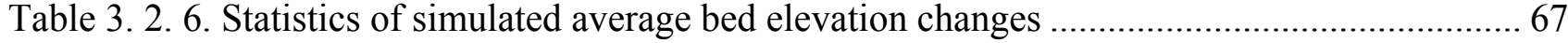

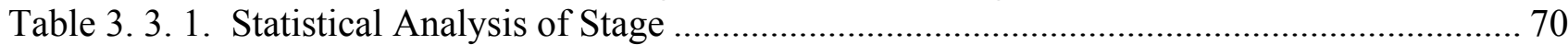

Table 3. 3. 2. Statistical Analysis of Average Change in Bed Elevation........................................... 71

Table 3. 3. 3. Thalweg Elevation Change Statistical Analysis ........................................................... 71

Table 3. 4. 1. Statistics of Modeling Results .................................................................................. 93

Table E. 1. Sediment Size Gradations From Craycroft Roadto I-10 Bridge .................................... 173 


\section{Sediment Transport Models}

Many one-dimensional or two-dimensional models available in the public domain are applicable for simulating flow hydrodynamics and alluvial channel morphodynamic processes (Duan and $\mathrm{Li}, 2003$ ). The public domain models including HEC-RAS, IALLUVIAL, TABS-MD, HEC-6, CCHE2D, ENSED2D, SRH-1D, and CASC2D were developed by various agencies, and can be downloaded online. Other sediment transport models, such as HEC-6T, FLO2D, Mike-21C, Delft2D, etc. are available commercially. Because of the cost of license, this study chose four public domain models: HEC-RAS, HEC-6, IALLUVIAL2, and SRH-1D.

Table 1.1 summarized the methodologies, capabilities, and limitations of the hydraulic models. Table 1.2 summarized the major components of sediment transport models including sediment transport equations, bed material sorting methods, and settling velocity methods. The technical details including governing equations, numerical methods, and parameterizations in the HEC-RAS, HEC-6, IALLUVIAL2, and SRH-1D models are described in Appendix A, B, C, and D, respectively.

Table 1. 1. Comparison of Hydraulic Model in HEC-RAS 4.0 and HEC-6

\begin{tabular}{|c|c|c|c|}
\hline \multirow{2}{*}{ Model } & \multicolumn{2}{|c|}{ HEC-RAS 4.0} & HEC-6 \\
\hline & Unsteady & Quasi-unsteady & Steady \\
\hline Governing Equation & St. Venant Eq. & $\begin{array}{c}\text { Energy Eq. } \\
\text { (momentum equ. for } \\
\text { hydraulic jump) }\end{array}$ & Energy Eq. \\
\hline Hydraulic Loss & friction loss & friction + contraction & friction + contraction \\
\hline Roughness & $\begin{array}{l}\text { composite } \\
\text { roughness with } \\
\text { wetted } \\
\text { perimeters }\end{array}$ & $\begin{array}{l}\text { composite roughness } \\
\text { with wetted perimeters }\end{array}$ & $\begin{array}{l}\text { roughness was } \\
\text { calculated by using } \\
\text { Strickler's equation or } \\
\text { Limerino's equation }\end{array}$ \\
\hline $\begin{array}{l}\text { Velocity distribution } \\
\text { factor }\end{array}$ & weighted & weighted & weighted \\
\hline $\begin{array}{l}\text { Supercritical or } \\
\text { subcritical }\end{array}$ & $\begin{array}{c}\text { sub/super/critical } \\
\text { flow }\end{array}$ & sub/super/critical flow & $\begin{array}{c}\text { sub/super/critical flow } \\
\text { without considering } \\
\text { energy loss }\end{array}$ \\
\hline Channel Network & Yes & Yes & Yes \\
\hline Bridge & Yes & Yes & $\begin{array}{l}\text { by changing cross } \\
\text { sections }\end{array}$ \\
\hline Numerical Solution & $\begin{array}{c}\text { Preissmann } \\
\text { implicit scheme }\end{array}$ & standard step method & standard step method \\
\hline
\end{tabular}


Table 1. 2. Comparison of Hydraulic Models in IALLUVIAL 2 and SRH-1D

\begin{tabular}{|c|c|c|c|}
\hline \multirow{2}{*}{ Model } & \multirow{2}{*}{$\begin{array}{c}\text { IALLUVIAL } 2 \\
\text { Steady }\end{array}$} & \multicolumn{2}{|c|}{ SRH-1D } \\
\hline & & Steady & Unsteady \\
\hline Governing Equation & Energy Eq. & Energy eq. & St Venant Eq \\
\hline Hydraulic Loss & $\begin{array}{l}\text { friction only. both } \\
\text { fixed and variable } \\
\text { friction factors } \\
\text { available. }\end{array}$ & $\begin{array}{c}\text { friction }+ \\
\text { contraction }\end{array}$ & only friction \\
\hline Roughness & composite & composite & composite \\
\hline $\begin{array}{l}\text { Velocity distribution } \\
\text { factor }\end{array}$ & No & yes & $\mathrm{N} / \mathrm{A}$ \\
\hline Supercritical/subcritical & Yes & $\begin{array}{c}\text { only } \\
\text { critical/subcritical } \\
\text { flow }\end{array}$ & subcritical only \\
\hline Channel Network & Yes & Yes & $\mathrm{N} / \mathrm{A}$ \\
\hline Bridge & No & yes & yes \\
\hline Numerical Solution & $\begin{array}{l}\text { standard step } \\
\text { method }\end{array}$ & $\begin{array}{l}\text { standard step } \\
\text { method }\end{array}$ & $\begin{array}{c}\text { Preissmann } \\
\text { implicit scheme }\end{array}$ \\
\hline
\end{tabular}


Table 1. 3. Comparison of Sediment Transport Model in HEC-RAS and HEC-6

\begin{tabular}{|c|c|c|c|c|}
\hline \multirow{2}{*}{\multicolumn{3}{|c|}{ Model }} & HEC-RAS & HEC-6 \\
\hline & & & $\begin{array}{l}\text { Quasi- } \\
\text { Unsteady }\end{array}$ & Steady \\
\hline \multicolumn{3}{|c|}{ Governing Equation } & $\begin{array}{c}\text { Mass } \\
\text { Conservation }\end{array}$ & Mass Conservation \\
\hline \multicolumn{3}{|c|}{ Mobile Bed Roughness } & No & Yes \\
\hline \multirow{2}{*}{$\begin{array}{c}\text { Bed } \\
\text { Material } \\
\text { Sorting } \\
\text { Method }\end{array}$} & \multicolumn{2}{|c|}{ Active Layer: two layer method } & Yes & Yes \\
\hline & \multicolumn{2}{|c|}{ Exner 5: three layer method } & Yes & Yes \\
\hline \multicolumn{3}{|c|}{ Cohesive Sediment } & Yes & $\begin{array}{l}\text { Krone (1962) equation for } \\
\text { deposition; Parthenaides } \\
\text { (1965) equation for scour }\end{array}$ \\
\hline \multicolumn{3}{|c|}{ Viscoisty varies with Temperature } & Yes & Yes \\
\hline \multirow{4}{*}{$\begin{array}{l}\text { Settling } \\
\text { Velocity } \\
\text { Method }\end{array}$} & \multicolumn{2}{|r|}{ Ruby (1933) } & Yes & \\
\hline & \multicolumn{2}{|r|}{ Tofalleti (1968) } & Yes & \\
\hline & \multicolumn{2}{|r|}{ van Rijn (1993) } & & \\
\hline & \multicolumn{2}{|r|}{ Report 12} & Yes & \\
\hline \multirow{12}{*}{$\begin{array}{l}\text { Sediment } \\
\text { Transport } \\
\text { Equations }\end{array}$} & \begin{tabular}{|l|} 
Suspended \\
Load Only
\end{tabular} & $\begin{array}{l}\text { Yang's (1973) stream } \\
\text { power for sands }\end{array}$ & & Yes \\
\hline & \multirow{7}{*}{$\begin{array}{l}\text { Bed Load } \\
\text { Only }\end{array}$} & $\begin{array}{l}\text { Meyer-Peter and Müller } \\
\text { (1948) }\end{array}$ & & Yes \\
\hline & & Bagnold (1960) & & \\
\hline & & Parker (1990) & & \\
\hline & & Wilcock and Crowe (2003) & Yes & \\
\hline & & Einstein-Brown (1952) & & \\
\hline & & Van Rijn (1984) & & \\
\hline & & $\begin{array}{l}\text { Yang's (1984) stream } \\
\text { power for gravel }\end{array}$ & & \\
\hline & \multirow{4}{*}{$\begin{array}{l}\text { Total } \\
\text { Load }\end{array}$} & $\begin{array}{l}\text { Ackers and White (HR } \\
\text { Wallingford, 1990) }\end{array}$ & & \\
\hline & & $\begin{array}{l}\text { Ackers-White (1973) } \\
\text { transport function }\end{array}$ & Yes & Yes \\
\hline & & Brownlie (1981) & & \\
\hline & & $\begin{array}{l}\text { Colby (1964) transport } \\
\text { function }\end{array}$ & & Yes \\
\hline
\end{tabular}




\begin{tabular}{|c|c|c|c|}
\hline \multirow{14}{*}{$\begin{array}{l}\text { Total } \\
\text { Load }\end{array}$} & $\begin{array}{l}\text { Copeland's (1990) } \\
\text { modification of Laursen's } \\
\text { relationship (Copeland and } \\
\text { Thomas 1989) }\end{array}$ & Yes & Yes \\
\hline & $\begin{array}{l}\text { DuBoys' transport function } \\
\text { (Vanoni 1975) }\end{array}$ & & Yes \\
\hline & $\begin{array}{c}\text { Engelund and Hansen } \\
(1972)\end{array}$ & Yes & \\
\hline & Karim-Kennedy (1990) & & \\
\hline & Karim-Kennedy II (1995) & & \\
\hline & Larsen (1958) & & \\
\hline & $\begin{array}{c}\text { Madden's (1985, } \\
\text { unpublished) modification } \\
\text { of Laursen's (1958) } \\
\text { relationship }\end{array}$ & & Yes \\
\hline & $\begin{array}{c}\text { Modification by Ariathurai } \\
\text { and Krone (1976) of } \\
\text { Parthenaides' (1965) } \\
\text { method }\end{array}$ & & Yes \\
\hline & $\begin{array}{l}\text { Madden's (1963) } \\
\text { modification of Laursen's } \\
\text { (1958) relationship }\end{array}$ & & Yes \\
\hline & $\begin{array}{l}\text { Toffaleti's (1966) transport } \\
\text { function }\end{array}$ & Yes & Yes \\
\hline & $\begin{array}{l}\text { Toffaleti (1966) and } \\
\text { Schoklitsch (1930) } \\
\text { combination }\end{array}$ & & Yes \\
\hline & $\begin{array}{l}\text { Toffaleti (1966) and } \\
\text { Meyer-Peter and Müller } \\
\text { (1948) combination }\end{array}$ & & Yes \\
\hline & $\mathrm{Wu}(2004)$ & & \\
\hline & $\begin{array}{l}\text { Yang's (1979) for total } \\
\text { load }\end{array}$ & Yes & \\
\hline & Yang et al (1996) & & \\
\hline
\end{tabular}


Table 1. 4. Comparison of Sediment Transport Model in IALLUVIAL 2 and SRH-1D

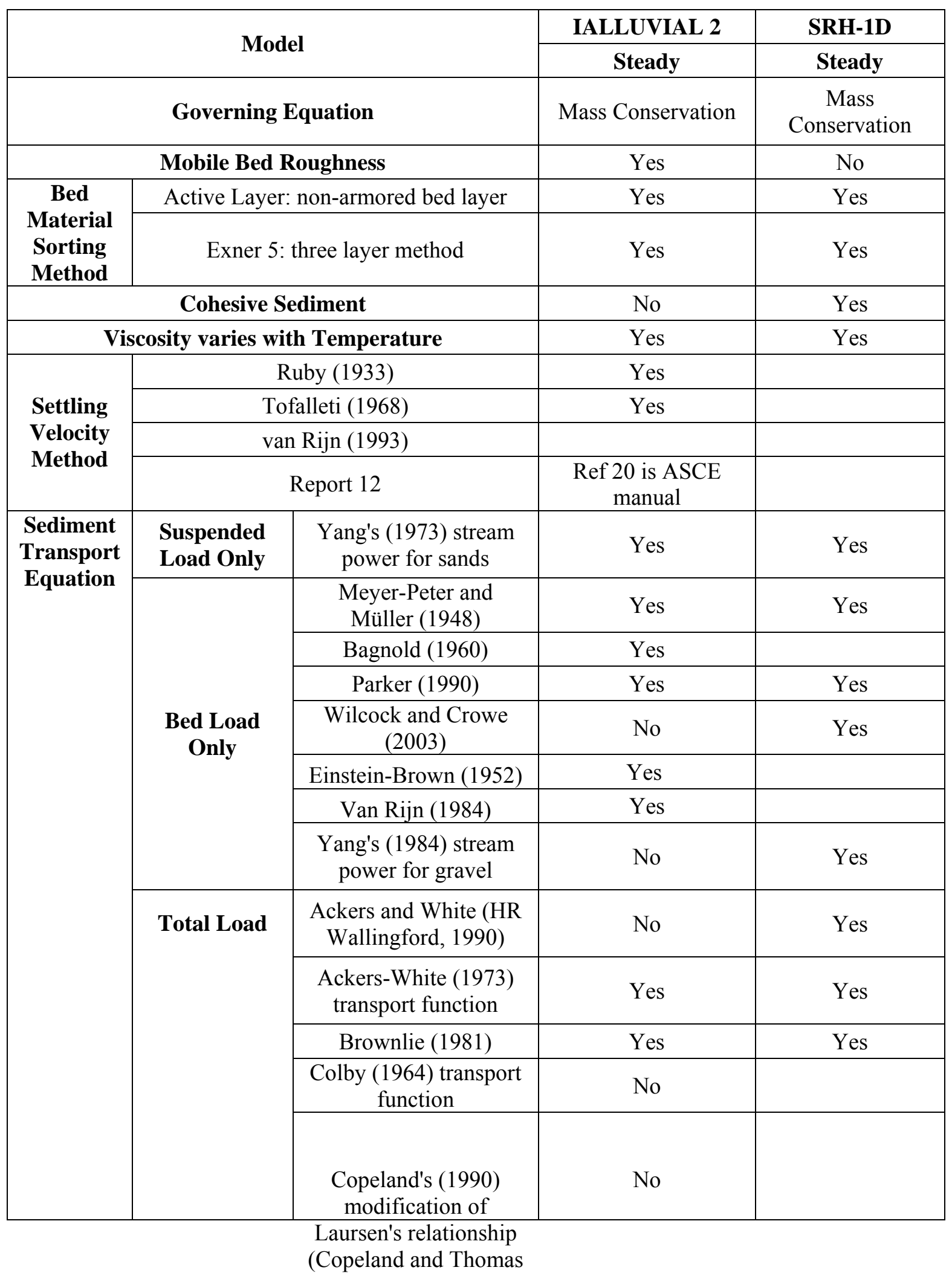




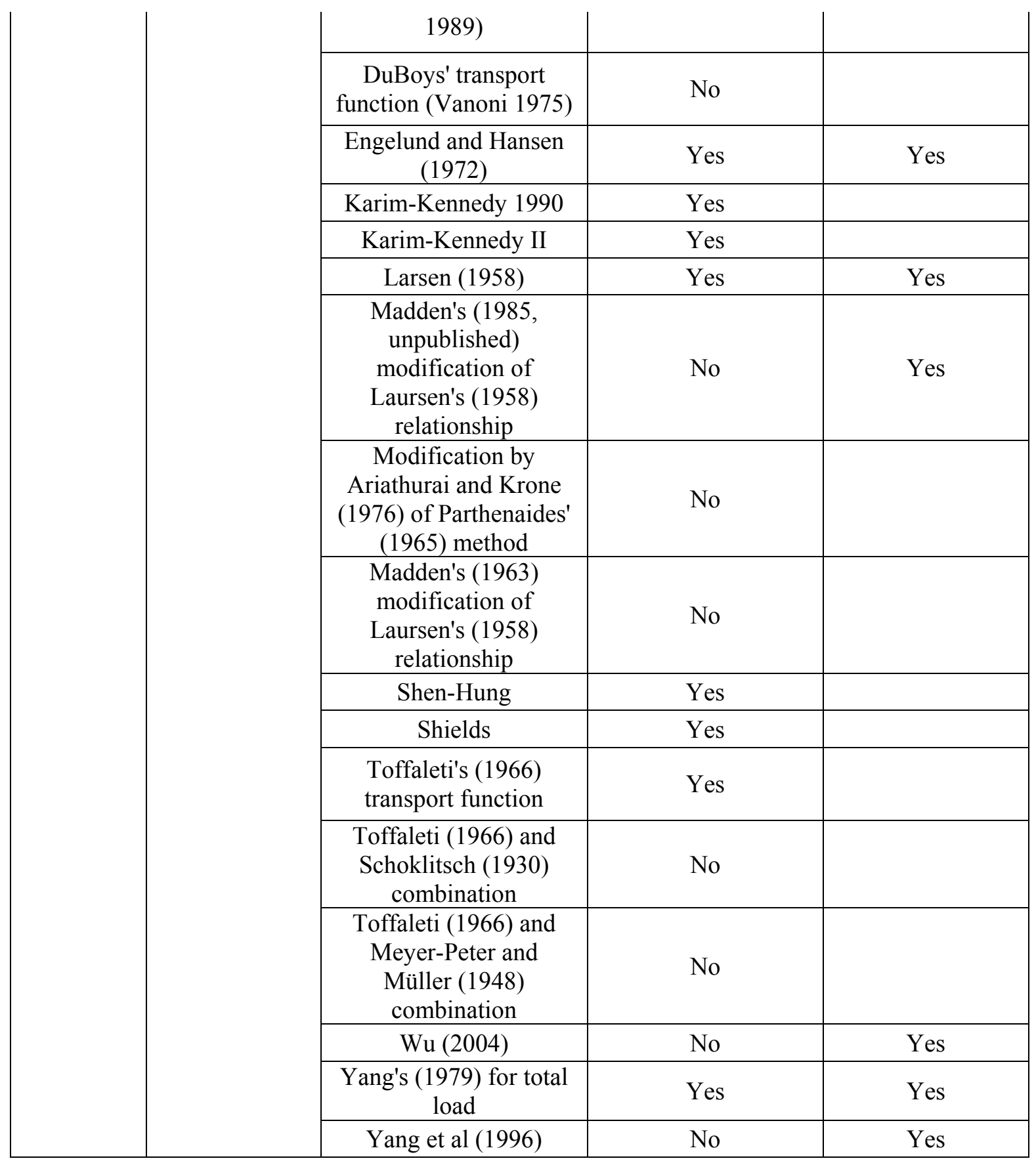




\section{Study Site: The Rillito River}

\subsection{Overview}

The study reach is a reach of the Rillito River from the Dodge Blvd to the I-10 bridges just upstream of the Santa Cruz River. JE Fuller Hydrology and Geomorphology (H\&G) Inc (2006) has documented the recent geomorphic changes with detailed cross sectional survey data obtained in September and October of 2006, respectively. Thalweg profiles and aggradation within cross sections were also analyzed. Numerous photos were included to illustrate sediment depositions at various locations.

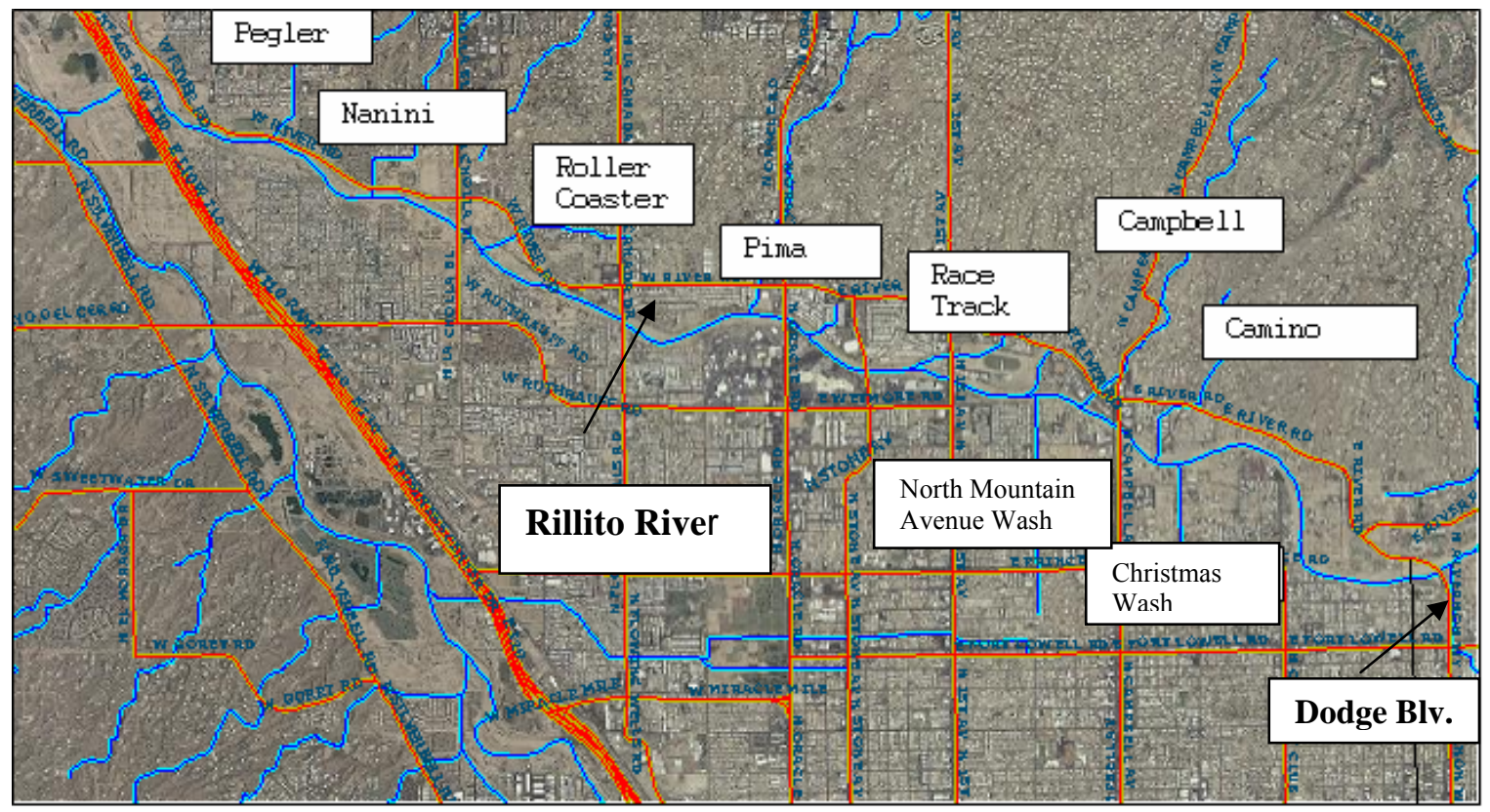

Figure 2. 1 Overview of the Rillito River and its Tributaries

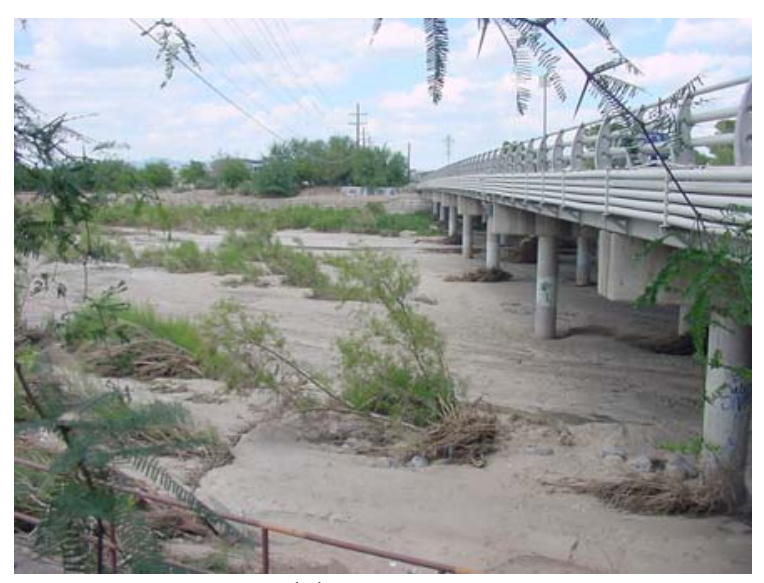

(a)

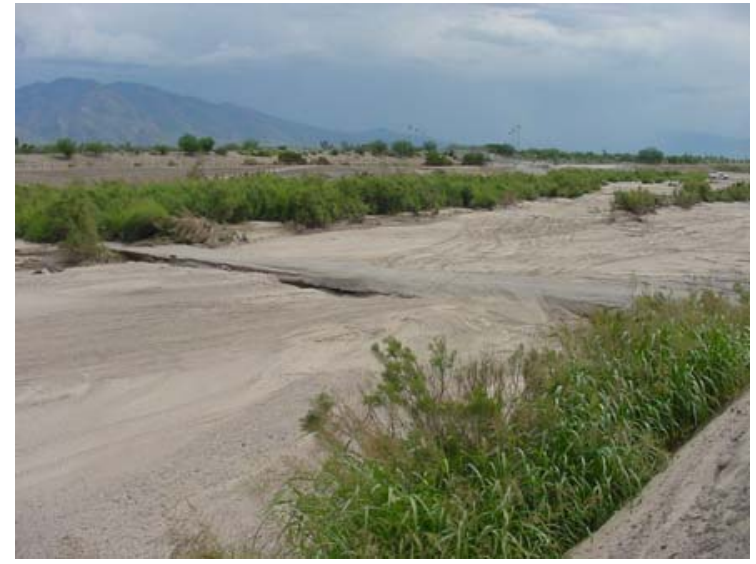

(b)

Figure 2. 2. Vegetation and sediment aggradation in the Rillito River 
Two USGS gages are located in the study reach: one at the Dodge Blvd bridge (Fig.2.3), and the other at the La Cholla bridge (Fig.2.4). Real time records of water surface elevation and discharge were obtained from the USGS. The flow hydrograph for the July, 2006 flood event at the Dodge Blvd bridge was used as the upstream input hydrograph, while the observed hydrograph at La Cholla was used to verify the modeling results.

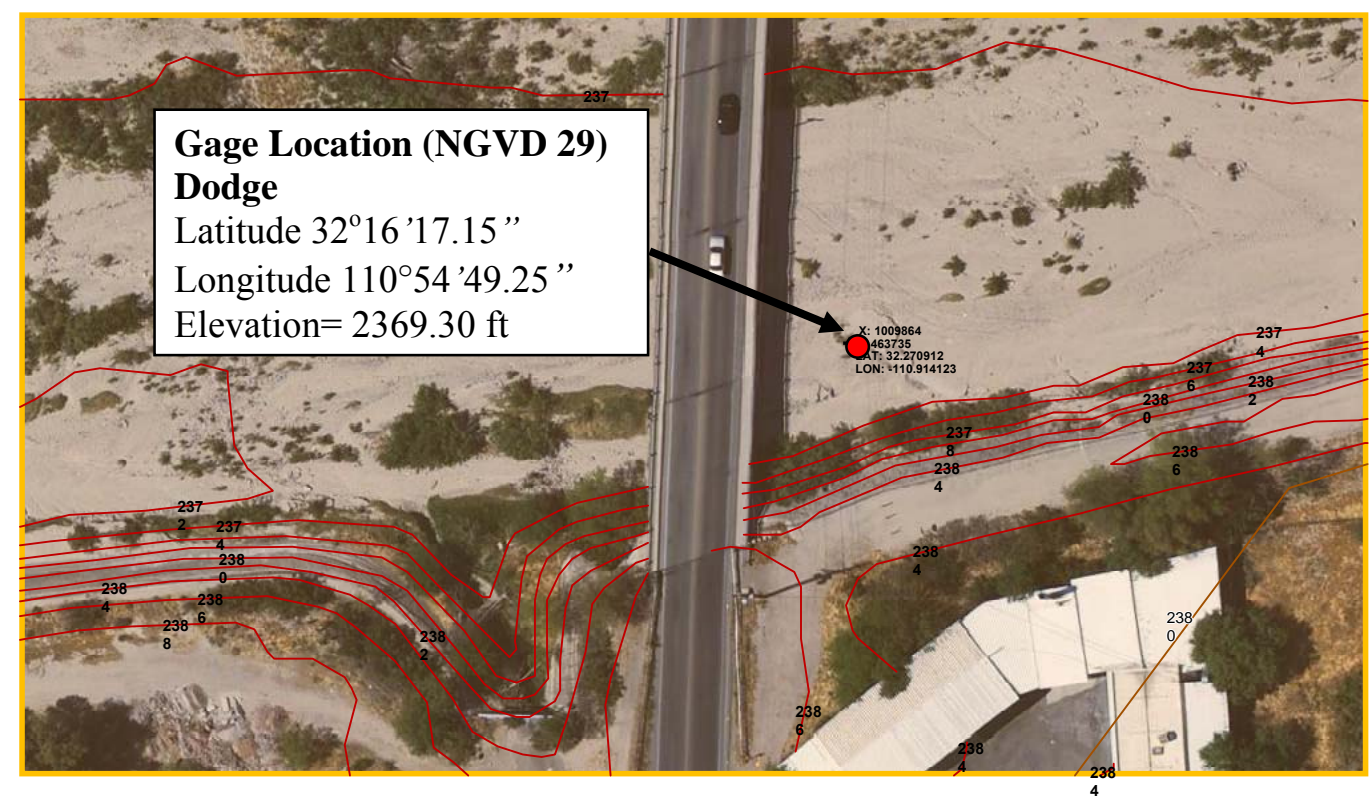

Figure 2. 3. Location of USGS Gage at Dodge

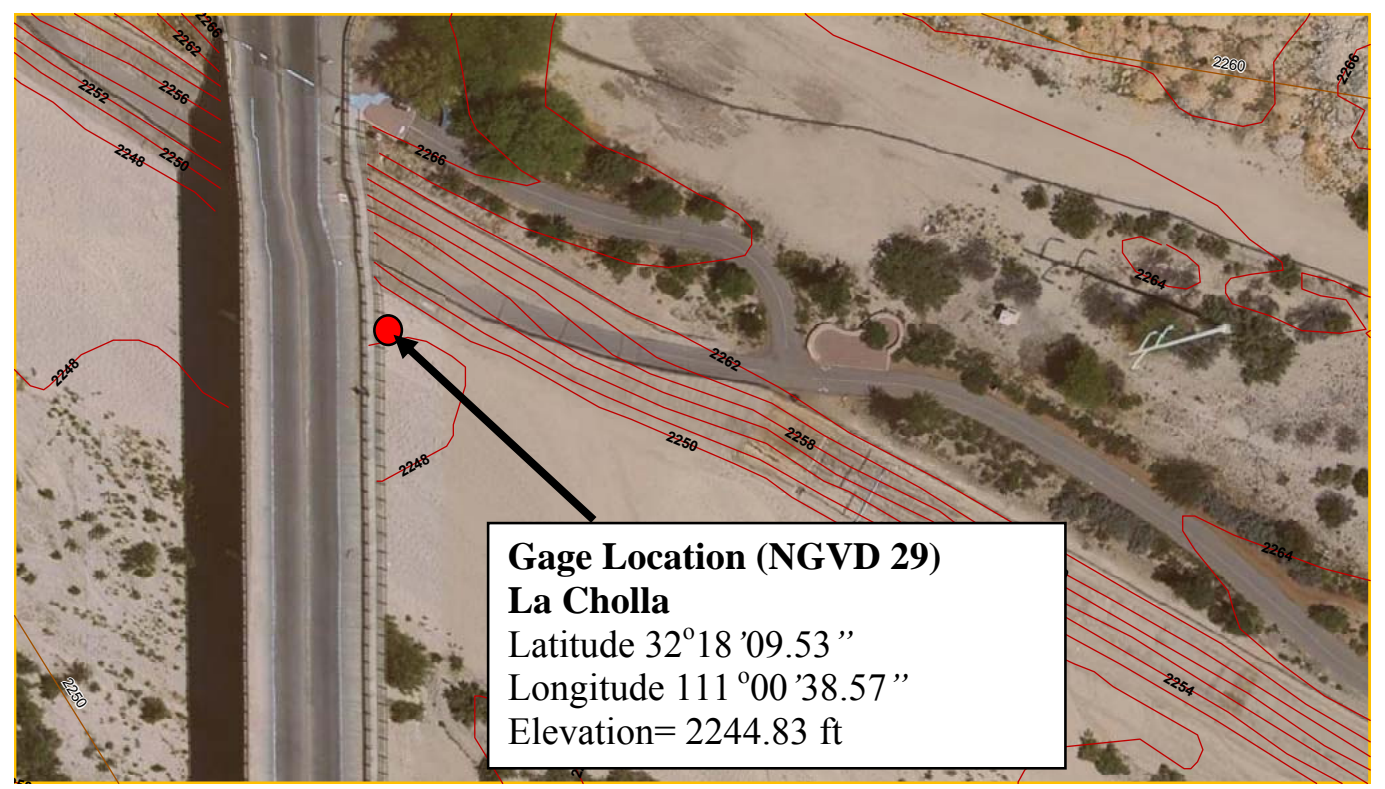

Figure 2. 4. Location of USGS Gage at La Cholla 
The stage hydrographs observed at Dodge and La Cholla gages were plotted in Fig.2.5. The elevations shown in Fig.2.5 are based on the NGVD 29 datum.

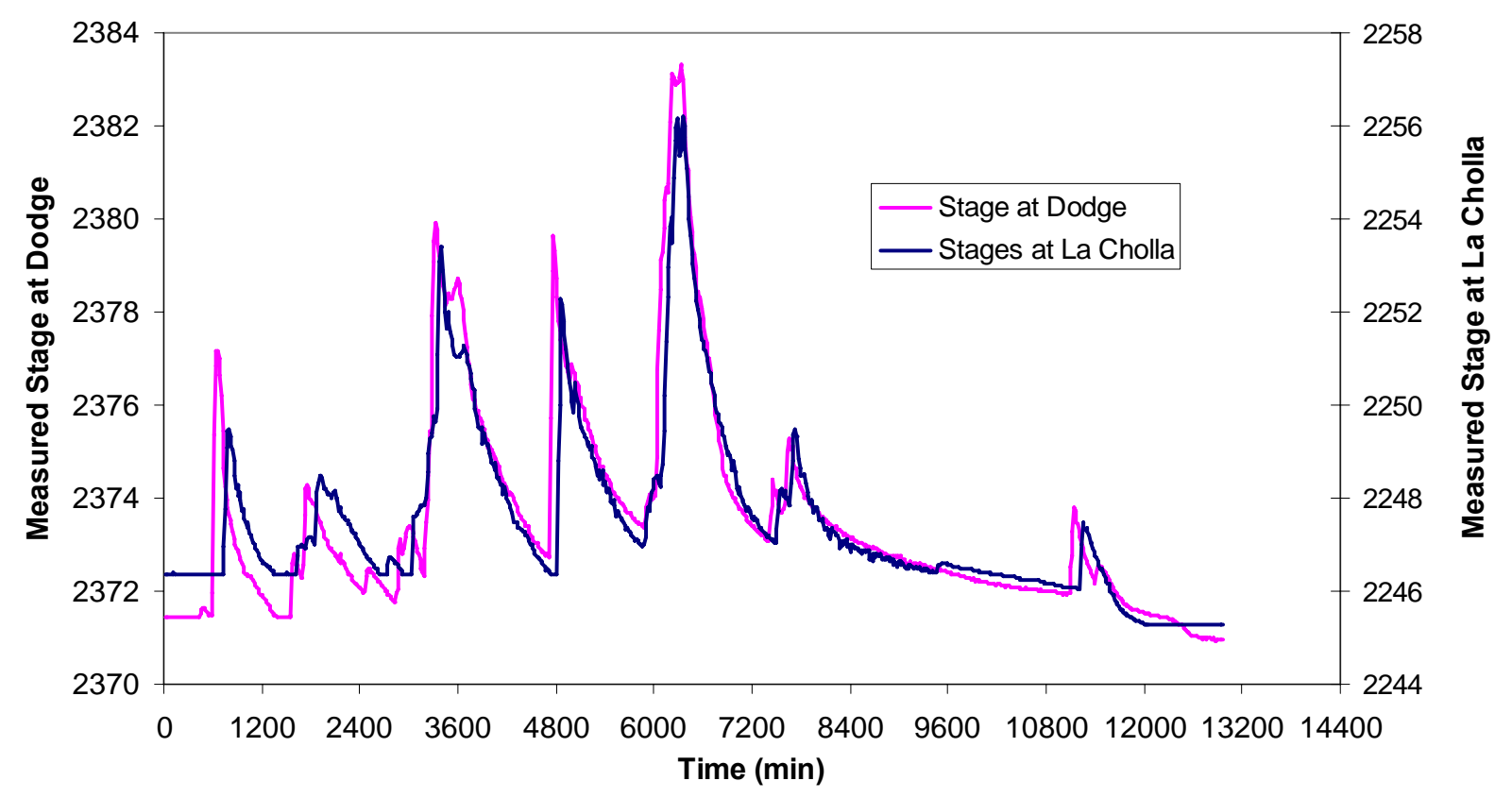

Figure 2. 5. Observed flow hydrograph at Dodge and La Cholla Gages

The study reach is about 10 mile long and was divided into more than 120 subreaches using the pre-flood LOMR cross section data, which were surveyed in 1998 The locations of these cross sections in a map were shown in Appendix F. Typically the distance between two consecutive cross sections is about $100-600 \mathrm{ft}$, and each cross section has about 80 to 200 stations. The upstream flow boundary condition is a flow hydrograph of 15 minutes intervals recorded at the Dodge Blvd bridge gage in Fig.2.5. Equilibrium sediment transport was assumed at the upstream and downstream boundary. The downstream boundary was chosen at a weir between the Eastbound I-10 Frontage Road bridge and the Eastbound I-10 bridge where flow depth was assumed critical. Fig.2.6 has two photos of the weir. Because sediment transport is equilibrium at this downstream cross section the elevation of the weir remains the same during the simulation. The flow hydrograph observed at La Cholla gage as shown in Fig.2.5 was used to verify the simulation results. 


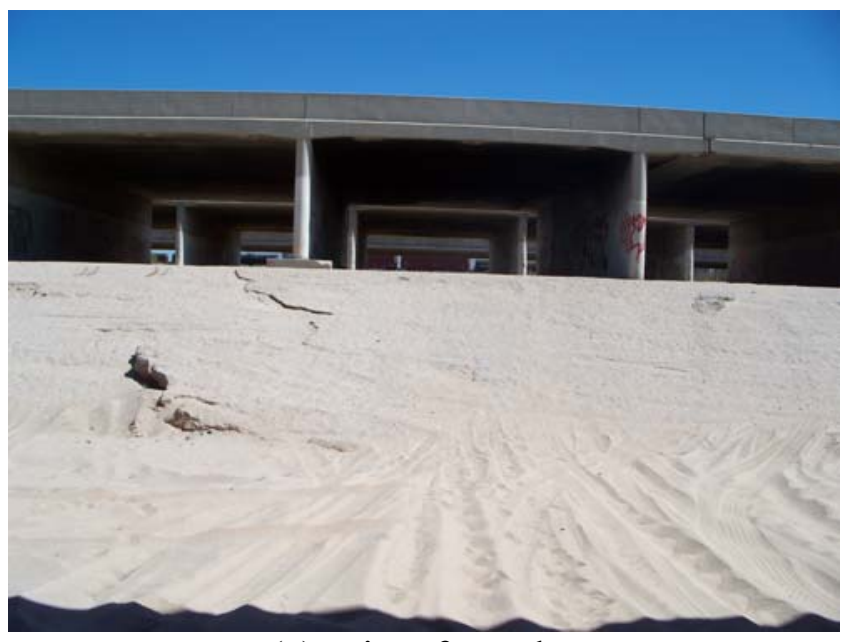

(a) View from downstream

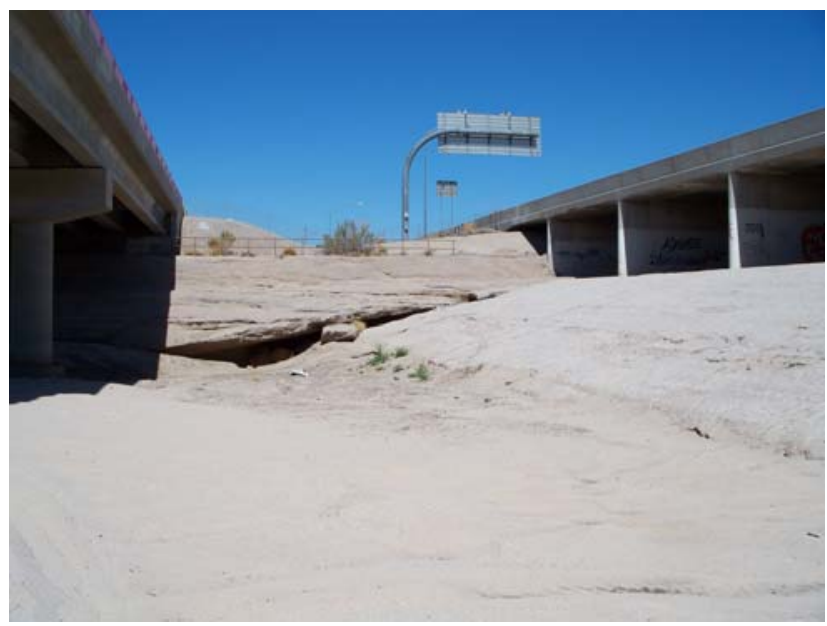

(b) View from the south bank

Figure 2. 6. Downstream boundary at the weir between I10 East and West bound bridges

\subsection{Sediment Data}

Surface- and substrate-bed materials were sampled at 14 cross sections located near bridges using the method described in Klingeman et al. (1979). To sample surface and substrate material, a location was chosen at the center of each cross section. Then, a surface area about $40 \mathrm{~cm}$ in diameter was removed to a depth equal to the size of the largest gravel, and all collected sediment comprised the surface-material sample. This same area was dug down approximately $0.3 \mathrm{~m}$, and substrate material was sampled at the bottom of the hole. Each sample weighed 0.5-1.0 kg. Surface material was sampled whenever visible bed material were observed. Substrate material was also sampled at the same location. These samples were dried and weighed at the soil laboratory at the Civil Engineering Department at the Univ. of Arizona. Twelve sieves were used, and their sizes are $6.35,4.76,2.38,2.00,1.18,1.00,0.85,0.50,0.30,0.25,0.15,0.08 \mathrm{~mm}$. The ASTM (American Society for Testing and Materials) standard sieving method was used to determine the size fractions in various sediment samples. Fig.2.7 and Fig.2.8 are the size gradation curves for surface and substrate material, respectively. Both surface and substrate materials become finer along the river. In general, the surface material is finer than the substrate, which indicates bed surface is continuously aggrading and bed surface armoring does not exist. 


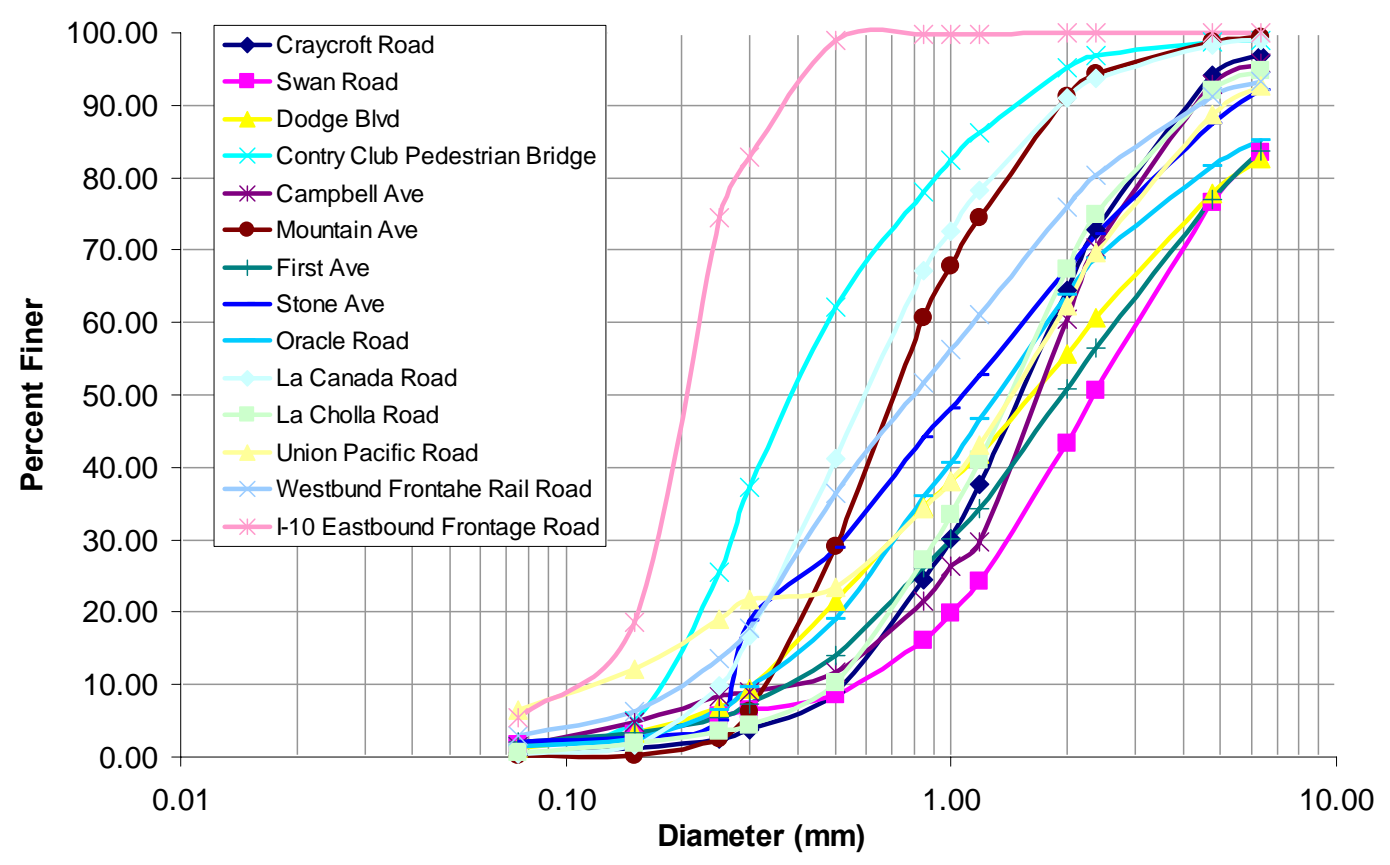

Figure 2. 7. Size distribution of surface bed material

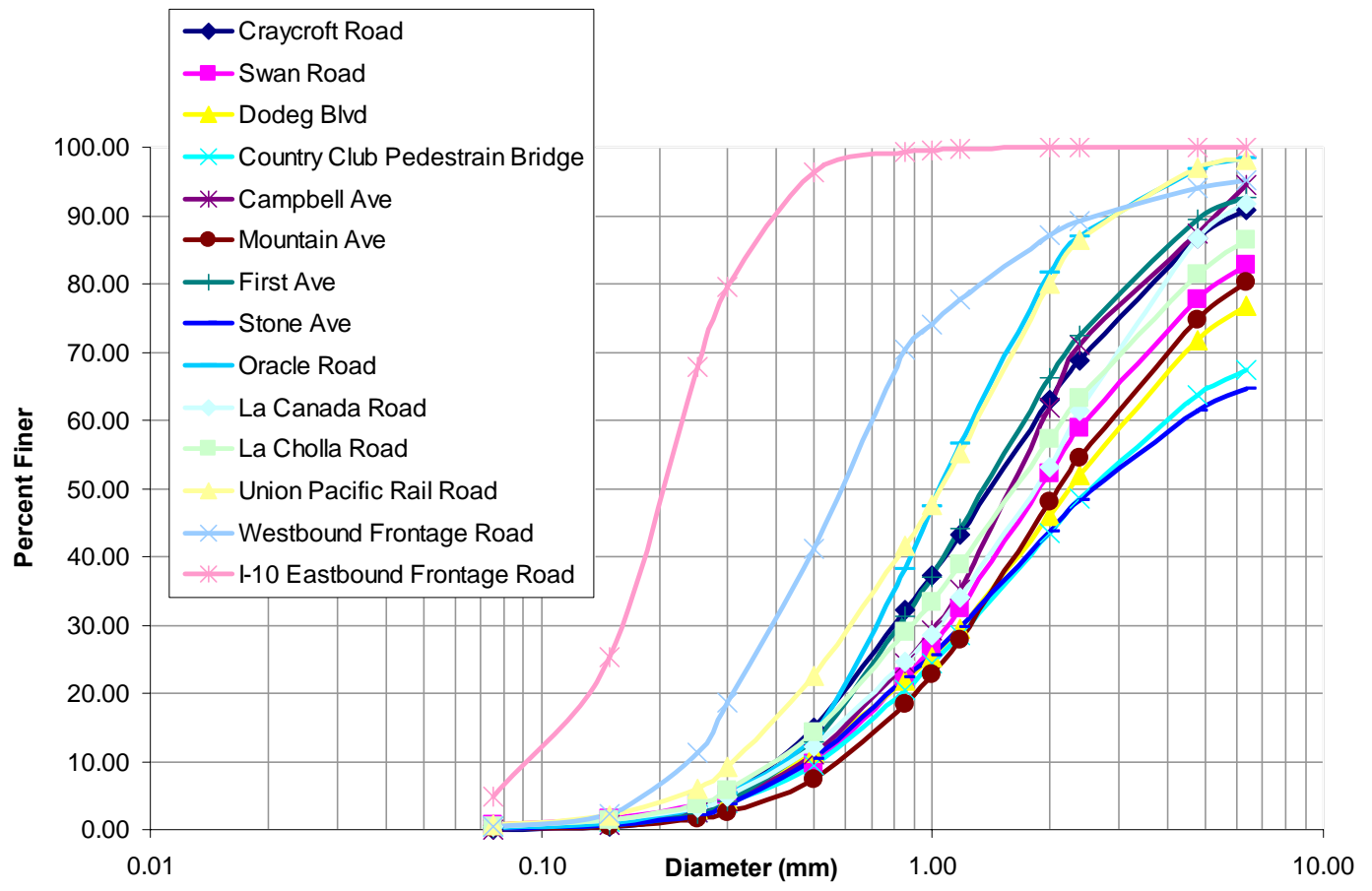

Figure 2. 8. Size distribution of substrate bed material 


\subsection{Roughness}

Bed roughness was determined by using measured discharge and stage relations at Dodge and La Cholla in Fig.2.5. Manning's equation was used as

$$
Q=\frac{1.49}{n} A R^{2 / 3} S_{f}^{1 / 2}
$$

Therefore,

$$
n=\frac{1.49}{Q} A\left(\frac{A}{P}\right)^{2 / 3} S_{f}^{1 / 2}
$$

where $\mathrm{Q}$ is discharge (cfs); $\mathrm{n}$ is Manning's roughness coefficient; A is flow area $\left(\mathrm{ft}^{2}\right)$, $\mathrm{R}$ is hydraulic radius, in which $\mathrm{R}=\mathrm{A} / \mathrm{P}, \mathrm{P}$ is wet parameter; $\mathrm{Sf}$ is energy slope.

The calculation assumed 1-D gradually-varied flow so that Manning's equation is valid. Flow area and wetted perimeter were interpolated linearly at points without measurements. Flow discharge and depth relations were directly obtained from USGS gage data shown in Fig.2.9. The loop indicated roughness varies at the rising and receding limbs of the hydrograph. Because the loop is very narrow the changes in roughness are not significant. No discharge and stage relation at the La Cholla gage was available; thus we assumed the flow hydrograph at Dodge is valid at the La Cholla bridge.

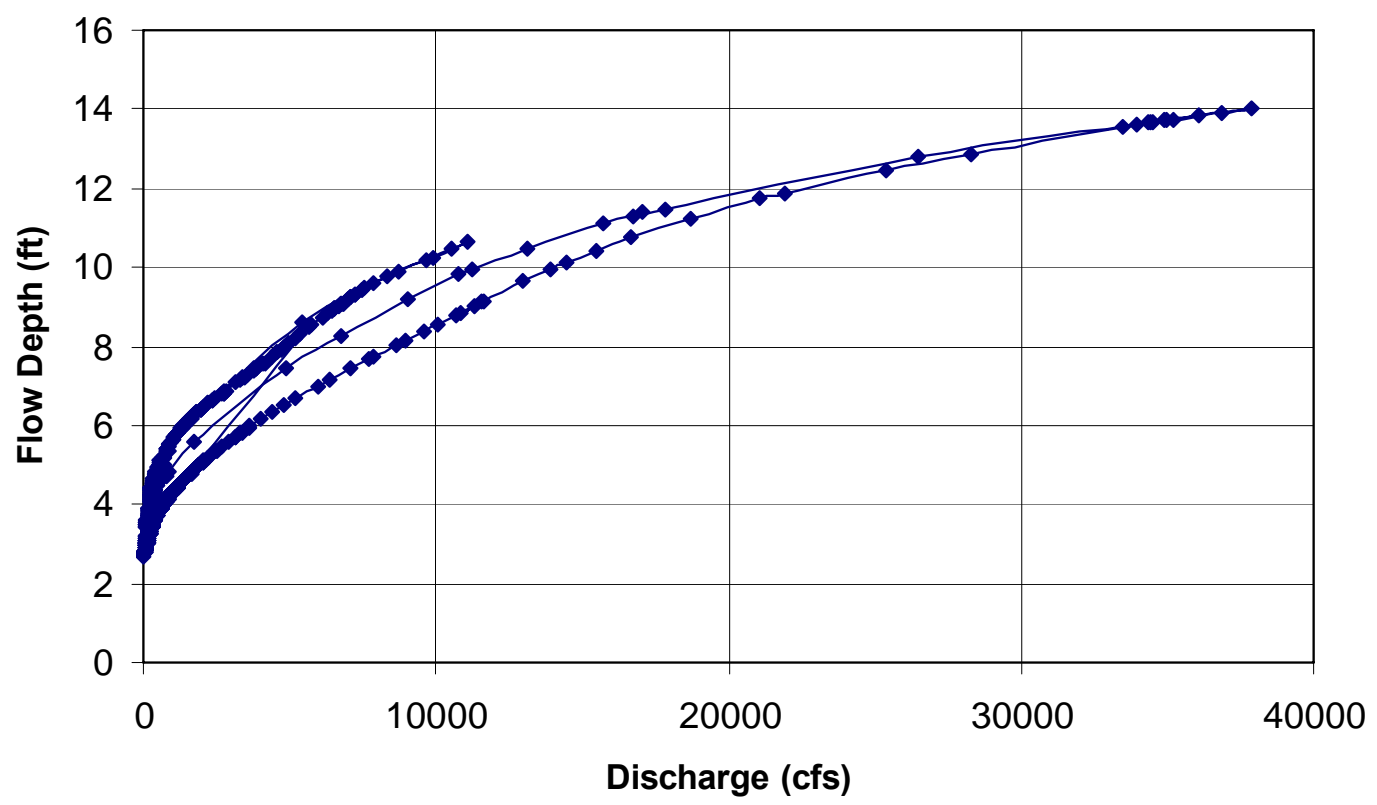

Figure 2. 9. Flow discharge versus flow depth at Dodge 
The relations between flow area, flow depth, and wetted perimeter were obtained from the results of a quasi-unsteady HEC-RAS model. The stage versus flow area and stage versus wetted perimeter curves at the Dodge gage were plotted in Fig.2.10 and Fig.2.11, respectively.

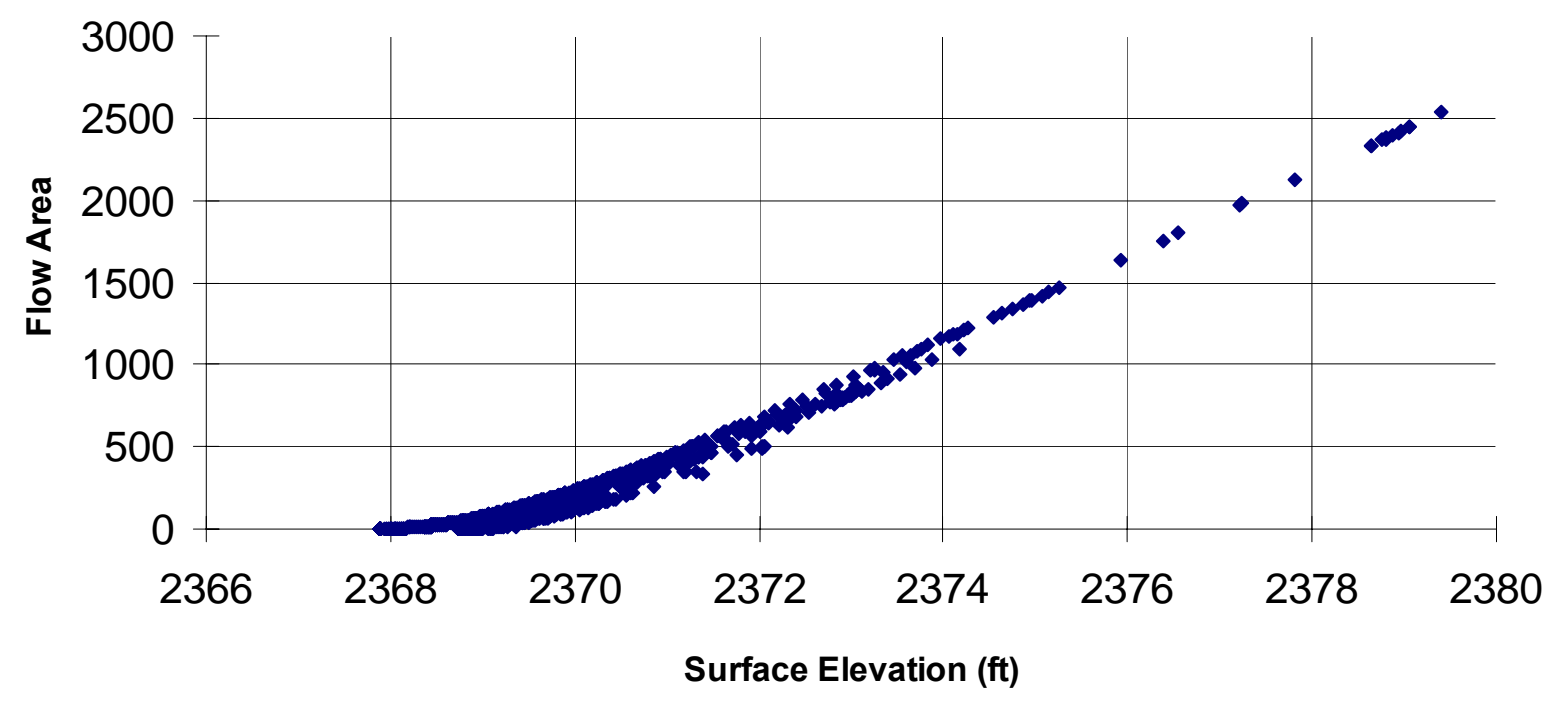

Figure 2. 10. Stages versus flow area relation at Dodge

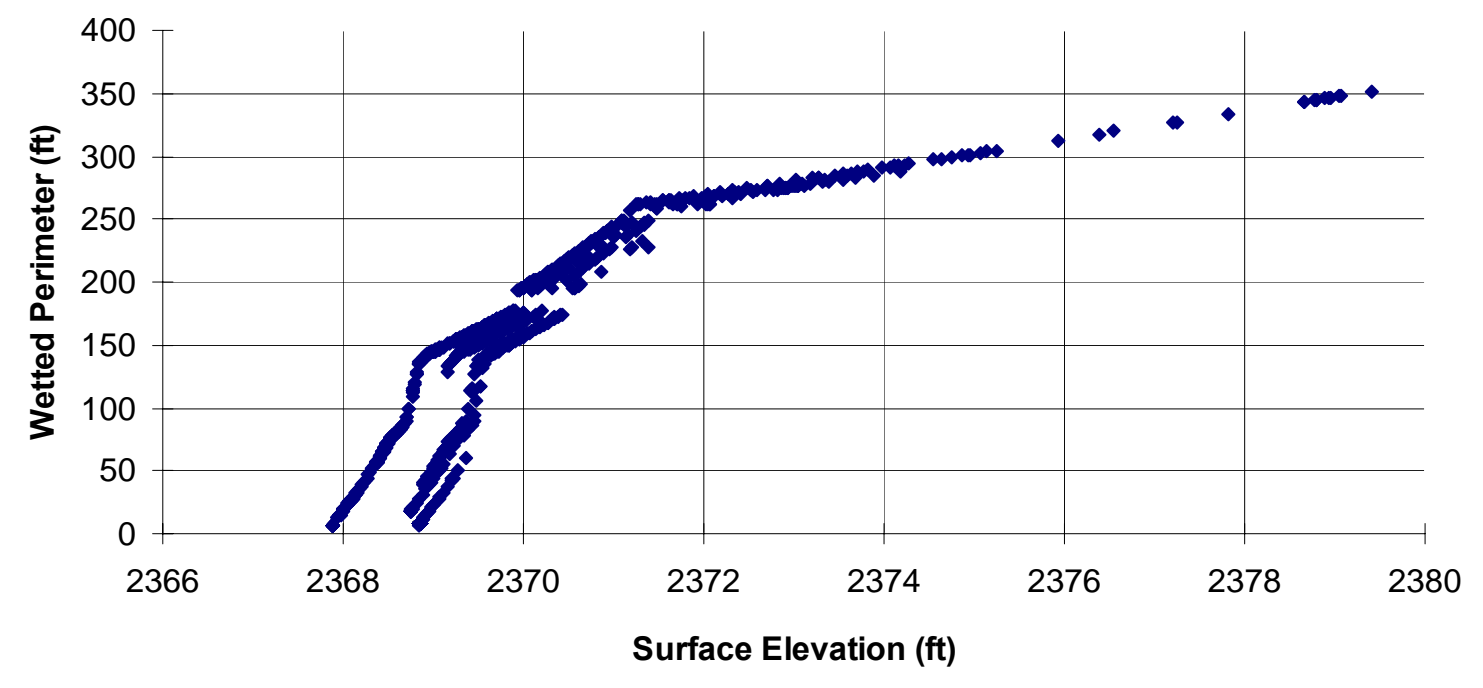

Figure 2. 11. Stages versus wetted perimeters at Dodge

The energy slopes at different stages and discharges are needed in Eq.2.2 for calculating the $n$ values at different discharges. The energy slopes vary with discharge, therefore we employed the 
results from HEC-RAS quasi-unsteady flow model to estimate the energy slopes. The variation of energy slope with time was shown in Fig.2.12.

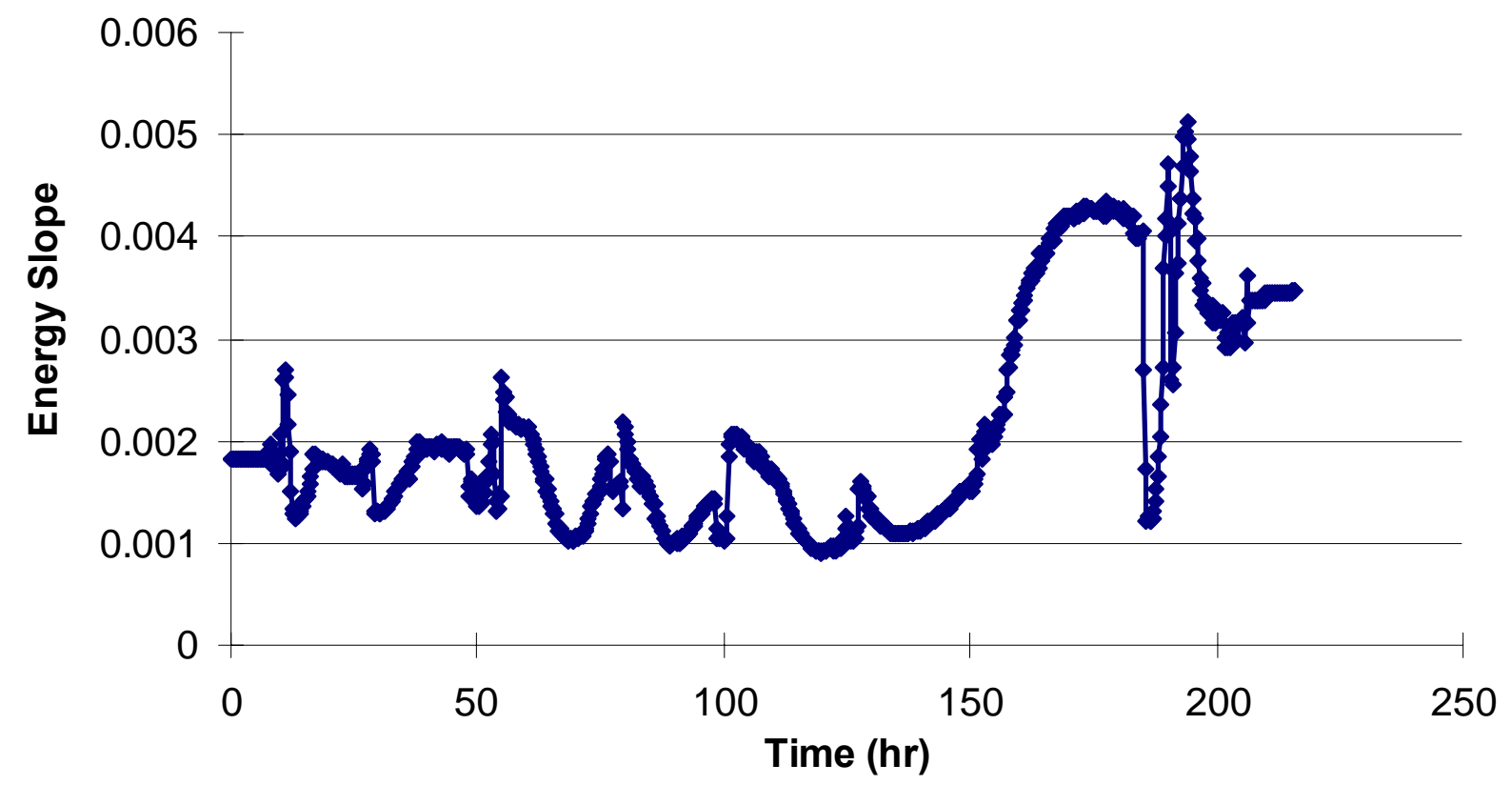

Figure 2. 12. Energy slope variation during the storm at Dodge

Based on Fig.2.9, 2.10, 2.11, and 2.12, the variation of roughness with discharges at Dodges and La Cholla were obtained and plotted in Fig.2.13 and Fig.2.14, respectively. 


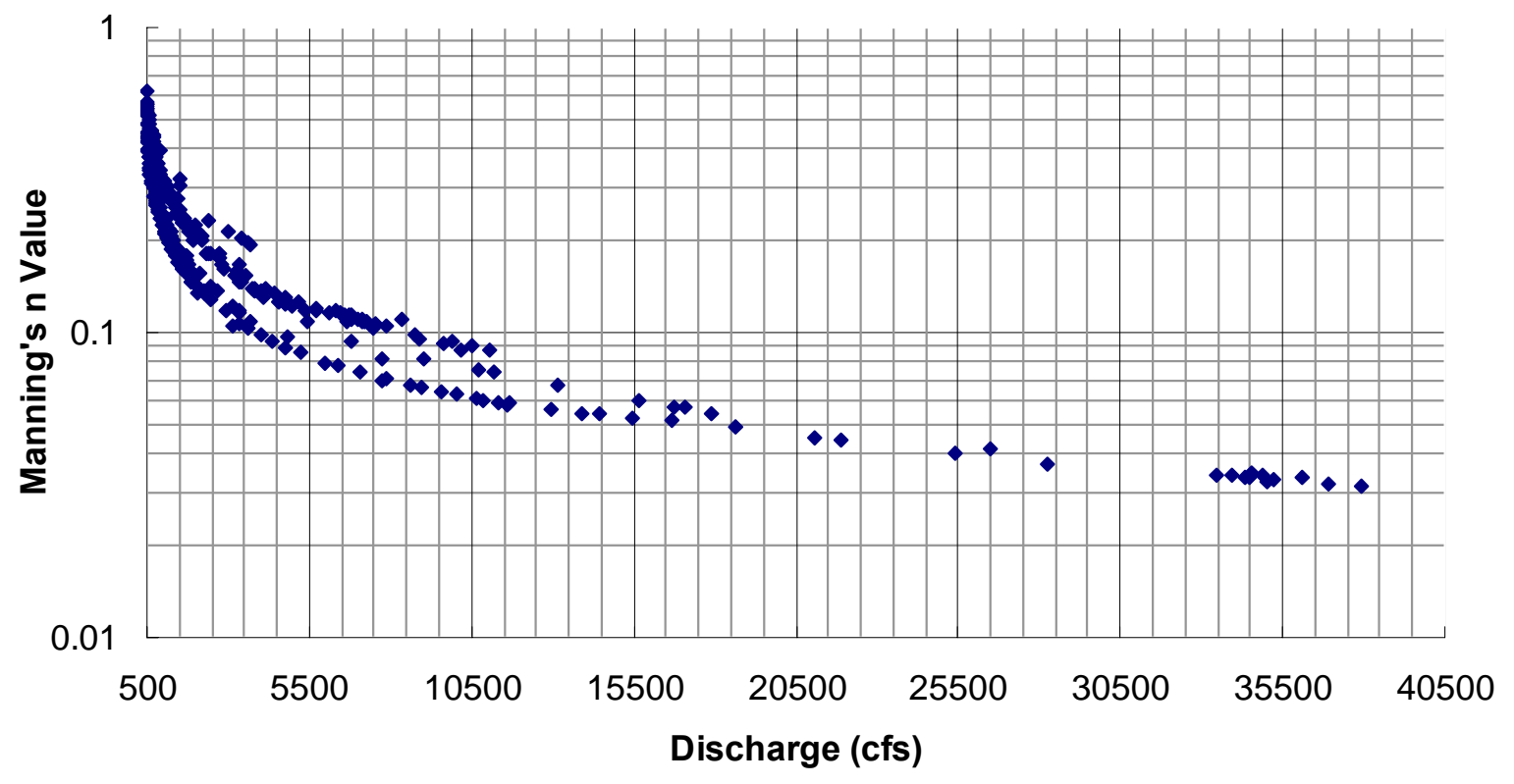

Figure 2. 13. Manning's roughness coefficient $n$ varies with discharges at Dodge

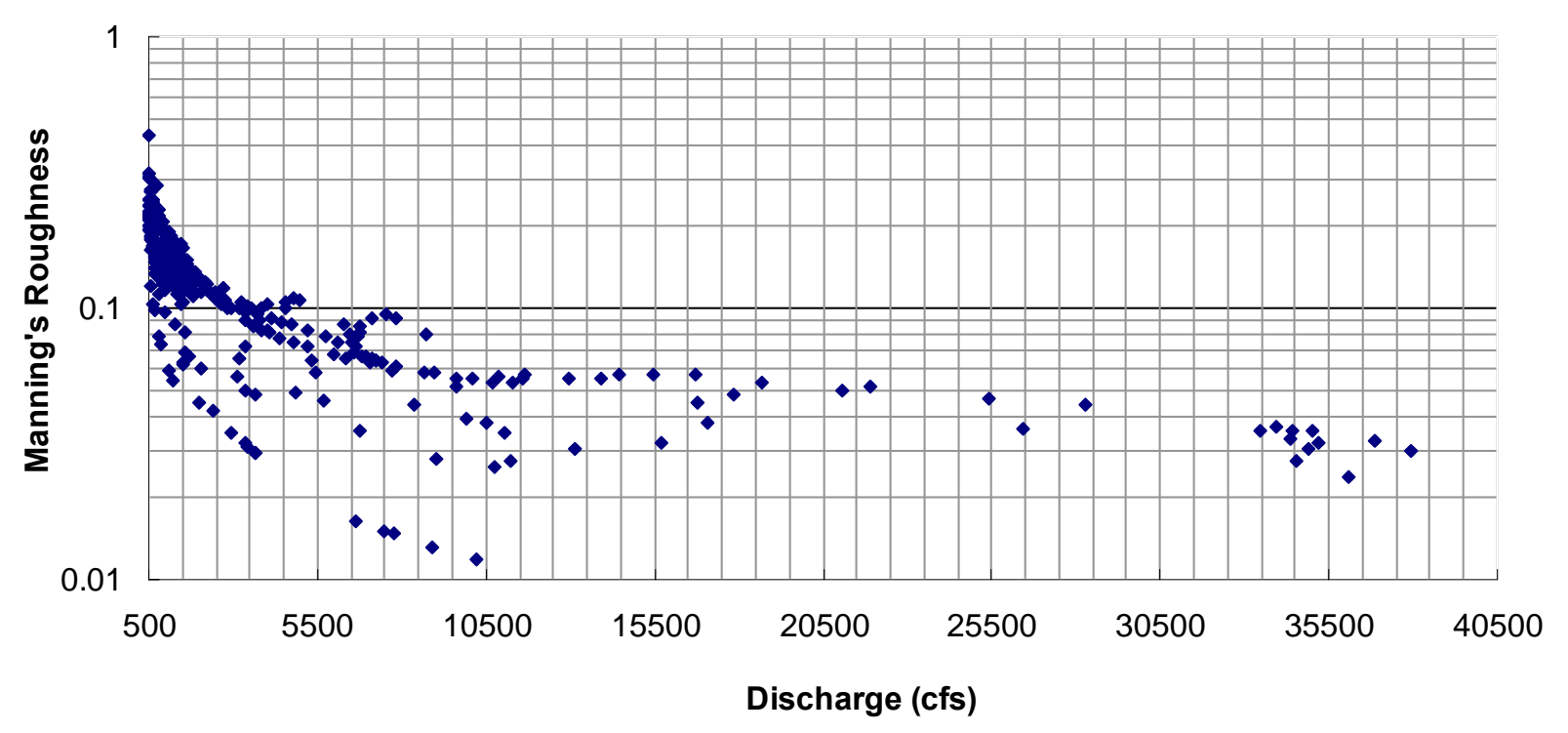

Figure 2. 14. Manning's roughness coefficient $n$ varies with discharges at La Cholla

Fig.2.13 showed that 1) $\mathrm{n}$ values are very large ranging from 0.1 to 0.6 when $500 \mathrm{cfs}<\mathrm{Q}<5,000$ cfs; 2) it ranges from 0.04 to 0.1 when $5,000<\mathrm{Q}<21,000 \mathrm{cfs} ; 3$ ) it reduces to 0.04 when $21,000 \mathrm{cfs}$ $<\mathrm{Q}<35,000 \mathrm{cfs} ; 3)$ at the extreme discharge $\mathrm{Q}>35,000 \mathrm{cfs}$, the $\mathrm{n}$ value further reduces to 0.03 . Fig.2.13 showed similar results at La Cholla gage except that 1 ) $n$ values range from 0.05 to 0.1 when $5,000<\mathrm{Q}<15,000 \mathrm{cfs} ; 2$ ) it reduces to 0.05 when $15,000 \mathrm{cfs}<\mathrm{Q}<35,000 \mathrm{cfs}$. In general, $\mathrm{n}$ 
values at La Cholla are slightly larger than that at Dodge for discharges ranging from 5,000 to 35,000 cfs. At low flow $\mathrm{Q}<5,000 \mathrm{cfs}$ and high flows $\mathrm{Q}>35,000 \mathrm{cfs}$, both cross sections yielded the same $\mathrm{n}$ values. As seen from the aerial photo, the Rillito river is heavily vegetated and vegetation related roughness is dominant at low flows so that Manning's $n$ values are large. On the other hand, at high flows $\mathrm{Q}>35,000 \mathrm{cfs}$, most vegetation was either washed out or significantly bent; therefore, roughness reduces to 0.03, which is normal for sandy rivers. At discharges between 5,000 and 35,000 cfs, channel roughness varies between 0.03 and 0.1 depending on the magnitude of vegetation-related resistance. At the same discharge, Manning's $n$ is bigger at the rising limb of hydrograph because of emerged vegetation, while at the receding limb, $n$ values are smaller due to less vegetation. This phenomena is also attributed to the ripple and dunes on bed surfaces during a continuous flow period.

Roughness variation in the Rillito river could result from the evolution of bed forms such as ripples and sand dunes during a hydrograph. To evaluate the effects of bed forms on bed roughness, this study applied Karim-Kennedy’s friction factor (Karim and Kennedy 1990), $f$, calculated as

$$
\begin{gathered}
\frac{f}{f_{0}}=1.20+8.92 \frac{\Delta}{y_{0}} \text { in which } f_{0}=\frac{8}{\left[5.75 \log \frac{12 y_{0}}{2.5 d_{50}}\right]^{2}} \\
\frac{\Delta}{y_{0}}=.08+2.24\left(\frac{\tau_{*}}{3}\right)-18.13\left(\frac{\tau_{*}}{3}\right)^{2}+70.9\left(\frac{\tau_{*}}{3}\right)^{3}-88.33\left(\frac{\tau_{*}}{3}\right)^{4} \text { for } \tau_{*}<=1.5
\end{gathered}
$$

where $f_{0}$ is the friction factor for fixed bed, $y_{0}$ is the normal depth for fixed bed. The relationship between velocity and roughness can be obtained as

$$
\frac{V}{\sqrt{(S G-1) g d_{50}}}=6.683\left(\frac{y_{0}}{d_{50}}\right)^{0.626} S^{0.503}\left(\frac{f}{f_{0}}\right)^{-0.465}
$$

where $\mathrm{S}$ is slope, $\tau_{*}<1.2$, bed form is in the lower regime, $1.2<\tau_{*}<1.5$, bed form is in the transition, $\tau_{*}>1.5$, bed form is in the upper regime.

Eq.2.4 can be converted into

$$
n=0.037 d_{50}^{0.126}\left(\frac{f}{f_{0}}\right)^{0.465}
$$

This means that when there are bed forms, roughness depends on not only the size of bed sediment but also vegetations and other micro-bed forms. 
The upper limit of the lower regime is defined as $\tau_{*}=1.3$; the lower limit of the upper regime is defined as $\tau_{*}=0.9$. Considering the effect of temperature on bed forms, Karim and Kennedy developed the following relationship,

$$
\begin{aligned}
& \frac{\Delta}{y_{0}}=-0.04+0.294\left(\frac{u_{*}}{w_{f}}\right)+0.00316\left(\frac{u_{*}}{w_{f}}\right)^{2}-0.0319\left(\frac{u_{*}}{w_{f}}\right)^{3}+0.00272\left(\frac{u_{*}}{w_{f}}\right)^{4} \text { for } 0.15<u_{*} / w_{f}<3.64 \\
& \frac{\Delta}{y_{0}}=0, \text { for } u_{*} / w_{f}<0.15 \text { or } u_{*} / w_{f}>3.64
\end{aligned}
$$

The results considering the effects of bed form at Dodge and La Cholla were plotted in Fig.2.15 and Fig.2.16, respectively.

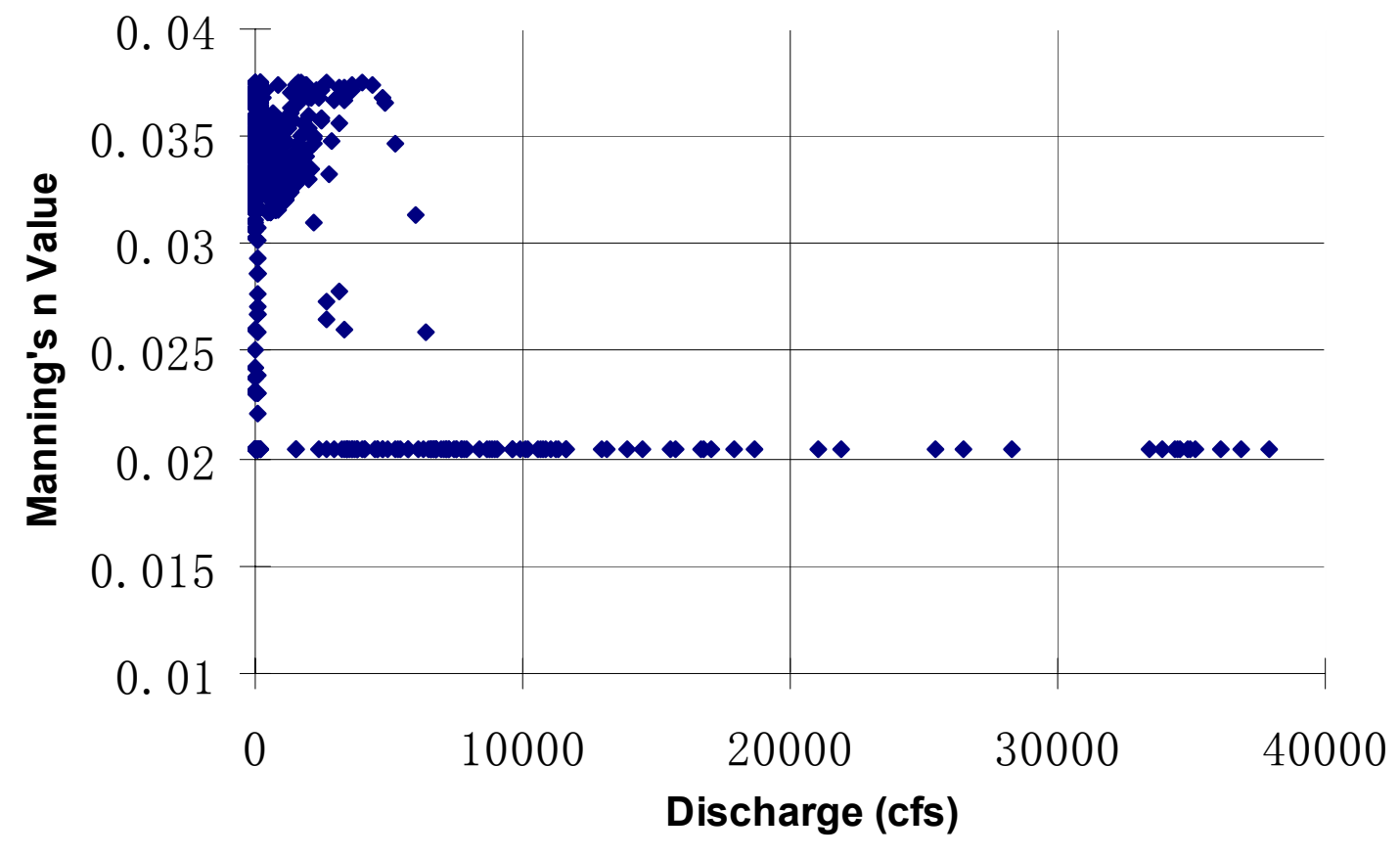

Figure 2. 15. Roughness variation with discharge considering bed forms at Dodge 


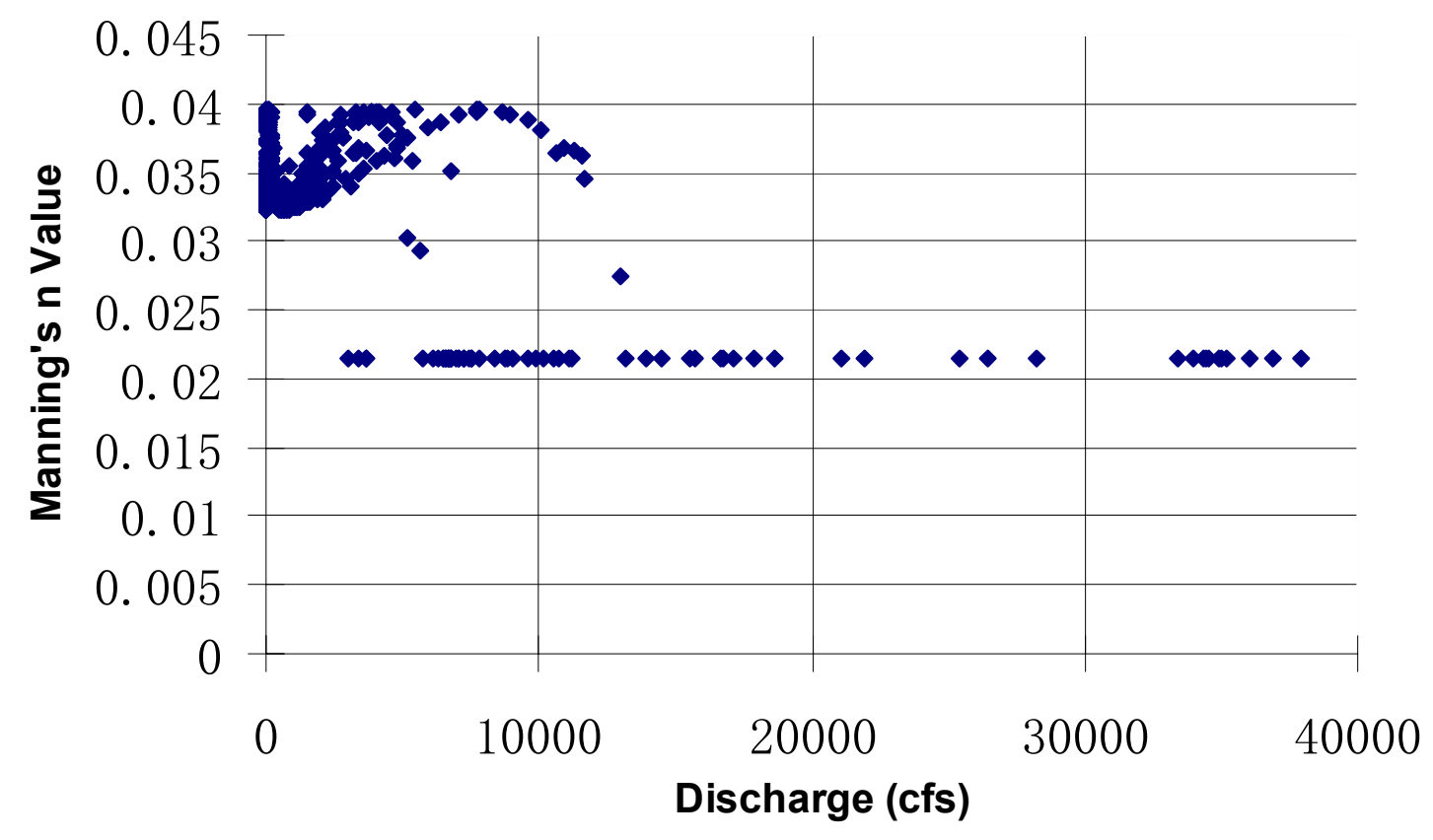

Figure 2. 16. Roughness variation with discharge considering bed forms at La Cholla

At Dodge, Fig.2.15 showed that 1) at low discharge $\mathrm{Q}<12,000 \mathrm{cfs}$, the $\mathrm{n}$ values are from 0.02 to $0.04 ; 2$ ) at high discharge $\mathrm{Q}>12,000 \mathrm{cfs}$, the $\mathrm{n}$ value approaches to a constant of 0.022 . At La Cholla, Fig.2.16 showed that 1) bed forms change from ripples to dunes and transition, then upper regime during the event; 2) the maximum height of dunes is $25 \%$ of flow depth (about $1-2 \mathrm{ft}$ ). One discharge corresponds to multiple $\mathrm{n}$ values at $\mathrm{Q}<10,000 \mathrm{cfs}$. 3) at low discharges $\mathrm{Q}<10,000 \mathrm{cfs}$, the $\mathrm{n}$ values are from 0.02 to $0.04 ; 4$ ) at high discharges, the $\mathrm{n}$ value approaches to a constant of 0.02 . Since the Karim-Kennedy method doesn't take vegetation roughness into account, the resultant roughness is much smaller than those using HEC-RAS simulated energy slopes. The smallest $\mathrm{n}$ value at high discharges is 0.022 , compared to 0.03 from the original HEC-RAS model.

In summary, the Manning's n coefficient in the Rillito River is significantly affected by the vegetation and varies with discharge. At low flows, vegetation is dominant and the roughness ranges from 0.1-0.6, while at medium high flows $\mathrm{Q}>21,000$, roughness ranges from 0.02 to 0.05 ; at high flows $\mathrm{Q}>35,000$, roughness is around 0.022 to 0.03 . 


\section{Model Parameterization}

\subsection{HEC-RAS Model}

The recently released HEC-RAS 4.0 version which includes a sediment transport module developed by Brunner and Gibson (2005) was employed in this study. The sediment transport model has a separate quasi-unsteady flow subroutine for flow simulation. The quasi-unsteady flow module calculates flow hydraulics at each discharge using the steady flow module. The HEC-RAS flow model has advantages over the other models in modeling the effects of hydraulic structures (e.g. bridges, weirs, and culverts). The current version only has the total bed material load transport equations.

\subsubsection{Unsteady Flow Model}

The boundary condition for unsteady flow is a stage hydrograph at the upstream boundary. The simulation period was from $07 / 27 / 06$ to $08 / 04 / 06$ totaling 216 hours, with a peak flow of $37,913.73$ cfs occurring at Dodge blvd bridge at 6:50 AM on 07/31/06. The time step is 15 minutes. There are two boundary conditions available in the unsteady flow analysis: "normal depth" and "rating curve". "Normal depth" was selected as the downstream boundary condition. The corresponding friction slope was chosen as 0.003 , the same as the bed slope. The water temperature during the monsoon season in the southern Arizona varies from 60 to $70^{\circ} \mathrm{F}$. Because the storm water originated from the high elevations in the Catalina Mountain all the model runs assumed the storm water temperature is low and approximately $60^{\circ} \mathrm{F}$.. The following is a list of calibration parameters for the unsteady flow model,

- Downstream boundary condition

- Bed slope for normal depth

- Roughness (Manning's n value)

- Base flow $(\mathrm{Q})$

- Bridge coefficient $\left(\mathrm{C}_{\mathrm{d}}\right)$

Manning's $\mathrm{n}$ values were 0.03 in the main channel and 0.06 for the floodplain. Bridge coefficients were used to take the minor loss into account. This study showed the modeling results of stage hydrograph are not very sensitive to bridge coefficients. The changes to bridge coefficients only affect the surface super-elevation upstream of the bridge. The influence to the downstream sections from the bridge is very minor. The bridge coefficient at the La Cholla bridge was 2.7 in this study.

The model is sensitive to the base flow condition. The model was calibrated by selecting $3,000,1,500,1,000,500,100$, and $20 \mathrm{cfs}$ as the base flow discharges. A rating curve between the discharge and water surface elevation can be established based on a discharge relation for a broad crested weir. If the "rating curve" was selected as the boundary condition, the model becomes unstable when the discharge is less than 1,500 cfs. The modeling results were similar if the base flow is greater than 1,500 cfs. If choosing "normal depth" boundary condition, the minimum base flow can be 20 cfs. Therefore, "normal depth" downstream boundary condition was chosen because it 
allows a smaller base flow and better stabilizes the model than the "rating curve" option. Fig.3.1.1 showed the results of using "normal depth" and "rating curve" as the downstream boundary conditions in which the "normal depth" downstream boundary condition showed more accurate results.

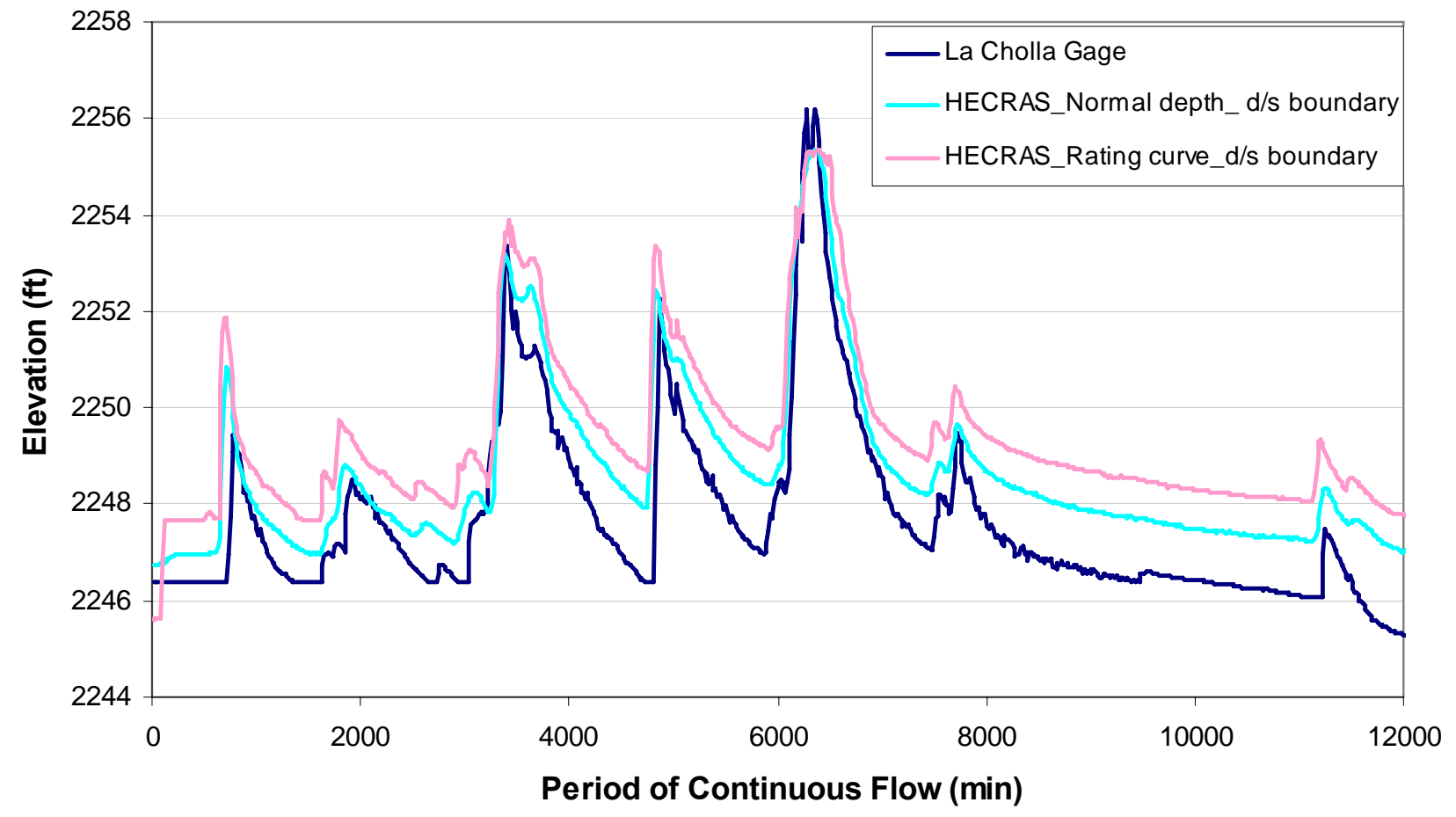

Figure 3. 1. 1. HEC-RAS simulated stage hydrographs at La Cholla using different downstream boundary conditions

The unsteady flow model theoretically is more accurate than the quasi-unsteady flow model because of its robust techniques in solving both the continuity and momentum equations. This study chose "normal depth" as the downstream boundary condition along with a constant Manning's roughness. The results in Fig.3.1.1. indicated that the model over-estimated stage hydrographs at the La Cholla bridge. An alternative to simulating unsteady flow hydrographs is to use HEC-RAS quasiunsteady flow analysis in which sediment transport will also be simulated. The sections following this section will compare the results of stage hydrographs from unsteady and quasi-unsteady flow model.

\subsubsection{Quasi-unsteady Flow Model}

The upstream boundary condition for quasi-unsteady flow is the flow hydrograph. The downstream boundary condition is "normal depth", the same as that for the unsteady flow model. Manning's roughness, friction slope, and water temperature are identical to those in the unsteady flow model. The simulation period and time step were also kept the same. 
Equilibrium sediment loads were chosen as the boundary conditions at both the upstream and the downstream. To obtain the size distributions of bed material, surface and substrate sediment samples were collected at each bridge during a field survey. The size distributions of substrate material at each bridge were used as the bed material gradation. At sections without surveyed data, the size distribution of bed material was interpolated based on the nearby surveyed data.

The sediment transport analysis requires the user to select maximum erodible depth, sediment transport formulas, sediment sorting method, and fall velocity method. The maximum erodible depth should be much greater than the observed maximum depth of erosion. Since there are no bedrock outcroppings in the sandy bed Rillito River, the erodible depth should be infinite in reality. The observed maximum erosion at the thalweg is less than $4 \mathrm{ft}$. Therefore, the maximum erodible depth was set to $10 \mathrm{ft}$ at mobile sections and was set as zero at the non-erodible sections having grade control structures.

Among four methods for calculating the fall velocity, Ruby's and Report 12 methods are commonly used. Ruby's method indirectly accounts for the effect of temperature on sediment fall velocity, while Report 12 method was recommended by American Society of Civil Engineers and included the effect of temperature and covered a wide range of sediment sizes. Since the storm has a short duration and temperature is not an important factor, Ruby's method was chosen in the sediment transport analysis.

Sediment in Rillito River is close to a well-mixed medium sand. The size distributions did not showed bi-modality of sand and gravels. Therefore, the default sorting method was selected for all the sediment analyses.

\subsubsection{Sediment Transport Formulas}

To evaluate sediment transport equations, a sediment analysis was run by selecting Ackers \& White (1973), Laursen (1958), and Yang (1973) equations while keeping the same boundary conditions, erodible depth, Manning's roughness coefficient, fall velocity method, and sediment sorting method. These sediment transport models are often appropriate for sand-rich channels like the Rillito River. The results of the simulated stage hydrographs at La Cholla using these sediment equations are shown in Figure.3.1.2. One can easily see that all the models predict accurately the stage at the peak flow of 37,913 cfs, and all the models under-predicted the stages at small discharges. The results from Yang (1973) equation most closely match the observed data. Using the Acker-White equation shown in the green color line yielded slightly lower stages that that of Yang's. The results from Laursen (1958) equation showed poorer results than the others. The differences in stage hydrographs using different sediment transport equations results from the differences in bed elevation changes when using different sediment transport equations.

Additionally, the predicted stage hydrographs lead the observed data about 120 mins at the peak discharge. This is expected because quasi-unsteady flow has adopted the standard-step method 
to solve the energy equation at each discharge so that the stage hydrograph at La Cholla is in phase with the stage hydrograph at Dodge.

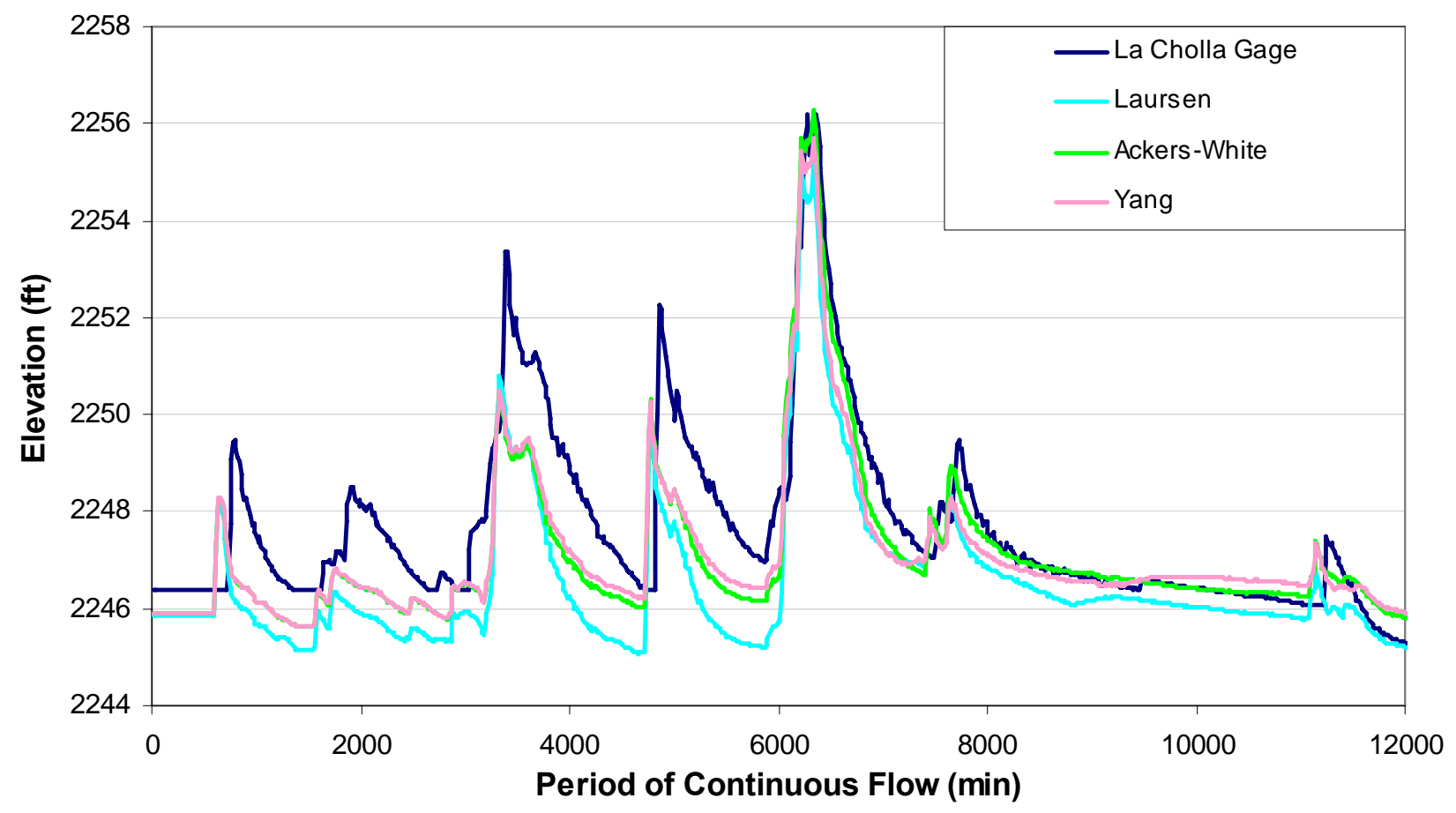

Figure 3. 1. 2. HEC-RAS simulated stage hydrographs at La Cholla using different sediment transport equations

The results of averaged bed elevation changes were compared with the observed data in Fig.3.1.3. The results from Yang's equation showed the best match to the observed data in Fig.3.1.3. The results from Acker-White (1973) equation also matched the observed data well, but gave a bad estimation at river mile close to 5.0. The Laursen (1958) results are worse than the others.

Fig.3.1.4 is the plot of bed elevation changes at the thalweg in which none of the results match the observed data. The results are expected as explained in section 5 that none of the models considered the differences of bed elevation changes between the main channel and the floodplain.

The statistic parameters to determine the accuracy of each model's results are mean error, Nash-Sutcliffe coefficient, correlation coefficient, and root mean square error. These parameters were calculated as follows,

$$
\text { Mean Error }=\frac{\sum_{\mathrm{i}=1}^{\mathrm{n}}\left(\mathrm{C}_{\mathrm{i}}-O_{i}\right)}{n}
$$




$$
\begin{gathered}
\text { Nash - Sutcliffe efficiency }=1-\frac{\sum_{i=1}^{n}\left(O_{i}-C_{i}\right)^{2}}{\sum_{i=1}^{n}\left(O_{i}-\bar{O}\right)^{2}} \\
\text { Correlation }=\frac{\sum_{i=1}^{n}\left(O_{i}-\bar{O}\right)\left(C_{i}-\bar{C}\right)}{\sqrt{\sum_{i=1}^{n}\left(O_{i}-\bar{O}\right)^{2}} \sqrt{\sum_{i=1}^{n}\left(C_{i}-\bar{C}\right)^{2}}} \\
\text { Root Mean Square Error }=\sqrt{\frac{1}{n} \sum_{i=1}^{n}\left[\left(C_{i}-O_{i}\right)-(\overline{C-O})\right]^{2}}
\end{gathered}
$$

where $\mathrm{C}$ is the modeling result, and $\mathrm{O}$ is the observed data. The subscription indicates each calculated or measured data, while the overhead bar denotes the averaged value. The mean error, correlation, and root mean square error are commonly used to evaluate the performance of models. The Nash-Sutcliffe efficiency factor has been widely applied to hydrology to determine the accuracy of streamflow forecast models. It can range from $-\infty$ to 1 . An efficiency of 1 corresponds to a perfect match of modeling results to the observed data. An efficiency of 0 indicates that the model predictions are as accurate as the mean of the observed data, whereas an efficiency less than zero occurs when the observed mean is a better predictor than the model. The closer the model efficiency is to 1 , the more accurate the model is.

Table 3.1.1 summarizes the statistics of the simulated stage hydrograph obtained by using different sediment transport equations. Table 3.1.2 and 3.1.3 summarized the statistics of the simulated averaged and at the thawleg bed elevation changes. One can see that the statistical parameters indicated that the Yang's sediment transport equation yielded the best results followed by Ackers-White and Laursen's equation.

Table 3. 1. 1. Statistical analysis of stage

\begin{tabular}{|c|c|c|c|}
\hline Parameters & Yang & Ackers-White & Laursen \\
\hline Correlation Factor & $\mathbf{0 . 8 6 7}$ & 0.861 & 0.845 \\
\hline Root Mean Squared Error & $\mathbf{1 . 0 8 8}$ & 1.094 & 1.455 \\
\hline Nash Sutcliffe Efficiency (E) & $\mathbf{0 . 6 8 2}$ & 0.678 & 0.432 \\
\hline
\end{tabular}


Table 3. 1. 2. Statistical analysis for average bed elevation change at the thalweg

\begin{tabular}{|c|c|c|c|}
\hline Parameters & Yang & Ackers-White & Laursen \\
\hline Correlation Coefficient & $\mathbf{0 . 3 4 5}$ & 0.093 & 0.273 \\
\hline Root mean squared error (RMSE) & $\mathbf{0 . 8 2 1}$ & 1.137 & 2.118 \\
\hline Nash Sutcliffe Efficiency (E) & $\mathbf{- 0 . 2 9 1}$ & -1.476 & -7.595 \\
\hline
\end{tabular}

Table 3. 1. 3. Statistical analysis for bed elevation change at the thalweg

\begin{tabular}{|c|c|c|c|}
\hline Parameters & Yang & Ackers-White & Laursen \\
\hline Correlation Coefficient & $\mathbf{0 . 2 3 8}$ & 0.060 & -0.141 \\
\hline Root mean squared error (RMSE) & $\mathbf{1 . 7 0 3}$ & 1.732 & 2.754 \\
\hline Nash Sutcliffe Efficiency (E) & $\mathbf{- 1 . 4 5 0}$ & -1.534 & -5.410 \\
\hline
\end{tabular}

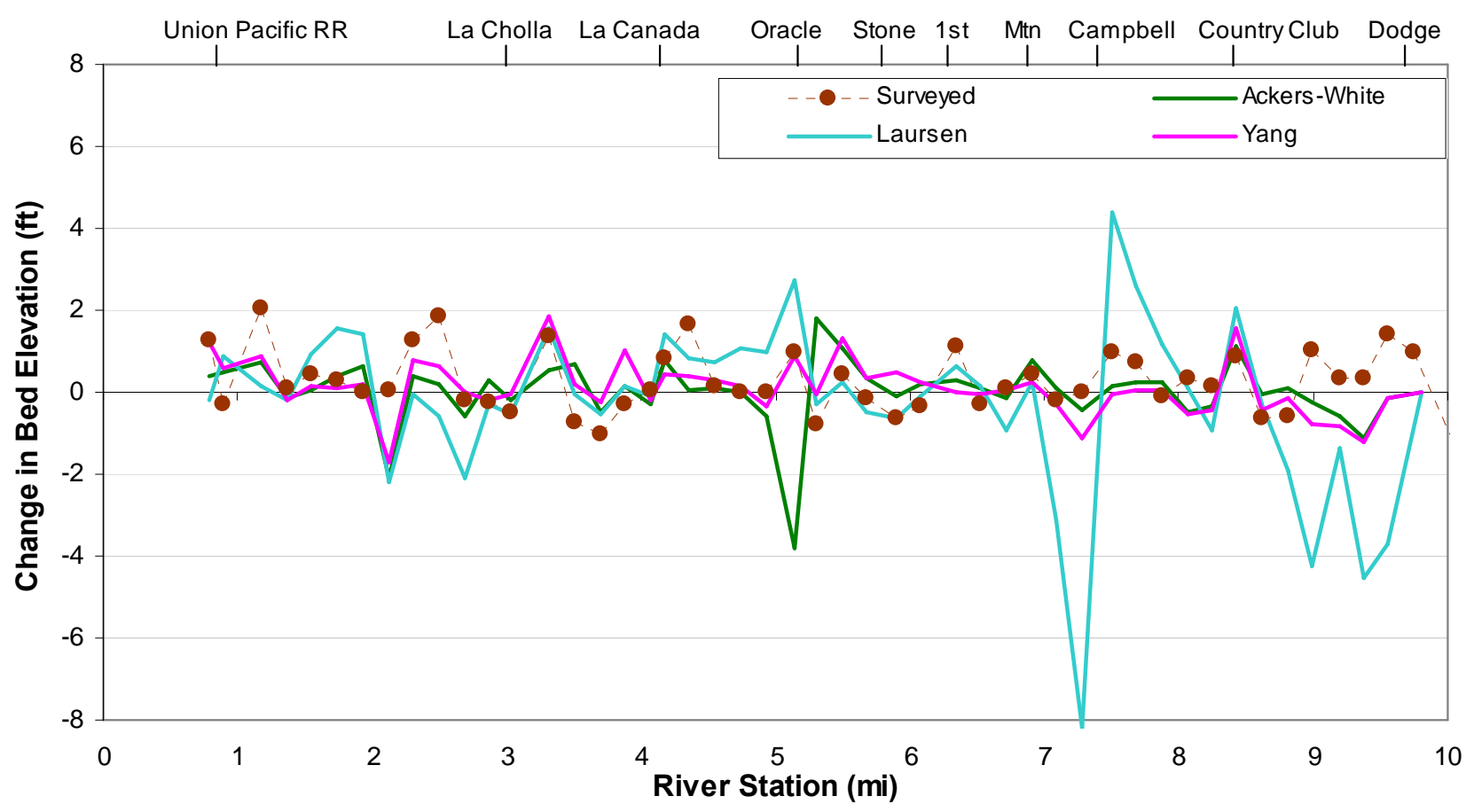

Figure 3. 1. 3. HEC-RAS simulated averaged bed elevation changes using different sediment transport equations 


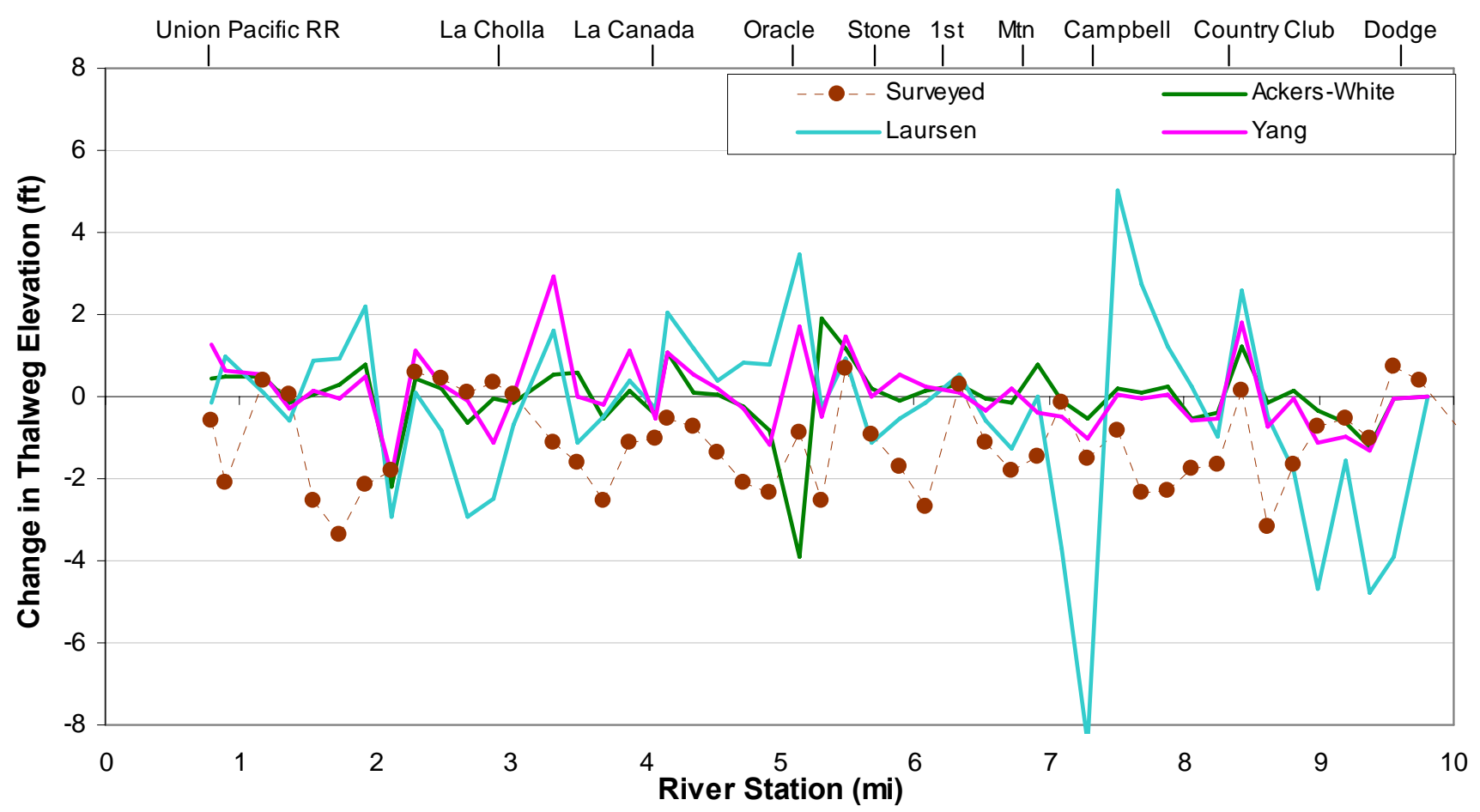

Figure 3. 1. 4. HEC-RAS simulated bed elevation changes at the thalweg using different sediment transport equations

\subsubsection{2. .Manning's n Value}

The sensitivity of modeling results to Manning's n values was examined by both doubling the original $\mathrm{n}$ value and reducing it to a half. The sensitivity analysis kept all the other model input parameters the same. The larger the $\mathrm{n}$ values, the higher the water surface elevation, and vice versa. The results of stage hydrographs with changed Manning's coefficients are plotted in Fig.3.1.5 together with the original results. One can see that an increase in Manning's coefficient has significantly raised water surface elevation at the peak discharge, but it did not considerably affect the stages at smaller discharges. In contrast, a reduction in Manning's $\mathrm{n}$ did not influence the predicted stage at the highest peak discharge, but did raise the stages at the receding limb of the hydrograph. The increased stages attributed to excessive depositions due to the smaller roughness as shown in Figs.3.1.6 and 3.1.7. Further reduction of $n$ value will fail the model. Therefore, the original $n$ value perhaps is the most suitable choice for the model.

Fig.3.1.6 and Fig.3.1.7 show the results of averaged and at the thalweg bed elvation changes by using the changed Manning's $n$ value. Both showed the increase or reduction of $n$ value did not produced better results. The statistical parameters of mean error, correlation, and RSME in Table 3.1.4 indicated Yang's equation using the original Manning's n value yielded the best match to the observed data.

From Figure 3.1.5, 3.1.6, and 3.1.7 and Table 3.1.4 we can conclude that the Manning's n value affected the peak stage, but barely influenced the stages at smaller discharges. Additionally, 
from Tables 3.1.5 and 3.1.6 an increase of $n$ value results in excessive aggradation, while a reduction of $n$ value results in more erosion.

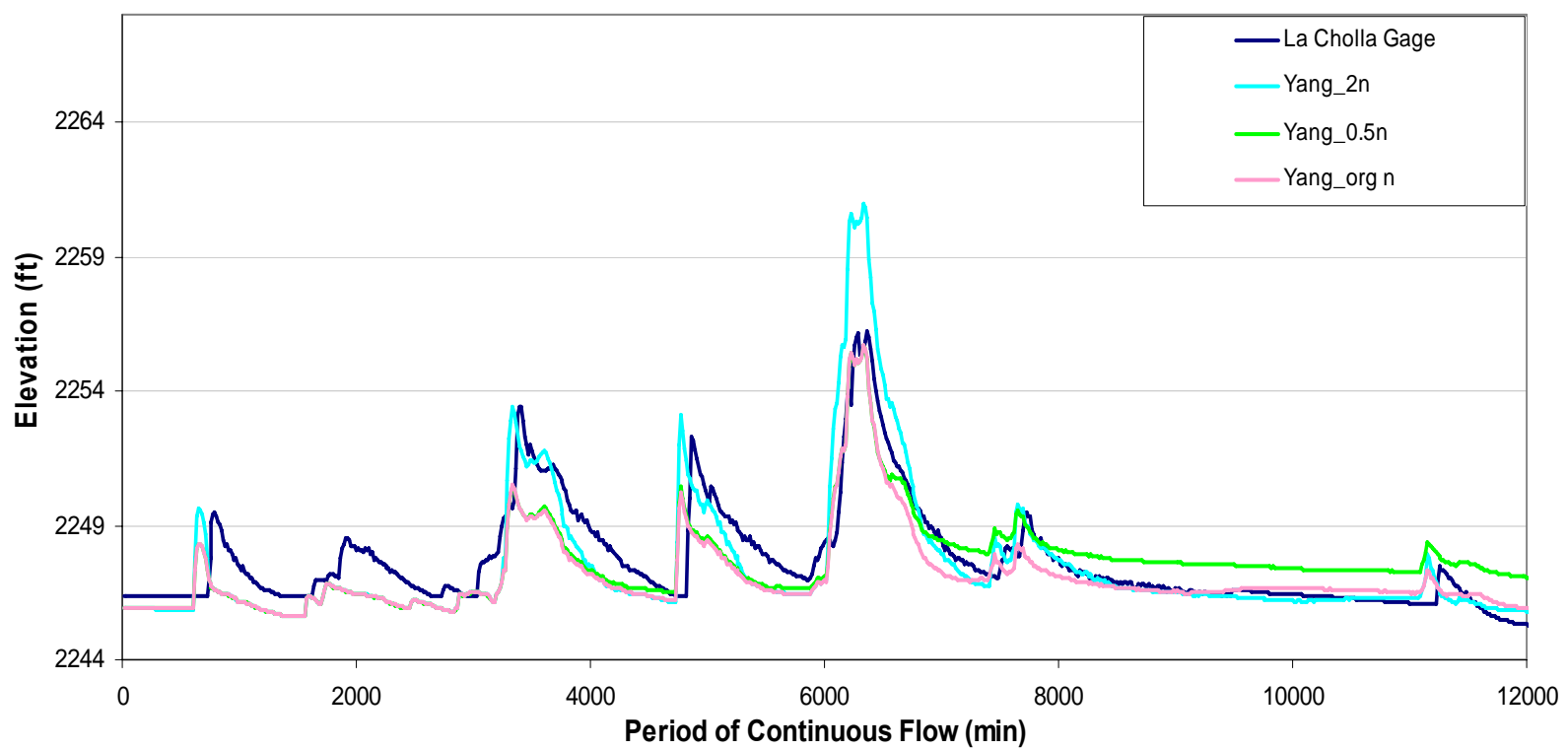

Figure 3. 1. 5. HEC-RAS simulated stage hydrographs at La Cholla using different Manning's n values

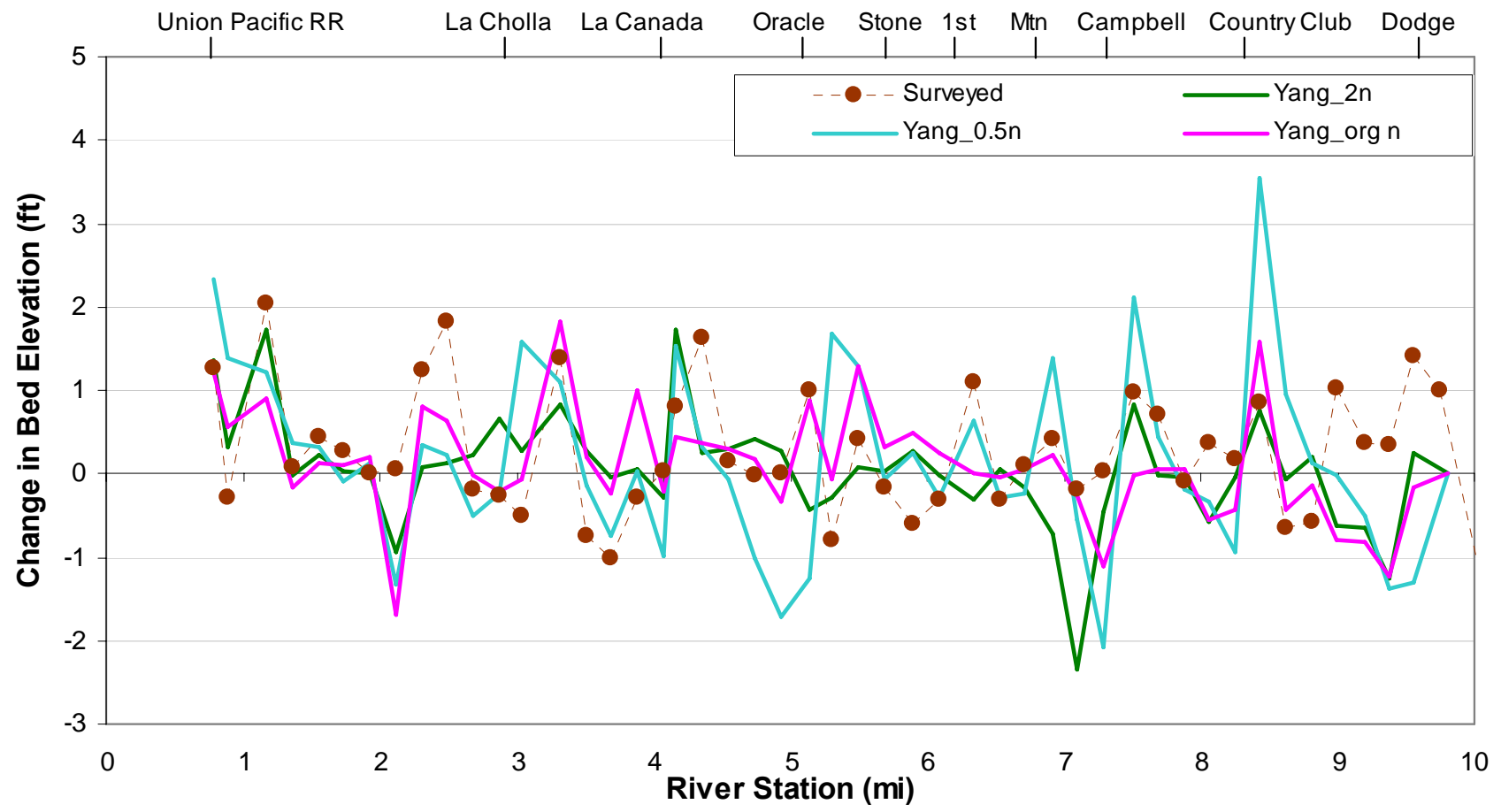

Figure 3. 1. 6. HEC-RAS simulated averaged bed elevation changes using different Manning's n values 


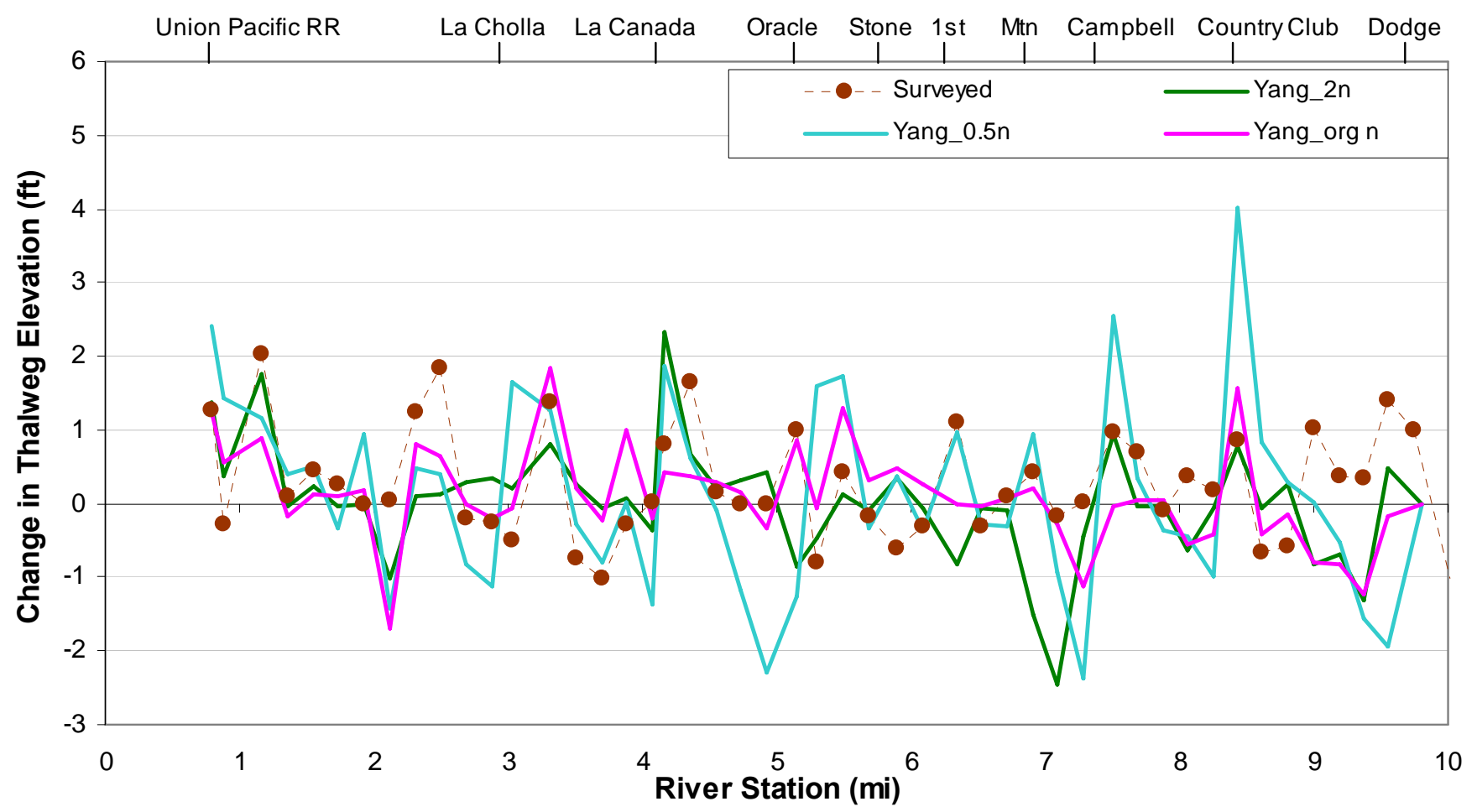

Figure 3. 1. 7. HEC-RAS simulated bed elevation changes at the thalweg using different Manning's n values

Table 3. 1. 4. Statistical analysis of stage

\begin{tabular}{|c|c|c|c|}
\hline Parameters & Yang_original n & Yang_0.5n & Yang_2n \\
\hline Correlation Factor & $\mathbf{0 . 8 6 7}$ & 0.207 & 0.424 \\
\hline Root Mean Squared Error & $\mathbf{1 . 0 8 8}$ & 1.277 & 1.254 \\
\hline Nash Sutcliffe Efficiency (E) & $\mathbf{0 . 6 8 2}$ & 0.562 & 0.578 \\
\hline
\end{tabular}

Table 3. 1. 5. Statistical analysis for average bed elevation change

\begin{tabular}{|c|c|c|c|}
\hline Parameters & Yang (origina) & Yang (2n) & Yang (0.5n) \\
\hline Correlation Coefficient & $\mathbf{0 . 3 4 5}$ & 0.298 & 0.219 \\
\hline Root mean squared error (RMSE) & $\mathbf{0 . 8 2 1}$ & 0.863 & 1.189 \\
\hline Nash Sutcliffe Efficiency (E) & $\mathbf{- 0 . 2 9 1}$ & -0.426 & -1.710 \\
\hline
\end{tabular}


Table 3. 1. 6. Statistical analysis for bed elevation change at the thalweg

\begin{tabular}{|c|c|c|c|}
\hline Parameters & Yang & Yang (2n) & Yang (0.5n) \\
\hline Correlation Coefficient & $\mathbf{0 . 2 3 8}$ & 0.128 & 0.179 \\
\hline Root mean squared error (RMSE) & $\mathbf{1 . 7 0 3}$ & 1.690 & 1.960 \\
\hline Nash Sutcliffe Efficiency (E) & $\mathbf{- 1 . 4 5 0}$ & -1.414 & -2.248 \\
\hline
\end{tabular}

\subsubsection{Change in Time Steps}

The sensitivity of modeling results to change in time steps was examined by running the model using $1 \mathrm{~min}, 1.5 \mathrm{mins}$ and 3 mins time steps for Exner equation. In the analysis all the other model input parameters were kept the same except for the time step.

Figs.3.1.8 and 3.1.9 showed the results of averaged and at the thalweg bed elvation changes by using the changed time steps. Both showed the increase or reduction of time steps did not produce better results. The statistical parameters of mean error, correlation, root square mean error, and Nash-Sutcliffe efficiency (E) in Tables 3.1.7 and 3.1.8 indicated Yang's equation using the default time step in HEC-RAS yielded the best match to the observed data. The default number of iterations for bed exchange calculation per flow time step in HEC-RAS is 10. Therefore, the time step for soliving the Exner equation is 0.1 times of flow time step equal to $1.5 \mathrm{~m}$ mins.

Table 3. 1. 7. Statistical analysis for average bed elevation changes using different time steps

\begin{tabular}{|c|c|c|c|}
\hline Parameters & Yang_1.5 min & Yang_1 min & Yang_5 min \\
\hline Mean Error & $\mathbf{- 0 . 2 0}$ & -0.20 & -0.15 \\
\hline Correlation factor & $\mathbf{0 . 3 5}$ & 0.29 & 0.20 \\
\hline Root Mean Squared Error (RMSE) & $\mathbf{0 . 8 2}$ & 0.90 & 0.88 \\
\hline Nash Sutcliffe Efficiency (E) & $\mathbf{- 0 . 2 9}$ & -0.73 & -0.68 \\
\hline
\end{tabular}

Table 3. 1. 8. Statistical analysis for the thalweg elevation change using different time steps

\begin{tabular}{|c|c|c|c|}
\hline Parameters & Yang_1.5 min & Yang_1 min & Yang_5 min \\
\hline Mean Error & $\mathbf{1 . 1 8}$ & 1.16 & 1.24 \\
\hline Correlation factor & $\mathbf{0 . 2 4}$ & 0.22 & 0.24 \\
\hline Root Mean Squared Error (RMSE) & $\mathbf{1 . 7 0}$ & 3.08 & 3.08 \\
\hline Nash Sutcliffe Efficiency (E) & $\mathbf{- 1 . 4 5}$ & -1.61 & -1.60 \\
\hline
\end{tabular}




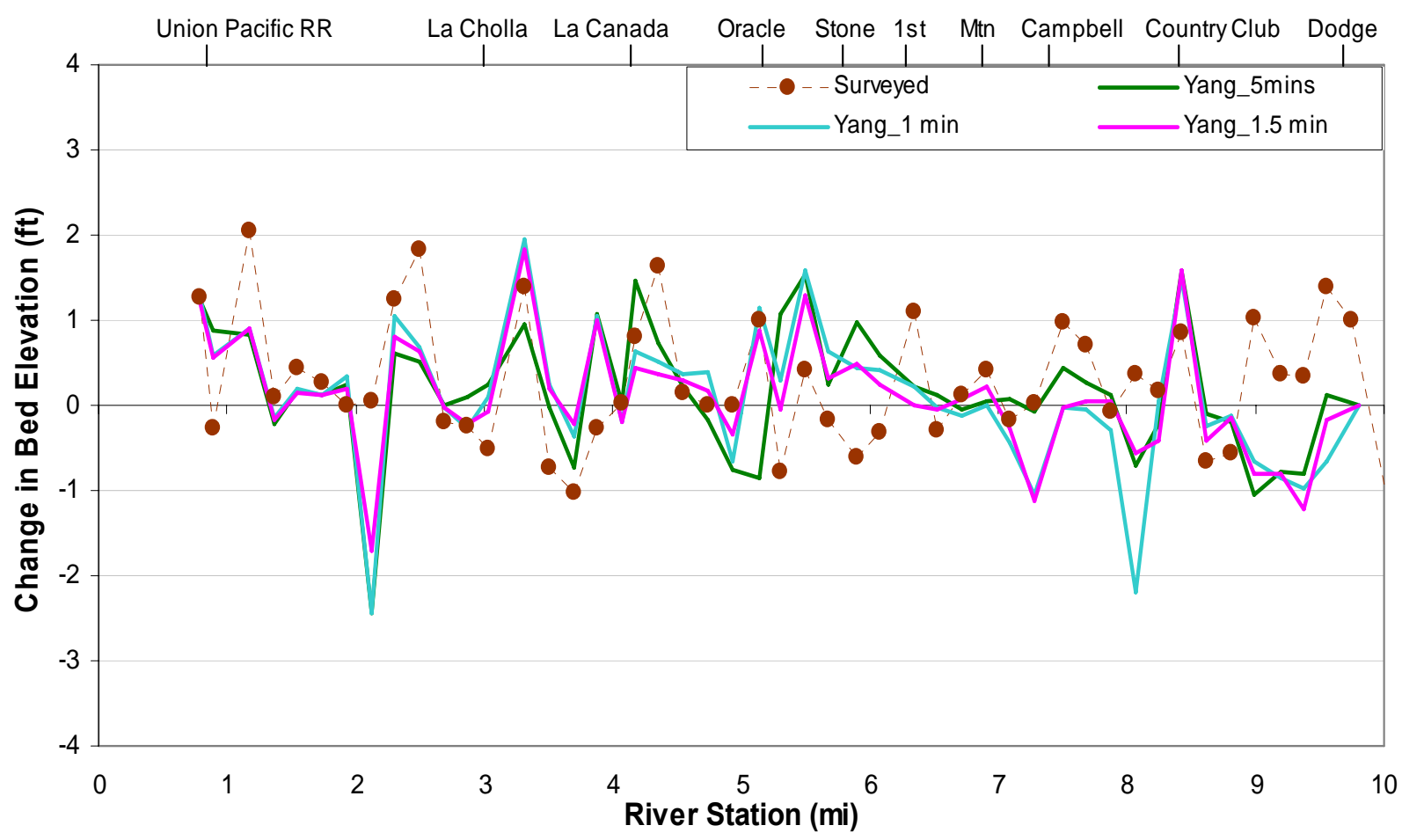

Figure 3. 1. 8. HEC-RAS simulated averaged bed elevation changes using different time steps

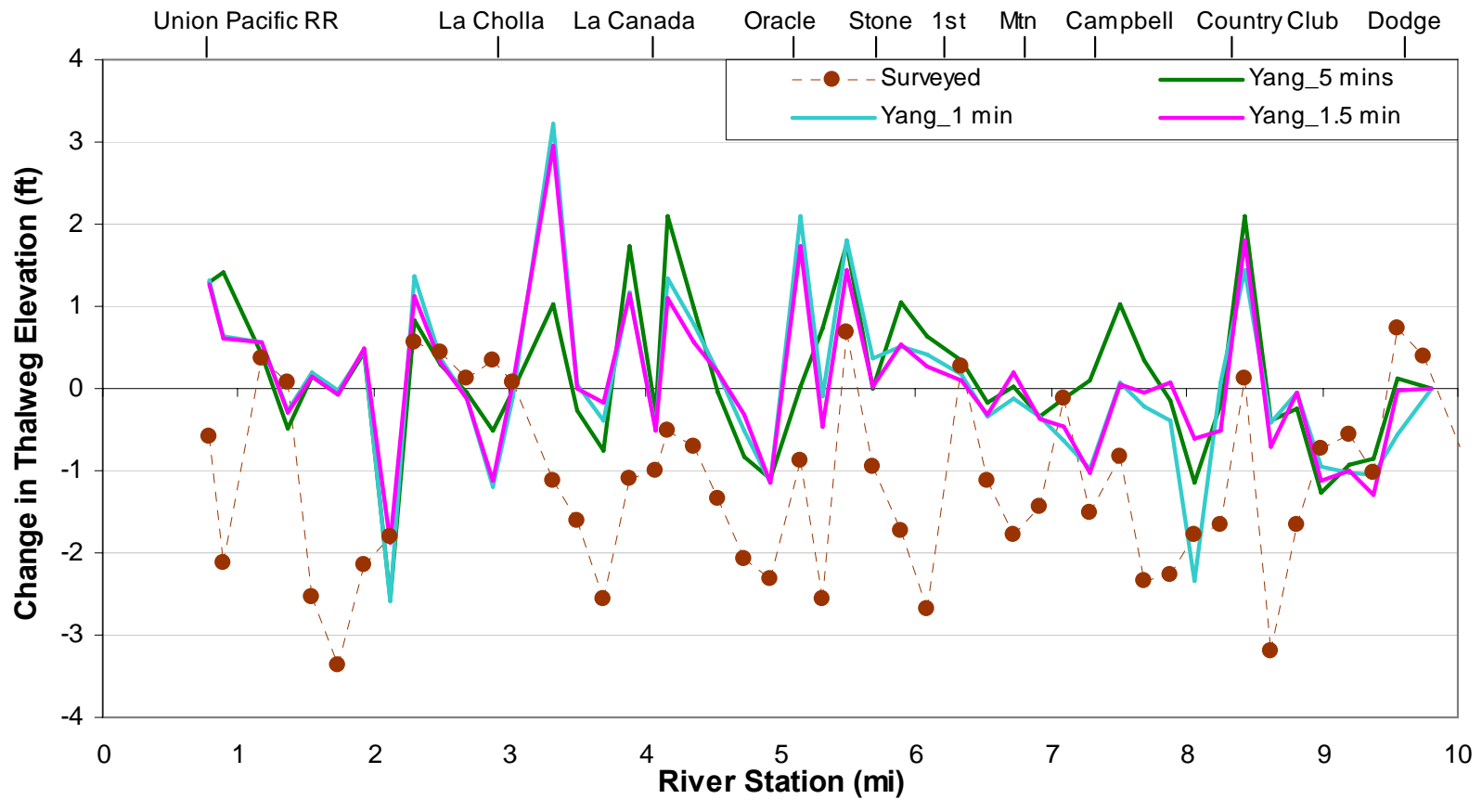

Figure 3. 1. 9. HEC-RAS simulated bed elevation changes at the thalweg using different time steps 


\subsubsection{Steady vs Unsteady Flow Model}

The results of stage hydrograph from the unsteady flow model showed overprediction whereas those from the quasi- unsteady flow showed underpredictions. From statistical analysis shown in Table 3.1.9, it is difficult to state which one is performing better. However, in the case of quasi-unsteady flow, Yang's equation is performing the best whereas for unsteady flow, the normal depth as boundary condition is performing the best.

Table 3. 1. 9. Statistical analysis of stage

\begin{tabular}{|c|c|c|}
\hline Parameters & Yang & Unsteady_flow \\
\hline Correlation Factor & $\mathbf{0 . 8 6 7}$ & 0.950 \\
\hline Root Mean Squared Error & $\mathbf{1 . 0 8 8}$ & 1.188 \\
\hline Nash Sutcliffe Efficiency (E) & $\mathbf{0 . 6 8 2}$ & 0.621 \\
\hline
\end{tabular}

Fig.3.1.10 shows that unsteady flow performs better than the quasi-unsteady flow for predicting stages at the peak. The unsteady flow model accurately predicted not only the peak discharges but also the arriving time of each peak. It also accurately predicted the observed stages at the rising limb of the stage hydrographs, but over-predicted the stages at the receding limb. This is attributed to the reduction of roughness due to deflected vegetation and wash-out dunes not being considered in the HEC-RAS model. Although the quasi-unsteady flow model accounted for the changes in bed elevations on stages, it generally under-predicted stages and only yielded a close match at the peak discharge of 37,913 cfs. Therefore, the unsteady flow model performs better than the quasi-unsteady flow model if flood stage is the only parameter to consider. However, quasiunsteady can yield a close match to the peak discharge after calibrating the roughness with some sacrifice in accuracy at other stages. 


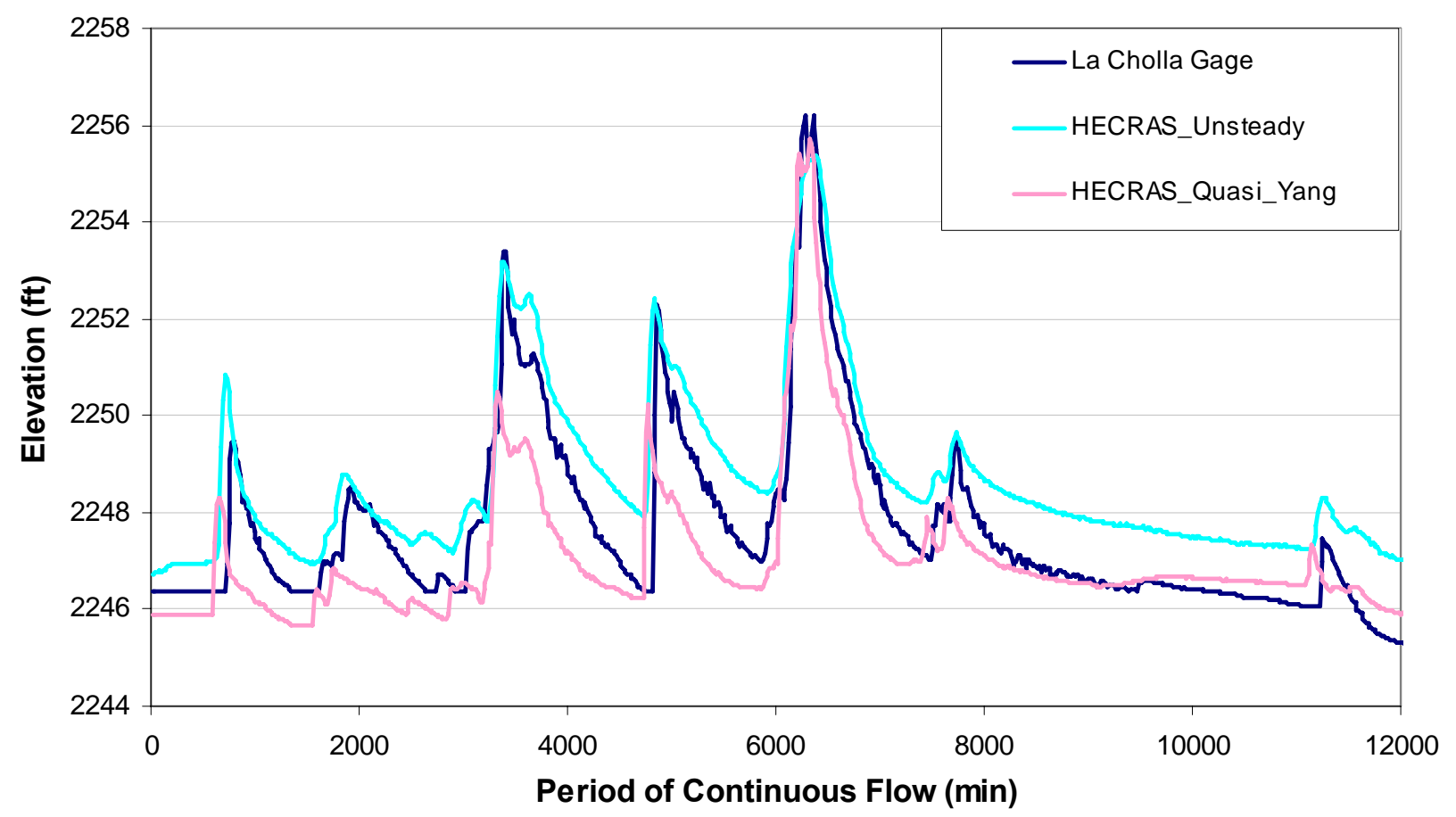

Figure 3. 1. 10. HEC-RAS simulated stage hydrographs at La Cholla using different flow models

\subsubsection{Deposited/Eroded Sediment Volume}

If deposition occurred between two cross sections, the change of sediment volume is positive. Otherwise, the change of volume is negative. The deposited or eroded sediment volume between two bridges was calculated by adding all the deposited $(+)$ and eroded (-) sediment volumes between two consecutive cross sections within the given reach. The total deposited or eroded sediment volume in the entire study reach was calculated by adding all the deposited/eroded sediment volumes for the study reach. The total deposited sediment volume is $+37,576$ cubic yards for the Yang's equation, and $+71,276 \mathrm{cu}$ yards for the Laursen equation and +40,949.27 cu yard for the Ackers-White equation. The results were compared with the original surveyed cumulative volume of 176,105 cu yards deposition calculated from the surveyed data in JE Fuller H\&G Inc. (2006) as shown in Figure 3.1.11. HEC-RAS has under predicted the total deposition although it correctly predicted that deposition rather than erosion occurred during the storm event. The calculated change of volume at each surveyed cross sections together with the surveyed data are plotted in Figure 3.1.12. Table 3.1.10 is the statistics of calculated deposited/eroded sediment volumes per mile between two consecutive bridges. The Laursen's equations yielded the highest deposited sediment volumes. 


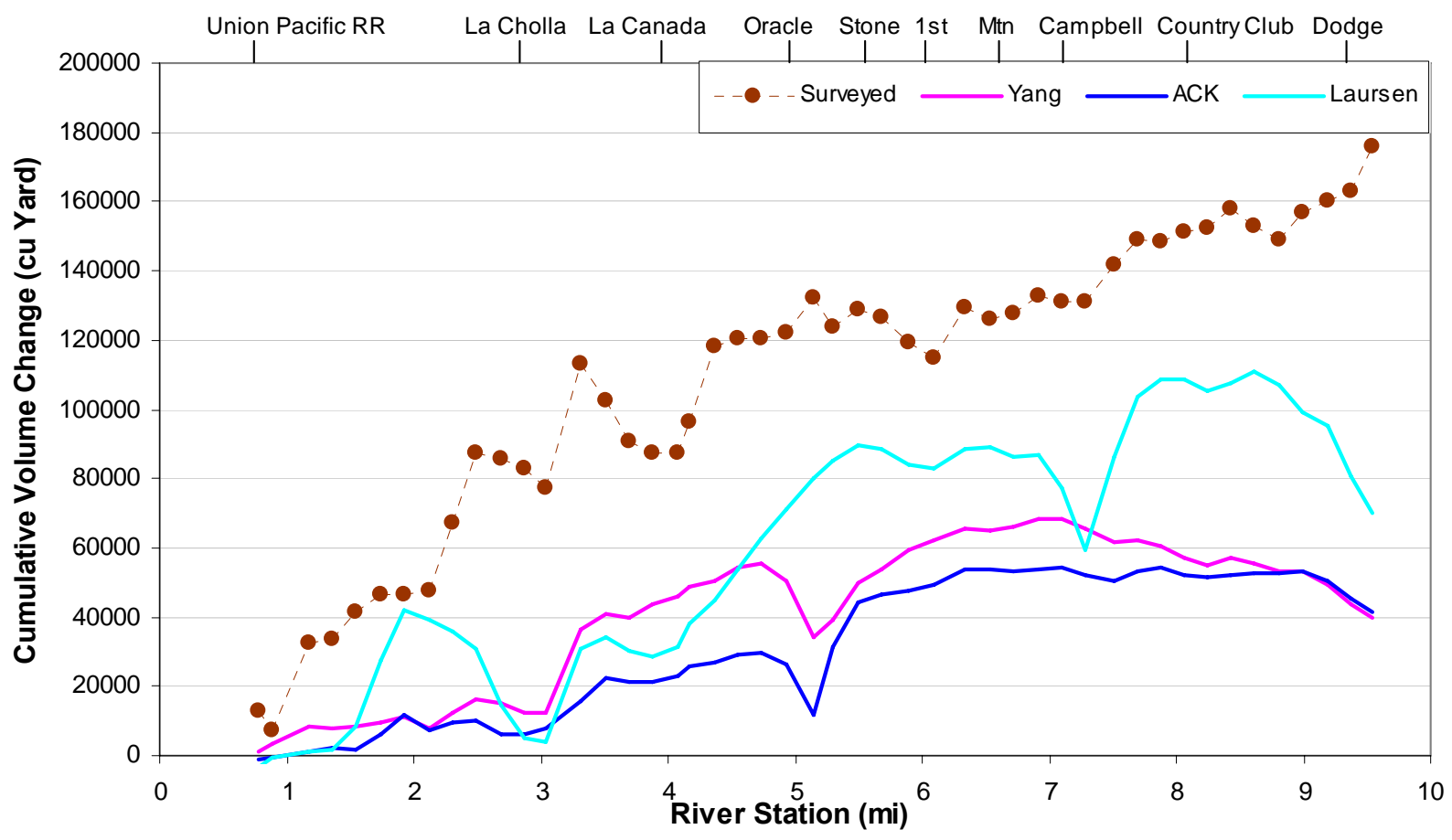

Figure 3. 1. 11. HEC-RAS simulated cumulative volume change for different sediment transport equations

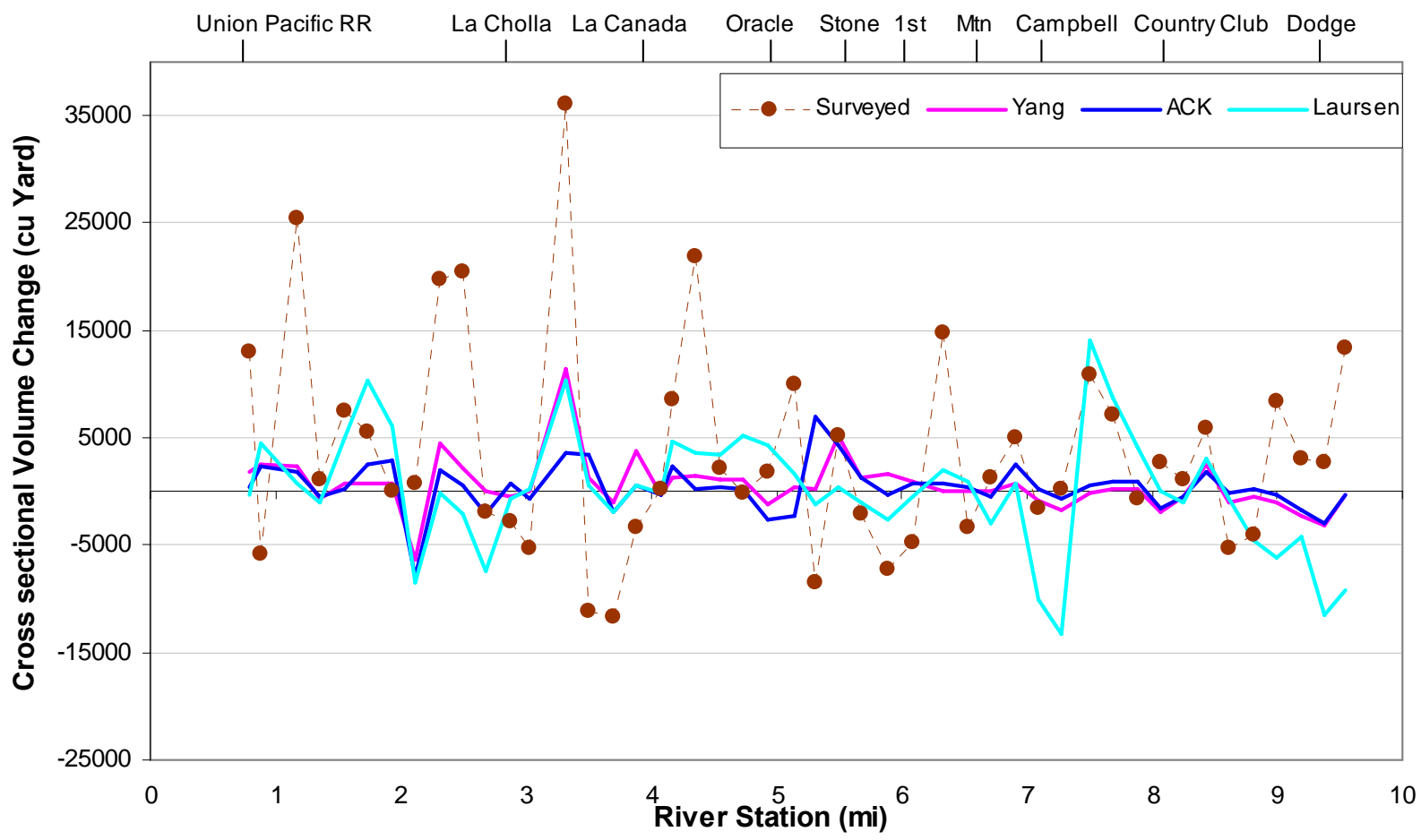

Figure 3. 1. 12. HEC-RAS simulated cross sectional volume change for different sediment equations 
Table 3. 1. 10. Statistical analysis for depositied/eroded sediment volume per mile between the bridges

\begin{tabular}{|c|c|c|c|}
\hline Statistics & Yang & Ackers-White & Laursen \\
\hline Mean Error & $-13,952.86$ & $-3,071.91$ & $3,661.93$ \\
\hline $\begin{array}{c}\text { Root Mean Square } \\
\text { Error(RMSE) }\end{array}$ & $31,814.75$ & $24,643.79$ & $29,688.47$ \\
\hline Nash-Sutcliffe Efficiency & -0.84 & -0.10 & -0.60 \\
\hline Correlation Coefficient & -0.09 & -0.41 & -0.58 \\
\hline Total Cum Volume (cu yard) & $37,576.01$ & $40,949.27$ & $71,276.32$ \\
\hline
\end{tabular}

\subsubsection{Identification of Best-Performing Sediment Model}

Different models were run for different maximum erodible depths and sediment transport equations by selecting Ruby as fall velocity method and Exner 5 as the sediment sorting method. To identify the best performing model, a sensitivity analysis was conducted for sediment transport formulas and Manning's roughness coefficient. A summary of statistical parameters for simulated stage hydrograph, averaged and at the thalweg bed elevation changes were shown in Table 3.1.1 to Table 3.1.3. As a result of the calibration, the quasi-unsteady flow model by using the Yang's equation were shown to provide the best match between the observed changes in stages, average and at the thalweg bed elevation changes.

The sensitivity analysis showed the model is sensitive to the roughness value, time step, and sediment transport equation. Although the $\mathrm{n}$ value varies during a flood event, especially in this vegetated ephemeral river, the HEC-RAS model treated roughness as a constant. The statistical parameters in Table 3.1.5 and 3.1.6 indicated Yang's equation yielded the best result for average bed elevation change and changes at the thalweg. The statistical parameters in Table 3.1.7 and Table 3.1.8 indicated that Yang's equation yielded the best result for the default time step embedded in the HEC-RAS model.

The modeling parameters for the best performing unsteady flow and quasi-unsteady flow models were listed below,

Calibrated/Final Parameters for unsteady flow analysis:

- Upstream boundary condition: stage hydrograph

- Downstream boundary condition: normal depth

- $\quad$ Bed slope for normal depth: 0.003

- Manning's n value: 0.03 for main channel, 0.06 for floodplain

- Bridge coefficient $\left(\mathrm{C}_{\mathrm{D}}\right)$ : 2.7 at La Cholla

- Initial conditions: $500 \mathrm{cfs}$ 
- Stability factor:

- Interval time: 15 mins

Calibrated/Final Parameters for sediment transport analysis :

- Material size: Surface, fines removed

- Upstream boundary condition for flow: Flow series

- Downstream boundary condition for flow: Normal depth

- Upstream boundary condition for sediment: Equilibrium load

- Downstream boundary condition for sediment: Equilibrium load

- $\quad$ Bed slope for normal depth: 0.003

- Base flow: $20 \mathrm{cfs}$

- Roughness (Manning's n Value): Original

- Sediment Transport Formulas: Yang

- Sorting Method : Exner 5

- Fall Velocity Method : Ruby

- Maximum erodible depth: $10 \mathrm{ft}$ at every cross section except at grade control structures , where the erodible depth is 0 .

- Interval time: 15 mins

The results of averaged and at the thalweg bed elevation changes from the best performing model were shown in Figs.3.1.13 and 3.1.14. The accumulative sediment depositions between two consecutive bridges per mile were shown in Fig.3.1.15. Table 3.1.11 summarizes the statistical parameters for the best performing model.

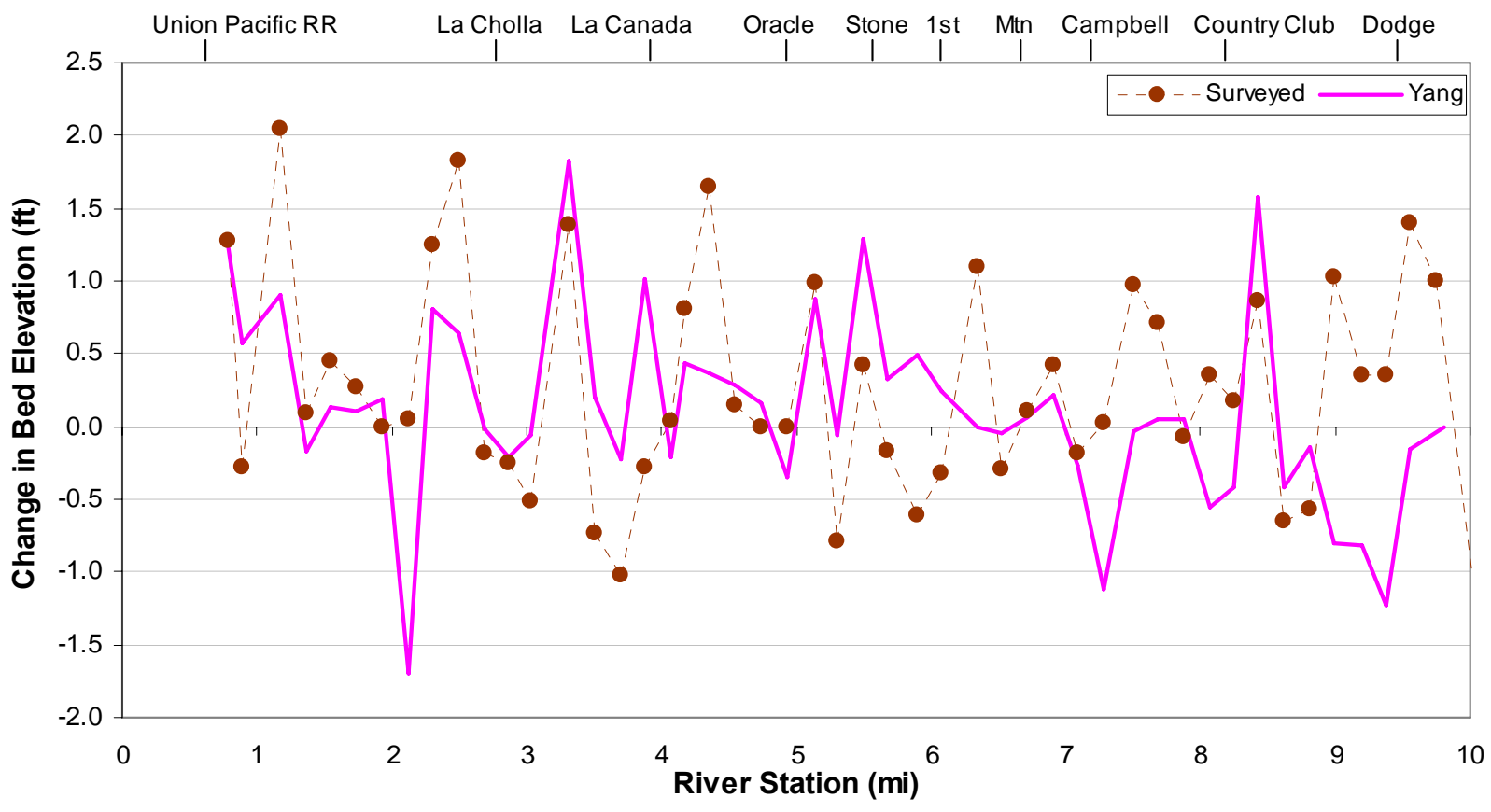

Figure 3. 1. 13. HEC-RAS best performed model for averaged bed elevation change 


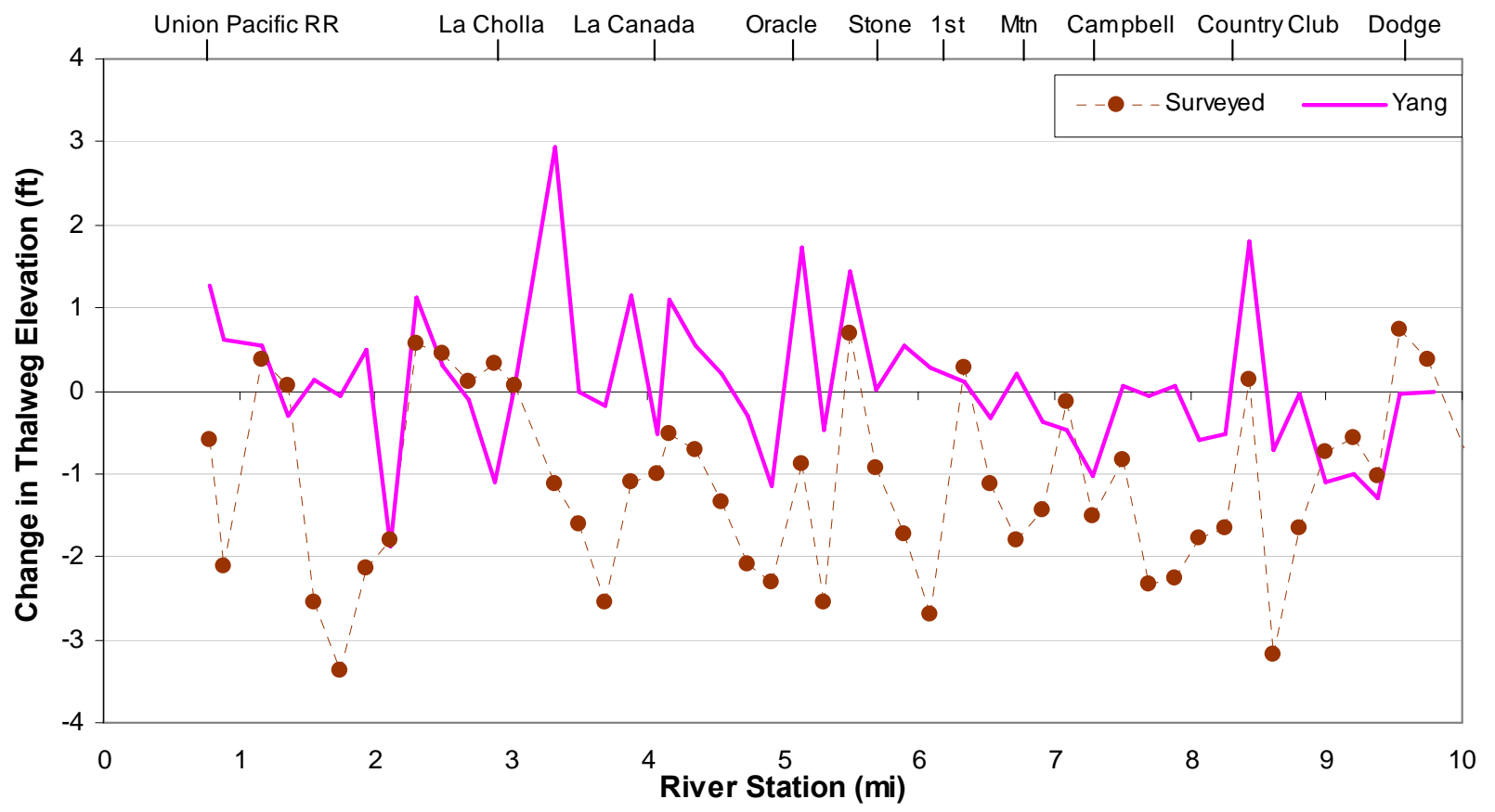

Figure 3. 1. 14. HEC-RAS best performed model of bed elevation changes at the thalweg

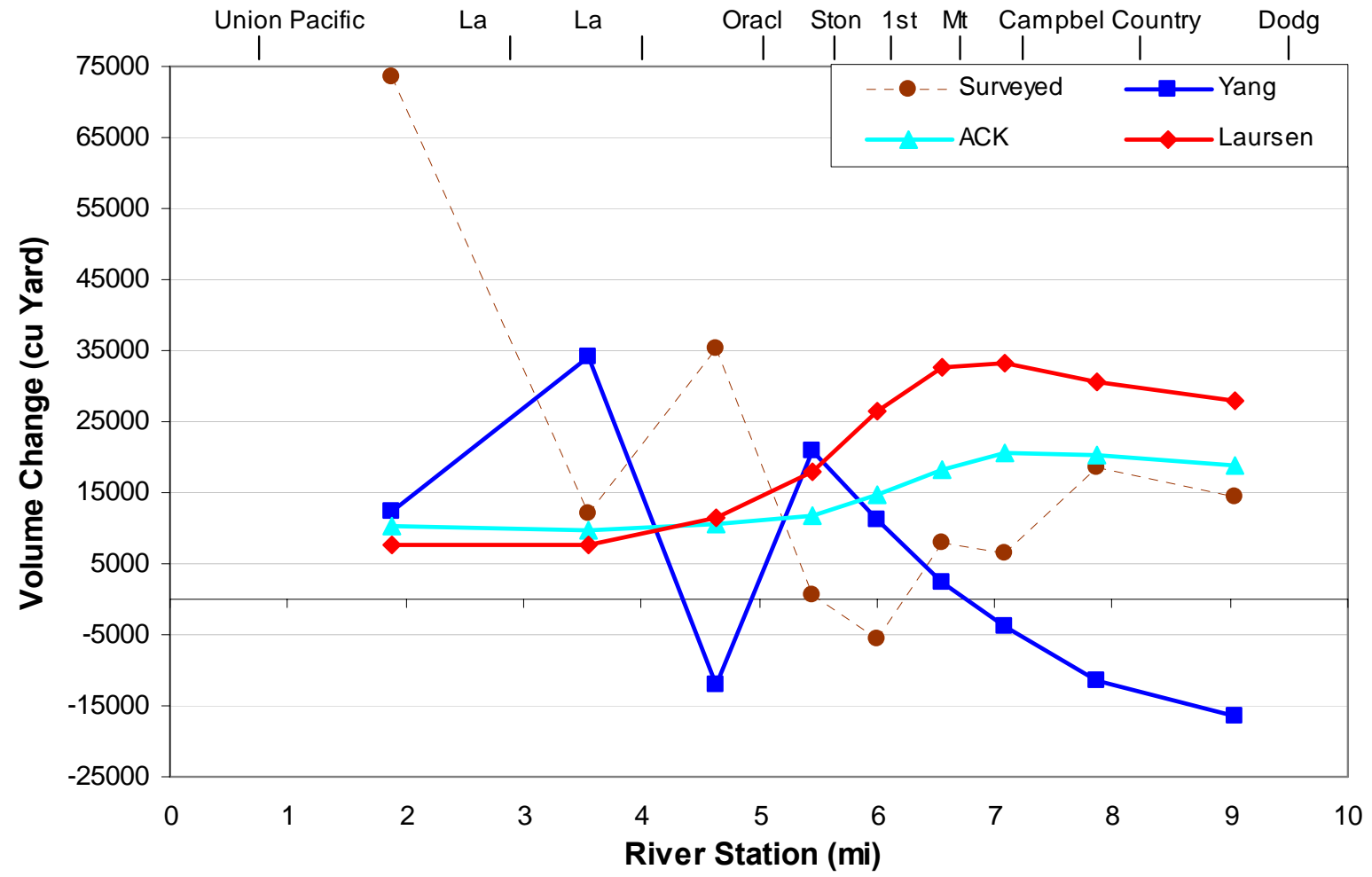

Figure 3. 1. 15. HEC-RAS simulated volume changes between bridges for different sediment equations 
Table 3. 1. 11. Statistical analysis for Yang's 73 equation

\begin{tabular}{|c|c|c|c|c|c|}
\hline \multirow{2}{*}{ Model Performance Factor } & \multicolumn{4}{|c|}{ HEC-RAS (Yang sand and gravel equations) } \\
\cline { 2 - 6 } & $\begin{array}{c}\text { Changes at } \\
\text { the } \\
\text { Thalweg }\end{array}$ & $\begin{array}{c}\text { Averaged } \\
\text { Bed } \\
\text { Elevation } \\
\text { Changes }\end{array}$ & Stage & Total Volume & $\begin{array}{c}\text { Volume } \\
\text { per mile }\end{array}$ \\
\hline Mean Error & 1.180 & -0.2 & -0.487 & $-2,590.322$ & - \\
\hline Nash-Sutcliffe Efficiency & -1.450 & -0.291 & 0.682 & 0.166 & -0.84 \\
\hline Correlation Coefficient & 0.238 & 0.345 & 0.867 & 0.490 & -0.09 \\
\hline Root Mean Squared Error (RMSE) & 1.703 & 0.821 & 1.088 & $8,751.958$ & $31,814.75$ \\
\hline
\end{tabular}

\subsubsection{Summary and Conclusions}

In this project, an unsteady analysis on the Rillito River was performed using the HEC-RAS model. The results show that the HEC-RAS 4 Beta model performs adequately for unsteady flow simulation after a parameter calibration. This indicates that the HEC-RAS model has the ability to simulate the process of the stage and flow hydrograph during a storm event. However, there is some limitation when applying a rating curve as a boundary condition as this tends to cause stability problems. Model stability is increased when utilizing normal depth as the downstream boundary condition as opposed to a rating curve. The geometry parameters, such as roughness factor, bridge coefficient, and contraction factor, can be evaluated and better estimated through the sensitivity analysis. In the Rillito Creek project, we think that the original Manning's coefficient would be a better estimate to be applied.

This project included the establishment, calibration and analysis of a sediment transport model used to simulate a flood event that occurred on the Rillito River in July 2006. The process included the evaluation of three separate transport equations as well as an in-depth calibration and sensitivity analysis on the basis of several key model parameters. Based on the findings of the project analysis, the performance of the model most closely approximated the observed changes in bed elevation using the Yang's equation with a maximum depth of 10 feet, a normal depth energy slope of 0.003 , using the Ruby fall velocity equation, and surface material in the channel. The model is quite sensitive to choice of sediment transport equation and Manning's n.

Overall, the performance of all the sediment transport equations was not particularly accurate. Limitations of a 1-D model prevent sediment simulation from predicting the correct trend of erosion or deposition at a particular cross section. This suggests that the model could have benefited from a more refined geometry data or that the existing sediment transport equations operating within HEC-RAS 4.0 are insufficient to accurately model this reach of the Rillito River. However, the process of calibration and sensitivity analysis significantly improved the performance of the model from the default conditions 


\subsection{HEC-6 Model Input Data}

HEC-6 is a one-dimensional continuous simulation model that uses a sequence of steady flows to represent discharge hydrographs. There is no provision for simulating the development of meanders or specifying a lateral distribution of sediment load across a cross section. The cross section is subdivided into two parts: one has a movable bed, and the other does not. The movable bed is constrained within the limits of the wetted perimeter. The elevations of the entire wetted part in a cross section will rise or fall uniformly if deposition or erosion occurs. An option is available, however, which causes the bed elevation to be adjusted in horizontal layers when deposition occurs. Bed forms are not simulated; however, $\mathrm{n}$ values can be input as functions of discharge, which indirectly permits the consideration of bed forms. The user can also determine those effects from measured data. Density flow and secondary currents are not simulated. HEC-6 can simulate sediment transport a river network system, but it is subject to three restrictions:

- Sediment transport in distributaries is not possible.

- Flow around islands; i.e., closed loops, cannot be directly accommodated.

- Only one junction or local inflow point is allowed between any two cross sections

HEC-6 is designed to analyze long-term scour and/or deposition. An application to a single flood event must be performed with caution. HEC-6 bed material transport algorithms assume that equilibrium conditions are reached within each time step; however, the prototype is often influenced by unsteady non-equilibrium conditions during flood events. Equilibrium may not occur under these conditions because of the continuously changing hydraulic and sediment dynamics. If such situations predominate, single event analyses should be performed only on a qualitative basis. For gradually changing sediment and hydraulic conditions, such as for large rivers with slow rising and falling hydrographs, single event analyses may be performed with confidence.

\subsubsection{Geometry}

Cross sectional geometry data were obtained from a HEC-RAS geometric input file. HEC-6 directly uses the input geometric data (e.g. stations, elevation) rather than generating rating curves of area and wetted perimeter to calculate hydraulic parameters. The format of geometric data input used in HEC-6 is similar to that of HEC-2. The HEC-RAS geometric input data was converted into HEC-6 geometry input data with the help of a converter program provided by Joseph Hopper (personal communications). Each cross section was subdivided into three parts called subsections; namely, the left overbank, main channel and right overbank. However, the input data for each cross section was written following left overbank, right overbank and channel. Manning's values vary from 0.06 to 0.065 for the overbanks and from 0.03 to 0.035 for the main channel.

Effective flow areas were specified as the area located between the left and right overbanks. HEC-6 has no provision for calculating flow at bridges other than by standard backwater calculations. Bridges were simulated by including the real geometry of each pier into the cross section to reflect the net reduction of flow area. This method allows the simulation of general scour 
due to contraction through the bridge. Fig.3.2.1 shows a bridge cross section in the HEC-6 model. The first figure shows the cross section with four piers in the middle that has been displayed using HEC-RAS. The second figure shows the bridge cross section in HEC-RAS.
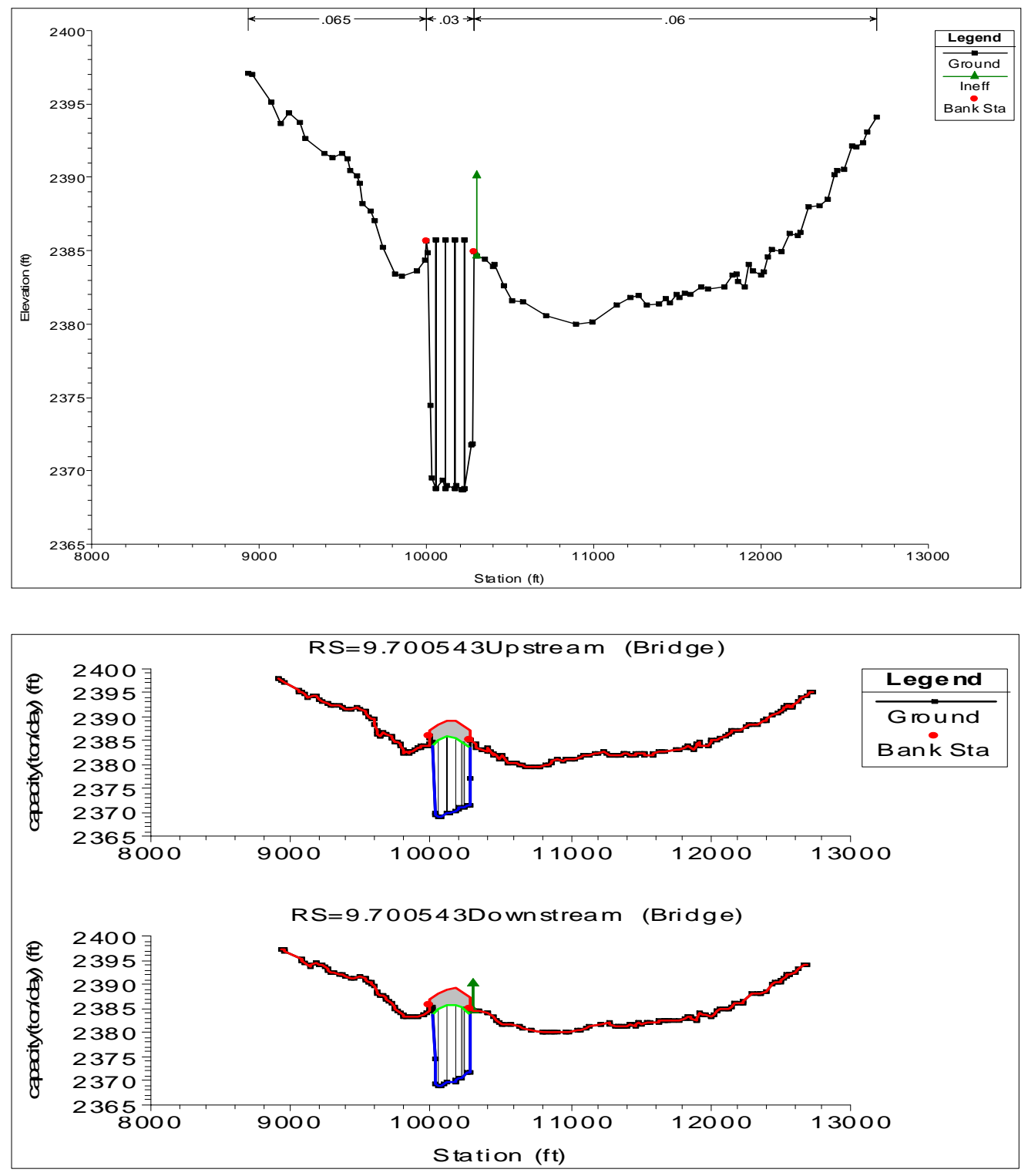

Figure 3. 2. 1. Schematic of a bridge cross section with piers

\subsubsection{Hydrology}

Flow hydrographs were used as an input for the model. The observed flow discharges hydrograph having 15-min time interval was the upstream boundary condition. A water surface elevation must be specified at the downstream boundary for the backwater calculation. A rating 
curve instead of a stage hydrograph was provided for prescribing the downstream boundary condition, which was calculated from a discharge relation for broad crested weirs as below,

$$
Q=\frac{2}{3}\left[\frac{2}{3} g\right]^{1 / 2} L H^{3 / 2}
$$

Where: $\mathrm{Q}$ = flow in cubic feet per second (cfs),

$\mathrm{g}=$ gravity- feet per second squared, $32.2\left(\mathrm{ft} / \mathrm{s}^{2}\right)$

$\mathrm{L}=$ width of the weir, $(273.75 \mathrm{ft})$

$\mathrm{H}=$ water depth $(\mathrm{ft})$

The weir elevation at the downstream boundary cross-section is $2204.68 \mathrm{ft}$. HEC-6 requires no more than 40 discharges to define the rating curve, so that discharges falling between two prescribed points were interpolated linearly.

Manning's $n$ values are required for each subsection of a cross section. It is not possible to automatically change $n$ values with respect to time. Constant (fixed) $n$ values are entered in the input file. Limerinos' (1970) relationship is available for the determination of Manning's $n$ based upon the hydraulic radius and the gradation of bed material. This relationship is written below,

$$
n=\frac{0.0926 R^{1 / 6}}{1.16+2 \log _{10}\left(\frac{R}{d_{84}}\right)}
$$

where $d_{84}=$ particle size in the stream bed of which $84 \%$ of the bed is finer, in feet

$\mathrm{R}=$ hydraulic radius, in feet

The friction loss in the HEC-6 model was calculated using the composite Manning's roughness, which was the averaged $n$ value of each subsection weighted by the area of each subsection.

\subsubsection{Sediment}

Sediment data includes fluid and sediment properties, inflow sediment load data, and gradations of bed material. The transport capacity relationship and unit weights of deposited material are also counted as the sediment input data. The transport capacity relationships to be used by HEC6 to compute sediment load for a given water discharge are:

1. Toffaleti's (1966) transport function.

2. Madden's (1963) modification of Laursen's (1958) relationship 
3. Yang's (1973) stream power for sands

4. DuBoys' transport function (Vanoni 1975)

5. Ackers-White (1973) transport function

6. Colby (1964) transport function

7. Toffaleti (1966) and Schoklitsch (1930) combination

8. Meyer-Peter and Müller (1948)

9. Toffaleti and Meyer-Peter and Müller combination

10. Madden's (1985, unpublished) modification of Laursen's (1958) relationship, and

11. Copeland's (1990) modification of Laursen's relationship (Copeland and Thomas 1989)

For this specific case, five sediment transport equations were able to run without crashing the program, those were Toffaleti (1966), Yang (1973), Ackers-White (1973), Madden's modification of Laursen (1985) and Toffaleti Meyer-Peter Müller (TMPM) (1985). From the statistical analysis and examining the results in Fig. 3.2.4, the best result was obtained by using Toffaleti's transport equation.

The grain sizes of sediment particles were provided as input data. Small sizes behave much differently from large sizes. Therefore, it was necessary to classify sediment material into a group suitable for application of different transport equations. Three basic classes considered by HEC-6 are clay, silt, and sands-boulders, which are identified and subdivided based on the American Geophysical Union (AGU) classification scale (Table 2-1, Vanoni 1975). Based on this classification, the sediment in the Rillito River was identified as "sand".

To analyze sediment transport, scour, and deposition along a river reach, knowledge of the relationship between the flow discharge $\left(Q\right.$ in $\mathrm{ft}^{3} / \mathrm{s}$ or $\left.\mathrm{m}^{3} / \mathrm{s}\right)$ and the corresponding sediment load $\left(Q_{\mathrm{s}}\right.$ in tons/day) for that flow is necessary. The most accurate method of computing this relationship is from a discharge gage, where suspended sediment samples are also periodically taken. Over the sampling period, these gaged data may be plotted to estimate an appropriate $Q-Q_{\text {s }}$ relationship, usually plotted as a straight line on a logarithmically scaled paper. Since there is no measurement of sediment load in the Rillito River, the $Q-Q_{\mathrm{s}}$ relationship was not available at the upstream boundary. This study assumed equilibrium load so that the inflow sediment load was calculated by using the Yang's equation (Yang 1973) as follows,

$$
\begin{aligned}
& \frac{V_{c}}{w_{f}}=\frac{2.5}{\log \left(u_{*} d_{50} / v\right)-0.06}+0.66 \text { for } 1.2<\frac{u_{*} d_{50}}{v}<70 \\
& \text { and } \frac{V_{c}}{w_{f}}=2.05 \text { for } \frac{u_{*} d_{50}}{v} \geq 70
\end{aligned}
$$

where; 


$$
\begin{aligned}
& V_{c}=\text { critical velocity, } \\
& w_{f}=\text { fall velocity }, \\
& \mathrm{u}_{*}=\text { shear velocity, } \\
& \mathrm{d}_{50}=\text { median grain size, and } \\
& v=\text { viscosity }
\end{aligned}
$$

Table 3.2.1 summarizes the results of sediment load versus flow discharge. This inflow sediment load table covered the entire range of discharges during this event.

Table 3. 2. 1. Flow discharge vs sediment load

\begin{tabular}{|r|r|}
\hline \multicolumn{1}{|c|}{$\mathbf{Q}$ (cfs) } & Qs (ton/d) \\
\hline 0.10 & 0.00 \\
22.60 & 7.28 \\
39.83 & 31.42 \\
239.98 & 583.91 \\
771.43 & $3,604.41$ \\
$2,021.62$ & $12,744.47$ \\
$5,957.20$ & $53,034.07$ \\
$12,972.65$ & $150,971.03$ \\
$15,690.39$ & $195,790.37$ \\
$21,067.44$ & $291,255.01$ \\
$34,992.93$ & $584,307.23$ \\
$36,888.18$ & $632,038.96$ \\
$39,000.00$ & $765,830.62$ \\
\hline
\end{tabular}

The calculated Q vs Qs calculated relationship results in the Figure 3.2.2 that shows the plotted straight line in the logarithmic-scale.

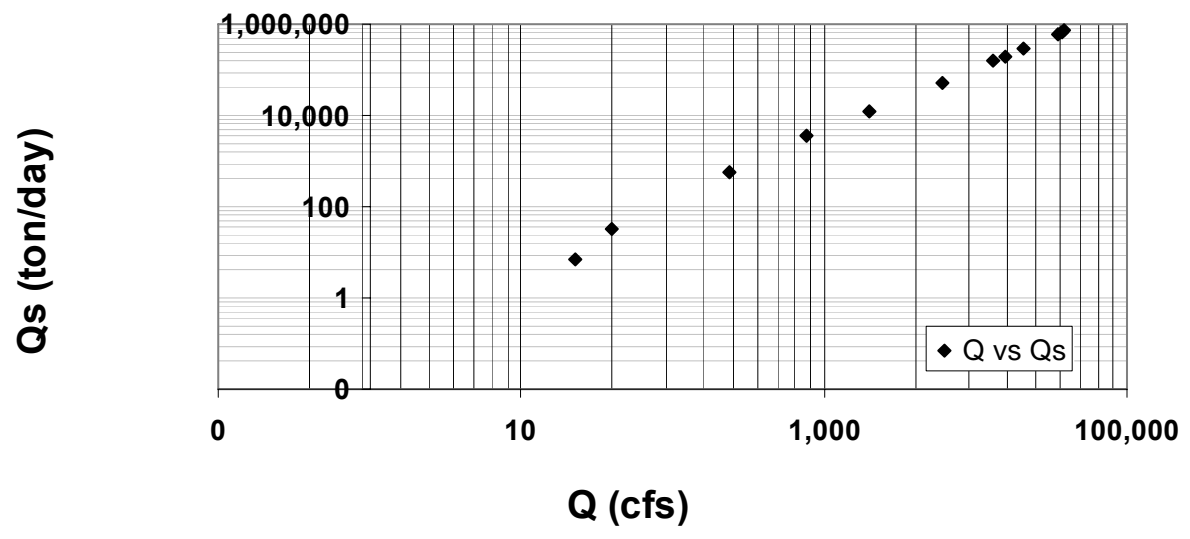

Figure 3. 2. 2. Flow discharge vs. sediment load 
Transport theory for sand relates the total moving sand and coarser load to the gradation of sediment particles on the bed surface. Armor calculations require the gradation of material beneath the bed surface and knowledge about the depth to bedrock or some other material that might prevent degradation. The gradation of substrate sediment material was shown as histograms to denote percent finer of a given sized material. Subsurface gradations are linearly interpolated for those cross sections with no survey data.

With regards to the sediment material in the stream bed, each cross section is divided into movable and fixed-bed portions. The movable bed limits can extend beyond the channel bank station. Scour and deposition will cause the movable bed to fall or rise by changing the cross section elevations within the movable bed at the end of each time step. The elevation of the channel bottom is specified in the input file. After determining the minimum channel elevation of each cross section, HEC-6 uses the channel bottom elevation to compute the depth of sediment material available for scour. The maximum depth of erodible bed material needs to be specified for each cross section. This study used $10 \mathrm{ft}$ as the maximum movable depth at all cross sections except for the sections having grade control structures, where the depth of movable bed layer is zero.

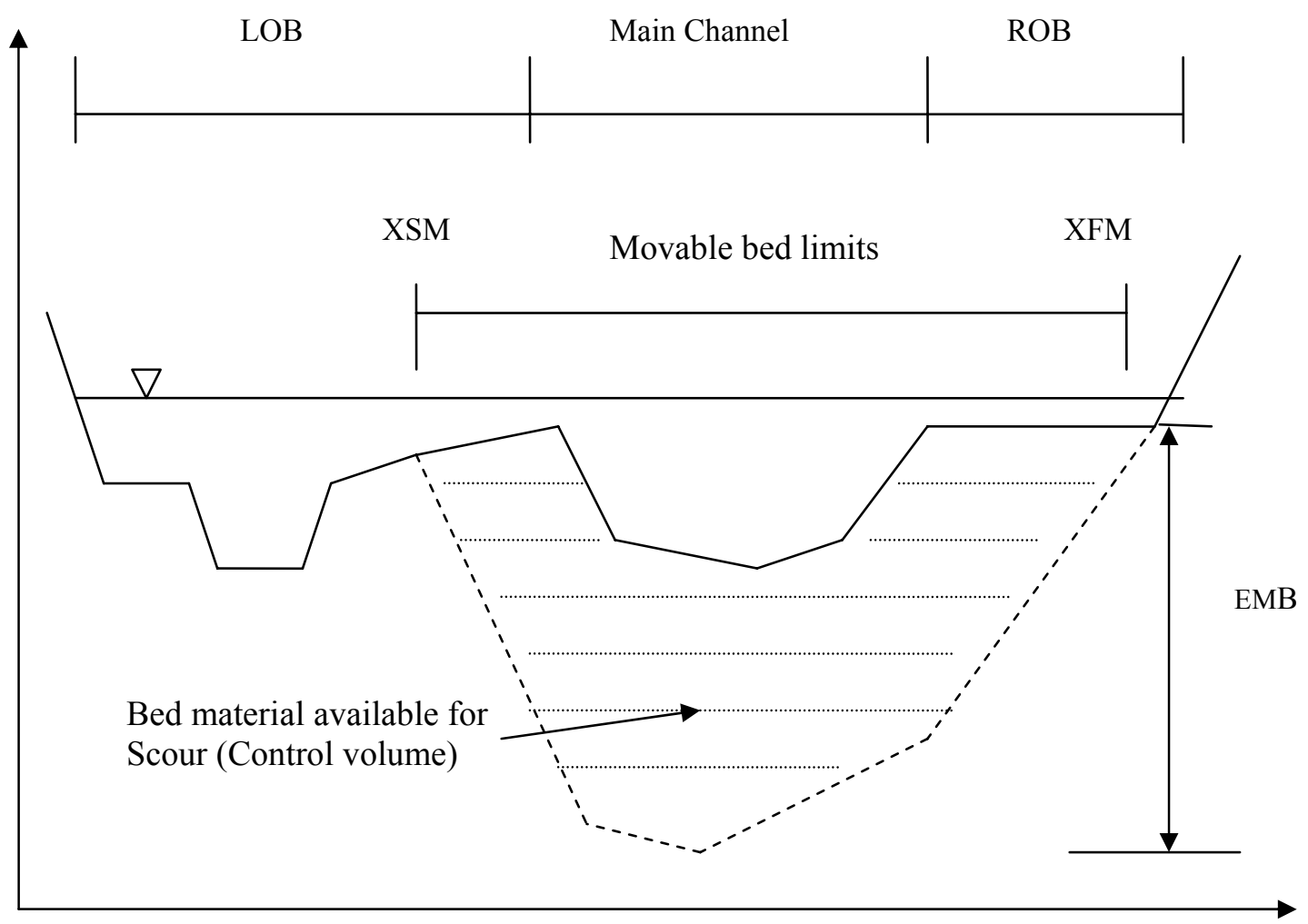

Figure 3. 2. 3. Movable bed material on the river bed 


\subsubsection{Choice of Transport Equation}

Sediment transport equations are for computing the sediment load from flow discharge for only the suspended load and/or bed load for those grain sizes found in the bed material, as these portions are most affected by stream modifications. Also, the various equations for sediment transport are appropriate only for certain ranges of sediment gradation.

HEC-6 was run using five transport equations, given that not all the available transport equations for this model were able to run for this specific case. The five equations suitable for the data were Toffaleti (1966), Yang (1973), the Madden-modified version of Laursen (1985), AckersWhite (1973) and Toffaleti -Meyer-Peter Müller. The results of stage hydrographs, cumulative sediment volumes, and changes in bed elevations were plotted in Figures 3.2.4 to 3.2.9. The water surface stage hydrograph was plotted comparing different outputs per transport equation to the USGS data at La Cholla, as shown in Fig. 3.2.4.

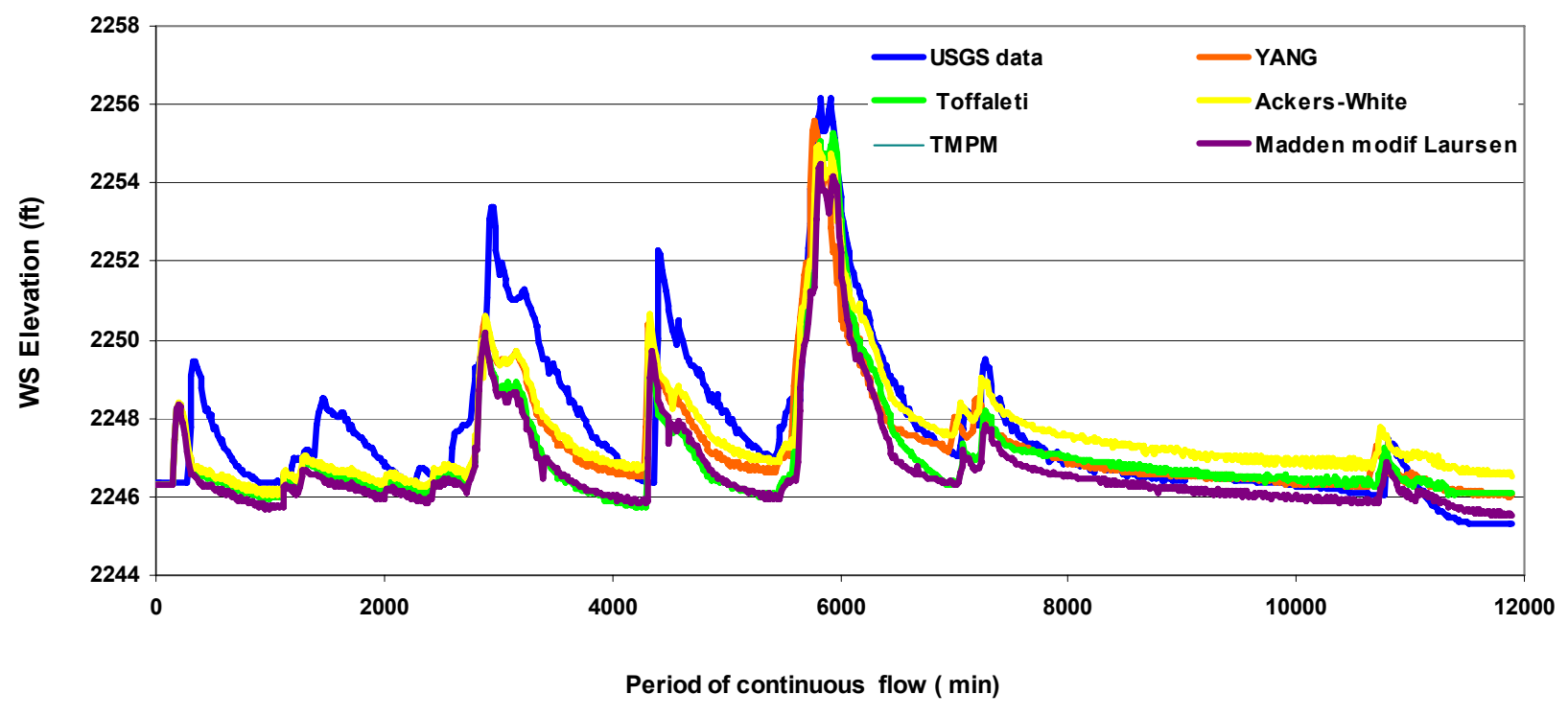

Figure 3. 2. 4. HEC-6 simulated stage hydrographs at La Cholla using different sediment transport equations (time step =15 min, Limerinos' equation was used) 
Table 3. 2. 2. Statistical analysis for the bed elevation change

\begin{tabular}{|l|c|c|c|}
\hline \multicolumn{4}{|c|}{ Statistics to the changes of elevations at the thalweg } \\
\hline Transport equation & Correlation & RMSE & Nash-Sutcliffe \\
\hline Yang X=5 min & 0.10 & 1.81 & -1.66 \\
\cline { 2 - 4 } Toffaleti & $\mathbf{0 . 3 6}$ & $\mathbf{1 . 5 3}$ & $\mathbf{- 0 . 9 1}$ \\
\cline { 2 - 4 } Ackers White & 0.27 & 1.55 & -0.95 \\
Maden modified Laursen & -0.09 & 8.06 & -51.81 \\
Toffaleti MPM & 0.31 & 1.49 & -0.81 \\
\hline \multicolumn{4}{|c|}{ Statictics to the changes of averaged bed elevations } \\
\hline Transport eq. & Correlation & RMSE & Nash-Sutcliffe \\
\hline Yang X=5 min & 0.28 & 1.44 & -0.69 \\
Toffaleti & $\mathbf{0 . 3 4}$ & $\mathbf{0 . 9 0}$ & $\mathbf{0 . 3 3}$ \\
Ackers White & 0.31 & 1.13 & -0.05 \\
Maden modified Laursen & -0.03 & 8.06 & -51.81 \\
Toffaleti MPM & 0.29 & 0.96 & 0.25 \\
\hline
\end{tabular}

Most of the transport equations gave reasonable results, however the results obtained by the Toffaleti's equation when compared with the averaged bed elevation change data actually seemed to be closer to the observed data in Fig. 3.2.8. When examining the comparison with the observed cumulative volume change, it is indeed noticeable that Toffaleti's results come closer to the observed data as shown in Fig. 3.2.5, and the same is perceptible when comparing the deposited/eroded sediment volumes between bridges as shown in Fig. 3.2.6. This statement is confirmed by the statistical analysis, as shown in the Table 3.2.3.

Table 3. 2. 3. Statistical analysis for changes in volume between two consecutive bridge cross sections

\begin{tabular}{|c|c|c|c|c|c|}
\hline $\begin{array}{c}\text { Statistics for all } \\
\text { Equations 15min time } \\
\text { step using Limerinos: }\end{array}$ & Yang & Toffaleti & $\begin{array}{c}\text { Ackers- } \\
\text { White }\end{array}$ & $\begin{array}{c}\text { Madden's } \\
\text { modified } \\
\text { Laursen }\end{array}$ & $\begin{array}{c}\text { Toffaleti } \\
\text { Meyer-Peter } \\
\text { Muller }\end{array}$ \\
\hline Mean Error & -1795 & -1840 & -1987 & -6673 & -1953 \\
Nash-Sutcliffe Efficiency & -4.93 & $\mathbf{- 1 . 3 4}$ & -2.86 & -868.42 & -1.76 \\
Correlation Coefficient & 0.10 & $\mathbf{0 . 5 7}$ & -0.03 & 0.03 & 0.22 \\
Root Mean Square Error & 32118 & 20189 & 25897 & 388902 & 21920 \\
\hline
\end{tabular}




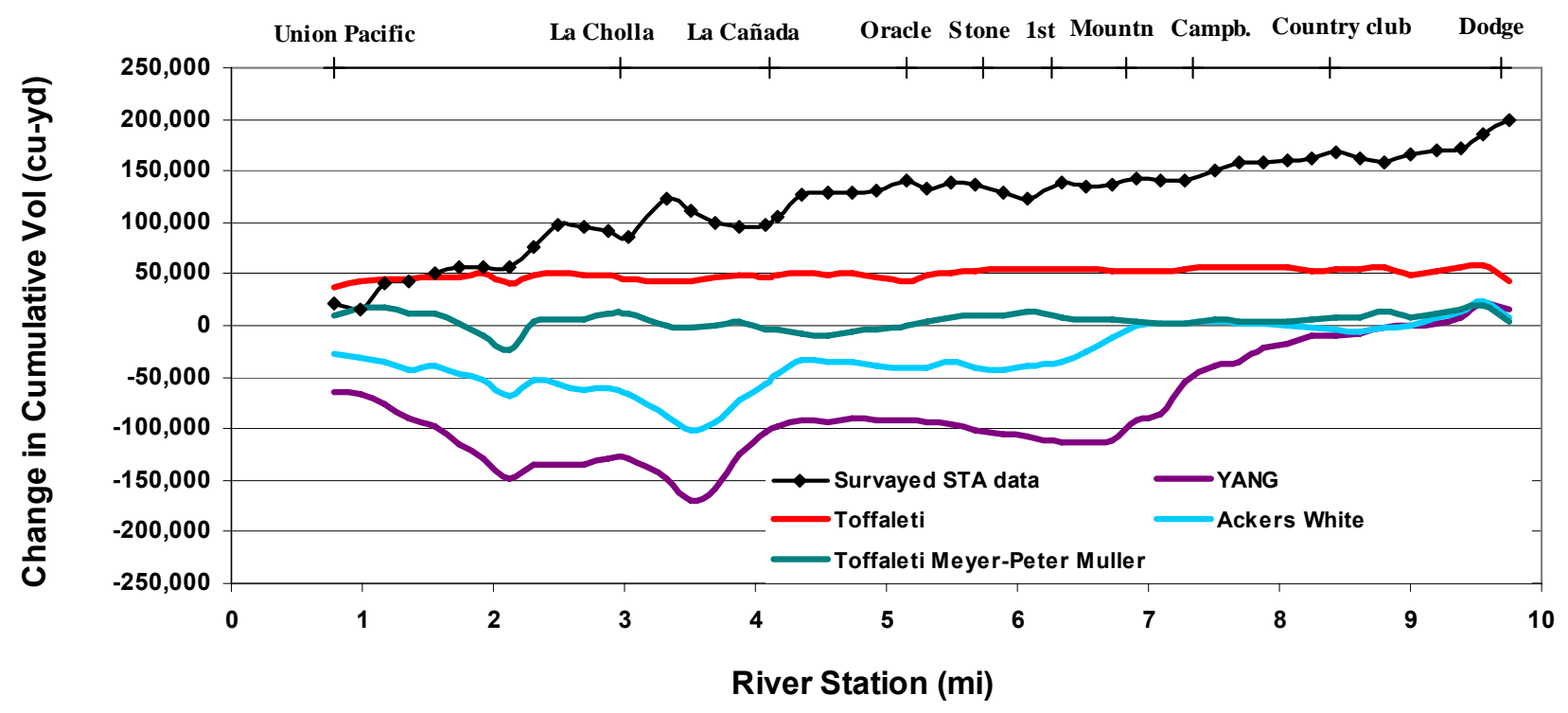

Figure 3. 2. 5. HEC-6 simulated cumulative volume change for different sediment transport equations

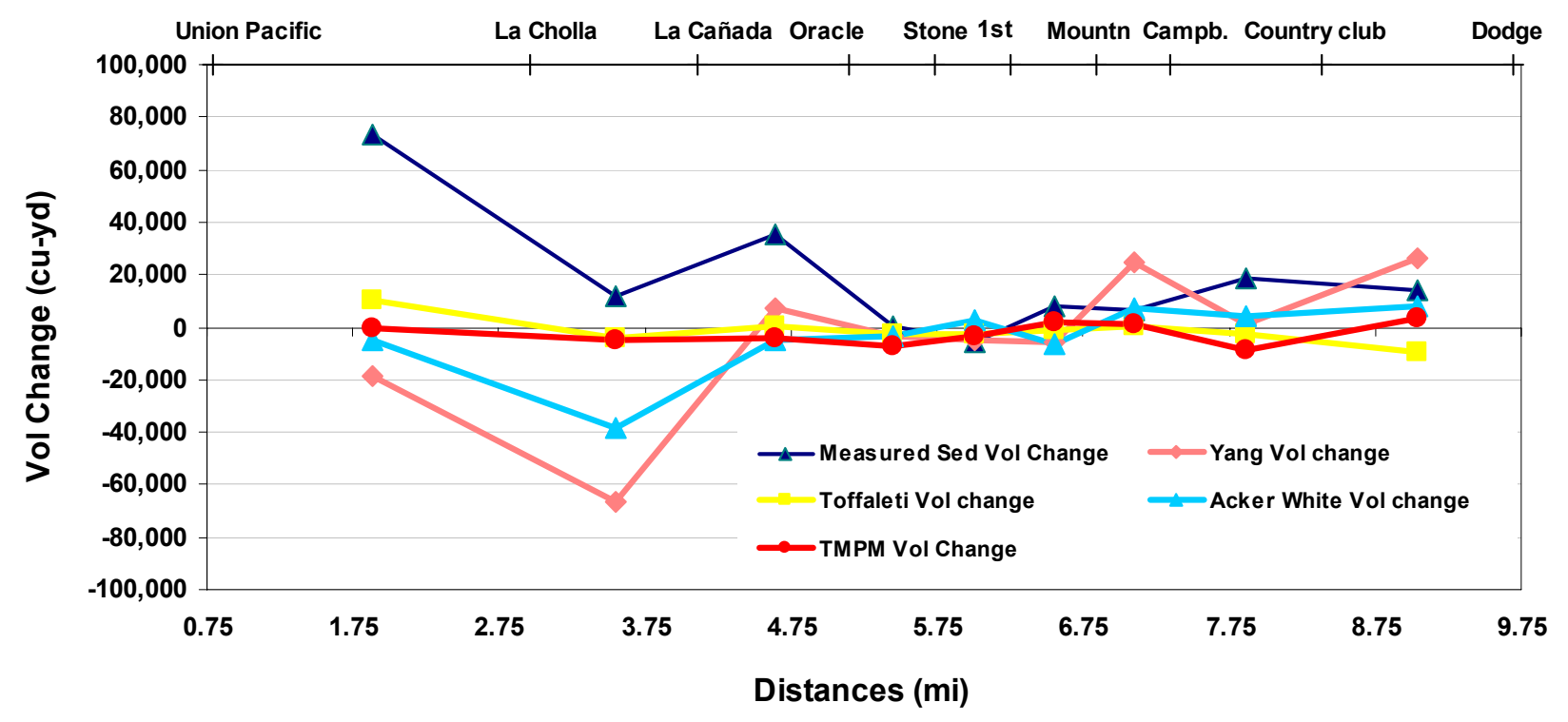

Figure 3. 2. 6. HEC-6 simulated deposited/eroded sediment volumes between bridges at 15min time step 


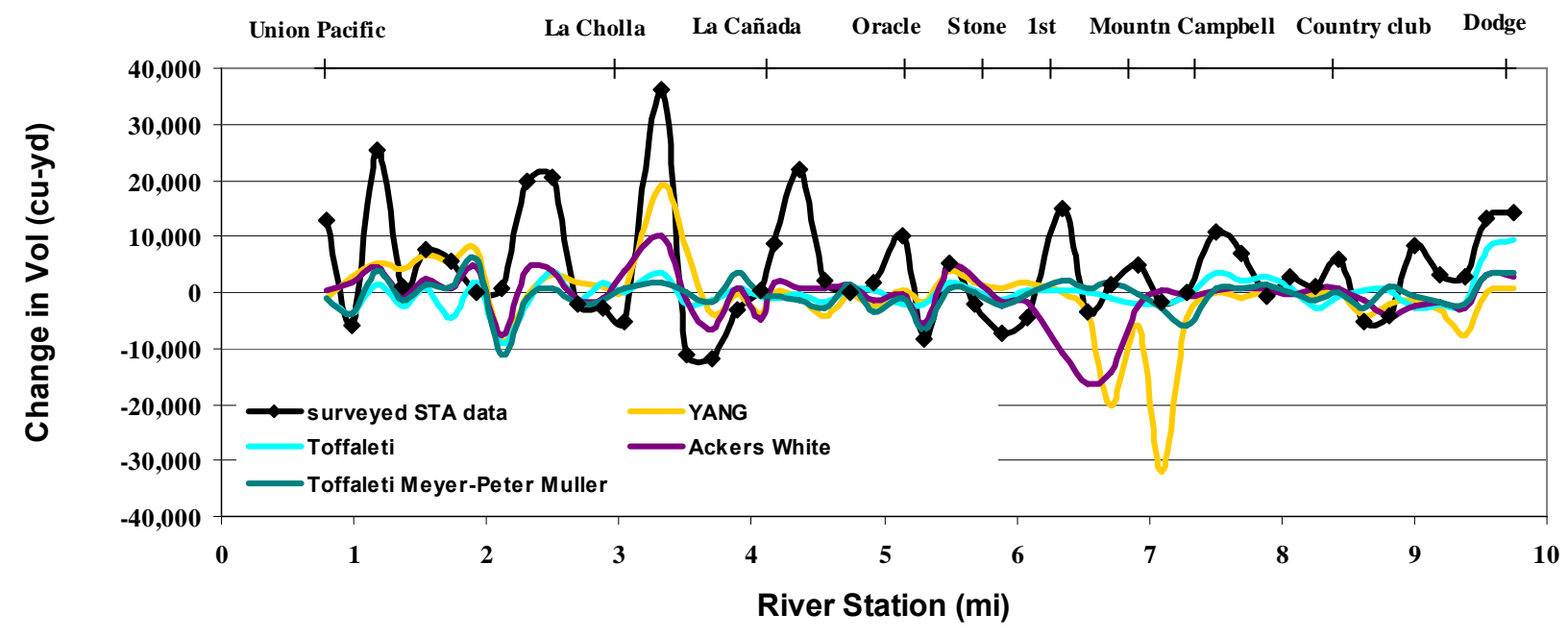

Figure 3. 2. 7. HEC-6 simulated change in channel volume (cu-yd) at $15 \mathrm{~min}$ time step using Limerinos relative roughness method.

The results of bed elevation changes using different sediments equations comparing to averaged and at the thalweg bed elevation changes are plotted in Figures 3.2.8 and 3.2.9, respectively.

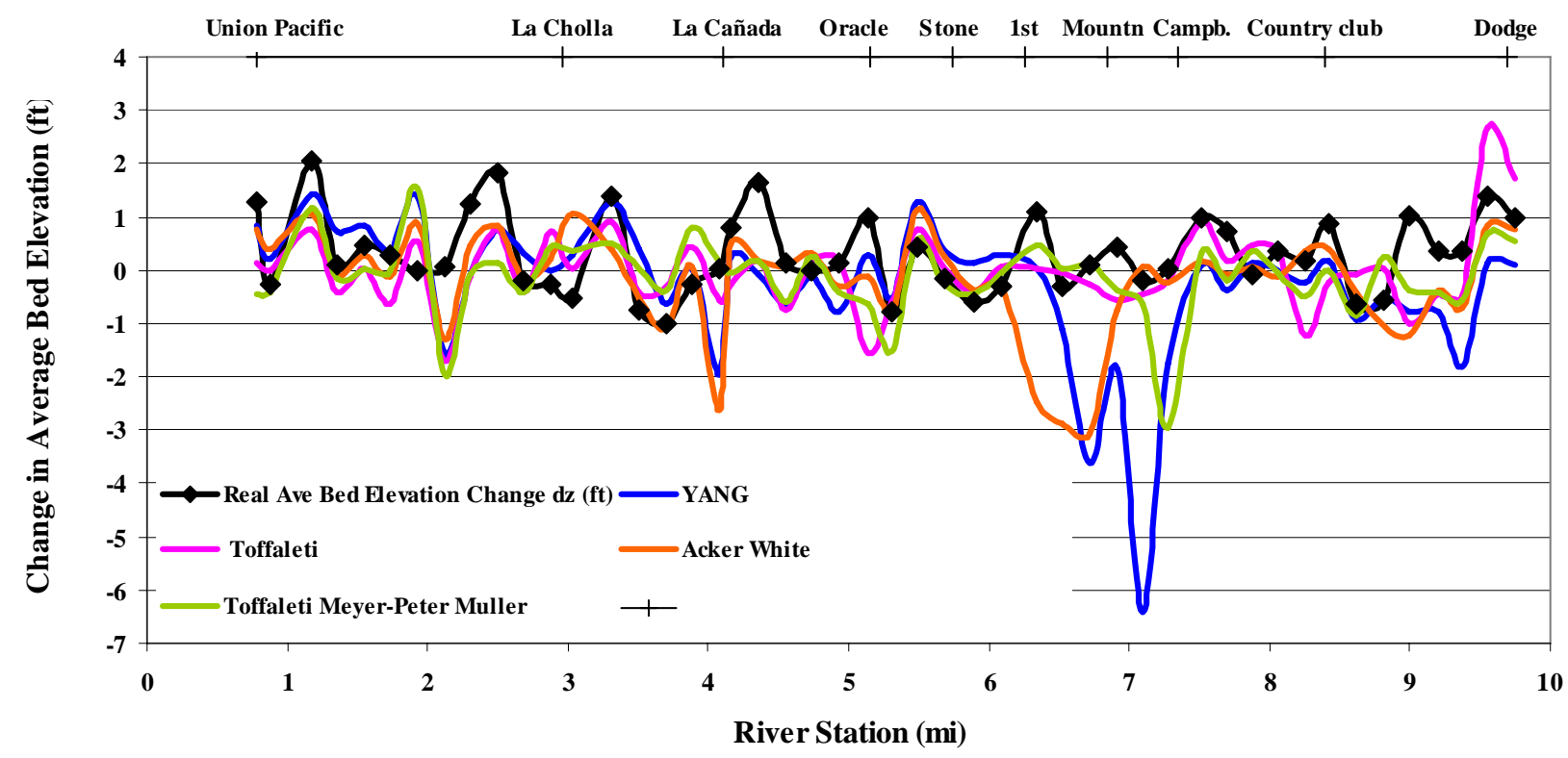

Figure 3. 2. 8. HEC-6 simulated bed elevation changes comparing to observed averaged bed change 


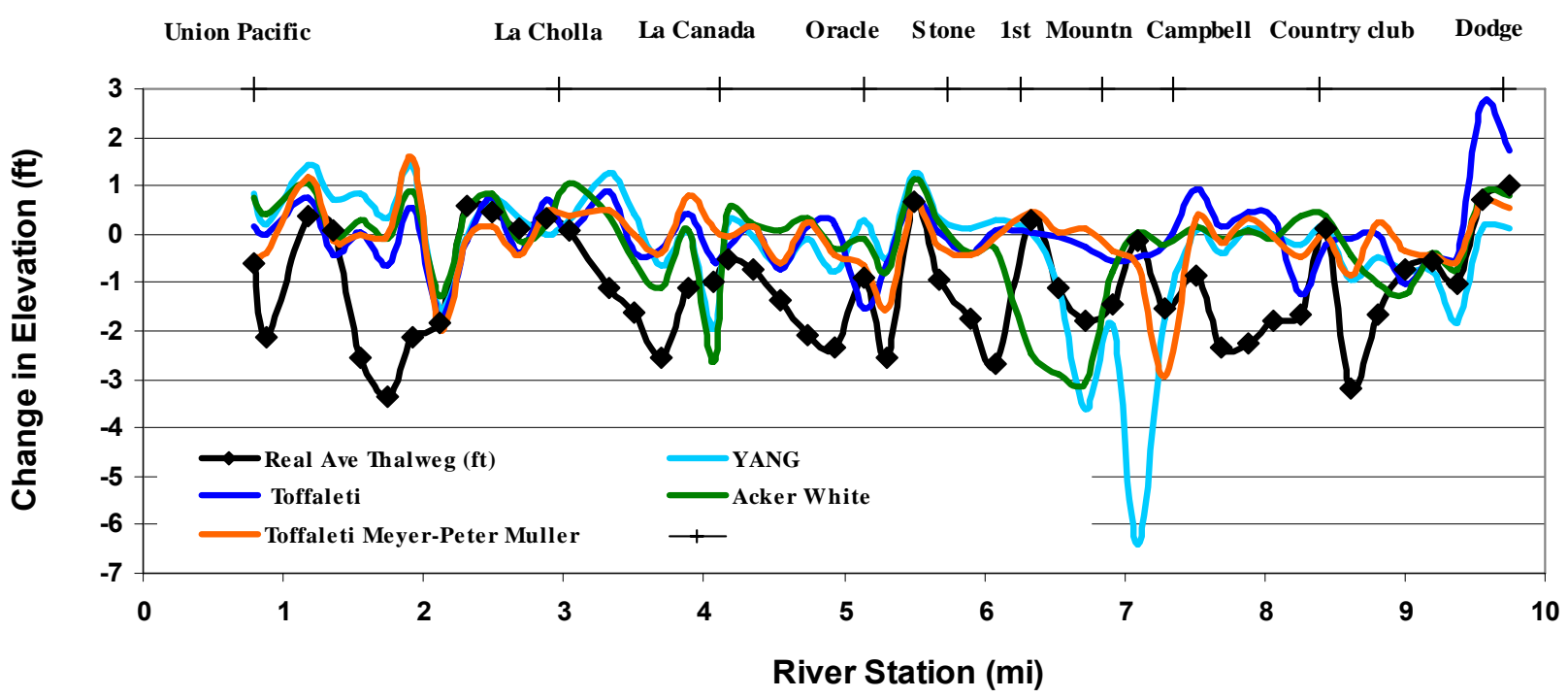

Figure 3. 2. 9. HEC-6 simulated bed elevation changes comparing to observed bed change at the thalweg

\subsubsection{Sensitivity Analysis}

\subsubsection{Limerinos' Equation}

Once the choice was made about the best matching sediment equation, several runs were performed to test the sensitivity of the model to the relevance of Limerinos' equation, Manning's roughness coefficients and the time steps. The decision of using Limerinos was based on having a more practical condition, where Manning's n values will vary with flow depth.

The Limerinos method (1970) has a narrow range of applications, primarily for very coarse sands through cobbles on steeper streams. A bed material gradation is necessary to apply this method. grain sizes for D84, D50, and D16 must be supplied to HEC-6 to use Limerinos. This method is also only applicable to the upper flow regime, which encompasses the bed forms for antidunes, chutes and pools, and plane bed. This analysis showed that the use of the Limerinos' equation has made the model less stable when compared to the water stage hydrograph or to the total deposited/eroded sediment volumes, as it was shown in Figure 3.2.10 and 3.2.11, respectively. However Figures 3.2.12, 3.2.13, and 3.2.14 showed that the effect of running the model with the Limerinos' (1970) relative roughness method seems to make the model less stable and the results are further from the observed data. This indicated the Limerinos' (1970) equation may not accurately reflect the changes of roughness with the hydraulic radius in the Rillito River because the vegetation effect on roughness was not taken into account accurately, or because of the limited samples of bed material gradation along the study reach. More accurate gradations potentially will improve the modeling results. 


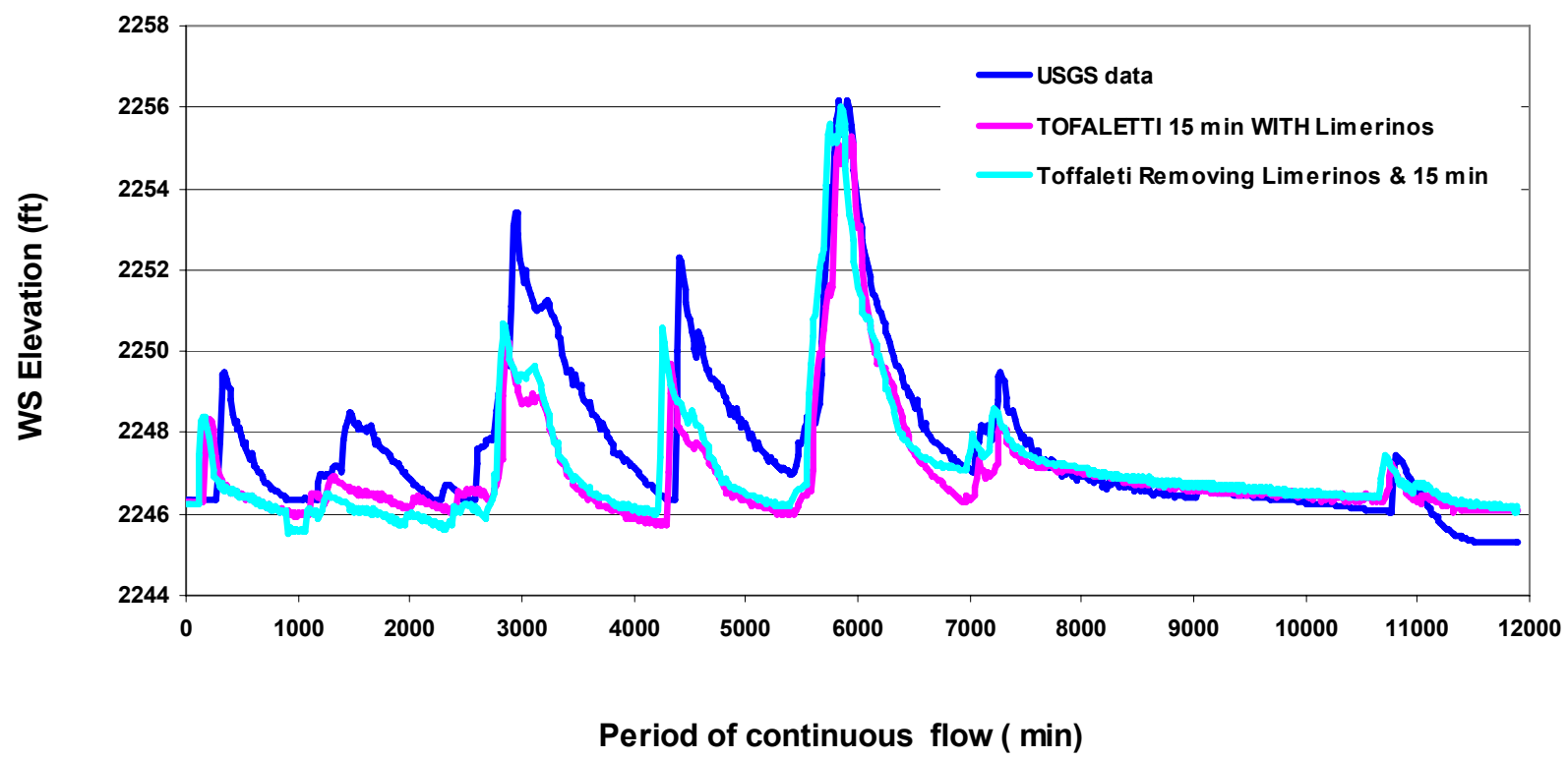

Figure 3. 2. 10. HEC-6 simulated stage hydrographs for sensitivity to the use of the Limerinos' equation

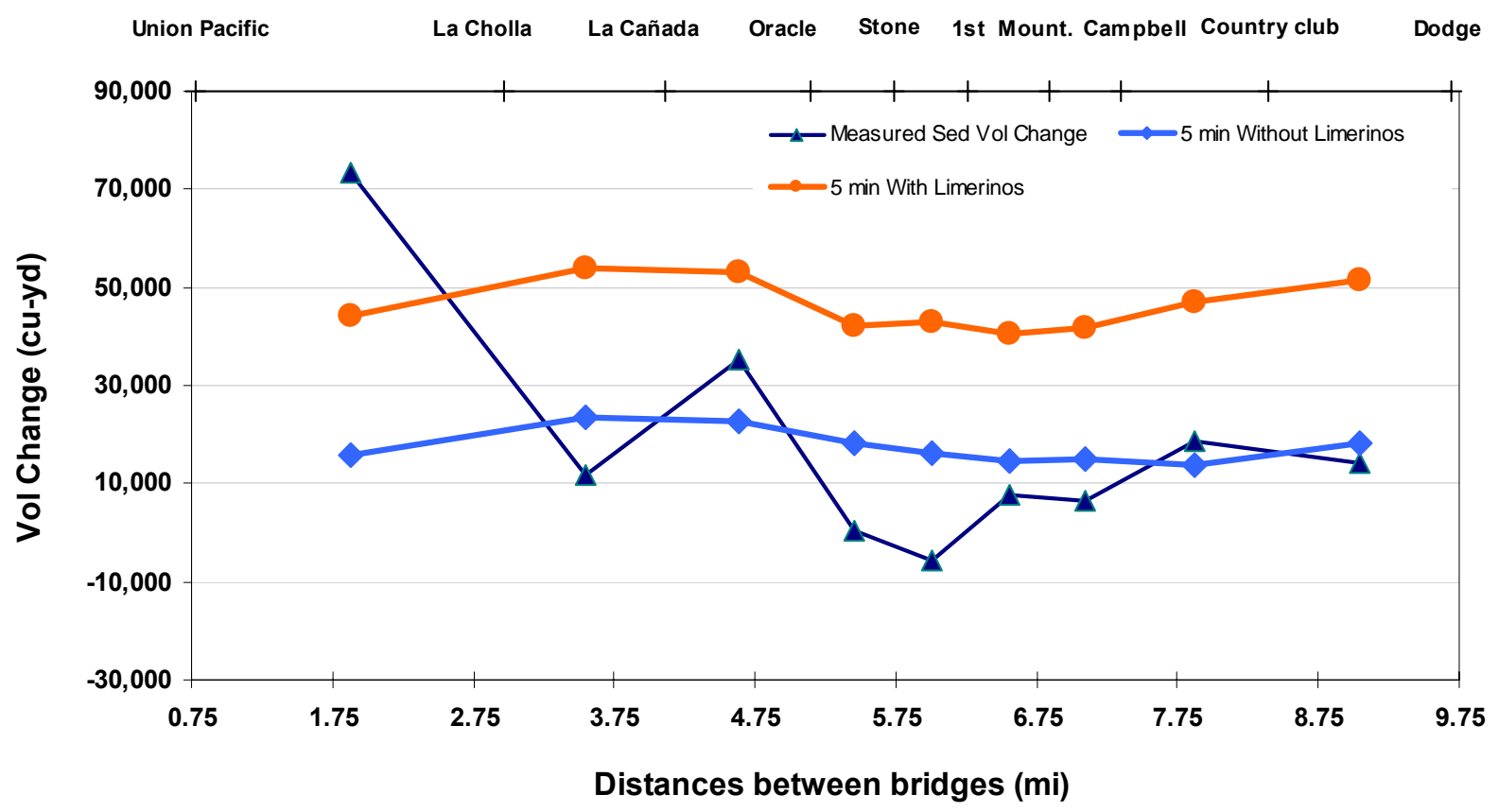

Figure 3. 2. 11. HEC-6 simulated deposited/eroded sediment volumes for sensitivity to the use of the Limerinos' equation 


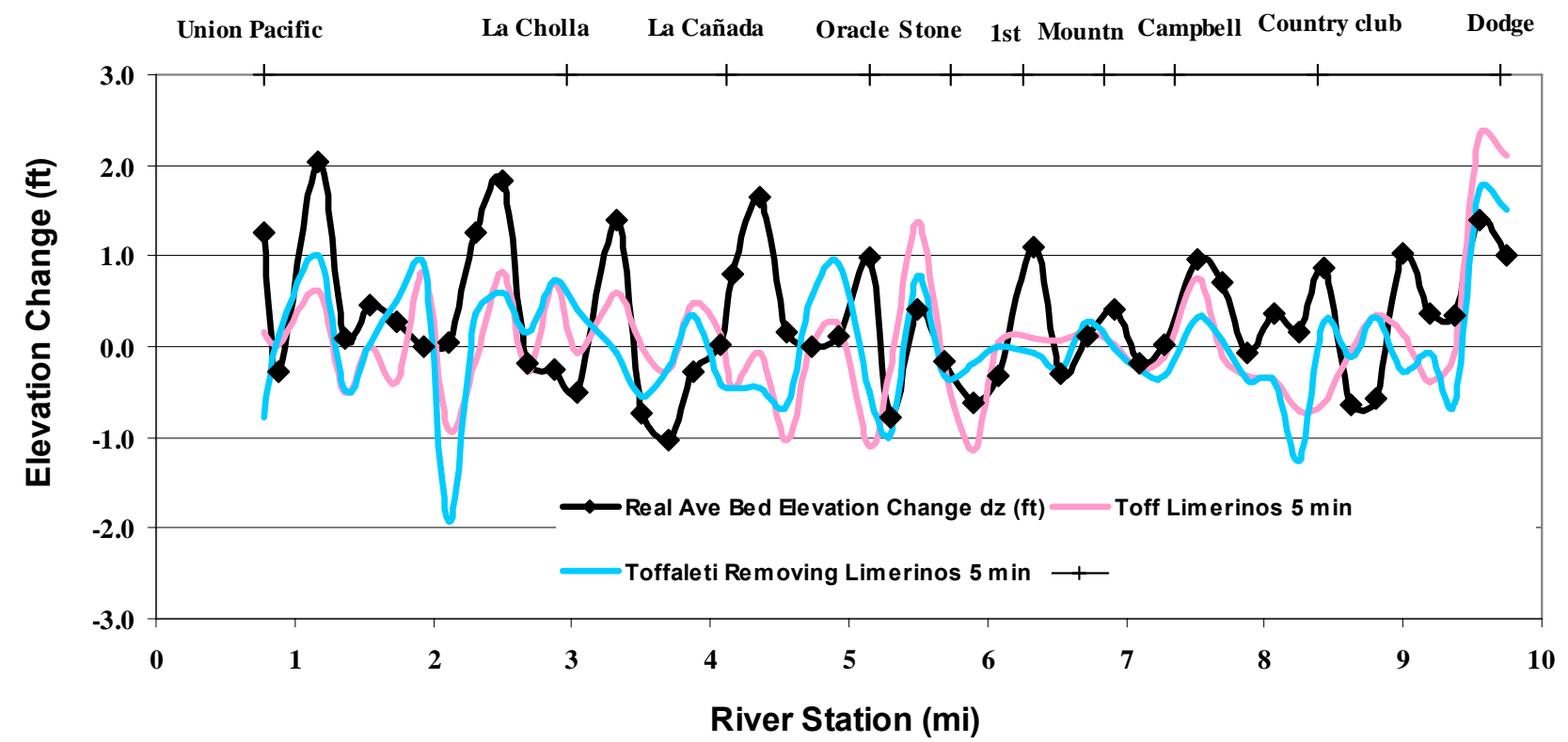

Figure 3. 2. 12. HEC-6 simulated average bed elevation change for sensitivity to the use of the Limerinos' equation.

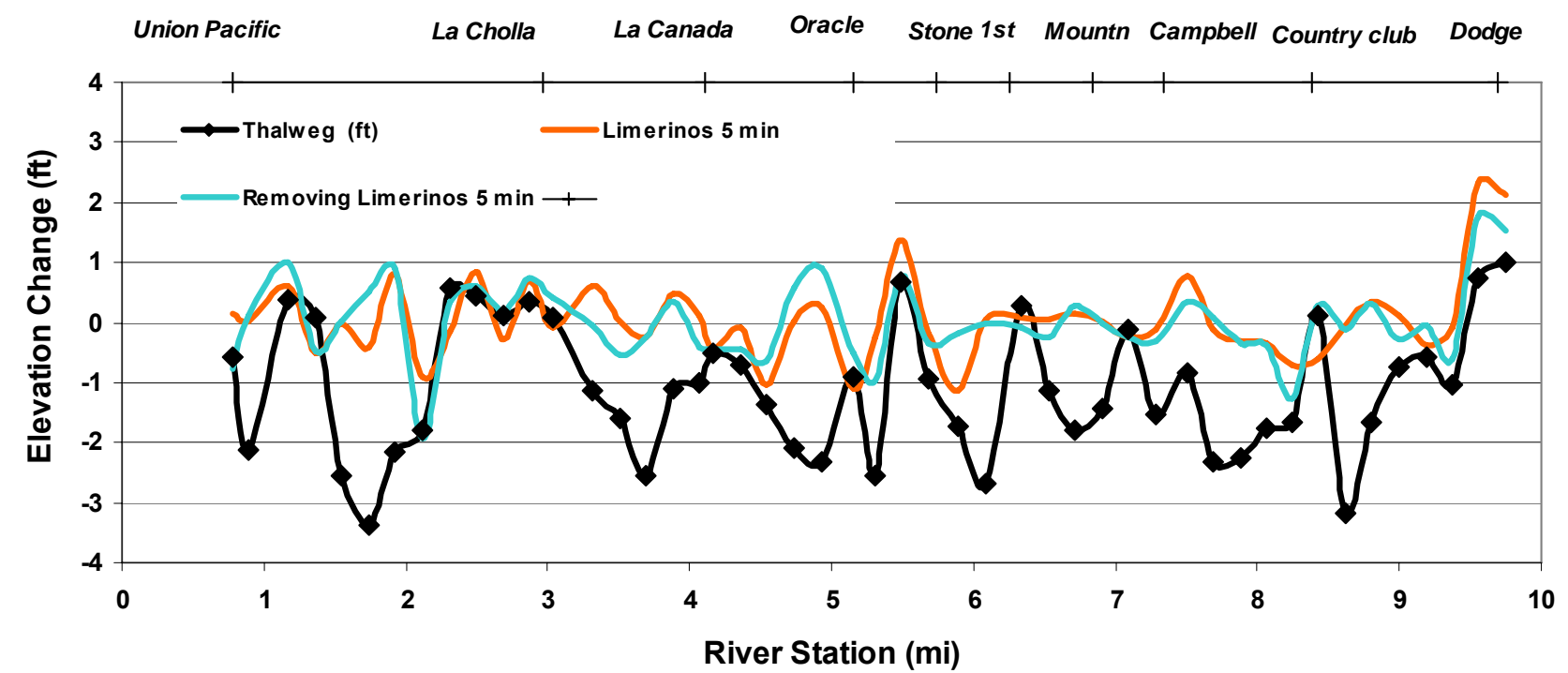

Figure 3. 2. 13. HEC-6 simulated elevation changes at the thalweg for sensitivity to the use of the Limerinos' equation

The statistical analysis for this parameter shown in Table 3.2.4 confirms the statements given above which were based on the comparisons to the changes in bed elevations at the surveyed cross sections. 
Table 3. 2. 4. Statistical Results for the Sensitivity to the Use of Limerinos' Equation.

\begin{tabular}{|l|c|c|}
\hline Statistics for Toffaleti :5 min & $\begin{array}{c}\text { Without } \\
\text { Limerinos }\end{array}$ & $\begin{array}{c}\text { With } \\
\text { Limerinos }\end{array}$ \\
\hline Normalized biased mean & 350 & 3549 \\
Nash-Sutcliffe Efficiency & -0.03 & -5.71 \\
Correlation Coefficient & 0.18 & 0.40 \\
Root Mean Square & 13,396 & 34,159 \\
\hline
\end{tabular}

Another parameter studied in the sensitivity analysis was the time step. The time step was set initially to $15 \mathrm{~min}$, which later on was reduced to $5 \mathrm{~min}$ by slicing the initial time step into smaller time steps. This change was made to check the stability of the model. The results showed that the simulated changes in bed elevation were actually more stable with 15-mins time step as shown in Fig.3.2.14 and 3.2.15, but it appears its influence on stage hydrographs are minor shown in Fig.3.2.16.

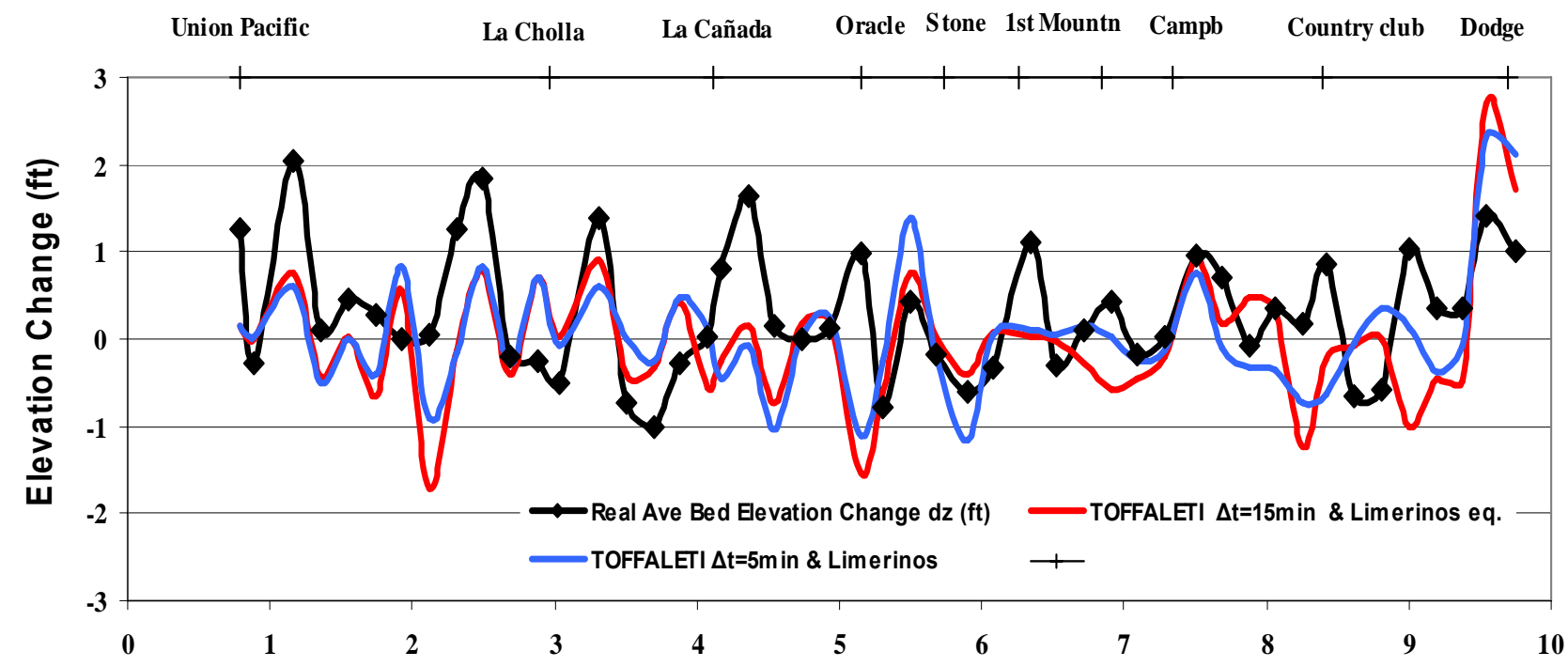

River Station (mi)

Figure 3. 2. 14. HEC-6 simulated average bed elevation change using different time steps 


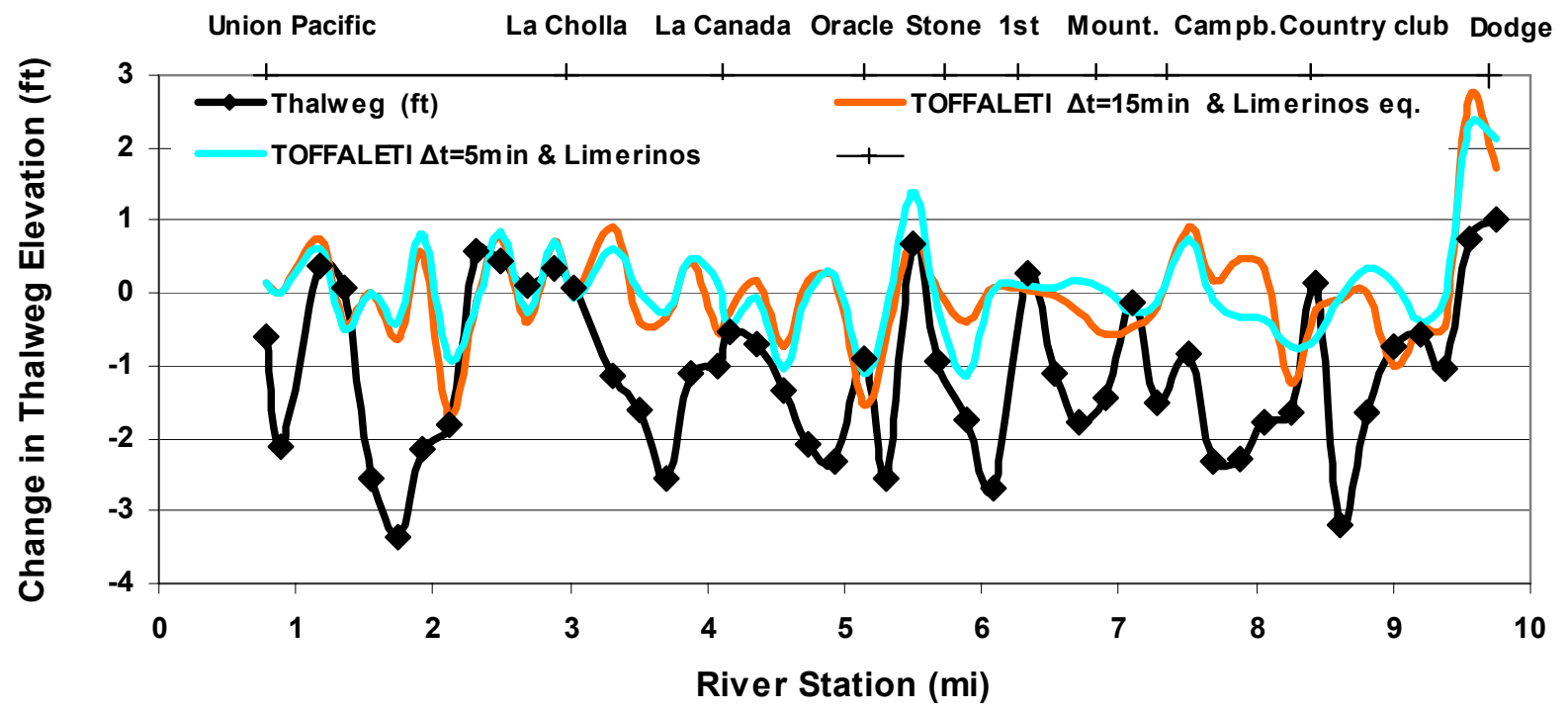

Figure 3. 2. 15. HEC-6 sensitivity to different time steps compared to elevation change at the thalweg

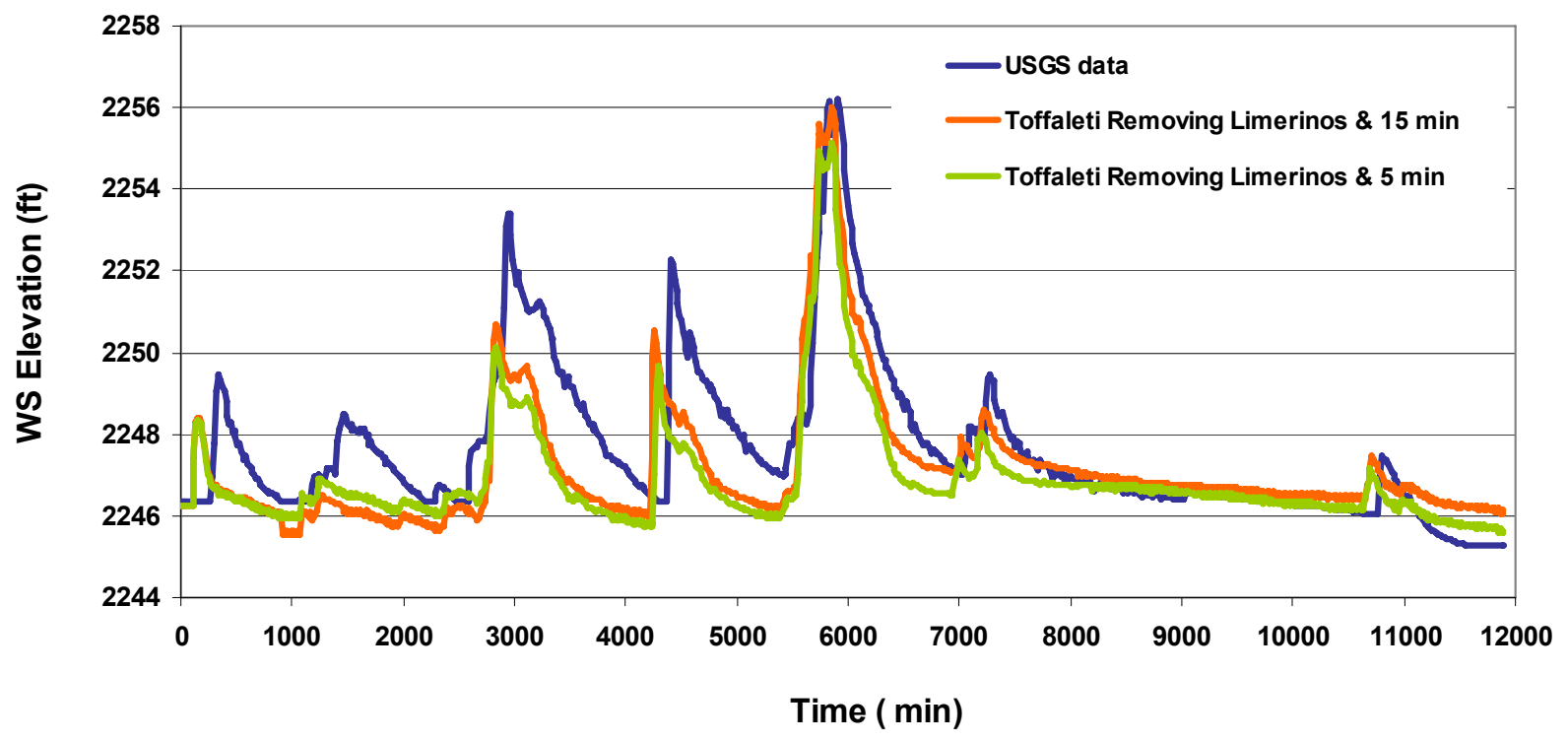

Figure 3. 2. 16. HEC-6 simulated stage hydrograph using different time steps

The output showed that Manning's n values have an important effect on the results, as shown in Figures 3.2.17 to 3.2.19. Roughness coefficients have an important effect on velocities and therefore as shown in Fig. 3.2.18, will result in different water surface elevations that influence the sediment transport as well. 


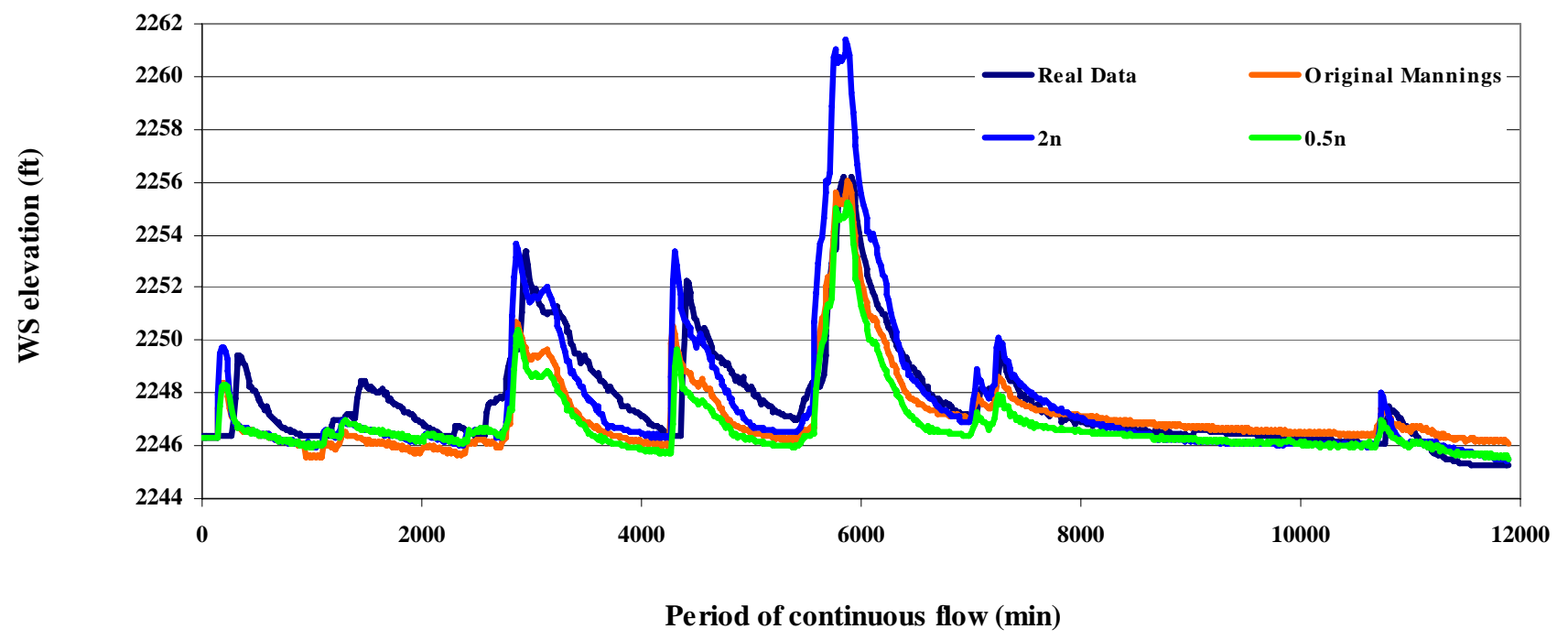

Figure 3. 2. 17. HEC-6 stage hydrograph using different Manning's coefficients

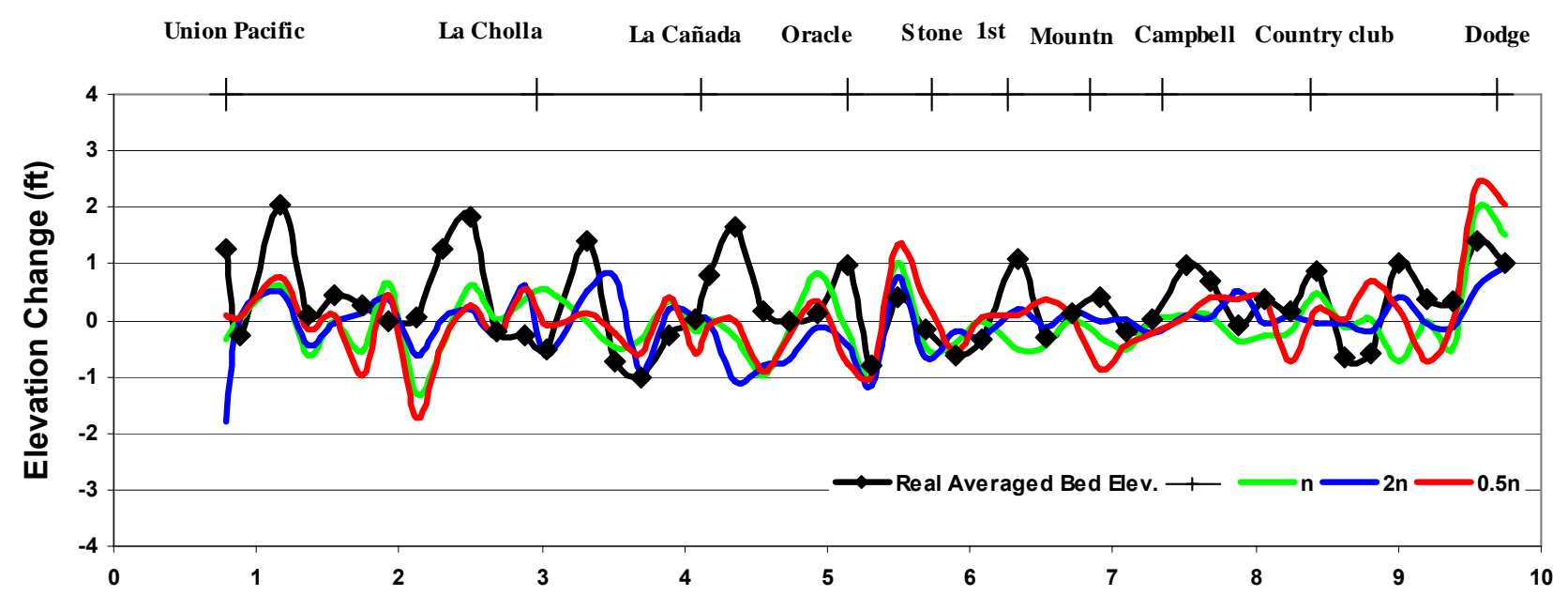

River Station (mi)

Figure 3. 2. 18. HEC-6 sensitivity to different Manning's n values compared to average bed elevation change 


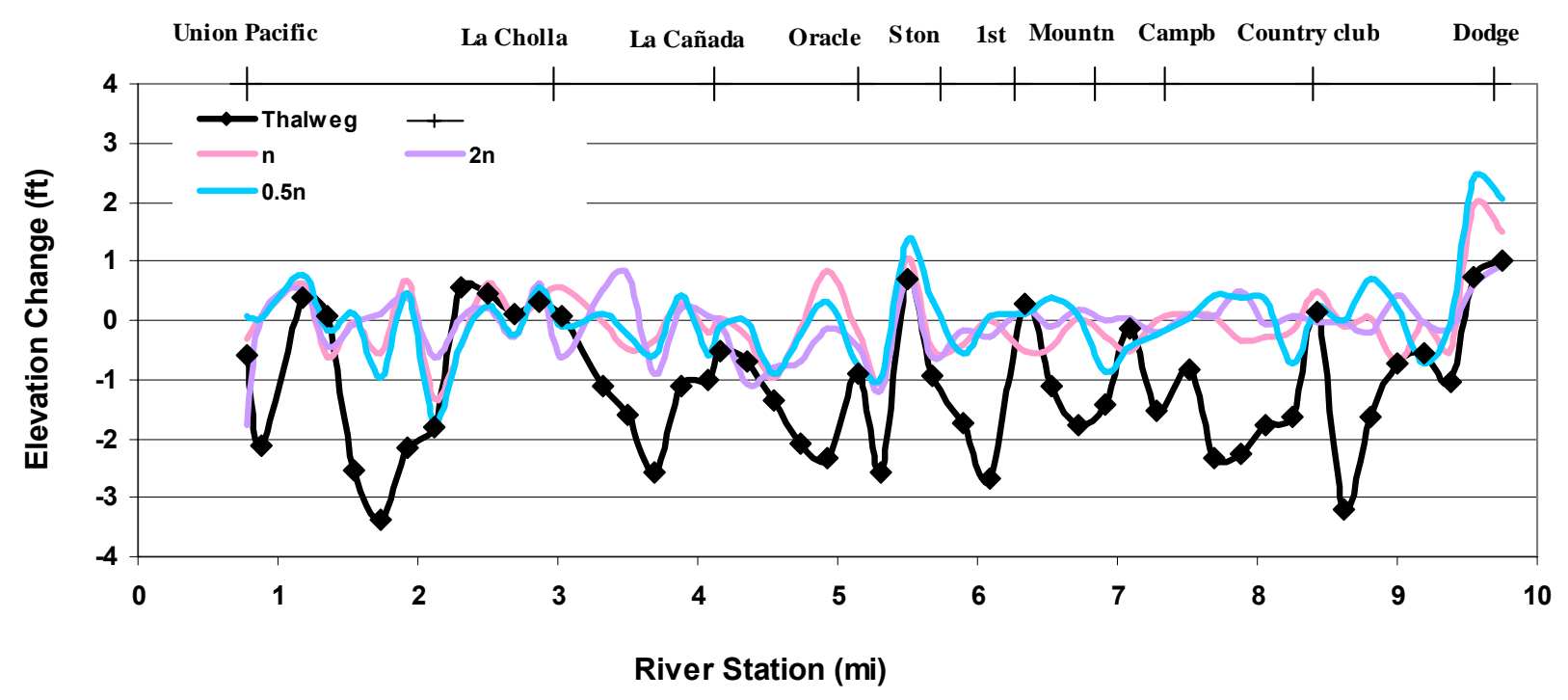

Figure 3. 2. 19. Sensitivity to different Manning's n values compared to elevation change at the thalweg

\subsubsection{Inflow Sediment Load}

Inflowing sediment loads are related to water discharge by sediment-discharge curves for the upstream boundary. For realistic computation of stream behavior, particularly scour and stable conditions, the gradation of the material forming the stream bed must be measured. HEC- 6 allows a different gradation at each cross section. The inflowing sediment load is related to water discharge by prescribing the discharge in cfs, total sediment load in tons per day and the fraction of the sediment load in each grain size class.

Given that a gage measured gradation of material was not available, a constant fraction of sediment load was first used to run the model, which was obtained from the bed gradation at the upstream cross section. However, at a later stage, a new method was applied as suggested by Mr. Ian Sharp (personal communication) to calculate the "re-circulation" of the sediment and obtain a representative fraction of load related to the sediment load-water discharge relationship based on a series of runs using one only water discharge-sediment load relationship starting at a low rate (i.e. 10 cfs) to obtain a first a fraction, this result was later used as a new fraction of sediment data to run a subsequent $Q-Q s$ relationship. The peak $\mathrm{Q}$ for this case was near 40,000 (cfs), therefore 10 models were prepared with Qs from 5 to 390,000 (tons/day). The hydrologic data consisted of short time steps of the same discharge repeated many times. To perform this calculations, six "dummy cross sections" were inserted upstream of the reach and the sediment data was obtained from the last cross section just before the "dummy reach". The "dummy sections" were just a copy of the upstream section but with elevations modified. 
The result showed that actually HEC-6 can be more sensitive to inflowing sediment curve, rather than roughness or time step.

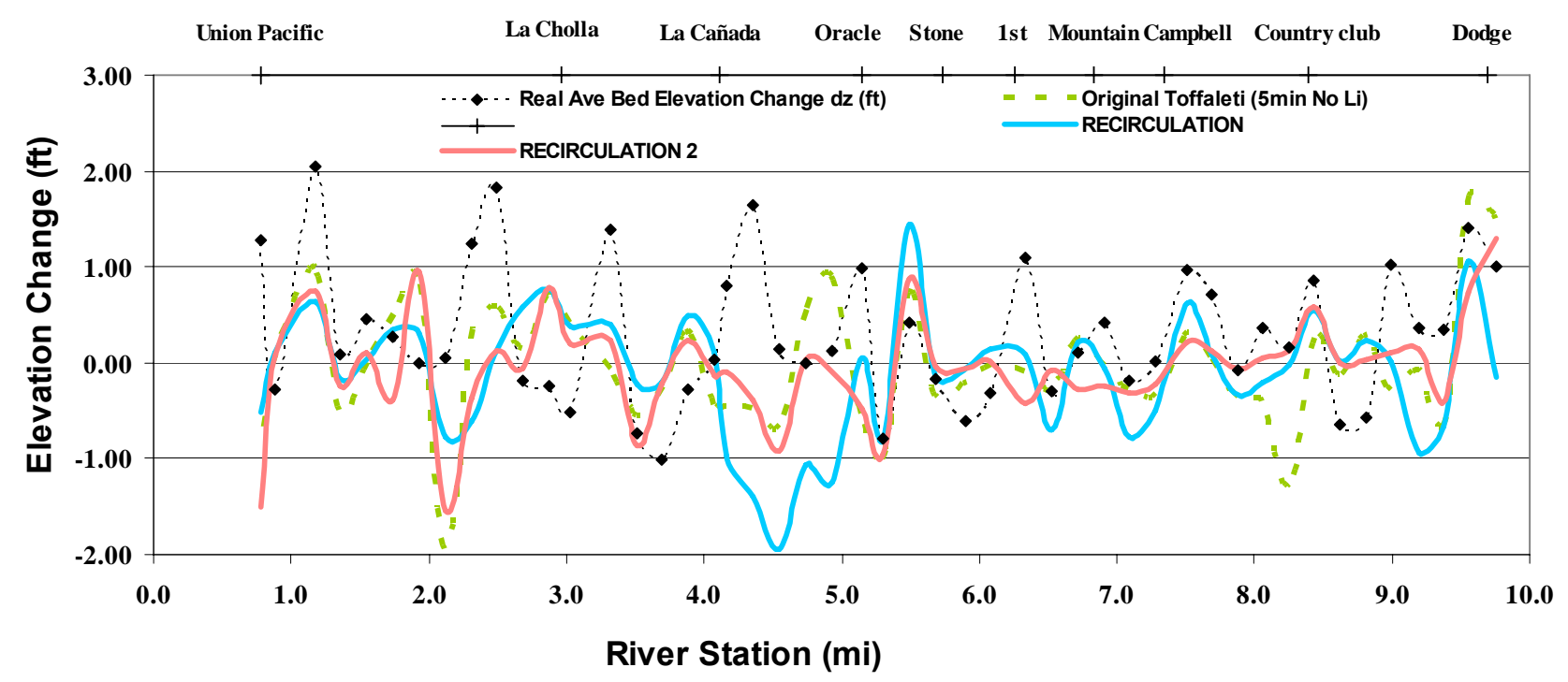

Figure 3. 2. 20. Sensitivity to inflowing sediment curve "Recirculation"

Figure 3.2.20 shows the effect of doing the "re-circulation" as explained before. Given that the result appeared to be somehow more stable, and considering the probability that the weighting factors for numerical integration method as well as the number of exchange increments used during each time step to recalculate the composition of material in the bed may possibly have influence on the sensitivity of the model, a new input was prepared using the re-circulation input and modifying the Iterations of the Exner computations, given that this affects computation time. If too small of a value is used, calculations may display oscillations in the amount of sediment being transported and in the bed profile. The value thus was increased from 5 to 50.

Different weighting factors were investigated for this modeling. Table 3.2 .5 shows the set of factors which appeared to give the most stable calculation as recommended by the HEC-6 manual; and thereby permits the longest time steps (Scheme 1) and the set which is the most sensitive to changes in bed elevation but requires shorter time steps to be stable (Scheme 2). Scheme 1 is often the best choice because the computed energy slope may vary drastically from section-to-section whereas the actual river's behavior may be dependent upon reach properties. The original run showed in the previous figure was using scheme 1, the last one called Recirculation-2 was using scheme 2.

Table 3. 2. 5. Representative Hydraulic Parameter Weighting Factors

\begin{tabular}{|l|r|r|r|r|r|r|r|l|}
\hline Scheme 1 & 0.5 & 0.5 & 0.25 & 0.5 & 0.25 & 0 & 1 & Most Stable \\
\hline Scheme 2 & 0 & 1 & 0 & 1 & 0 & 0 & 1 & Most Sensitive \\
\hline
\end{tabular}


The statistics showed more correlation to the new inflowing sediment values, as shown in table 3.2.6.

Table 3. 2. 6. Statistics of simulated average bed elevation changes

\begin{tabular}{|l|c|c|c|}
\hline & Correlation & RMSE & Nash-Sutcliffe \\
\hline Recirculation & 0.09 & 1.01 & -0.96 \\
Recirculation improved & $\mathbf{0 . 1 8}$ & $\mathbf{0 . 9 0}$ & $\mathbf{- 0 . 5 5}$ \\
\hline
\end{tabular}

\subsubsection{Conclusions}

The unprecedented flood event in the summer of 2006 has caused deposition in the Rillito river. As a consequence, the deposited sediment was shown to raise the river bed. The HEC-6 model quantitatively predicted scour and deposition along the study reach. The modeling parameters of the best performing model were summarized as the followings,

- Time step: 15 minutes

- Manning's n: 0.035 in the main channel and 0.065 for the left and right overbanks.

- Contraction and expansion coefficients: $0.1 \sim 0.3$

- Water temperature: $60^{\circ} \mathrm{F}$

- Boundary conditions:

- Upstream: the stage hydrograph at the Dodge blvd. as flow boundary condition, while inflow sediment load and its gradation were used as the sedimeny boundary condition

- Downstream: the discharge vs stage rating curve calculated from a discharge relation for broad crested weir was the flow boundary condition. The sediment boundary condition is the equilibrium load, which means bed elevations at the downstream section remains a constant.

- Bed Material Gradation: The surveyed gradations of bed material at each bridge cross section were used in the model.

However, as a model that can predict the general scour and deposition, the model could not predict the deposited sediment volume as close to the observed data, but came close to the bed elevation changes. Therefore, HEC-6 proved to be an effective model for predicting changes in scour and deposition, but cannot predict the total deposited or eroded sediment volumes accurately. 


\subsection{IALLUVIAL2 Model}

IALLUVIAL2 is a one-dimensional quasi-unsteady mobile-bed flow and sediment transport model. Flow simulation is the backwater analysis using the standard step method. The latest version incorporates 25 different sediment transport formulas, and six different friction-factor equations. This study only examined the friction relations and sediment formulas suitable to ephemeral streams.

\subsubsection{Input Data}

Geometry data for this study was provided by JE Fuller H\&G Inc. (2006) in HEC-RAS format. IALLUVIAL2 requires the geometry input data in HEC-2 format, and therefore a converter program, was supplied by Joseph Hopper for this purpose. With the exception of minor changes (e.g. removal of cross sections with short reach lengths, removal of extreme floodplain areas, and addition of grade control cross sections), this geometry was used in the IALLUVIAL2 model. Dummy cross sections were added to both the upstream and downstream ends of the model reach to ensure steady uniform flow at both boundaries. The last cross section at either end was copied upstream or downstream four times with bed elevations adjusted according to the averaged slope for the entire reach, which is about 0.003 . To minimize area changes between cross sections, the cross-sectional geometry was trimmed on both banks so that the overall width of a cross section was about 1,500 ft. Only the extreme floodplains were affected; the main channel geometry remained unmodified. The new version of IALLUVIAL2 allows for 500 points so no filtering of the nodes was required. To increase the stability and computational efficiency of the model, eight cross sections with reach lengths of $55 \mathrm{ft}$ or less were removed from the study reach, with their reach lengths being incorporated into the next cross section upstream. This elimination of cross sections may not be necessary when bridge cross sections are present because the distance from a bridge cross section to its adjacent cross section needs to be small enough to provide a smooth flow transistion. In addition to the provided river cross sections, grade control cross sections were inserted at their surveyed locations into the model geometry.

IALLUVIAL2 also simulates sediment sorting and has an option for bed armoring and modeling vertical bed material heterogeneity. The porosity of the bed sediments was set to 0.4 . The bed material sorting parameter was used, but not the armoring parameter, because the bed sediments were mostly sand. The bed was fully erodible except at the grade control cross sections. The erodible depth was used to define the bed erodibility, which was set to $0.01 \mathrm{ft}$ at the grade control cross sections and the default of $100 \mathrm{ft}$ at the rest of cross sections, as the bed is mostly sand with no bedrock outcroppings. Since the actual bed sediment distribution during the 2006 flood events was unknown, substrate bed material distributions were used in the simulation; these distributions were obtained from a sieve analysis from sediment samples taken in the Rillito river.

The boundary conditions in IALLUVIAL2 are bed slopes at the upstream and downstream boundary, downstream water surface elevation, and sediment inflow. Both the upstream and downstream bed slopes were calculated from the geometry data provided by JE Fuller H\&G Inc. (2006). The calculated bed slopes were 0.0028 at the downsteam and 0.003 at the upstream. The 
downstream boundary condition was critical depth due to the presence of a broad crested weir at the last cross section. Since there was no method of specifying critical depth at the downstream boundary in IALLUVIAL2, the manual instructed the users to allow the model to compute the water surface elevation at that section although a subcritical flow regime was chosen.

The sediment boundary condition in IALLUVIAL2 is the sediment inflow at the upstream boundary. Equilibrium loads, or $100 \%$ of the transport capacity were assumed at the upstream boundary. If known, sediment concentrations in ppm (parts per mil) may be used instead. The quasisteady flow analysis was run in 15 minute increments for 793 time steps to match that of the observed hydrograph and stage data.

Among the 25 sediment transport equations included in the IALLUVIAL2 model, six were used in this study to determine the most appropriate one for the Rillito River. These equations were based on Karim-Kennedy (1981), Ackers-White (1973), Toffaleti (1968), Laursen (1958),Yang (1973), Karim-Kennedy II (1990). The friction factor equation chosen was Manning's equation, since this is the most common one used in other models. The value of Manning's $n$ as given by the JE Fuller H\&G Inc. (2006) HEC-RAS file was about 0.03 for the main channel and about 0.06 for the floodplains. However, in the HEC-RAS files from JE Fuller H\&G Inc. small deviations from these values were used at locations with dense emergent vegetation. These deviations were also incorporated into the IALLUVIAL2 geometry file using the $\mathrm{NC}$ record. Thus the values of Manning's n varied spatially throughout the study reach, but did not vary with discharge (Q).

The following is a summary of input parameters for the best performing model.

- Minimum reach length $=56 \mathrm{ft}$

- Erodible depth $=100 \mathrm{ft}$ (default)

- Inerodible depth $=0.01 \mathrm{ft}$

- Manning's $\mathrm{n}=0.03-0.035$ for main channel, $0.55-0.65$ for flood plains (given)

- Sediment size distribution $=$ determined by sieve analysis of field survey (see Section 3...)

- $\quad$ Number of sediment size fractions $=10$ (see above)

- Sediment sorting $=$ used

- Bed armoring $=$ not used

- Bed porosity $=0.4$

- Upstream bed slope $=0.003$

- Downstream bed slope $=0.028$

- Upstream boundary condition = sediment inflow at equilibrium (100\%) of transport capacity (model calculated)

- Downstream boundary condition $=$ water surface elevation (model-computed)

- Flow regime $=$ subcritical

- Length of flow time step $=15$ minutes

- Length of sediment time step = same as flow

- $\quad$ Number of timesteps $=793$

- Baseflow $\mathrm{Q}=50 \mathrm{cfs}$ 
- Water temperature $=70^{\circ} \mathrm{F}$

\subsubsection{Calibration Results}

\subsubsection{Sediment Transport Equations}

Six sediment transport equations and the Manning's friction factor equation were used to determine the most accurate sediment equations. The same input file was run for each equation combination and a statistical analysis of the results was performed and shown in Tables 3.3.1, 3.3.2, and 3.3.3. The mean error $(\mathrm{C}-\mathrm{O})$, where $\mathrm{C}$ is the calculated value and $\mathrm{O}$ is the observed value, Nash-Sutcliffe efficiency factor (E), correlation coefficient (r), and the root mean squared error (RMSE) were calculated for the errors in water surface elevation, average bed elevation changes, at the thalweg bed elevation changes, and total eroded/deposited sediment volume. The mean error of the averaged bed elevation changes was used as the primary indicator of model performance. Based on this performance factor, if using the Toffaleti sediment transport and the Manning's friction factor relation, the results most closely matched the observed ones. Overall, of all the statistical parameters examined, the Toffaleti / Mannings equations produced the highest correlation and smallest mean error and RSME. Despite that, the Laursen sediment transport equation produced slightly better results at the thalweg. Therefore, the simulated results best matched the observations if choosing the Toffaleti equation for the sediment transport and Manning's equation for the friction relation.

Table 3. 3. 1. Statistical Analysis of Stage

\begin{tabular}{|c|c|c|c|}
\hline Performance Factor & Toffaletti & Ackers-White & Laursen \\
\hline Mean Error & 0.181 & -0.341 & -0.333 \\
\hline Correlation Coefficient & 0.898 & 0.908 & 0.907 \\
\hline Root Mean Square Error & 0.875 & 0.934 & 0.908 \\
\hline Nash-Sutcliffe Efficiency & 0.795 & 0.766 & 0.779 \\
\hline Performance Factor & Karim-Kennedy II & Yang 73 & Karim-Kennedy \\
\hline Mean Error & -0.522 & -0.862 & -0.579 \\
\hline Correlation Coefficient & 0.901 & 0.893 & 0.897 \\
\hline Root Mean Square Error & 1.012 & 1,245 & 1.048 \\
\hline Nash-Sutcliffe Efficiency & 0.725 & 0.585 & 0.706 \\
\hline
\end{tabular}


Table 3. 3. 2. Statistical Analysis of Average Change in Bed Elevation

\begin{tabular}{|c|c|c|c|}
\hline Performance Factor & Toffaletti & Ackers-White & Laursen \\
\hline Mean Error & -0.433 & -0.704 & -0.871 \\
\hline Correlation Coefficient & 0.059 & 0.142 & 0.318 \\
\hline Root Mean Square Error & 0.858 & 1.076 & 1.176 \\
\hline Nash-Sutcliffe Efficiency & -0.379 & -1.170 & -1.594 \\
\hline Performance Factor & Karim-Kennedy II & Yang 73 & Karim-Kennedy \\
\hline Mean Error & -1.044 & -1.365 & -1.146 \\
\hline Correlation Coefficient & 0.004 & 0.144 & 0.060 \\
\hline Root Mean Square Error & 1.535 & 1.699 & 1.646 \\
\hline Nash-Sutcliffe Efficiency & -0.932 & -4.414 & -4.080 \\
\hline
\end{tabular}

Table 3. 3. 3. Thalweg Elevation Change Statistical Analysis

\begin{tabular}{|c|c|c|c|}
\hline Performance Factor & Toffaletti & Ackers-White & Laursen \\
\hline Mean Error & 0.879 & 0.674 & 0.488 \\
Correlation Coefficient & -0.040 & 0.086 & 0.144 \\
Root Mean Square Error & 1.447 & 1.343 & 1.255 \\
Nash-Sutcliffe Efficiency & -0.766 & -0.523 & -0.328 \\
\hline \multicolumn{4}{|c|}{} \\
\hline Performance Factor & Karim-Kennedy II & Yang 73 & Karim-Kennedy \\
\hline Mean Error & 0.191 & -0.069 & 0.165 \\
Correlation Coefficient & -0.076 & 0.024 & -0.037 \\
Root Mean Square Error & 1.564 & 1.353 & 1.532 \\
Nash-Sutcliffe Efficiency & -1.064 & -0.545 & -0.981 \\
\hline
\end{tabular}


The stage hydrographs calculated by the Toffaleti / Manning's equation combination nearly matched the measured stages, only overestimating slightly, seen in Figure 3.3.1, with the observed data. The Toffaleti and Manning's combination underestimated slightly the early peaks, and overestimated slightly later peaks, starting with the peak flow. The other equations underestimated the stage to varying degrees. The results of stage hydrographs very well present the observed data.

In the real case, the average bed elevation change was positive, showing deposition, and the average change at the thalweg was negative, showing scour. Regardless of sediment transport equations or friction factors, IALLUVIAL2, in general, predicted overall scour as the bed elevation change, rather than the observed deposition for the simulated event, as seen in Figure 3.3.2. For the change in elevation at the thalweg, the model predicted scour as was seen in the real case. This is illustrated in Figure 3.3.3. The model's prediction of scour even though deposition was observed throughout the majority of the reach can be attributed to several tributaries that contributed sediment to the study reach. IALLUVIAL2 does have the ability to model tributaries using sediment $\left(\mathrm{q}_{\mathrm{s}}\right)$ specified as the input data. However, based on the geometry provided, the total change of sediment volume calculated was scour, as can readily be seen in Figures 3.3.4 and 3.3.5. 

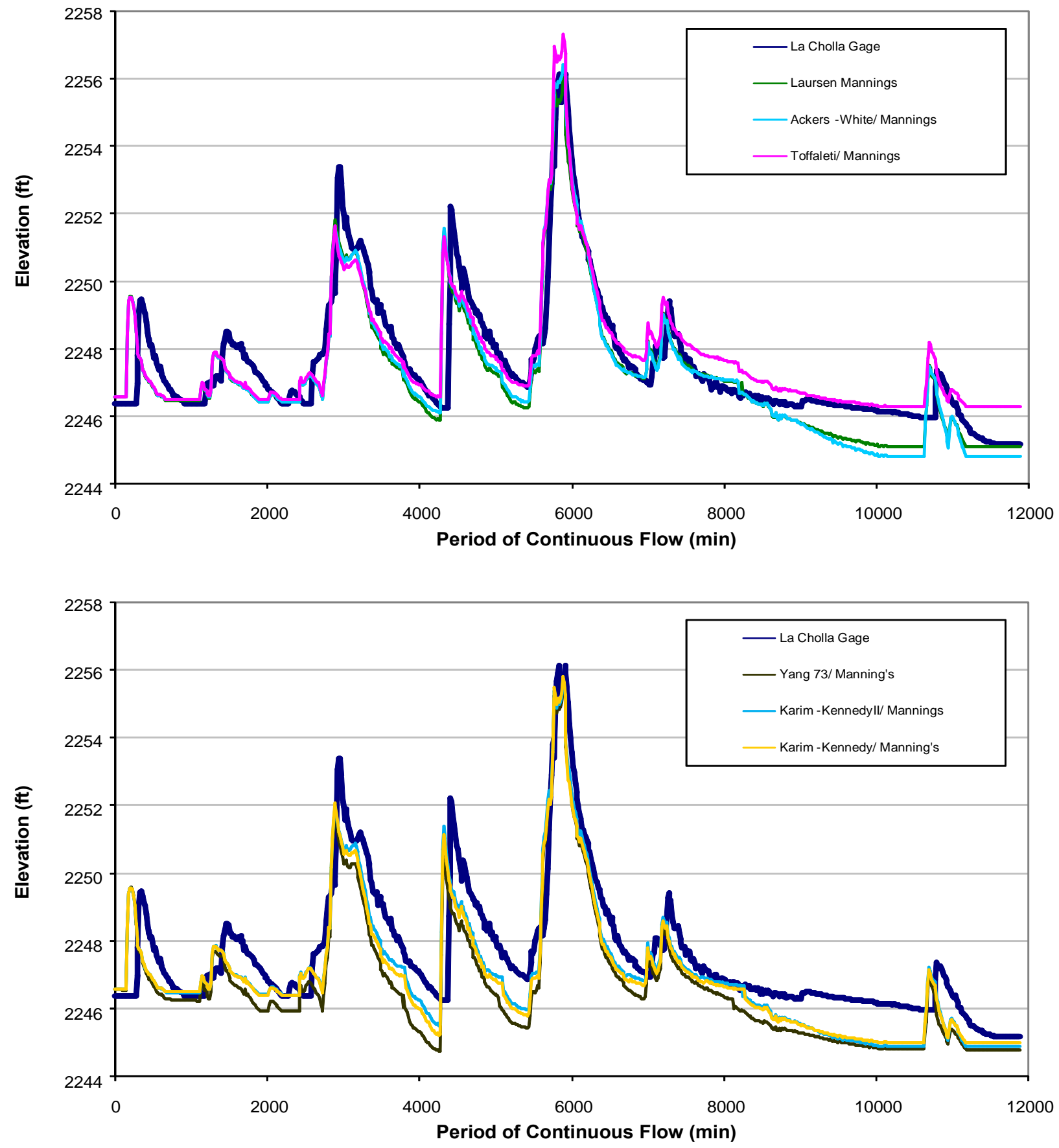

Figure 3. 3. 1. IALLUVIAL2 simulated stage hydrographs at La Cholla 

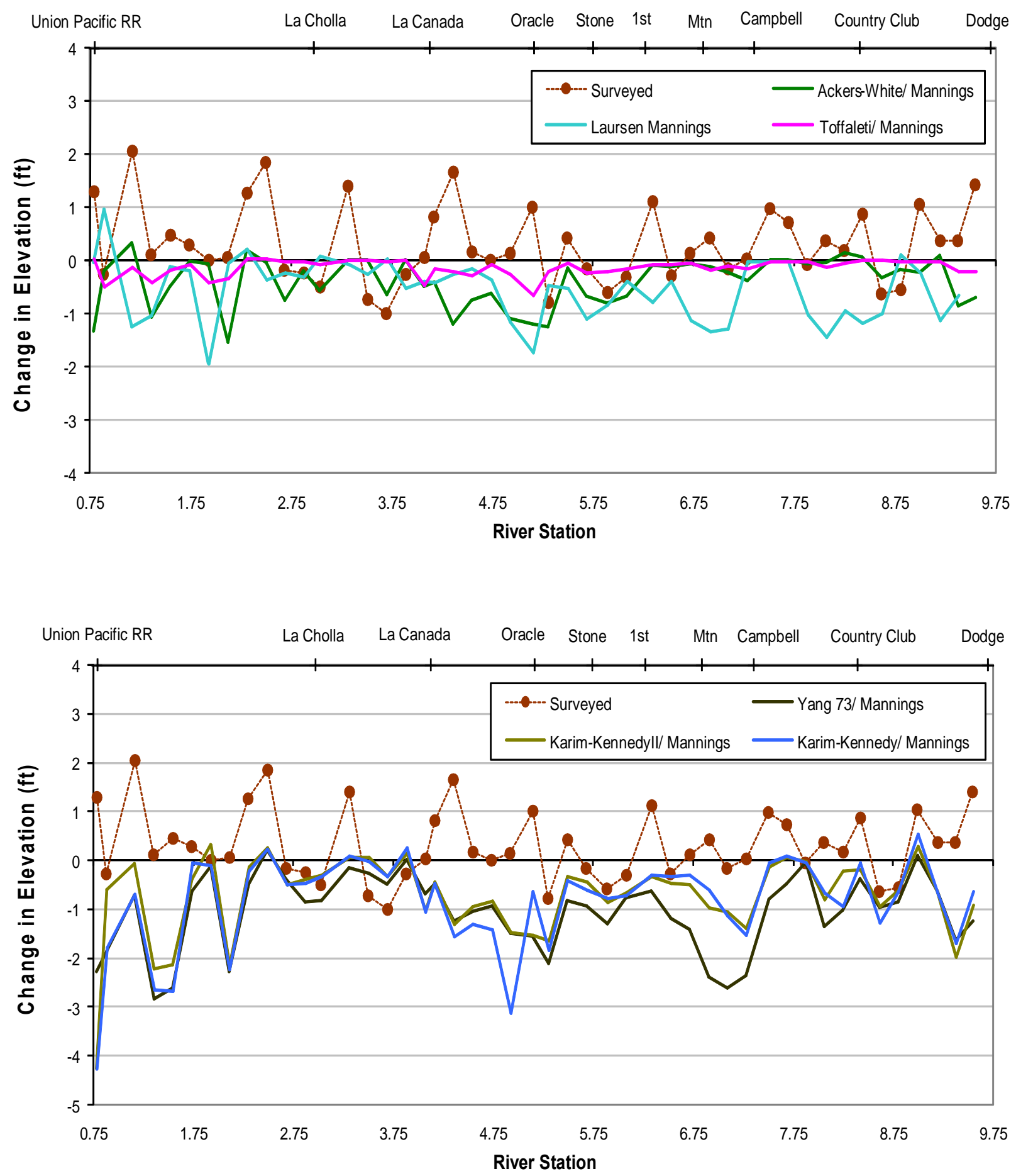

Figure 3. 3. 2. IALLUVIAL2 simulated average change in bed elevation 

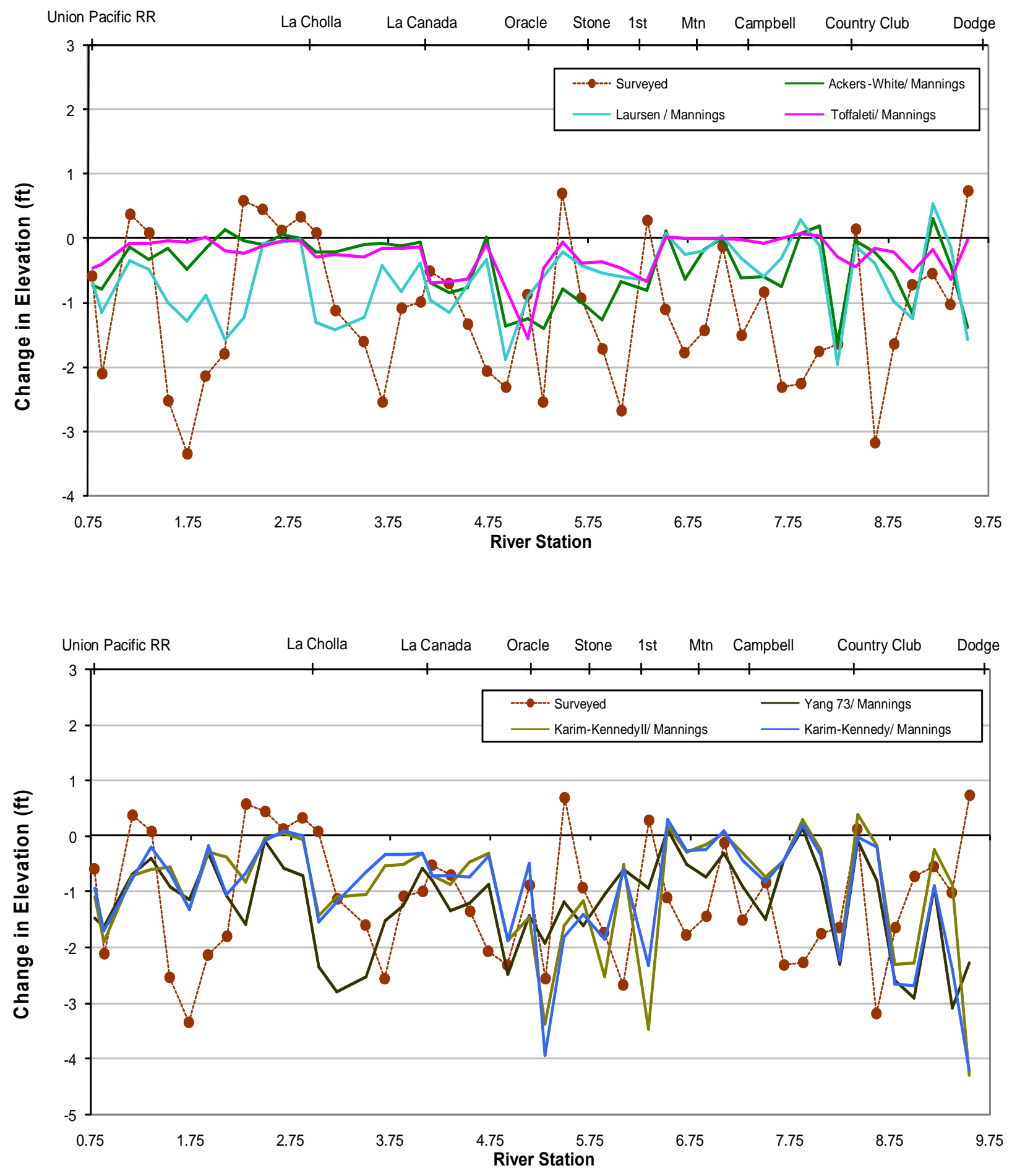

Figure 3. 3. 3. IALLUVIAL2 simulated changes in thalweg elevation 


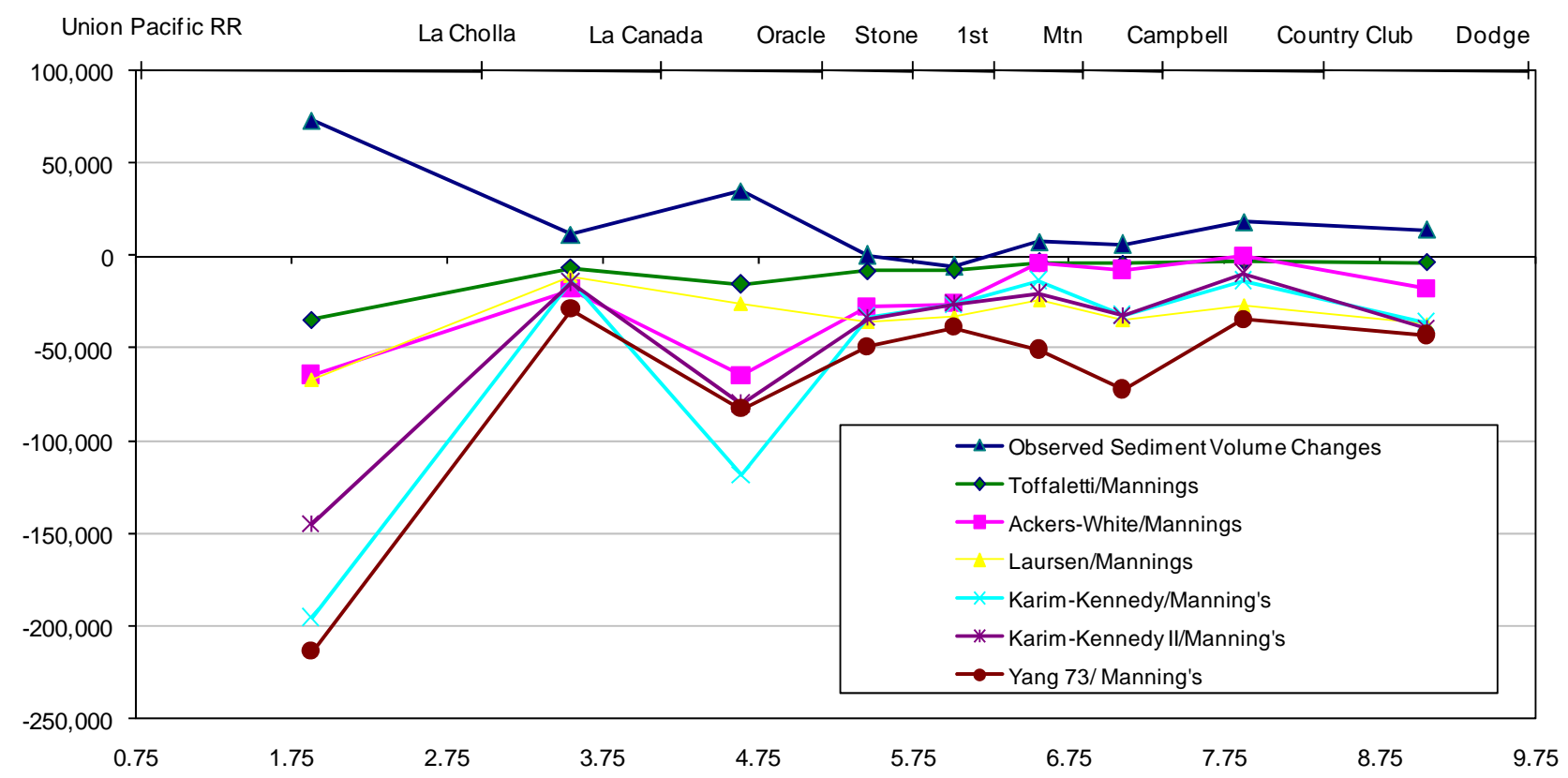

Figure 3. 3. 4. IALLUVIAL2 simulated deposited/eroded sediment volumes, per mile, between two bridges

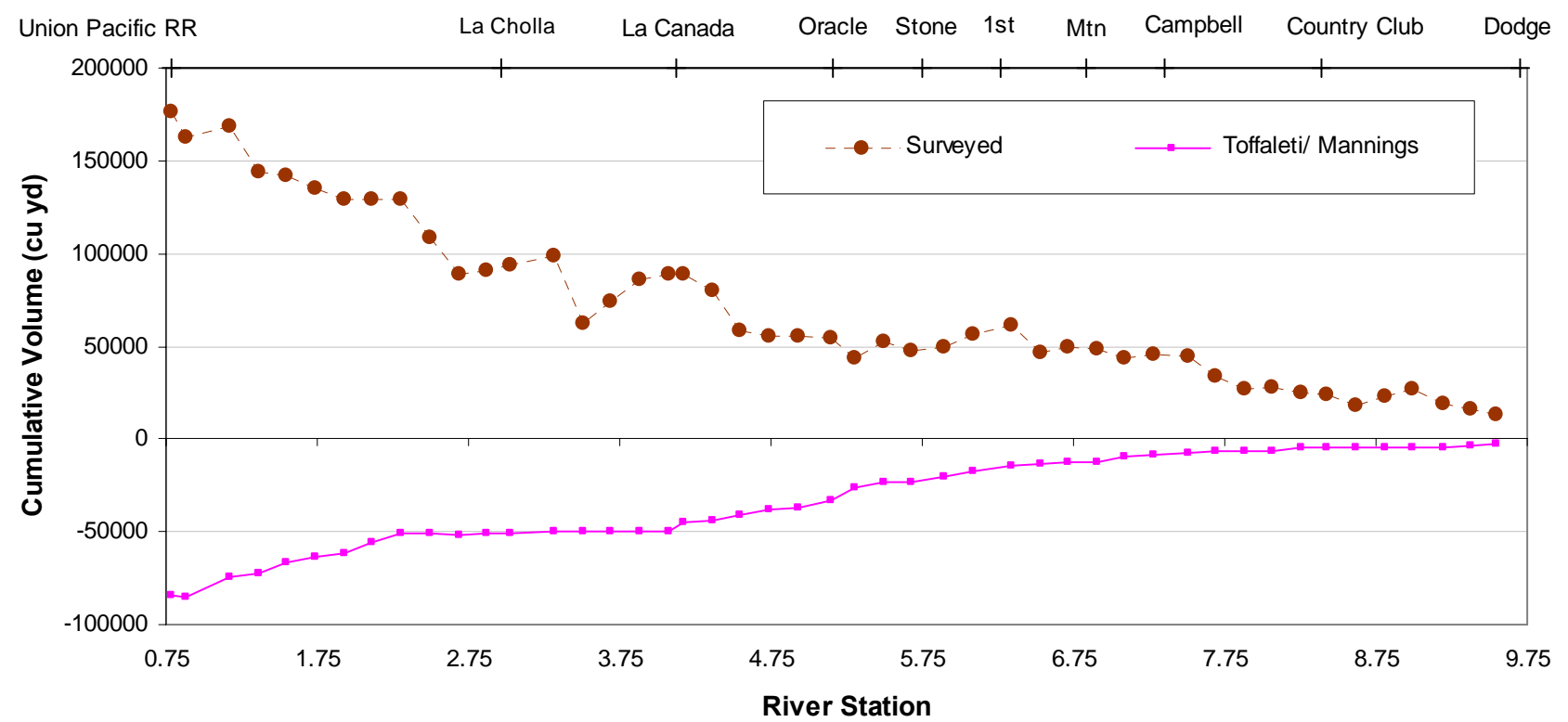

Figure 3. 3. 5. IALLUVIAL2 simulated deposited/eroded cumulative sediment volumes between two bridges 


\subsubsection{Sensitivity Analysis}

\subsubsection{Roughness}

To examine the model's sensitivity to the value of Manning's $n$, the values were increased to twice the original values of Manning's $n$ and half the original values. Toffaleti's sediment transport and manning's roughness equations were used; all other parameters and inputs remained the same. As shown in Figures 3.3.6, doubling the values of $\mathrm{n}$ results in a much larger overprediction of water surface elevations. This also caused the model to become unstable, as can be seen by the very large peak towards the end of the simulation. The model was less sensitive to a $50 \%$ decrease in $n$, only showing slight differences from the original stage predictions. For the average change in bed elevation, the $50 \%$ increase in $n$ caused more scour in some cross sections but less in others than did the original $n$ value. However, for the lowest value of $n$ there was less scour overall than the original values, and even some deposition was seen near the First St. bridge, as shown in Figure 3.3.7. For the most part, both the increase and decrease in $n$ resulted in less scour in the thalweg than did the original $\mathrm{n}$ value. The $50 \%$ reduction in $\mathrm{n}$ caused more deposition and less scour than was seen in the model prediction with the original value of $n$, as shown by the light blue line in Figure 3.3.8.

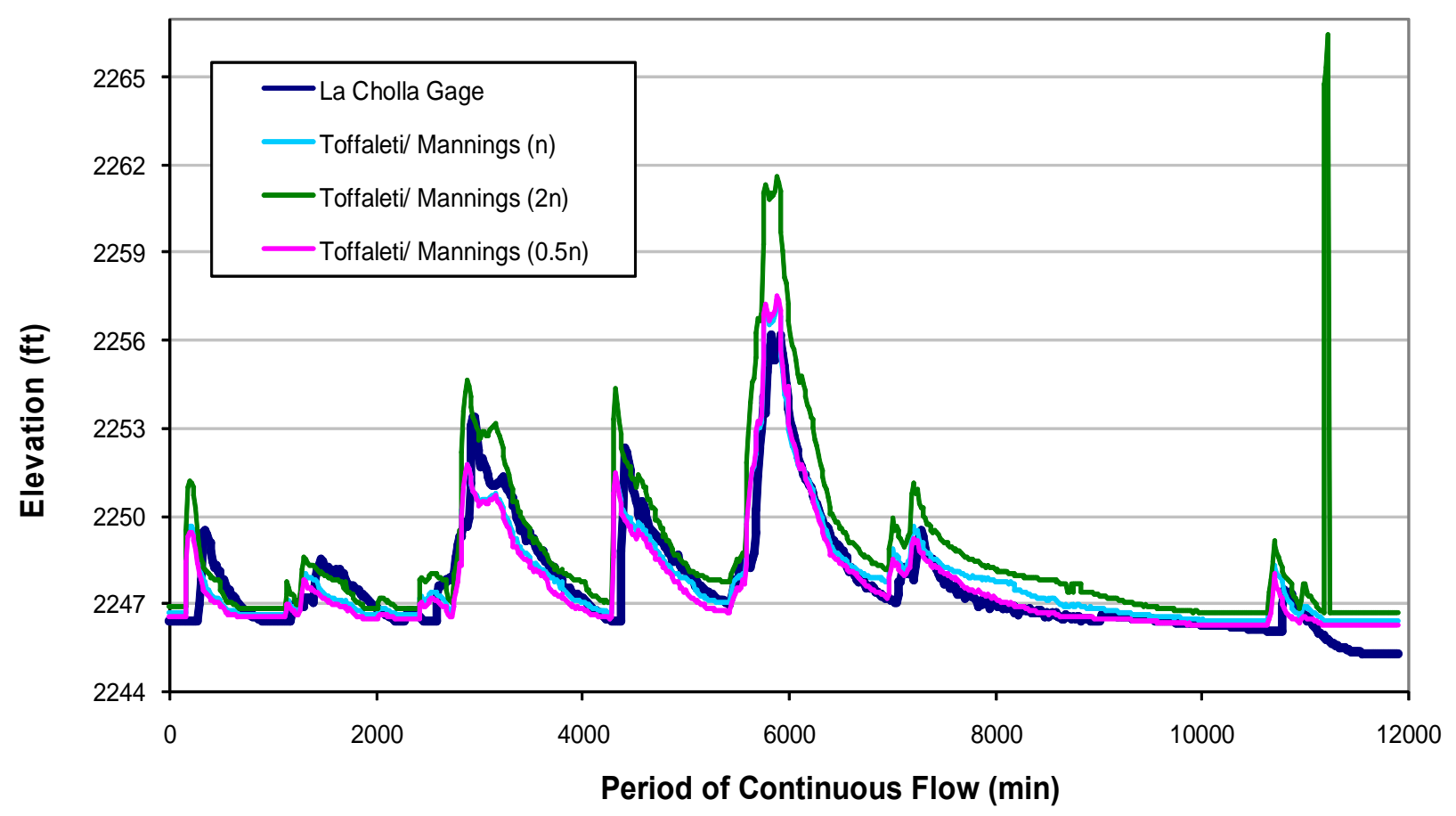

Figure 3. 3. 6. La Cholla Stage Results - Change in Manning's n 


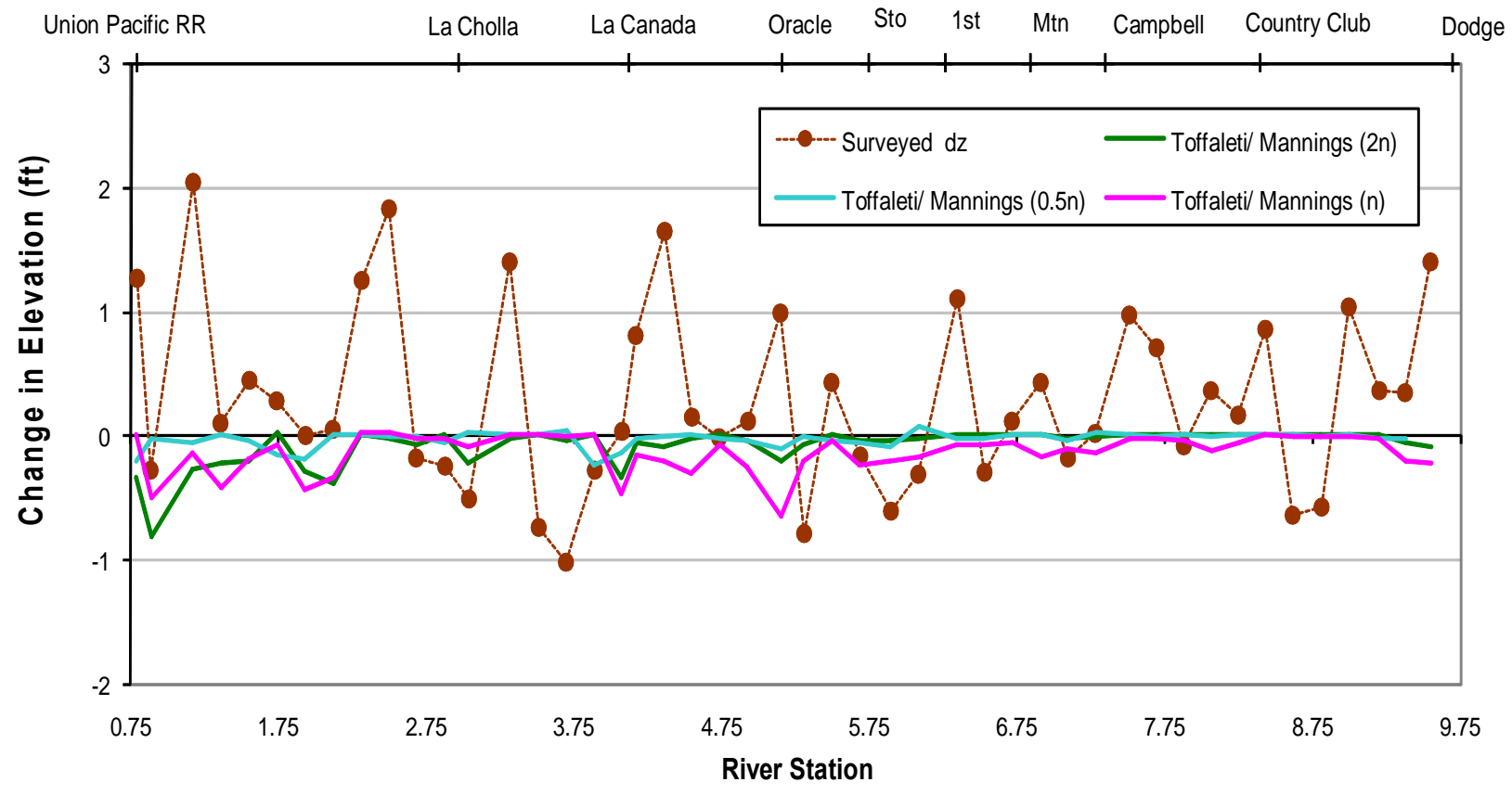

Figure 3. 3. 7. IALLUVIAL2 simulated averaged change in bed elevation with change in Manning's n

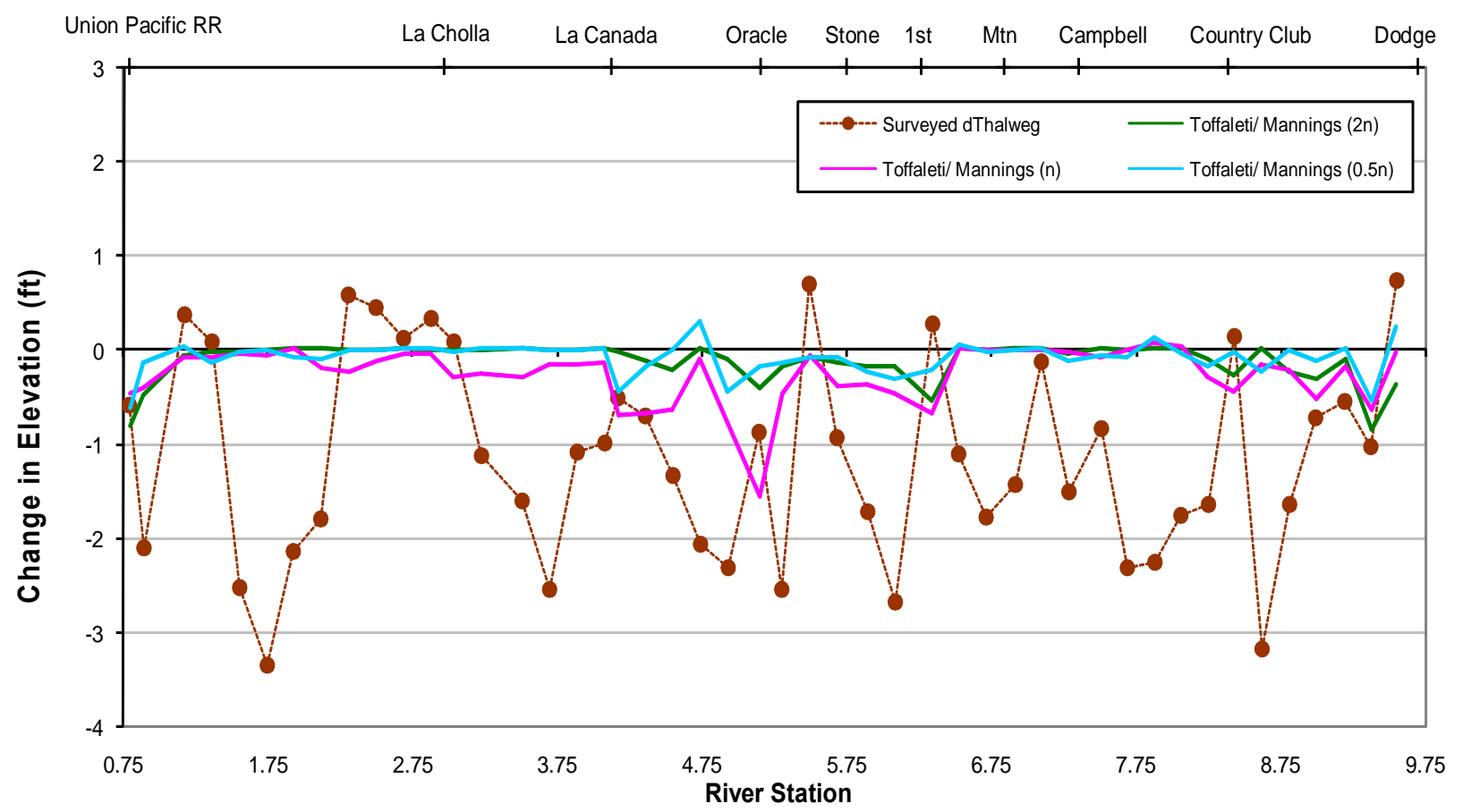

Figure 3. 3. 8. IALLUVIAL2 simulated average change in the thalweg with change in Manning's n 


\subsubsection{Variable Roughness}

IALLUVIAL2 has the capability to model variable roughness if a friction relation other than Manning's equation is used. When using Manning's equation as the friction relation, the userselected values of $\mathrm{n}$ remain constant throughout the simulation, regardless of the magnitude of flow. Other friction factor relations allow for a change in channel roughness with a change in discharge (Q). For this study, three different friction factor relations, Karim-Kennedy, Brownlie and Karim, were used to determine the sensitivity of the model to varying roughness with Q. All other parameters were held constant and the sediment transport equation used was that of Toffaleti. For the water surface elevations, the Karim-Kennedy and Karim relations produced stages similar to that of the observed data, although they overestimated the peak flow while underestimating the smaller peaks. The Brownlie relation showed great instability throughout the simulation, as can be seen in Figure 3.3.9. However, for the average change in bed elevation, all three equations underestimated the deposition and at the thalweg underestimated the scour, as shown in Figures 3.3.10 and 3.3.11. As seen with the constant roughness simulations, the model again showed an overall scour of the bed.

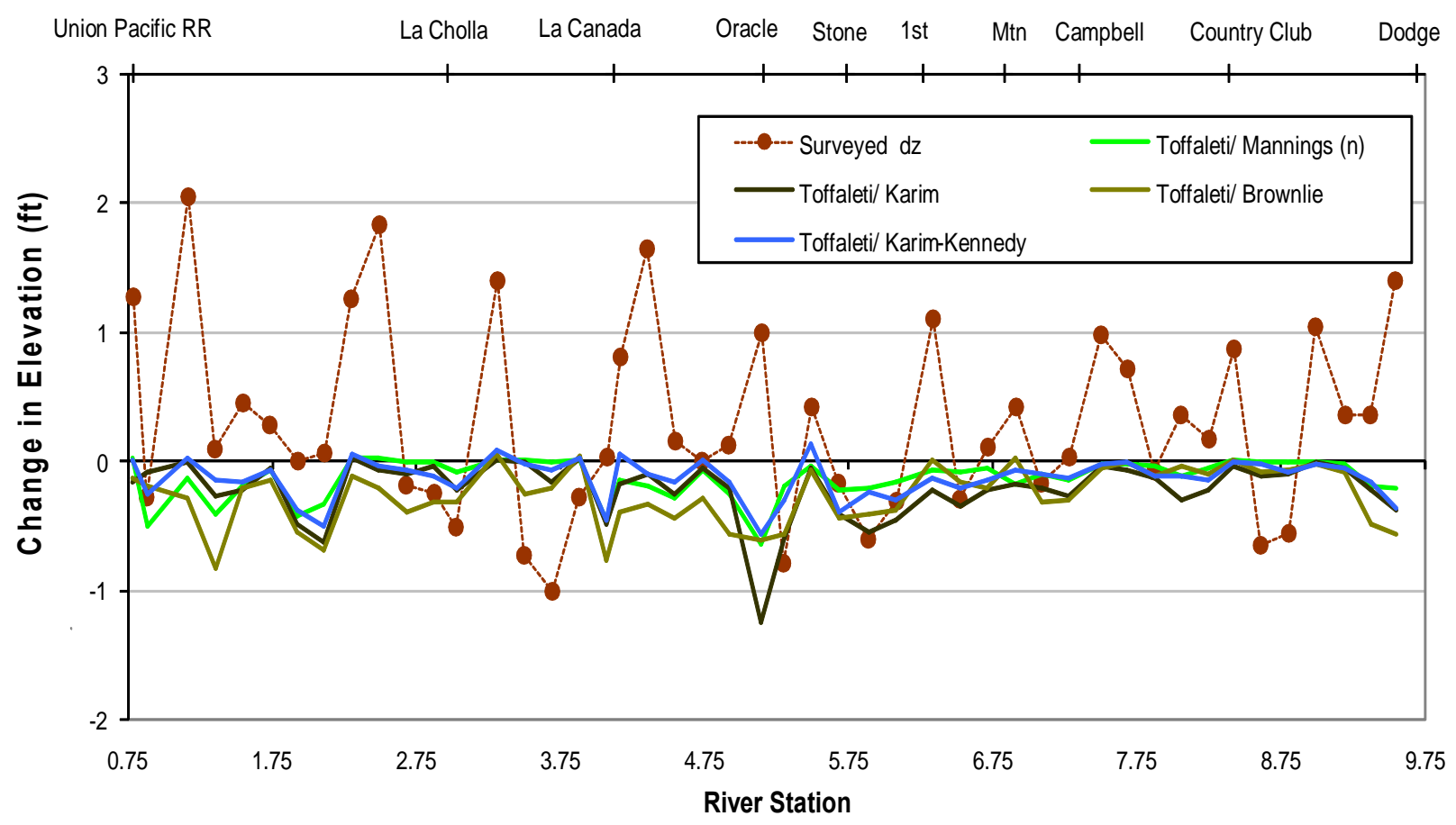

Figure 3. 3. 9. IALLUVIAL2 simulated averaged bed elevation changes using variable roughness 


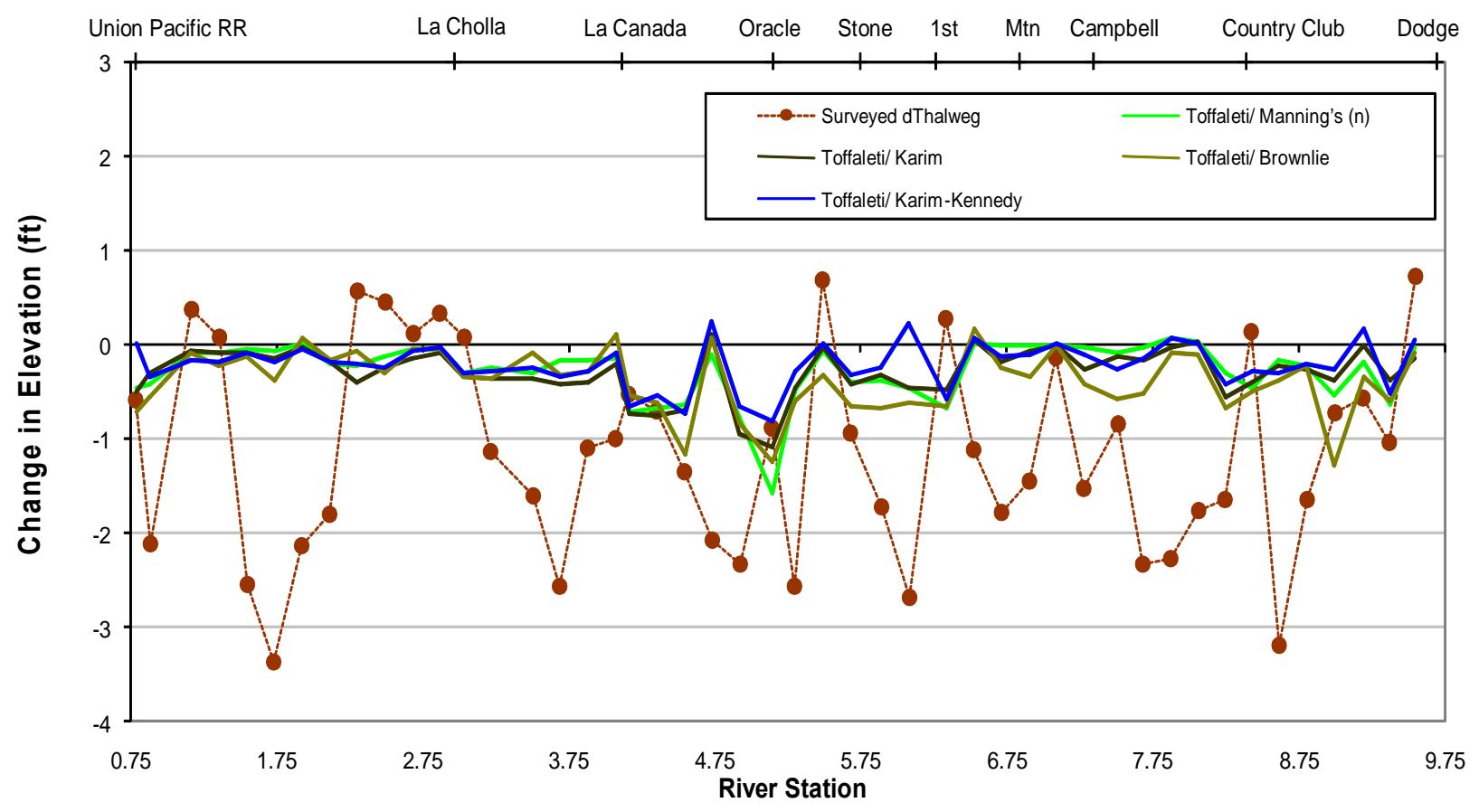

Figure 3. 3. 10. IALLUVIAL2 simulated averaged change in bed elevation using variable roughness

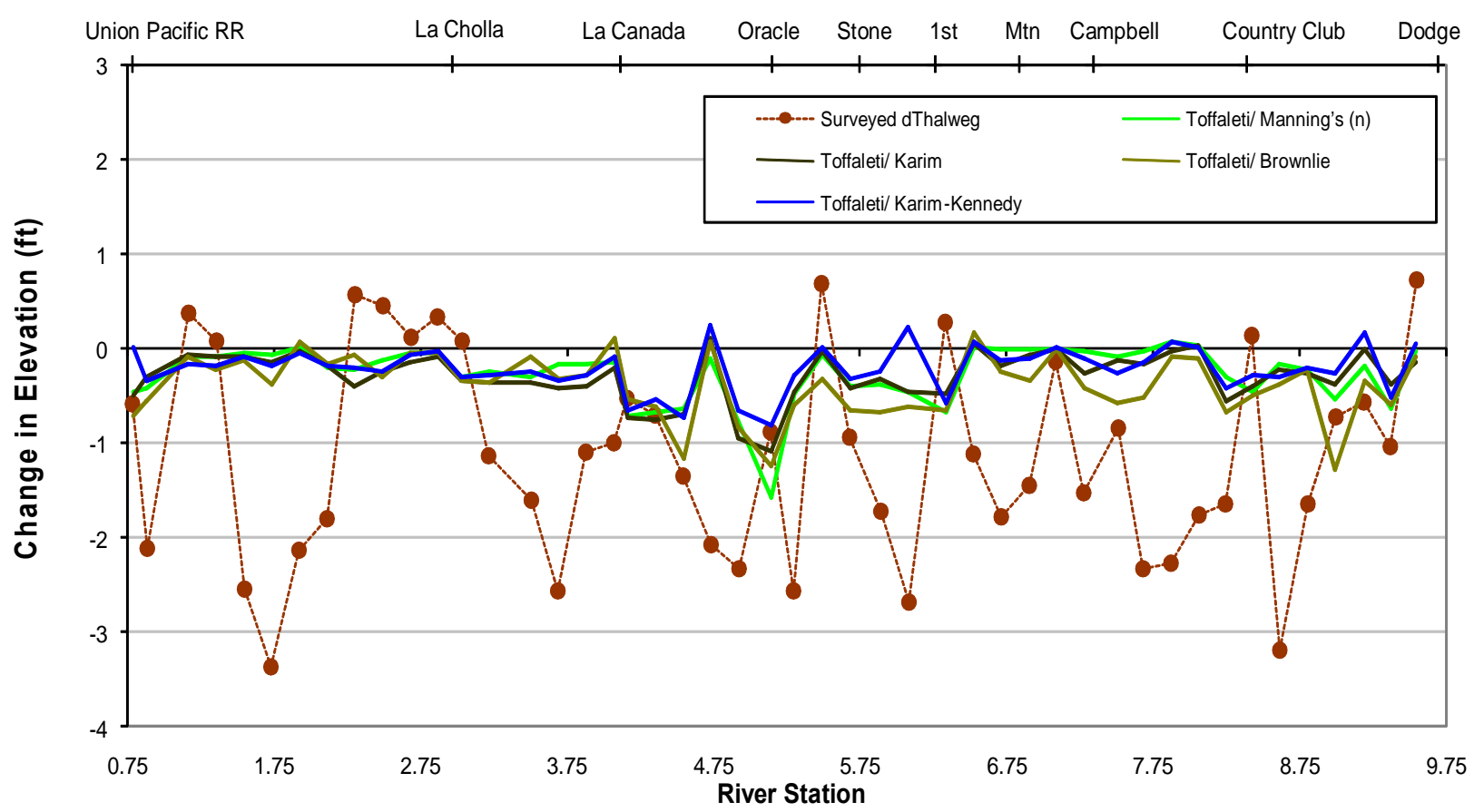

Figure 3. 3. 11. IALLUVIAL2 simulated changes at the thalweg using variable roughness 


\subsubsection{With or Without Fine material $(<0.125 \mathrm{~mm})$}

Lastly, the model's sensitivity to the presence of fine materials was examined. The sieve analysis of the bed sediments gathered in the Rillito showed the presence of fine sediments. Since very fine sediments, those less than $0.125 \mathrm{~mm}$ in size, are generally seen as washload, it may be more realistic to eliminate those sediments from the simulation. For this study, the Toffaleti sediment transport equation was used, along with the Manning's friction relation. All parameters from the original analysis remained unchanged; only the sediment distribution was adjusted to eliminate the finer sediments. The results showed that the stage results were not very sensitive to the change, but that the sediment simulation was. As can be seen in Figure 3.3.12, the predicted water surface elevations with fines or without are very similar. However, in Figures 3.3.13 and 3.3.14, both the changes in average bed elevation and at the thalweg showed more scour and even more deposition in places with fines than without. The removal of fines dampened the model's response in the sediment analysis. The model overall showed better results with the fines than without, but still greatly underestimated the overall amount of deposition seen in the real case.

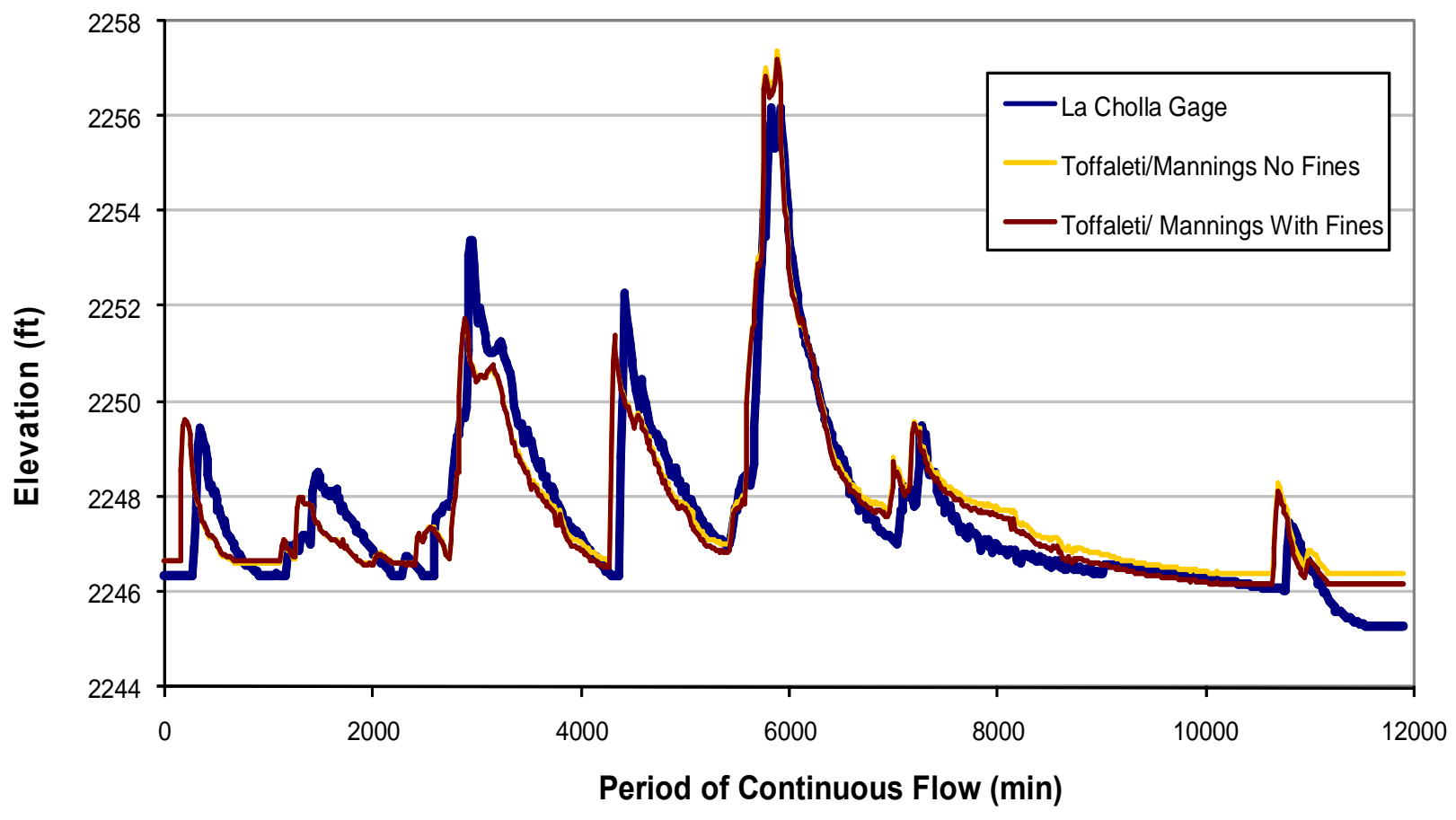

Figure 3. 3. 12. IALLUVIAL2 simulated La Cholla stages with change in sediment distribution 


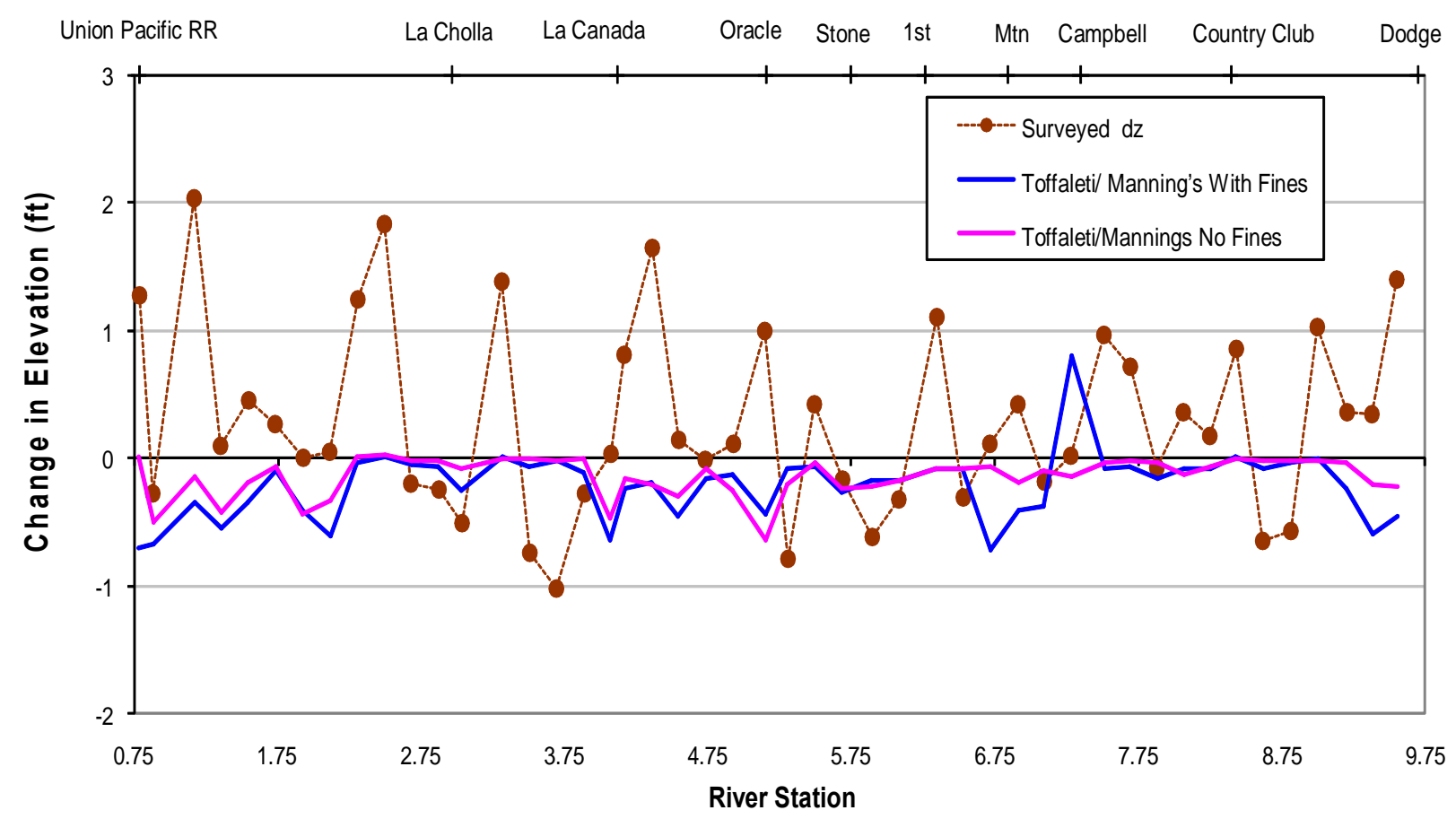

Figure 3. 3. 13. IALLUVIAL2 simulated average change in bed elevation with change in sediment distribution

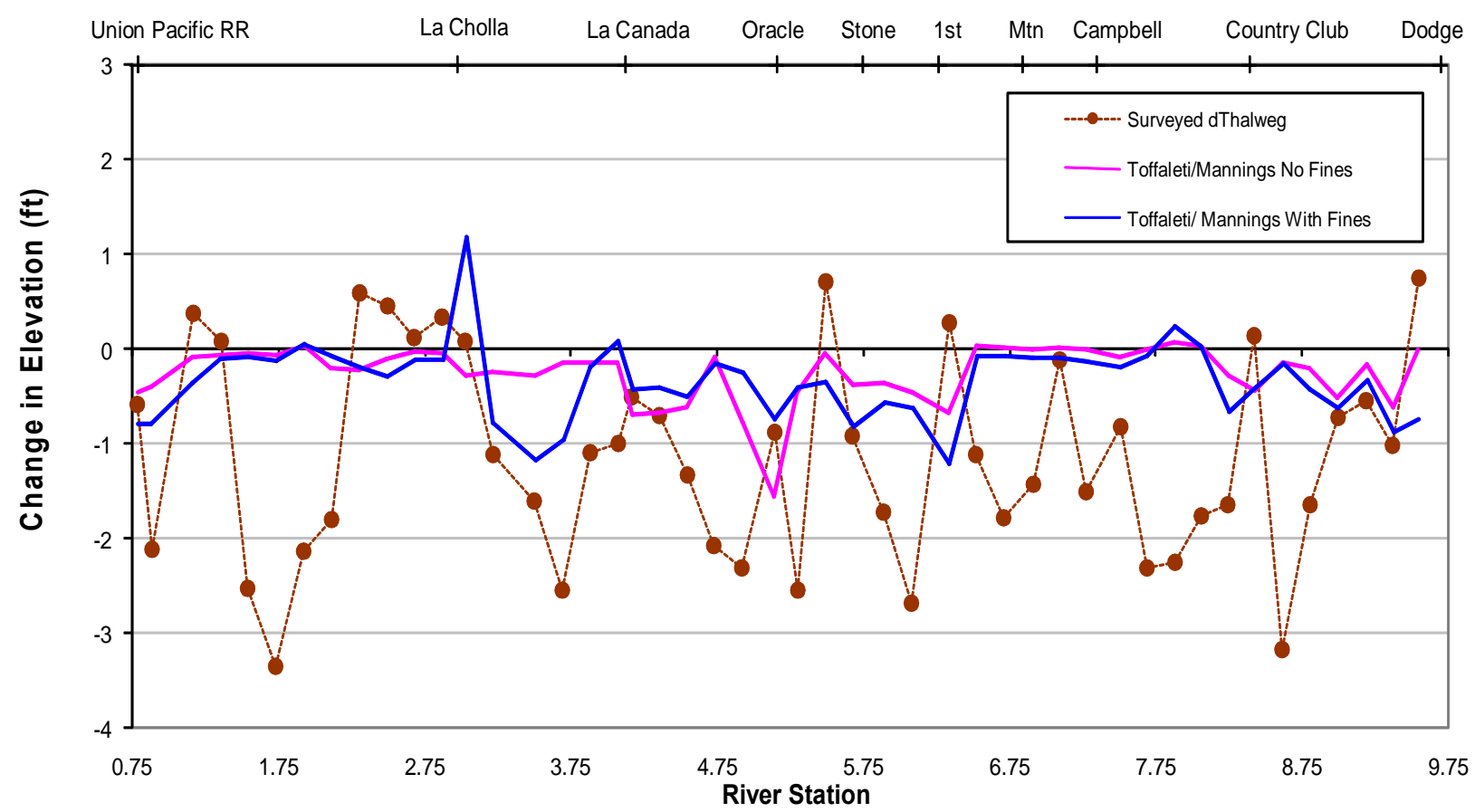

Figure 3. 3. 14. IALLUVIAL2 simulated change in the thalweg elevation with change in sediment distribution 


\subsubsection{Summary and Conclusions}

A quasi-steady flow and sediment transport analysis was performed. IALLUVIAL2 predicted quite well the stage hydrograph of the 2006 flood events on the Rillito River. The modeled stage lagged behind the observed stage at La Cholla by about 2 hours. This was due to the quasi-steady nature of the analysis, and the input hydrograph from several miles upstream at Dodge Blvd that was used in the input file. However the model performed poorly in the sediment transport analysis. It did not predict the deposition that was seen overall in the bed, although it was able to predict scour at the thalweg. This may be because IALLUVIAL2 distributes deposition evenly across the mobile bed, but scour is distributed according to shear stress. As stated previously, several factors could have been responsible for this lack of deposition, including the aforementioned unmodeled tributaries that could have deposited large amounts of sediment in the river reach. Another factor could be the geometry input file. As was mentioned in Section 2, IALLUVIAL2 has some guidelines about the lengths of the reach length and time step. Since the same geometry designed for the HEC-RAS model was used for all the models, this may have affected the performance of the IALLUVIAL2 model if the ratio of reach length to timestep was not within those guidelines.

Based on the findings of the project analysis, the performance of the IALLUVIAL model most closely approximated the observed changes in bed elevation using the Toffaleti sediment transport equation with a maximum erodible depth of 100 feet, Manning's friction factor equation, and the given values of Manning's $\mathrm{n}$. The model is somewhat sensitive to choice of sediment transport equation, friction factor equation, and presence of fines. The stage prediction is sensitive to a large increase in roughness, but not so sensitive to a large decrease. However, too large of a reduction in Manning's n will cause the simulation to abort.

Overall, the performance of all six of the chosen sediment transport equations was not particularly accurate. Limitations of a 1-D model prevent the sediment simulation from predicting the correct trend of erosion or deposition at a particular cross section. This suggests that the model could have benefited from more refined geometry data or that a single-reach modeling approach may be insufficient to model this reach of the Rillito River, since there are several major tributaries affecting the river.

The model was most sensitive to large increases and to very large decreases in the Manning's roughness and to the presence of fine particles $(<0.125 \mathrm{~mm})$. The model was not as sensitive to using a variable roughness relation as opposed to using Manning's equation. 


\subsection{SRH-1D Model}

SRH-1D is a quasi-unsteady quasi-2D mobile bed model. The hydraulic model is similar to that of HEC-RAS and IALLUVIAL2. The sediment transport model has included many sediment transport formulas. Since flow was divided into several stream tubes, the model can differentiate degradation/aggradation in the main channel from floodplain. Consequently, channel width is adjustable in the simulation. Nevertheless, the bridge module in SRH-1D model was very sensitive to bridge parameters (e.g. bridge elevations, opening). It requires many trials with different bridge parameters to obtain a stable solution. The model is also capable of simulating sediment transport under unsteady flow condition.

\subsubsection{Input Data}

\subsubsection{Model Parameter}

The model input data file consists of project title, geometry data, flow series, simulation data, and sediment data. Geometry data, flow series, and simulation data are the same as those for the HEC-RAS model. Nine sediment size groups ranging from $0.016 \mathrm{~mm}$ to $64 \mathrm{~mm}$ were used after removing the portion of fine sand. Although the model can simulate the total dissolved substances this study did not consider any dissolved solids. SRH1D requires that the mobile bed be divided into two or more layers. This study assumed a two-layer mobile bed material.

SRH-1D simulates flow and sediment transport under both steady and unsteady conditions. In the case of steady flow, the sediment transport simulation is also steady. This also applies to the unsteady flow and sediment solutions. There are also various unsteady flow solvers available; in this study, however, the steady simulation is applied in order to be comparable with other models.

The choice of time step influences the stability and accuracy of the model. In general, the smaller the time step, the more stable and accurate the results. However, the CPU time for each simulation is directly proportional to the number of total time steps. This study fixed the time step as $15 \mathrm{~min}$ in order to be the same as the time interval of the observed hydrograph and stage data.

\subsubsection{Upstream flow boundary condition}

The upstream flow boundary condition can be a junction to another river, a stage hydrograph, or a flow hydrograph. Interpolation is required when a simulation time falls between two specified data if using a stage or flow hydrograph as the upstream boundary condition. For unsteady flow simulation, the interpolation is linear with respect to time. For a steady flow simulation, flow discharge or stage do not change until the time of the next input flow discharge. This study used the observed discharge hydrograph as the upstream flow boundary condition.

For a steady or quasi-unsteady flow simulation, either the stage hydrograph or the stage vs discharge rating curve can be specified as the downstream boundary condition, while for the 
unsteady flow case, a flow hydrograph at the downstream boundary is needed. A weir boundary condition can also be used when the weir elevation, width, and discharge coefficient are given. This study specified the rating curve between flow discharge and water surface elevation as the downstream boundary condition.

\subsubsection{Internal boundary conditions}

Many of the same boundary conditions applicable at the downstream boundary can also be used at internal cross sections. Therefore, bridges and radial gates can be modeled as internal boundaries. This model treated 11 bridges as internal boundaries, and applied the stage versus discharge rating curve as the boundary conditions. SRH 1D does not permit the use of real geometry of each bridge, rather the bridge cross section must be simplified in order to be accepted by the SRH-1D model.

\subsubsection{Geometry}

The SRH-1D model requires the same geometric data as that for other models, but in a different format. The geometric data consists of a series of discrete cross sections along the study reach. The cross sections are chosen by the user to reflect important river hydraulic characteristics, such as all the existing controls. The reach length should be appropriately the distance that flow travels in one time step. It also should also depend on the complexity of cross sections (User's Manual for SRH-1D v.2.0.5).

The Manning's roughness coefficient in SRH-1D is similar to the HEC-RAS model. The Manning's roughness coefficient can be different for the main channel and floodplain. However, the Manning's roughness coefficients remain unchanged in SRH-1D model in the simulation.

SRH-1D also provides a geometry data converter that performs the conversion of the geometry file from HEC-RAS into the one required by SRH-1D model. The geometry file for SRH1D was directly converted from the geometry data file for HEC-RAS model. However, a careful check of the converted file is needed to avoid mistakes occurring during the conversion. For example, the converter will lose points for an obstruction in the HEC-RAS model defined by more than two points.

In this study, all modifications to the geometry were applied to the HEC-RAS model first, and then converted into SRH-1D geometry file. The Manning's roughness coefficient is also converted directly from the HEC-RAS model. A sensitivity analysis to the Manning's roughness was conducted, and the results were compared to select the best value for the model.

\subsubsection{Sediment Model Parameter}

Sediment model parameters control the implicit factor for sediment transport computation and the number of time steps for sediment computation in one time step of flow computation. The implicit factor should be set to 1 . The number of sediment time steps can be greater than 1 if the 
model behaved unstable. Stability can be increased by shortening the overall time step. The sediment size distributions are also given in this data group. In this study, the sediment time step is the same as the flow time step.

\subsubsection{Sediment Boundary Condition}

The sediment load entering the study reach at the upstream boundary must be specified for each size fraction. There are several methods to specify the incoming sediment loads:

1. Assume an equilibrium sediment load. If this option is chosen, the sediment load coming into the reach is calculated based on the size distribution of bed material and the selected sediment transport equation.

2. Use the sediment rating curve. The sediment rating curve is a power relationship between flow discharge and total sediment load. The total sediment load was divided into fractional sediment load using a table of flow discharge and fraction of total sediment load for each size group.

3. Define a table correlating the total sediment load with flow discharge table. This option is similar to the previous option except that a table is used for determining the sediment discharge instead of a power function.

4. Specify a time series of sediment load. The user may directly specify the amount of sediment entering the reach as a function of time. The total sediment load was divided into several fractional loads in a way similar to the previous two options.

This study used equilibrium sediment load as the sediment boundary conditions. The equilibrium load was calculated from the selected sediment transport equation. All 17 sediment transport equations provided are tested and the results are compared with the observed data for determining the best performing model.

\subsubsection{Bed Material}

The fraction of each size sediment on the initial river bed is required for each river reach. These data were given at selected sampled locations and interpolated to the rest cross sections. In this study, sediment samples are collected close to each bridge, and the sediment size distribution are obtained by the sieve analysis shown in Section 3.

\subsubsection{Water Temperature}

Water temperature was input for each subreach as a time series. Because the simulation period is only a few days, a constant temperature is assumed. The water temperature in this study was set as $60 \mathrm{~F}$. 


\subsubsection{Erosion and Deposition Limits}

The erosion and deposition limits, namely, erodible depth, control the allowable extents of cross sectional change. No deposition is allowed above the maximum vertical limit and no erosion is allowed below the minimum vertical limit. Erosion was not permitted at the points outside the horizontal erodible limit. This restriction also applies to the horizontal deposition limit. In this study, there are thirteen grade control structures in the studied reach, which do not allow any erosion. The erodible depth was set as $0.01 \mathrm{ft}$ at these sections having grade control structures; otherwise it was infinite.

\subsubsection{Results}

\subsubsection{Sediment Transport Equations}

This study conducted simulations by using seven total load equations by Yang(1973), Yang (1979), Engelund (1972), Wu et al. (2000), Wallingford (1990) (the revised Ackers-White), LaursenMadden (1993), and Brownlie (1981), respectively, while keeping all other input data unchanged. The results of simulated stage hydrographs at La Cholla using these sediment equations are shown in Fig.3.4.1 and Fig.3.4.2. The simulated stage hydrographs matched well with the observed hydrograph at most of the low to medium flows, but predicted about $1 \sim 2 \mathrm{ft}$ higher stage at the peak. This phenomenon resulted from the reduction of roughness at high flows that was not considered by the SRH-1D model. One can see that all of seven sediment transport equations predicted similar hydrographs, which indicated that the results of stage hydrographs from the SRH-1D model was not sensitive to sediment transport equations. Since bed roughness remains the same in the simulation, the minor differences of stage hydrographs are due to the differences in calculated bed elevation changes when using different sediment transport equations.

Additionally, the predicted stage hydrographs lead the observed data about 120 mins at the peak discharge. This is expected because quasi-unsteady flow has adopted the standard-step method to solve the energy equation at each discharge so that the stage hydrograph at La Cholla is in phase with the stage hydrograph at Dodge, as shown in the results of other models. 


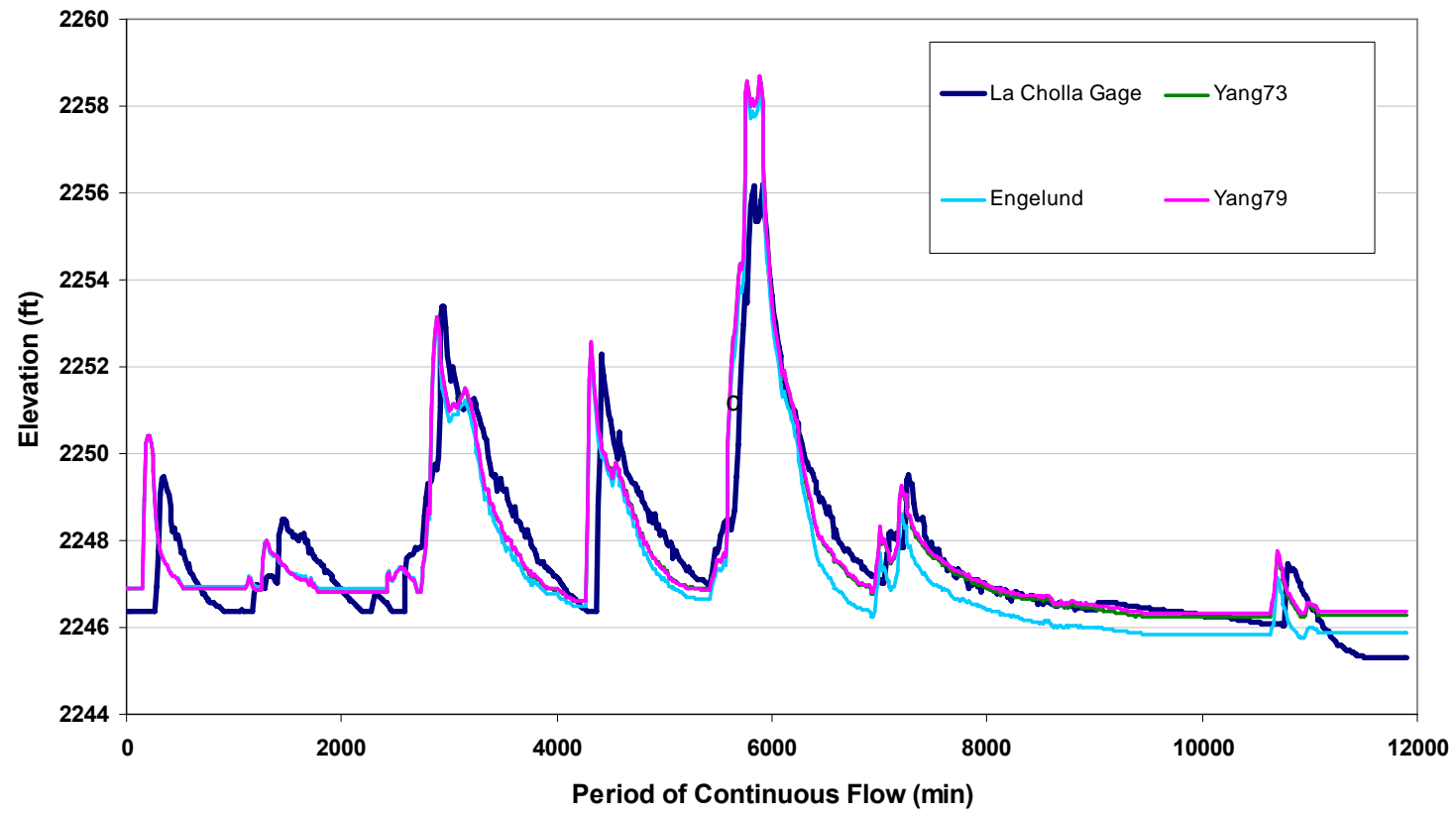

Figure 3. 4. 1. SRH-1D simulated stage hydrographs at La Cholla using Yang73, Engelund, Yang79 Equation

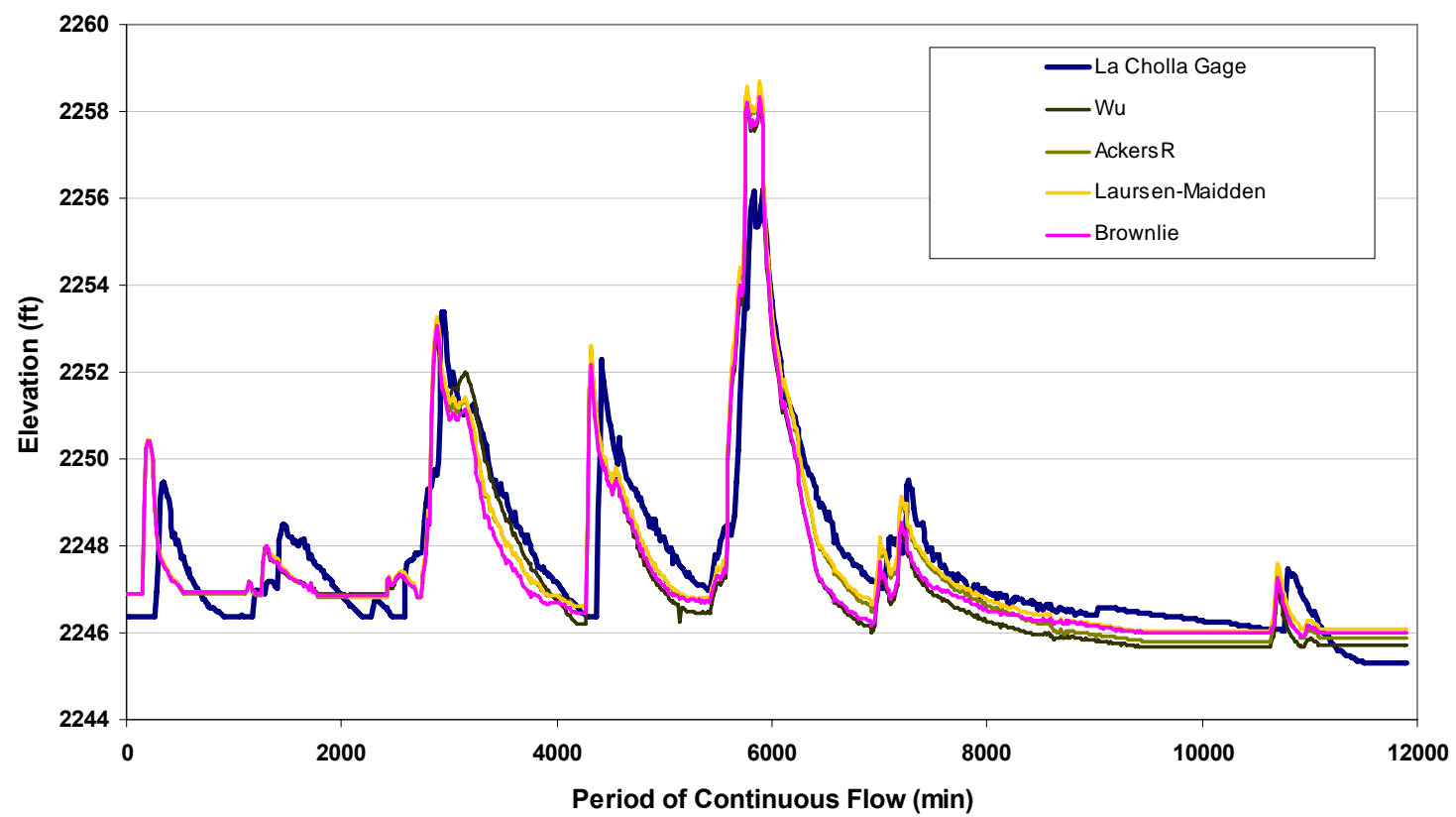

Figure 3. 4. 2. SRH-1D simulated stage hydrograph at La Cholla using AckersR, LaursenMadden and Brownlie Equation 
The results of averaged bed elevation changes were compared with the observed data in Fig.3.4.3 and Fig.3.4.4. Overall, none of these sediment equations predicted the changes of the average bed elevations accurately. The equations of Engelund (1972), Wu (2000), and Brownlie (1981) correctly predicted the depths of deposition near the Country Club, Campbell, Stone and Oracle bridge, but fail at the other locations. The rest of the models have under-predicted the erosion/deposition depth at every cross section. The results of averaged bed elevation are very sensitive to the configuration of bridges, however, the SRH-1D model does not permit the detailed geometric data at bridge cross sections. The simulated changes of averaged bed elevations greatly depend on the simplified bridge geometry required by the model rather than the real bridges. Therefore, modelers need to make the simplified bridge cross sections as close as possible to the real bridge cross sections to get realistic modeling results.

Fig.3.4.5 and Fig.3.4.6 showed the simulated bed elevation changes at the thalweg in which none of the results match the observed data. The results are expected and explained in Section 5 because none of the models considered the differences of bed elevation changes between the main channel and the floodplain.

Fig.3.4.7 showed the deposited/eroded sediment volume between two consecutive bridges. Obviously, none of the models predicted close matches to the observed data at all of the cross sections. The results from the Laursen-Madden (1993) equation followed the trend of the observed data, but deviated too much to be considered as a feasible model.

Table 3.4.1 summarizes the statistics of the simulated results by using different sediment transport equations. One can see that the statistical parameters indicated that the LaursenMadden(1993) sediment transport equation yielded the best results followed by Yang (1973) equation. 


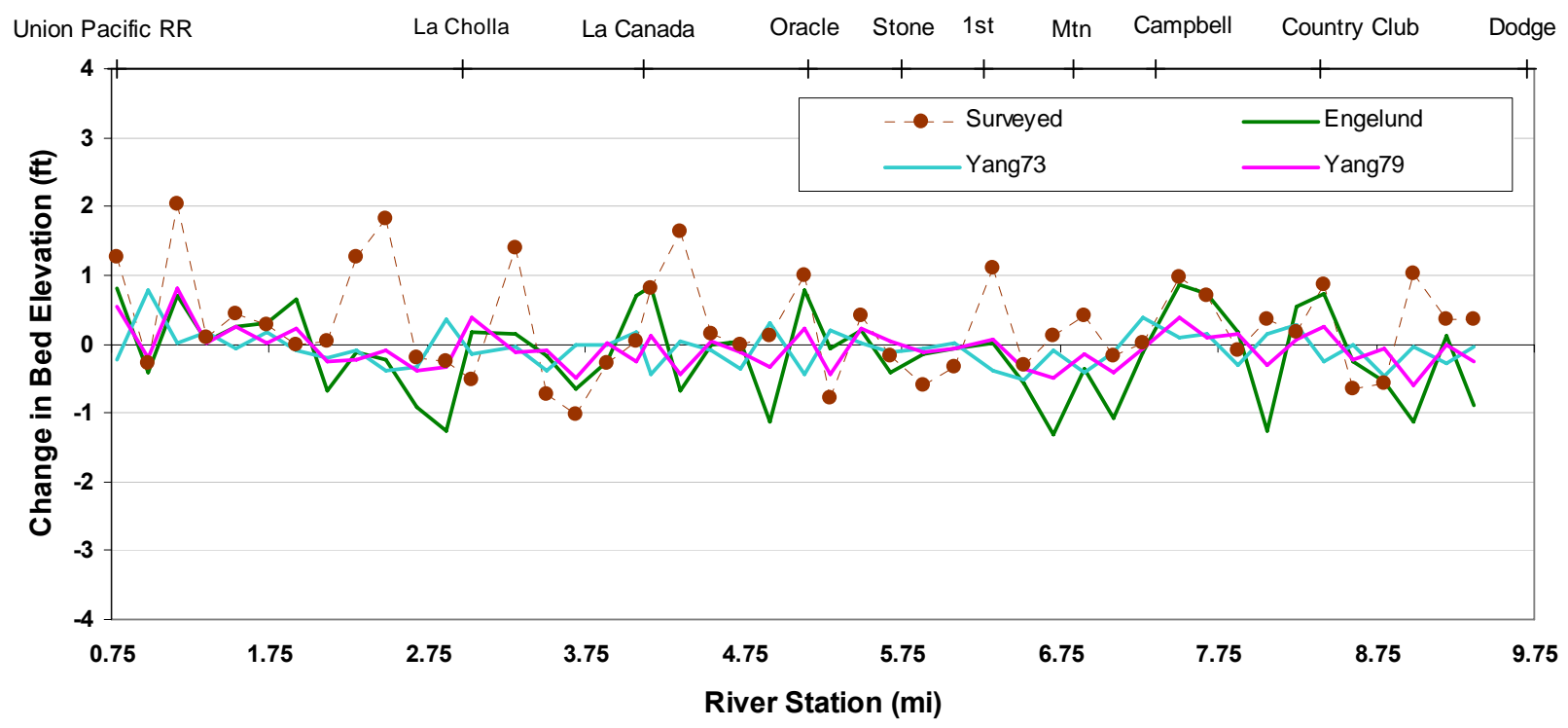

Figure 3. 4. 3. SRH-1D simulated averaged change in bed elevation using Yang73, Engelund and Yang79 Equation

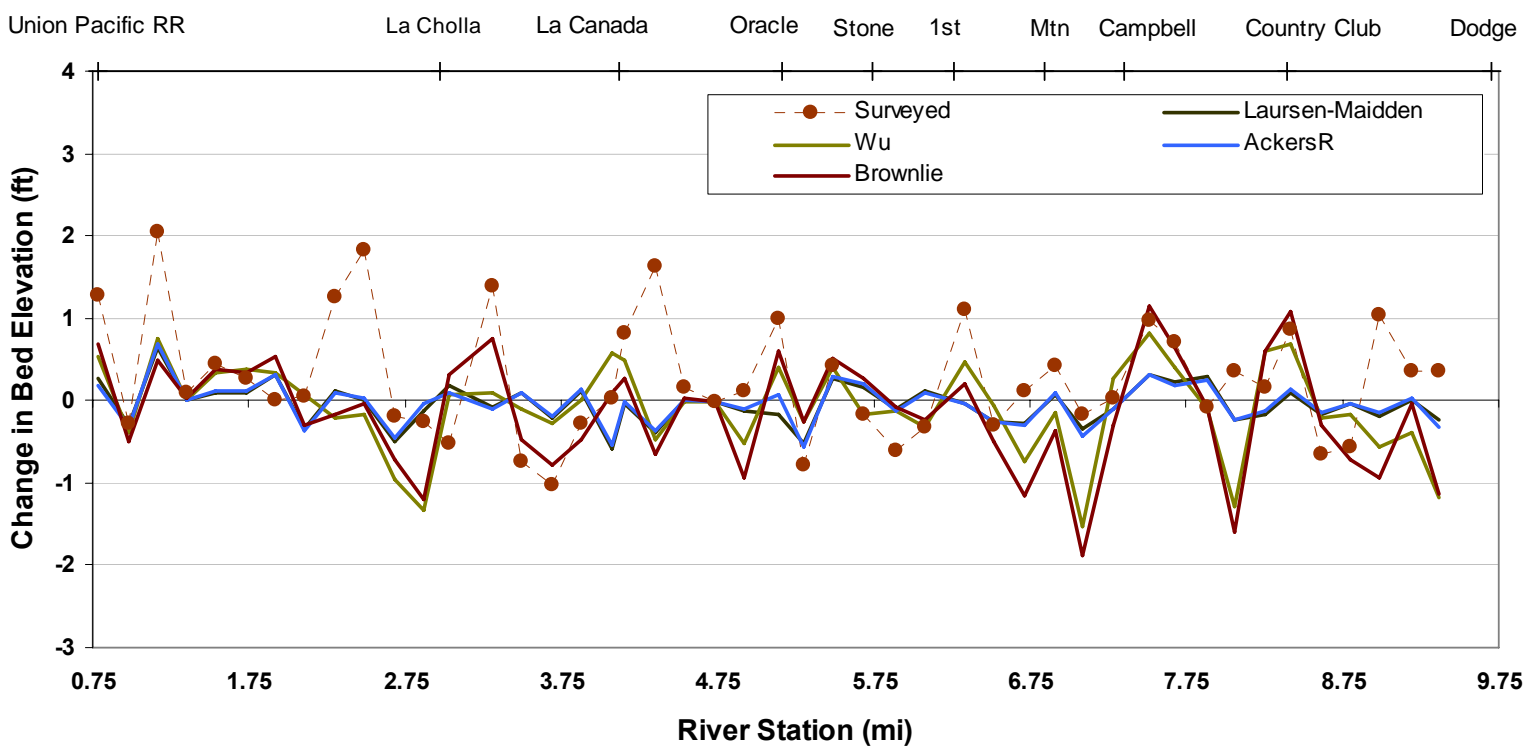

Figure 3. 4. 4. SRH-1D simulated averaged change in bed elevation using Wu, AckersR, Laursen-Madden and Brownlie Equation 


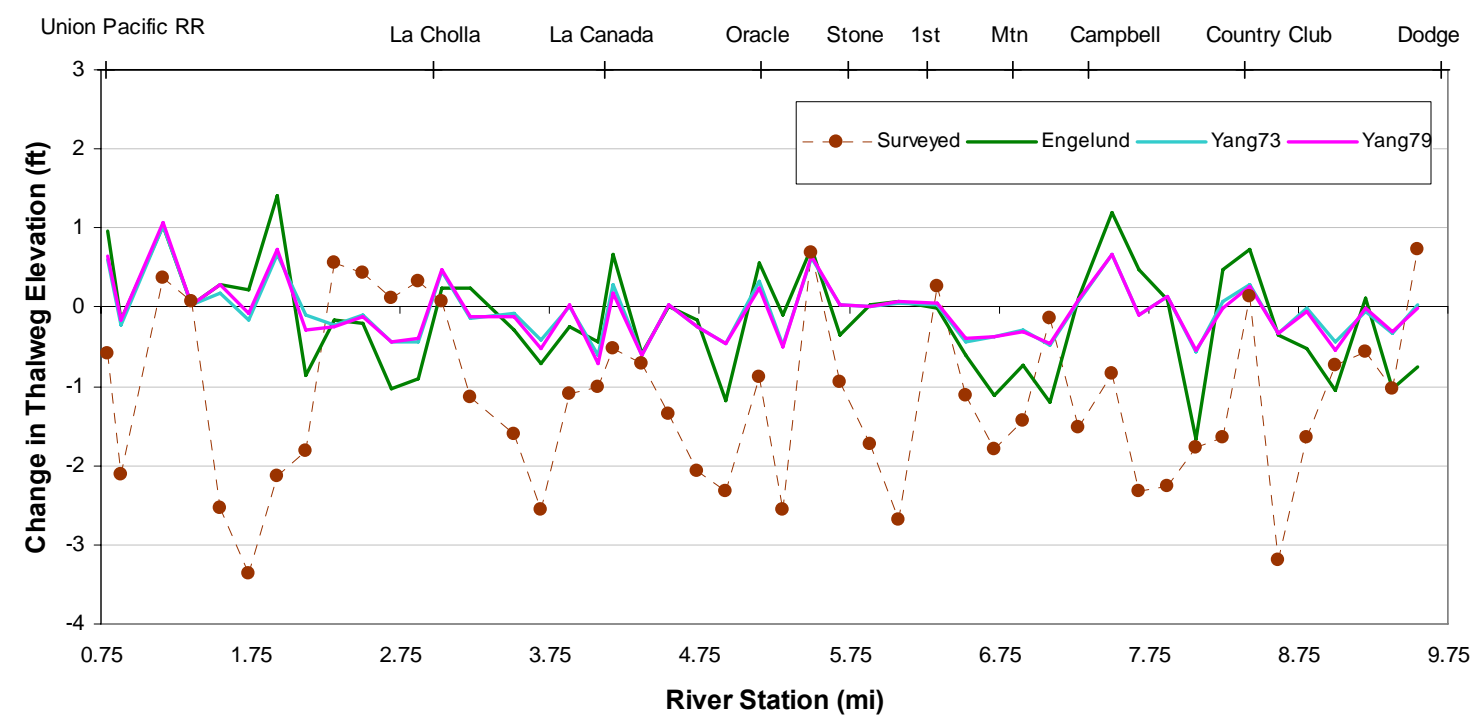

Figure 3. 4. 5. SRH-1D simulated change in the thalweg elevation using Yang73, Engelund and Yang79 Equation

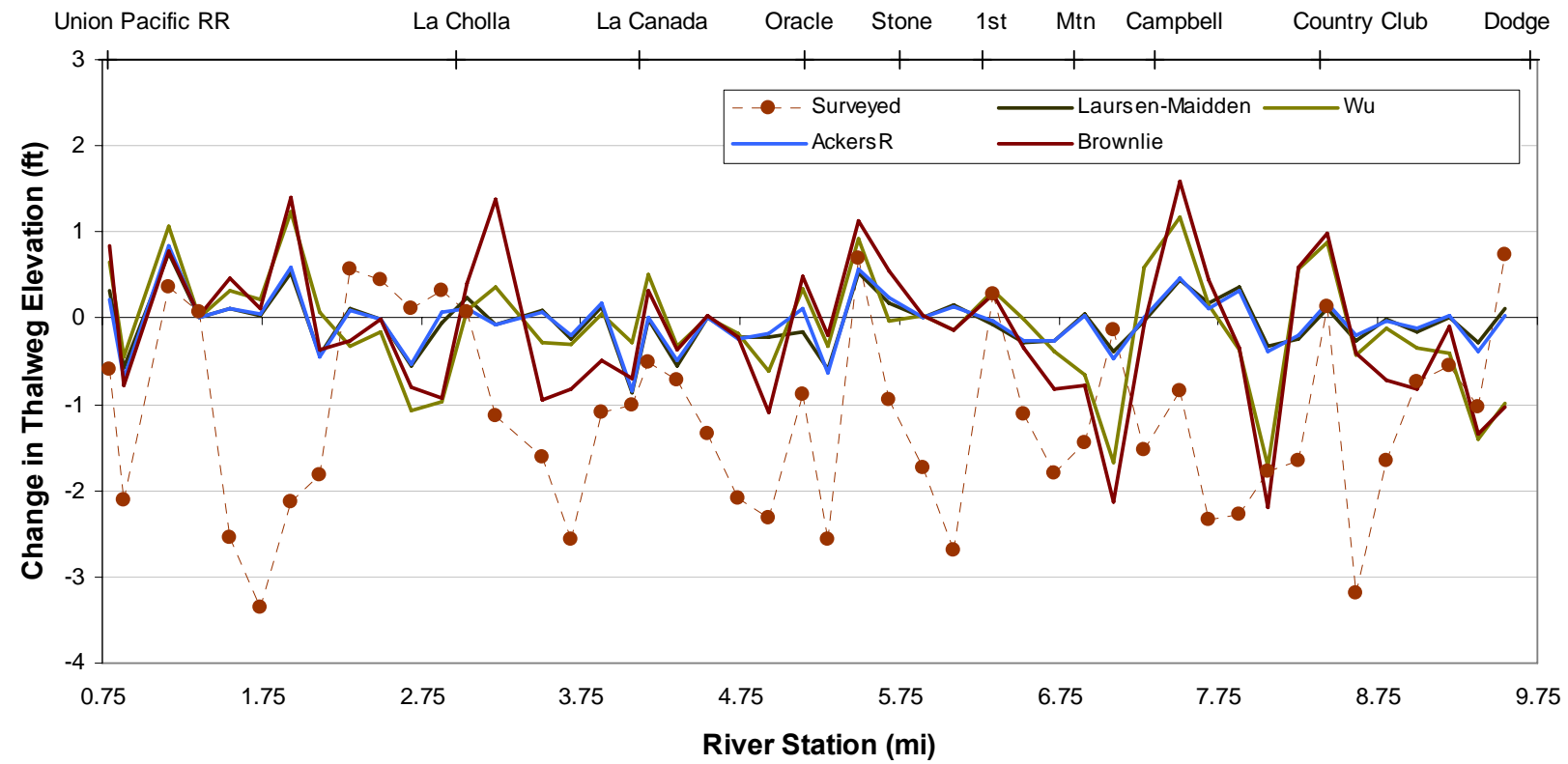

Figure 3. 4. 6. SRH-1D simulated change in the thalweg elevation using Wu, revised AckersWhite (1990), Laursen-Madden and Brownlie Equation 


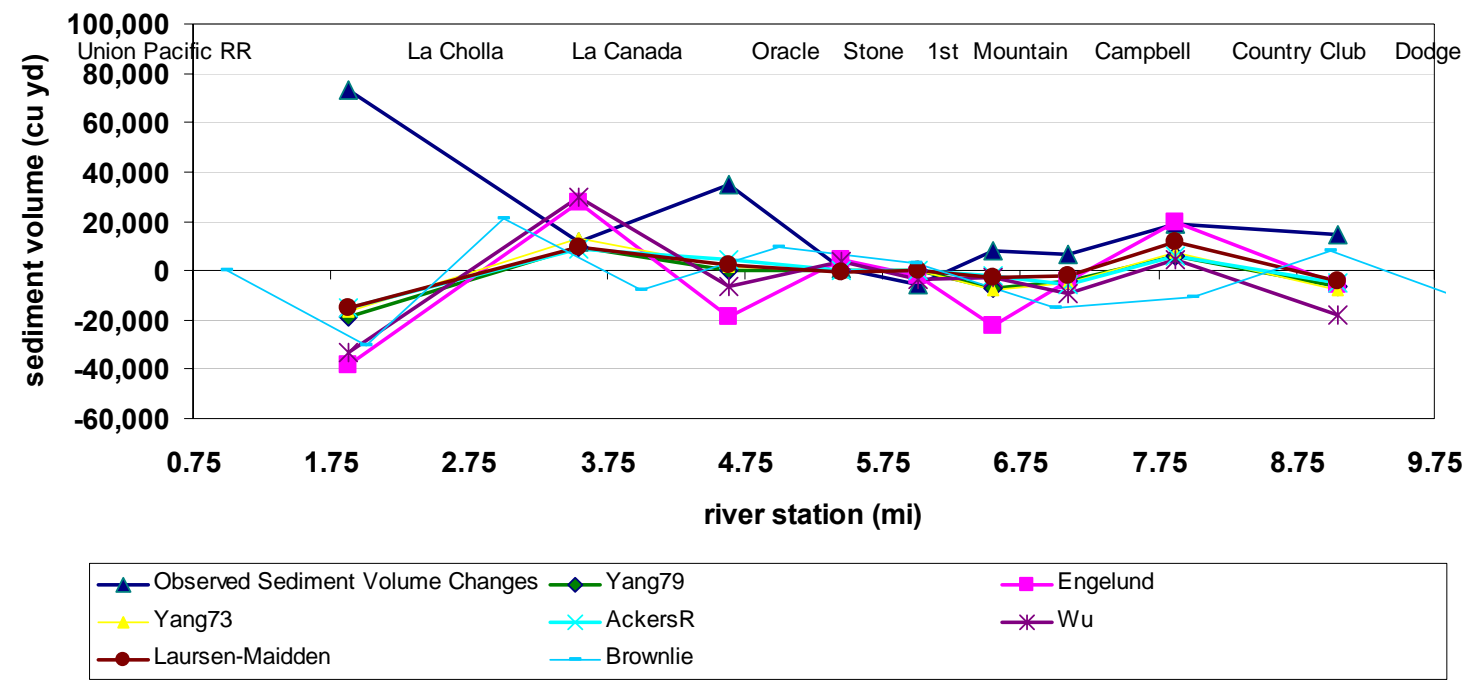

Figure 3. 4. 7. SRH-1D simulated deposited/eroded sediment volumes using different sediment transport equations 
Table 3. 4. 1. Statistics of Modeling Results

(a) Statistics of Stage

\begin{tabular}{|c|c|c|c|}
\hline Performance Factor & Yang73 & Yang79 & LaursenM \\
\hline Mean Error & 0.036 & 0.072 & -0.040 \\
Correlation Coefficient & 0.882 & 0.880 & 0.886 \\
Root Mean Square Error & 0.994 & 0.998 & 0.998 \\
Nash-Sutcliffe Efficiency & 0.735 & 0.733 & 0.733 \\
\hline \multicolumn{4}{|c|}{} \\
\hline Performance Factor & Engelund & Brownlie & AckersR \\
\hline Mean Error & -0.253 & -0.232 & -0.136 \\
Correlation Coefficient & 0.877 & 0.869 & 0.888 \\
Root Mean Square Error & 1.049 & 1.053 & 1.008 \\
Nash-Sutcliffe Efficiency & 0.705 & 0.702 & 0.727 \\
\hline \multicolumn{3}{|c|}{} \\
\hline Performance Factor & $\mathrm{Wu}$ & & \\
\hline Mean Error & -0.306 & & \\
\hline Correlation Coefficient & 0.882 & & \\
\hline Root Mean Square Error & 1.072 & & \\
\hline Nash-Sutcliffe Efficiency & 0.692 & & \\
\hline
\end{tabular}


(b) Statistics of Average Changes in Bed Elevation

\begin{tabular}{|c|c|c|c|}
\hline Performance Factor & Yang73 & Yang79 & LaursenM \\
\hline Mean Error & -0.323 & -0.332 & -0.313 \\
\hline Correlation Coefficient & 0.361 & 0.355 & 0.327 \\
\hline Root Mean Square Error & 0.758 & 0.764 & 0.761 \\
\hline Nash-Sutcliffe Efficiency & 0.054 & 0.039 & 0.048 \\
\hline Performance Factor & Engelund & Brownlie & AckersR \\
\hline Mean Error & -0.395 & -0.417 & -0.306 \\
\hline Correlation Coefficient & 0.263 & 0.312 & 0.345 \\
\hline Root Mean Square Error & 0.931 & 0.942 & 0.754 \\
\hline Nash-Sutcliffe Efficiency & -0.427 & -0.461 & 0.064 \\
\hline Performance Factor & $\mathrm{Wu}$ & & \\
\hline Mean Error & -0.355 & & \\
\hline Correlation Coefficient & 0.230 & & \\
\hline Root Mean Square Error & 0.904 & & \\
\hline Nash-Sutcliffe Efficiency & -0.344 & & \\
\hline
\end{tabular}


(c) Statistics of Bed Elevation Changes at the Thalweg

\begin{tabular}{|c|c|c|c|}
\hline Performance Factor & Yang73 & Yang79 & LaursenM \\
\hline Mean Error & 1.135 & 1.130 & 1.134 \\
\hline Correlation Coefficient & 0.246 & 0.228 & 0.210 \\
\hline Root Mean Square Error & 1.517 & 1.519 & 1.523 \\
\hline Nash-Sutcliffe Efficiency & 0.072 & 0.069 & 0.064 \\
\hline Performance Factor & Engelund & Brownlie & AckersR \\
\hline Mean Error & 1.060 & 1.052 & 1.145 \\
\hline Correlation Coefficient & 0.059 & 0.101 & 0.218 \\
\hline Root Mean Square Error & 1.598 & 1.625 & 1.528 \\
\hline Nash-Sutcliffe Efficiency & -0.03 & -0.065 & 0.058 \\
\hline Performance Factor & $\mathrm{Wu}$ & & \\
\hline Mean Error & 1.115 & & \\
\hline Correlation Coefficient & 0.022 & & \\
\hline Root Mean Square Error & 1.636 & & \\
\hline Nash-Sutcliffe Efficiency & -0.079 & & \\
\hline
\end{tabular}

\subsubsection{Sensitivity Analysis}

The sensitivity of modeling results to Manning's $\mathrm{n}$ values was examined by both increasing the $\mathrm{n}$ value to twice its original and reducing it to $50 \%$. The sensitivity analysis kept all other model input parameters the same. The larger the $\mathrm{n}$ values, the higher the water surface elevation, and vice versa. The results of stage hydrographs with changed Manning's $\mathrm{n}$ coefficients are plotted in Fig.3.4.8 together with the original results. It can be seen that the water surface elevation has fallen about $2 \mathrm{ft}$ when reducing Manning's $\mathrm{n}$ values to $50 \%$, and has risen about $2 \mathrm{ft}$ when doubling Manning's $\mathrm{n}$ values. As the discharge increases, the effect of the Manning's $\mathrm{n}$ value will also increase. Further reduction of $\mathrm{n}$ value will fail the model. Based on this sensitivity analysis and the back-calculated $\mathrm{n}$ values using the observed hydrographs, the original $\mathrm{n}$ values are most suitable for this study case.

Fig.3.4.9 and Fig.3.4.10 showed the results of averaged and at the thalweg bed elevation changes by using the changed Manning's $n$ value with the Laursen-Madden (1993) sediment 
transport formula. The effect of the Manning's $\mathrm{n}$ values to the change of bed elevation is complex, and do not seem to be significant. Both figures showed the increase or reduction of $n$ value did not produce better results as referred to the observed data. This also confirms the use of the original Manning's $n$ values in the study.

Figure 3.4.8 showed that the Manning's n value affected the stage hydrograph. No obvious correlations between the Manning's n values and the changes of bed elevations were observed.

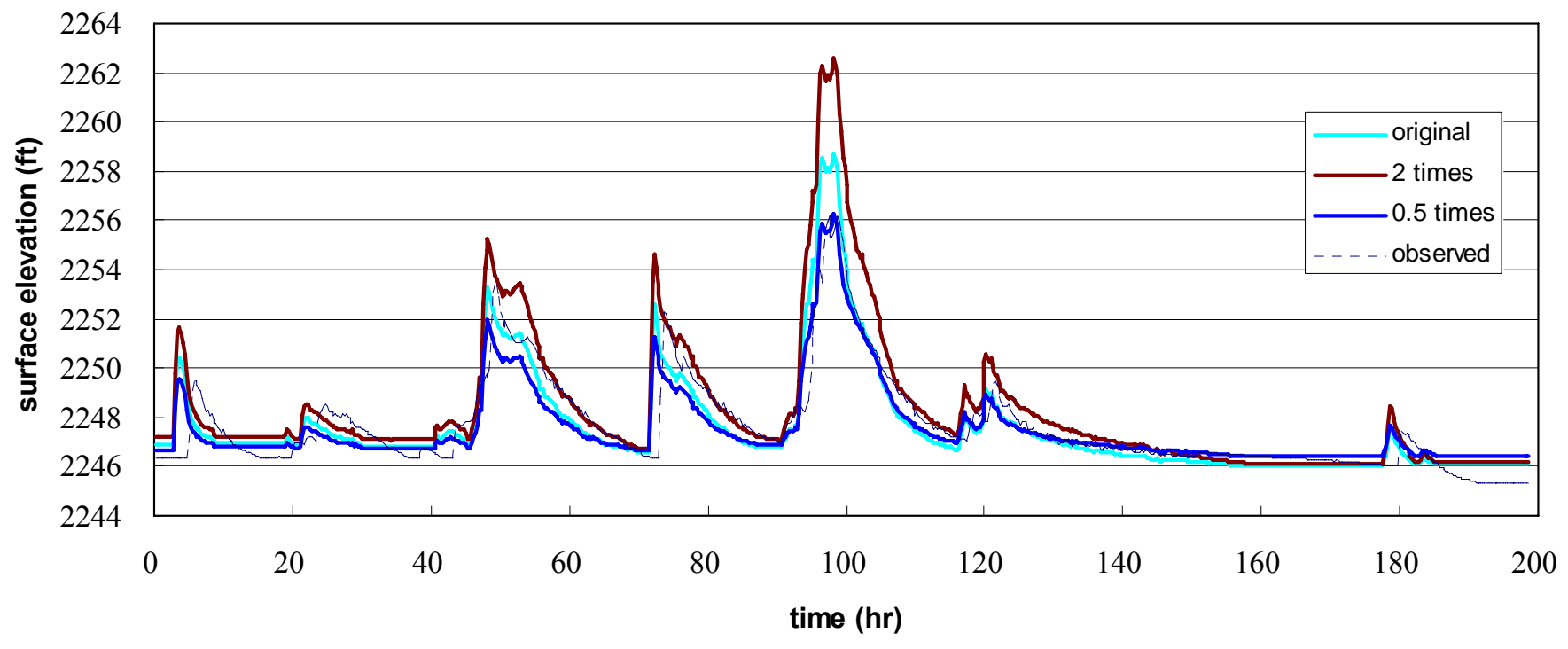

Figure 3. 4. 8. SRH-1D simulated stage hydrograph at La Cholla using different roughness factors 


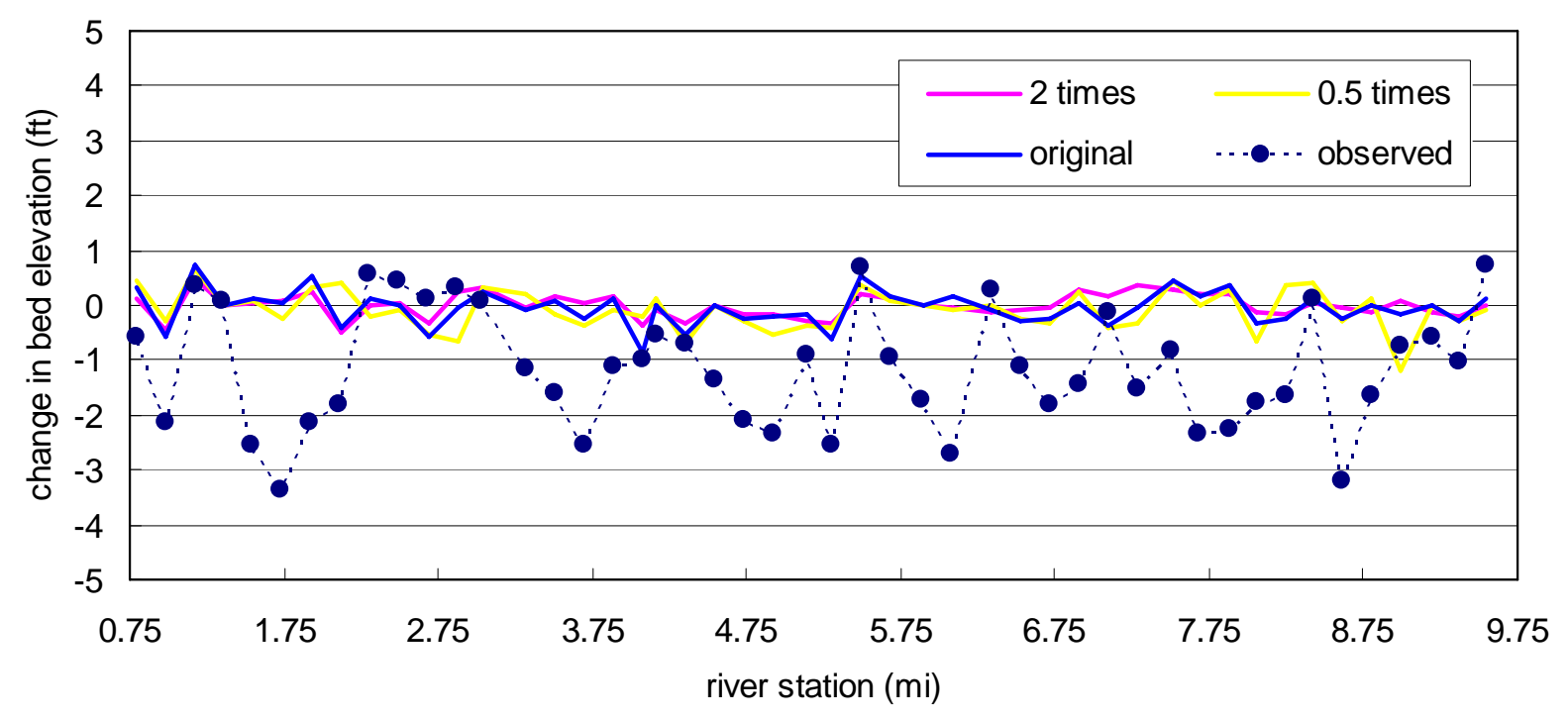

Figure 3. 4. 9. SRH-1D simulated change in bed elevation at the thalweg using different roughness factors

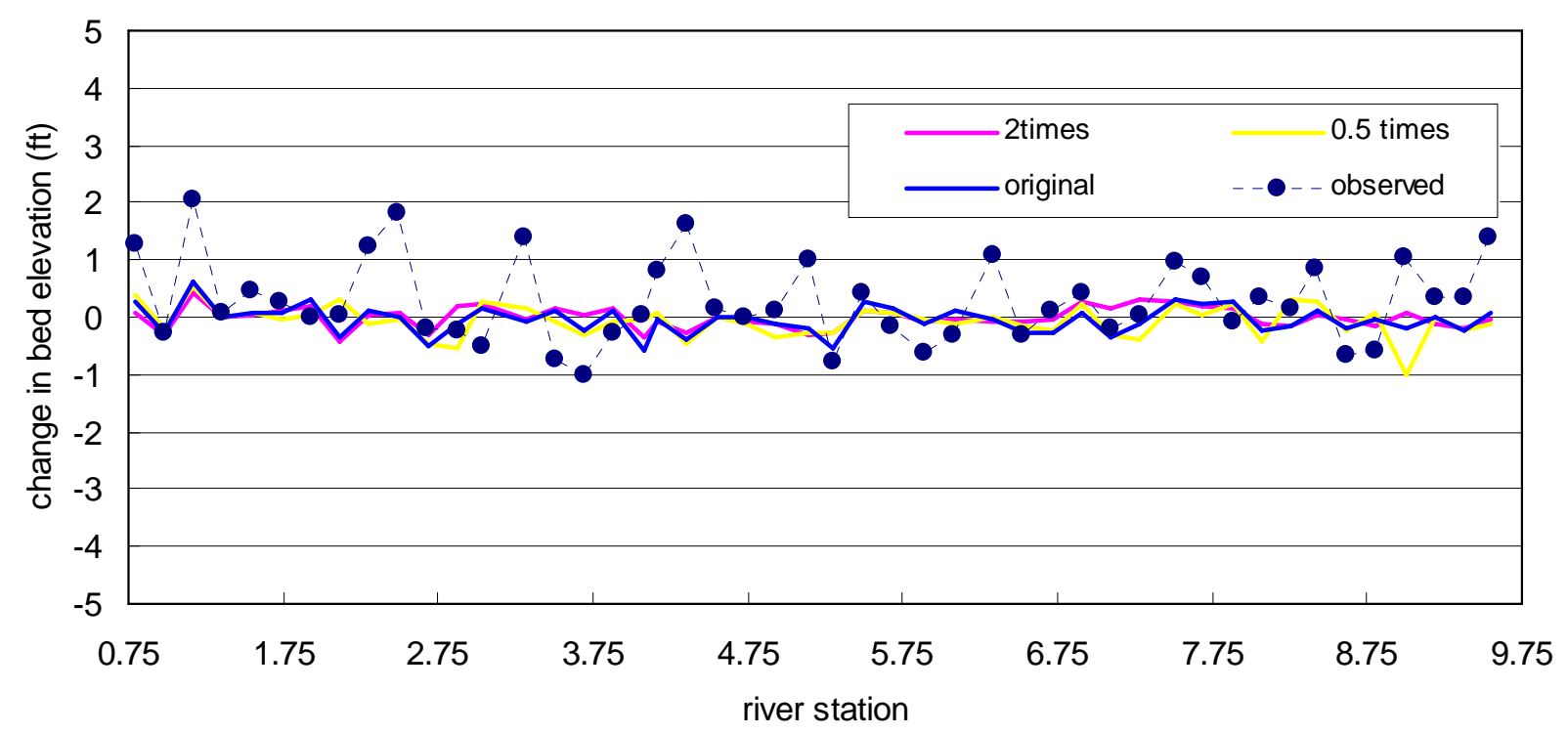

Figure 3. 4. 10. SRH-1D Simulated change in averaged bed elevation by different roughness factors 


\subsubsection{Identification of Best-Performing Sediment Model}

Different sediment transport formulas and Manning's $\mathrm{n}$ values were selected to run the same simulation. Among all the results, the use of Lausen-Madden (1985) equation and the original Manning's $\mathrm{n}$ value provided the best matches to the observed stages and changes in bed elevations. The results of sensitivity analysis also showed that the Laursen-Madden(1985) equation yielded the best match to the observed erosion/deposition volume. The input parameters for the best performing model are listed below,

- Number of rivers simulated: 1

- Number of sediment size classes: 11

- Number of bed layers: 2

- Type of flow simulation: steady flow simulation

- Changes in suspended sediment concentration: insignificant

- Tolerance of calculation: 0.0001

- Total time of simulation: $198.5 \mathrm{hr}$

- Minimum flow to be considered: $100 \mathrm{cfs}$

- Time step of calculation: $15 \mathrm{~min}$

- Time step of output: $15 \mathrm{~min}$

- Upstream boundary condition: flow hydrograph at the Dodge Blvd

- Downstream boundary condition: discharge-stage rating curve at the downstream

- Internal boundary condition: 11 bridges simplified

- Number of cross section simulated: 123

- Implicit factor used in the sediment transport solution: 1.0

- Number of sediment time step performed during one flow computation: 1

- Number of time step bank adjustment is performed: 0

- Upstream sediment boundary condition: equilibrium load, calculated by the selected transport formula

- Number of locations where bed materials are specified: 12

- Water temperature: 60F

- Bed erosion limitation: non-erodible at grade control structures, and infinite erodible depth at other locations.

- Sediment transport formula: Laursen-Madden (1985) 


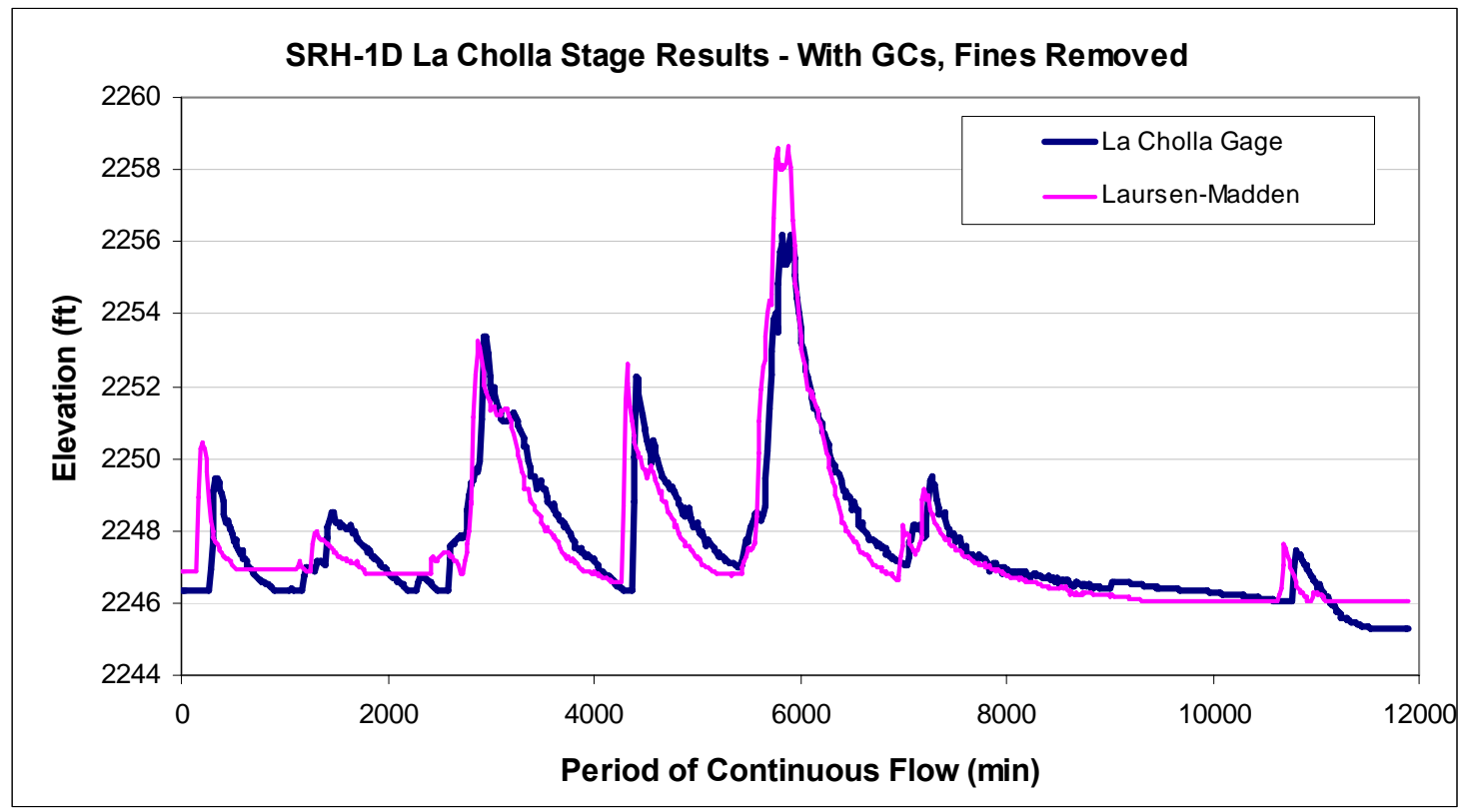

Figure 3. 4. 11. SRH-1D best performing model for averaged stage hydrograph

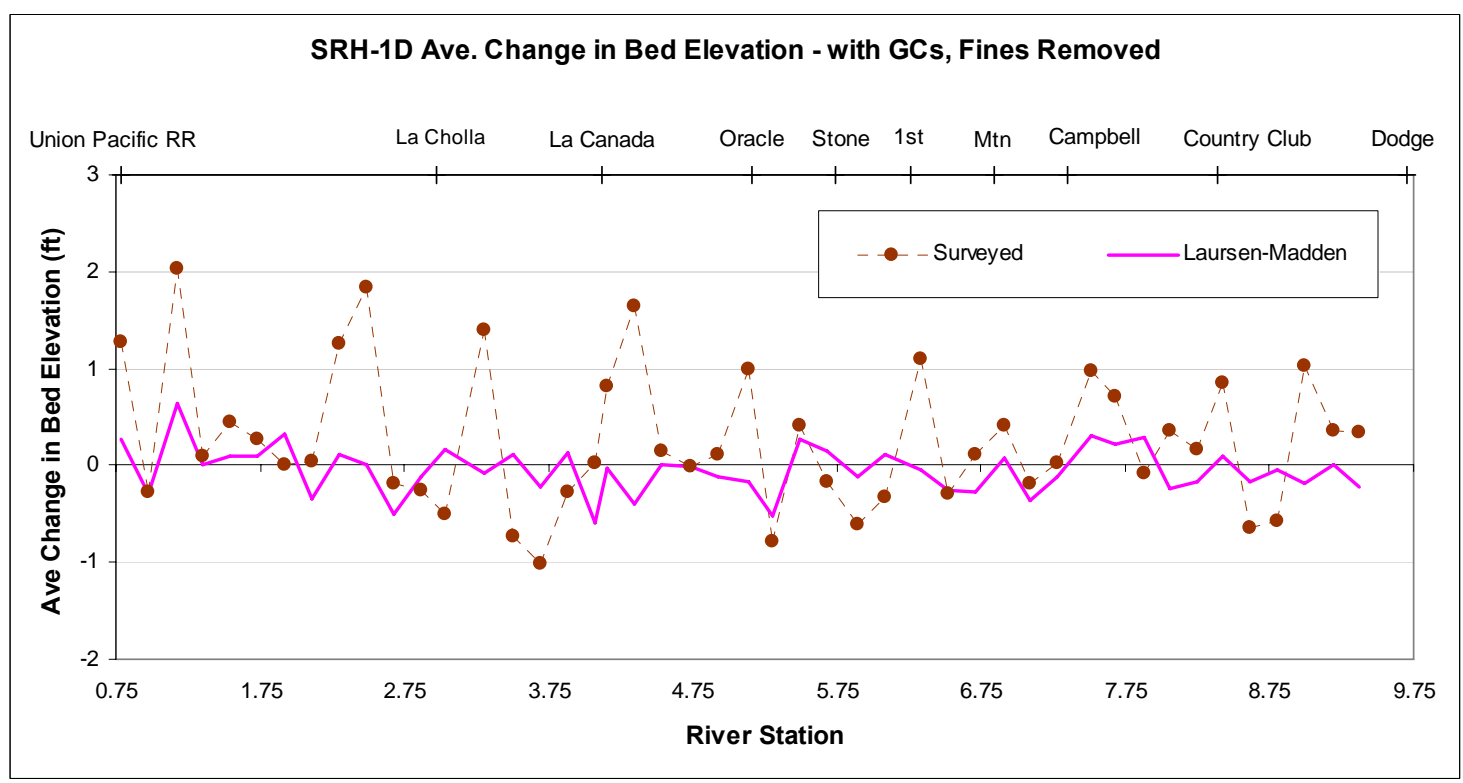

Figure 3. 4. 12. SRH-1D best performing model for averaged bed elevation change 


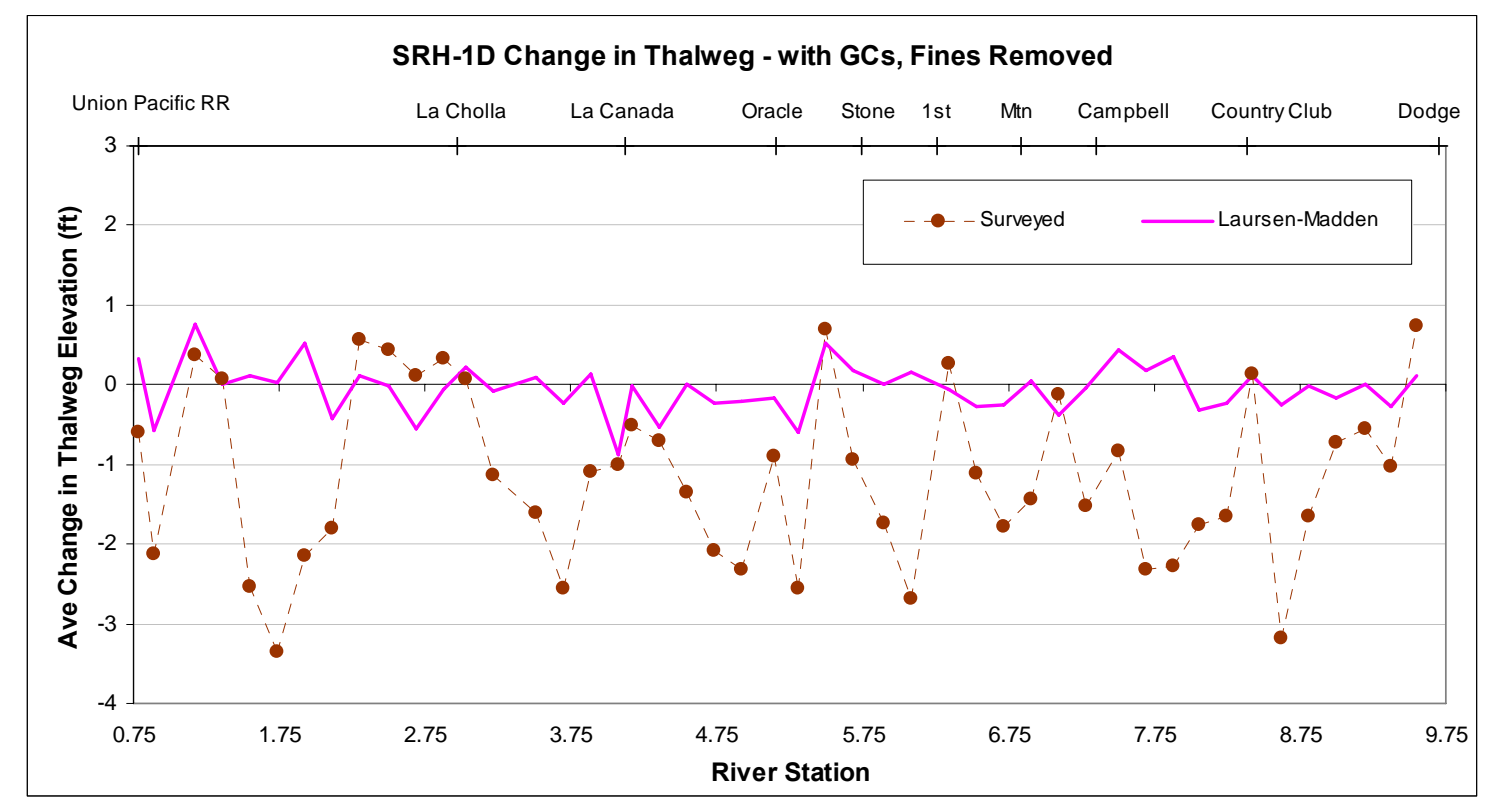

Figure 3. 4. 13. SRH-1D best performing model for change of bed elevation at the thalweg

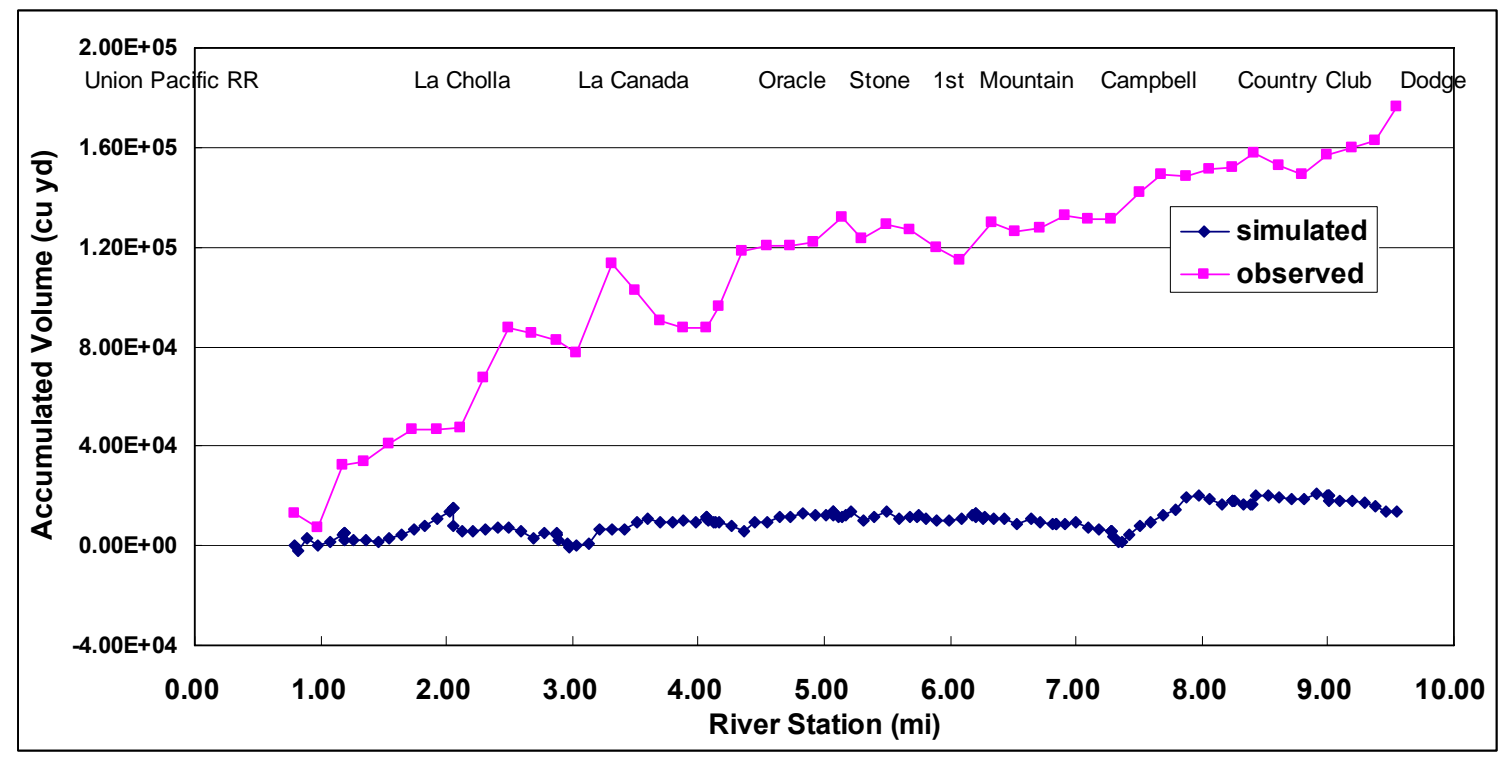

Figure 3. 4. 14. SRH-1D best performing model for simulated accumulated volume

\subsubsection{Summary and Conclusions}

The SRH-1D model has similar capabilities as the HEC-6, HEC-RAS, and IALLUVIAL2 model. The recently released version of SRH-1D is capable of simulating bank erosion and channel planform evolution, which the other models can not. The SRH-1D model has been updated with 
several recently published sediment transport equations, for instance, the Wilcock and Crowe (2003) bed load equation, whereas other models have not been updated frequently.

However, the simulated results of stages revealed the sensitivity of stage hydrographs to the bridge configurations. Cross sections with bridges need to be treated carefully to get accurate simulation of stage hydrographs. As to the bed elevations the SRH-1D model significantly underpredicted the changes of bed elevation. The predicted averaged or at the thalweg bed elevation changes were less than $1 \mathrm{ft}$, but the observed changes could be as much as $3 \mathrm{ft}$. These underestimations of bed elevation changes are consistent with the under-estimation of deposited sediment volume, The statistical parameters also verified these observations from plots.

If the best performing sediment equation must be selected, the results of Laursen-Madden (1985) equation predicted the overall trend of deposition and qualitatively matched the observed bed elevation changes. In fact, the SRH-1D seems unlikely to produce accurate matches to the observed data regardless of sediment transport equations, bridge factors, or Manning's $n$ values. The reasons are undetected without examining the source program. Therefore, the application of SRH-1D model to a flood flow similar to the one in this study requires extra cautions. 


\section{Model Comparison}

\subsection{Stage Hydrograph}

The simulated water surface elevation at the La Cholla bridge was shown in Fig.4.1 (a) and (b). The dark blue line in Fig.4.1 (a) is the observed water surface elevation, and the purple, green, and brown lines are simulated water surface elevations from HEC-RAS unsteady flow model, HECRAS quasi-unsteady flow model, and HEC-6 model, respectively. Similarly, Fig.4.1 (b) showed the simulated surface hydrographs from HEC-RAS unsteady flow model in purple, IALLUVIAL2 in green, and SRH-1D in dark-purple lines.

From Fig.4.1 (a) and (b), one found that the HEC-RAS unsteady flow model over-predicted the stage hydrographs at La Cholla, while all the quasi-unsteady flow models have under-predicted. Table 1 is the statistics of the differences between calculated and measured. Fig.4.1 (a) and (b) also indicated the HEC-RAS unsteady flow model, HEC-6, and IALLUVIAL 2 in general over-predicted stages, while the HEC-RAS quasi-unsteady flow and SRH-1D models under-predicted stages. The correlation factor is from 0.876 to 0.95 . The Nash-Sutcliffe coefficient ranges from 0.621 to 0.795 . The root mean square error between predicted and measured stages varies from 0.875 to $1.188 \mathrm{ft}$. These statistical parameters indicated that the predicted stages are approximately correct with a mean error close to $1.0 \mathrm{ft}$. These results showed that the quasi-unsteady flow model yielded as accurate results as the unsteady flow. Since the quasi-unsteady flow and steady flow models are not capable of predicting phase lags of hydrographs, the results from the steady flow model had the same phases and were consistent with the measured stages at the Dodge gage. The overall underpredictions of surface elevation are also attributed to the inadequacy in including the effects of vegetation on flow resistance.

Based on the statistics parameters shown in Fig.4.1 the IALLUVIAL2 model yielded the largest Nash-Sutcliffe efficiency factor and the smallest RSME. The model has over-predicted stages by about $1 \mathrm{ft}$. Therefore, if stage is the only factor to judge these models, IALLUVIAL 2 has the best results. 


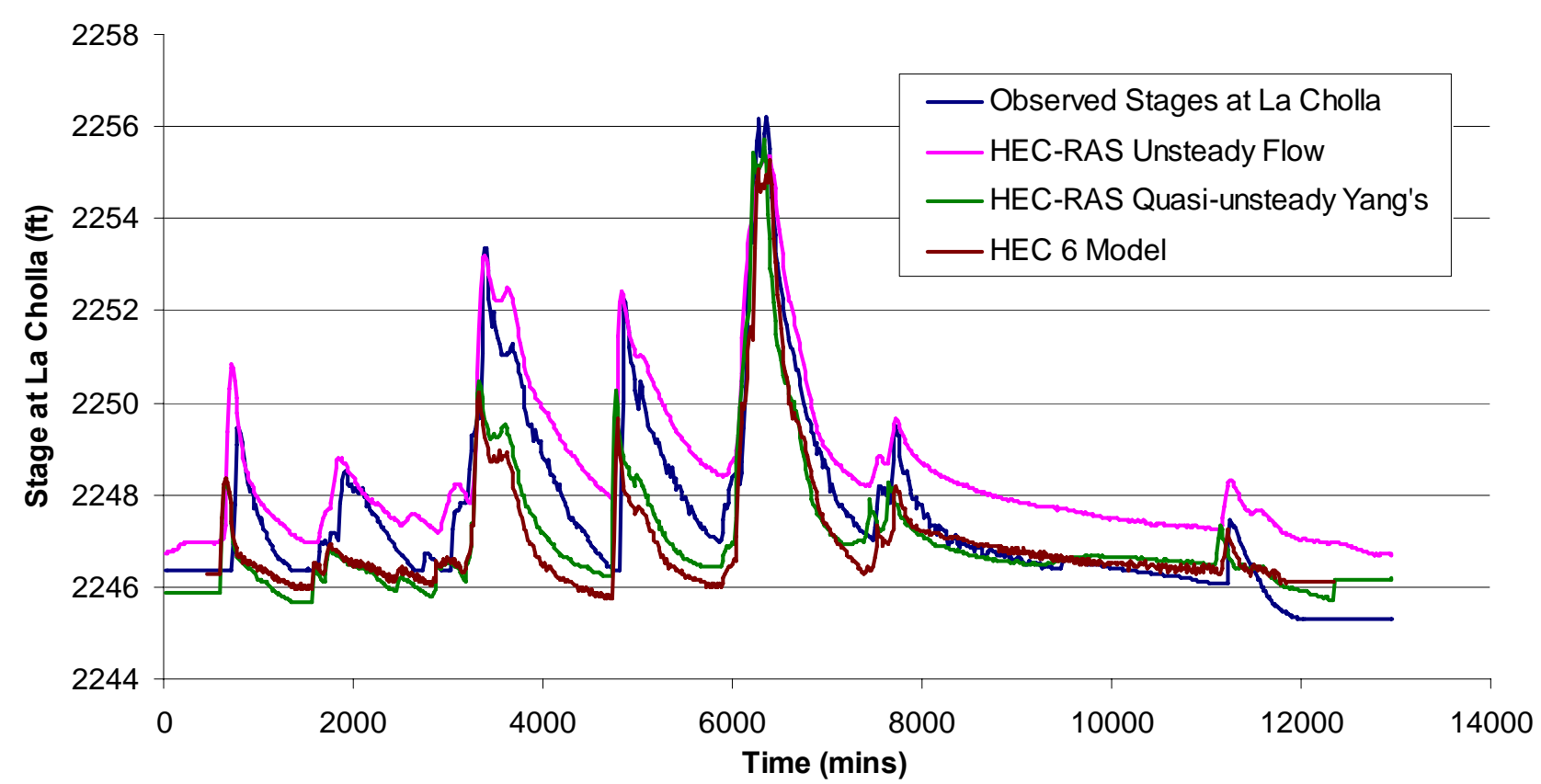

(a)

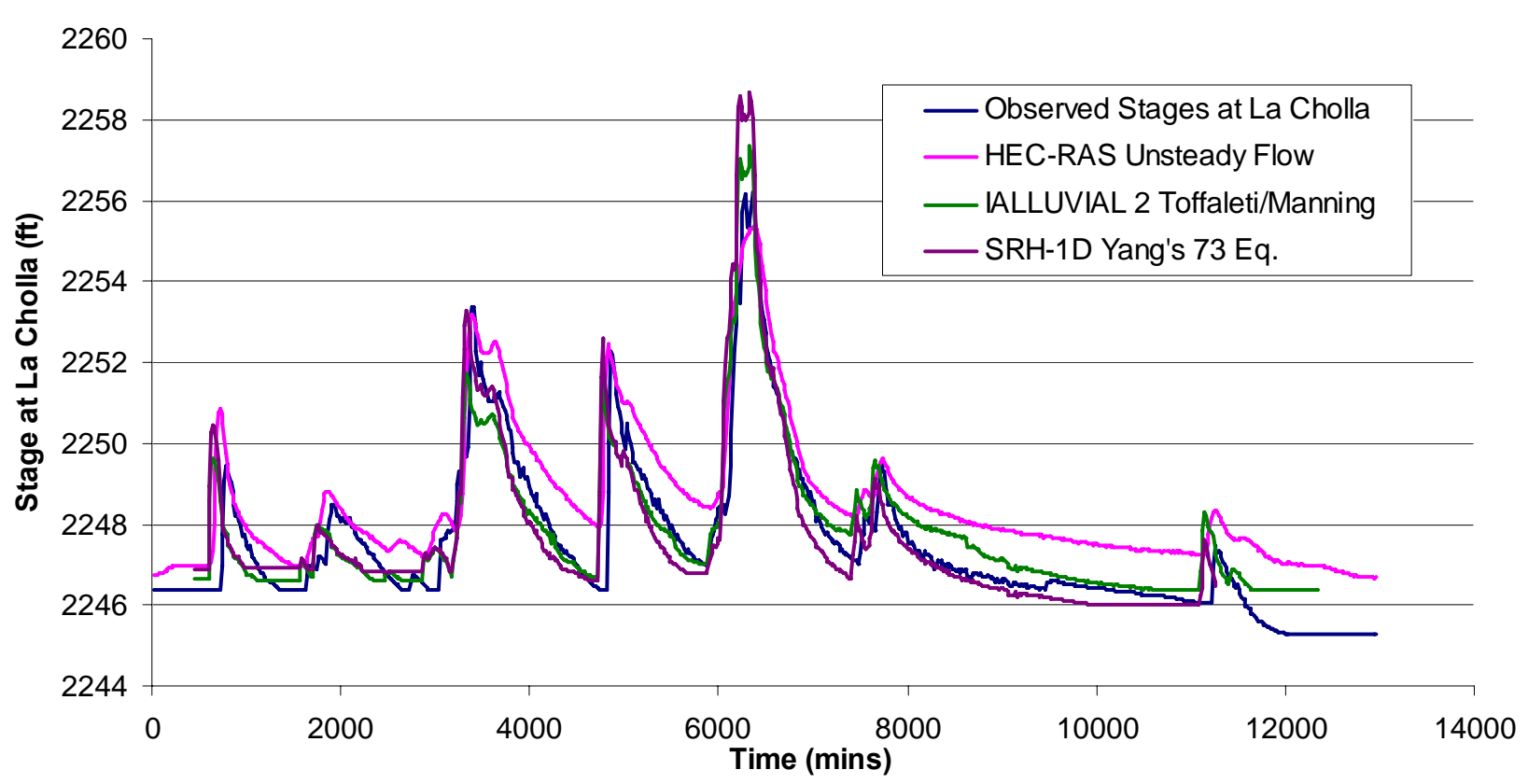

(b)

Figure 4. 1. Comparison of simulated stages at La Cholla by using different models 
Table 4. 1. Statistics of the simulated stages at La Cholla bridge

\begin{tabular}{|c|c|c|c|c|c|}
\hline $\begin{array}{c}\text { Model Performance } \\
\text { Factor for Stage }\end{array}$ & $\begin{array}{c}\text { HEC-RAS } \\
\text { Unsteady } \\
\text { Flow }\end{array}$ & $\begin{array}{c}\text { HEC-RAS } \\
\text { (Yang 73) }\end{array}$ & $\begin{array}{c}\text { HEC-6 } \\
\text { (Toffaleti) }\end{array}$ & $\begin{array}{c}\text { IALLUVIAL2 } \\
\text { (Toffaleti) }\end{array}$ & $\begin{array}{c}\text { SRH-1D } \\
\text { (Laursen- } \\
\text { Madden) }\end{array}$ \\
\hline Mean Error & 1.75 & -0.487 & 0.44 & 0.181 & -0.040 \\
\hline Nash-Sutcliffe & 0.621 & 0.682 & 0.7 & 0.795 & 0.733 \\
\hline Correlation Coefficient & 0.95 & 0.867 & 0.88 & 0.898 & 0.886 \\
\hline Root Mean Square & 1.188 & 1.088 & 1.06 & 0.875 & 0.998 \\
\hline
\end{tabular}

\subsection{Averaged Bed Elevation Changes}

Fig.4.2 (a) and (b) compared the simulated and observed averaged bed elevation changes. The measured average bed elevation changes were surveyed by JE Fuller H\&G Inc. The dark blue lines denoted the surveyed bed elevation changes in Fig.4.2 (a) and (b). The simulated results from HECRAS and HEC-6 were plotted in green and purple lines in Fig.4.2 (a). The results of IALLUVIAL and SRH-1D are plotted in blue and orange lines in Fig.4.2 (b). The statistical parameters of modeling results are summarized in Table 4.2.

If using the Nash-Sutcliffe coefficient to evaluate the results, both HEC-6 and SRH-1D predicted better results than the mean of observed data because of the positive Nash-Sutcliffe efficiency factors. The Nash-Sutcliffe coefficient from the results of the HEC-6 model is 0.33 much larger than the 0.048 from the SRH-1D model. This indicated that SRH-1D's predictions are slightly better than the mean of observed data, while the HEC-6 model is more accurate than the SRH-1D model. On the other hand, both HEC-RAS and IALLUVIAL 2 yielded negative NashSutcliffe coefficients, which indicated that both models are less accurate than the mean of the observed data. However, Fig.4.1(b) showed the results of SRH-1D were very close to zero and did not match any of the deposition and erosion peaks. In contrast, although HEC-RAS has a negative Nash-Sutcliffe coefficient its results closely matched the observed data at many locations. Fig..4.1 (a) also showed the results of HEC-RAS and HEC-6 are very similar. Therefore, the Nash-Sutcliffe efficiency factor alone is not sufficient for evaluating the modeling results. Based on Fig..4.1 (a) and (b) and the statistic parameters in Table 1 the results suggested that both HEC-6 and HEC-RAS are applicable.

Additionally, the mean error from all four models are negative, which indicated that they all under-predicted sedimentation. The correlation coefficients from HEC-RAS, HEC-6, and SRH-1D are consistent, ranging from 0.32 to 0.345 , while IALLUVIAL 2 has a correlation of 0.059 . The RMSE of calculated averaged bed elevation changes are from 0.761 to $0.90 \mathrm{ft}$ from all four models. Although none of the models yielded a perfect match to the observed data, Fig4.1 (a) showed the results of HEC-6 and HEC-RAS matched the observed data at many locations along the study reach. 
However, HEC-6 and HEC-RAS have under-estimated sediment deposition at river mile 8.99, 6.33, $4.25,2.49,1.17$. This could be attributed to the tributaries that join the Rillito River upstream of these locations. Since these tributaries were not gaged, their effects on localized sediment depositions are not known.

In summary, this study suggested both the HEC-6 and HEC-RAS models can approximately predict the averaged bed elevation changes. The results from HEC-6 and HEC-RAS are very similar, and apparently better than that from IALLUVIAL 2 and SRH-1D. The HEC-6 model is better than the HEC-RAS model if using the Nash-Sutcliffe efficiency factor as the indicator. The RMSE from all the models is less than $1 \mathrm{ft}$.

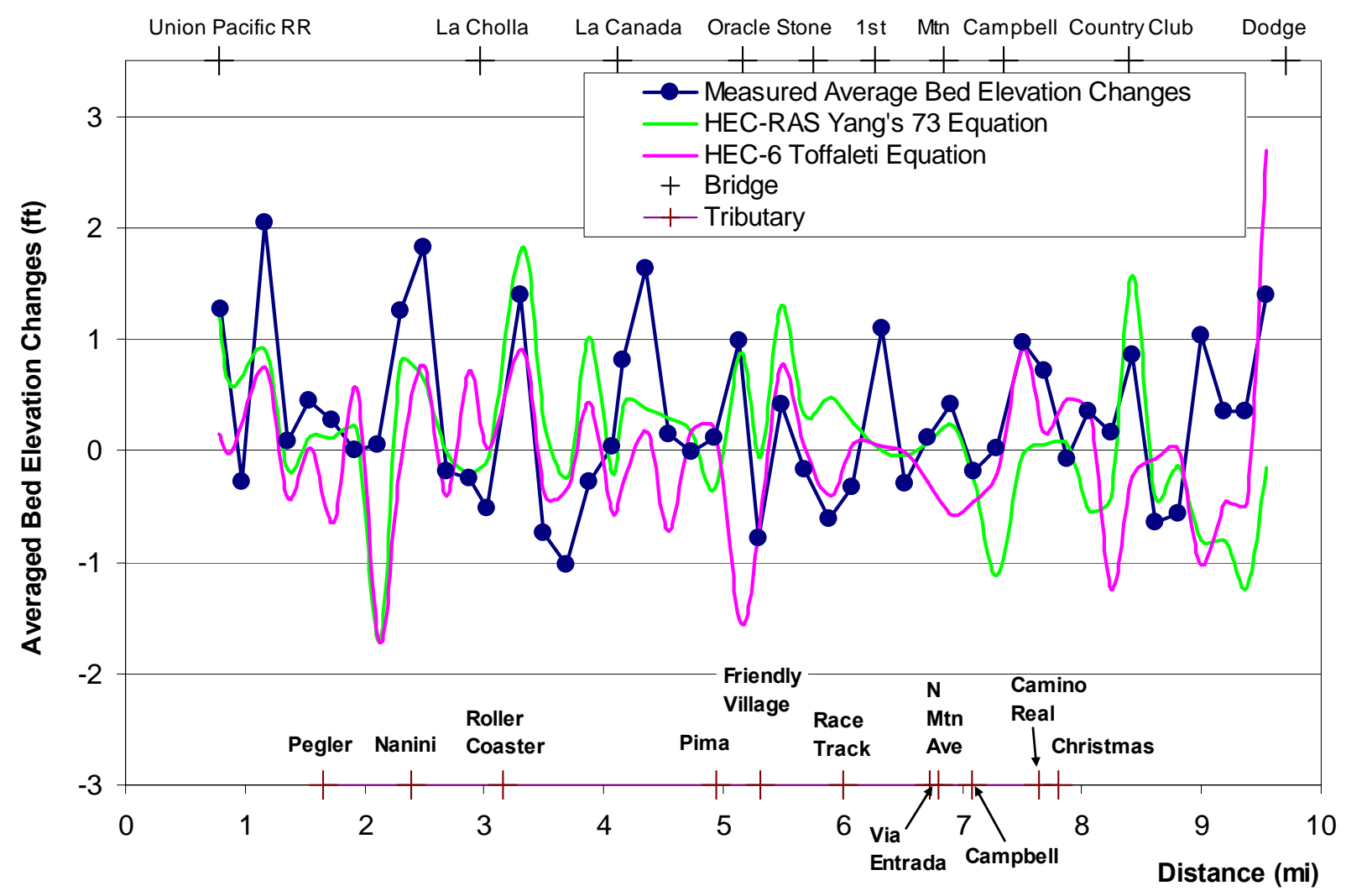

(a) 


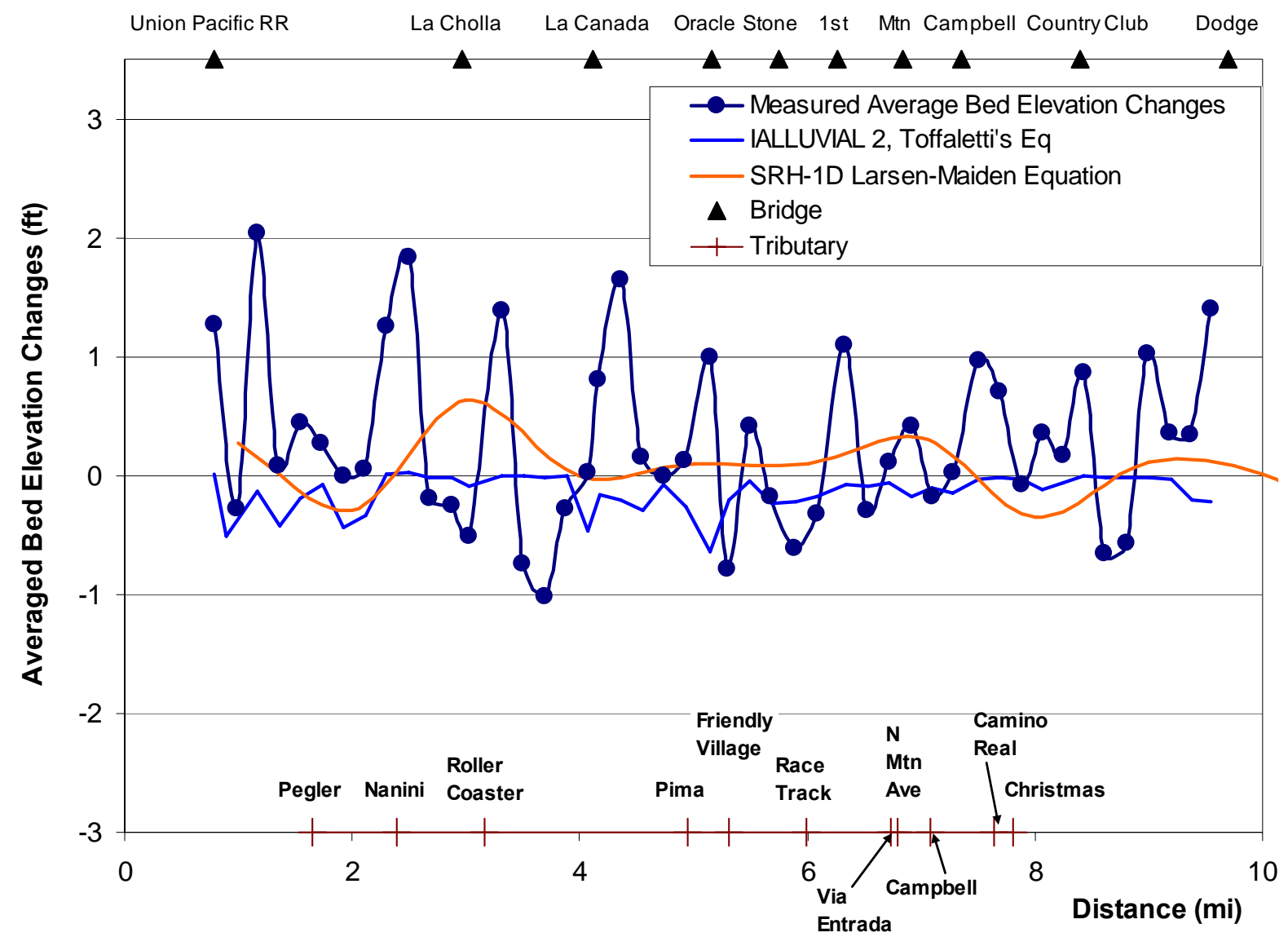

(b)

Figure 4. 2. Comparison of simulated averaged bed elevation changes by using different models

Table 4. 2. Statistics of the simulated averaged bed elevation changes

\begin{tabular}{|c|c|c|c|c|}
\hline $\begin{array}{c}\text { Model Performance } \\
\text { Factor for Averaged } \\
\text { Bed Elevation Changes }\end{array}$ & $\begin{array}{c}\text { HEC-RAS } \\
\text { (Yang 73) }\end{array}$ & $\begin{array}{c}\text { HEC-6 } \\
\text { (Toffaleti) }\end{array}$ & $\begin{array}{c}\text { IALLUVIAL } \\
\text { 2 (Toffaleti) }\end{array}$ & $\begin{array}{c}\text { SRH-1D } \\
\text { (Laursen- } \\
\text { Madden) }\end{array}$ \\
\hline Mean Error & -0.2 & -0.33 & -0.433 & -0.313 \\
\hline Nash-Sutcliffe Efficiency & -0.291 & 0.33 & -0.379 & 0.048 \\
\hline Correlation Coefficient & 0.345 & 0.34 & 0.059 & 0.327 \\
\hline Root Mean Square & 0.821 & 0.9 & 0.858 & 0.761 \\
\hline
\end{tabular}

\subsection{Bed Elevation Changes at the Thalweg}


As to the bed elevation changes at the thalweg shown in Fig.4.2 (a) and (b), none of the simulated results accurately predicted the observed scouring in the main channel. HEC-6 and HECRAS both showed deposition rather than scouring in the main channel, while the results from IALLUVIAL 2 and SRH-1D are very close to zero. These results are expected because none of the models differentiate bed elevation changes in the main channel and floodplain. All the models have distributed the eroded or deposited sediment across each cross section uniformly at each time step. In reality, the main channel will be eroded during the flood rising limb, and sediment will be deposited on the floodplain at the receding limb. Therefore, most natural rivers experience erosion in the main channel and deposition on the floodplain during a flood event. The observed data clearly indicated the degradation of the main channel and aggradation of the floodplains. Based on the survey, the averaged bed elevation has been raised $0.29 \mathrm{ft}$, while the thalweg has been lowered $1.15 \mathrm{ft}$.

The statistics of simulated results are summarized in Table 4.2. One can see that the NashSutcliffe efficiency factors are negative for HEC-6, HEC-RAS, and IALLUVIAL 2, while it is nearly zero for the SRH-1D model. This indicated that SRH-1D's results are the closest to the observed mean of $-1.15 \mathrm{ft}$. The mean errors from all the models ranged from 0.879 to $1.18 \mathrm{ft}$, which is much bigger than that from the averaged bed elevation changes. The correlations are worse than those for the averaged bed elevation changes as well. The RMSE values range from 1.447 to $1.70 \mathrm{ft}$. These statistics suggested none of the models are capable of predicting bed elevation changes at the thalweg because these models are designed for predicting the averaged bed elevation changes.

In summary, none of the models can be used for predicting bed elevation changes at the thalweg. The modeling results are averaged bed elevation changes without considering the differences of sediment transport rate in the main channel and floodplain. 


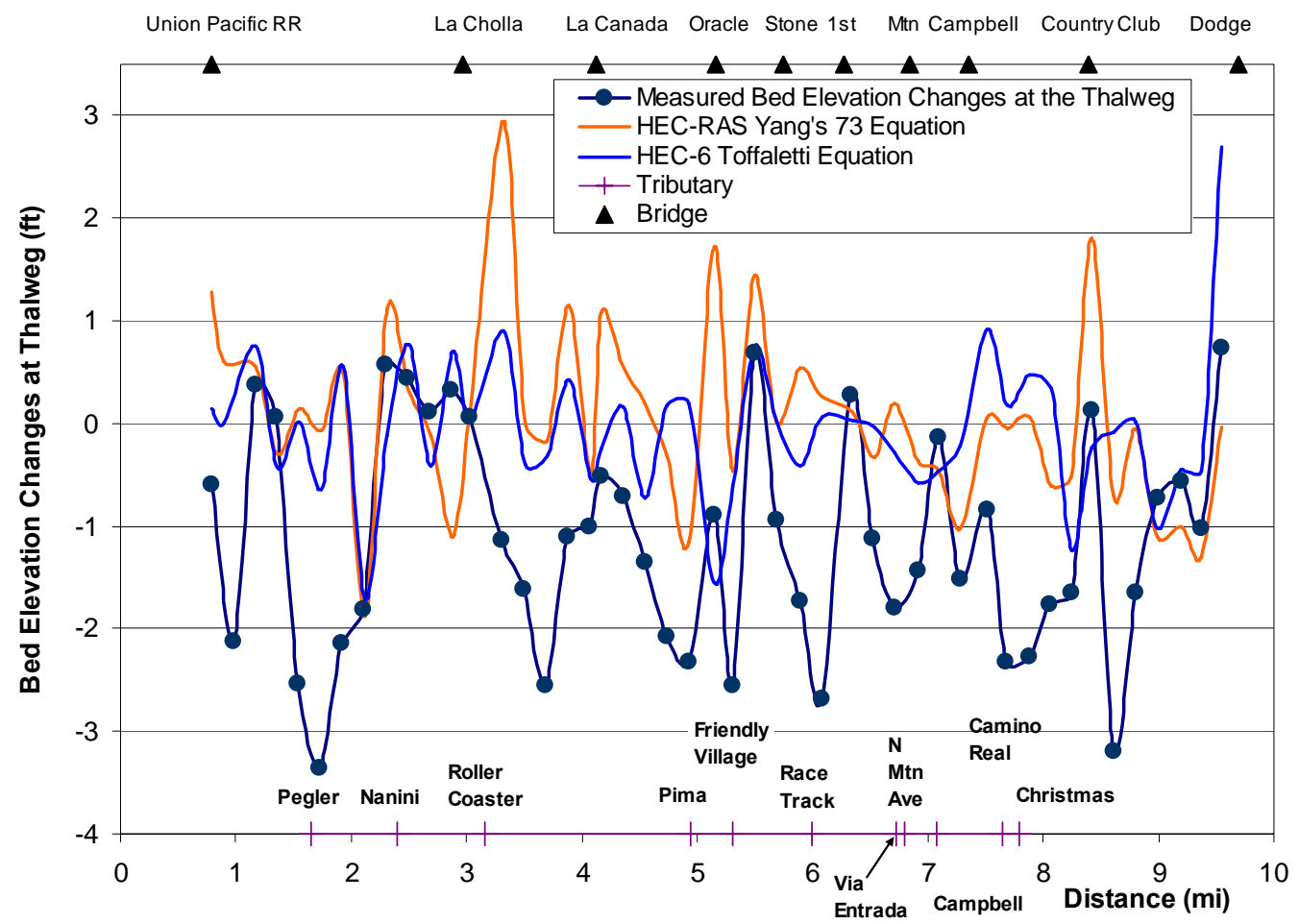

(a)

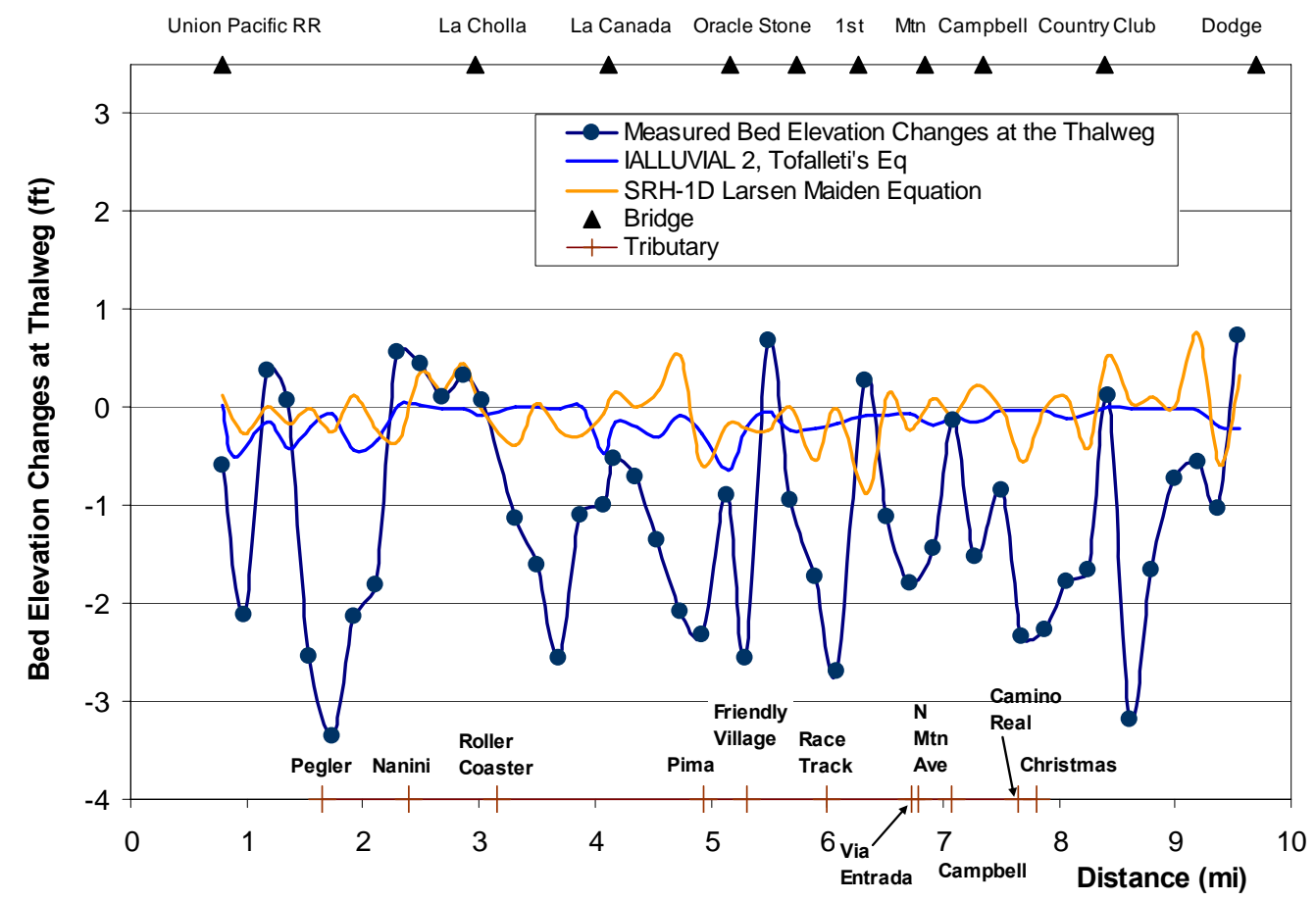

(b)

Figure 4. 3. Comparison of simulated bed elevation changes at the thalweg by using different models 
Table 4. 3. Statistics of the simulated bed elevation changes at the thalweg

\begin{tabular}{|c|c|c|c|c|}
\hline $\begin{array}{c}\text { Model Performance } \\
\text { Factor for Bed Elevation } \\
\text { Changes at the Thalweg }\end{array}$ & $\begin{array}{c}\text { HEC-RAS } \\
\text { (Yang 73) }\end{array}$ & $\begin{array}{c}\text { HEC-6 } \\
\text { (Toffaleti) }\end{array}$ & $\begin{array}{c}\text { IALLUVIAL } \\
\text { 2 (Toffaleti) }\end{array}$ & $\begin{array}{c}\text { SRH-1D } \\
\text { (Laursen- } \\
\text { Madden) }\end{array}$ \\
\hline Mean Error & 1.18 & 1.08 & 0.879 & 1.134 \\
\hline Nash-Sutcliffe Efficiency & -1.45 & -0.91 & -0.766 & 0.064 \\
\hline Correlation Coefficient & 0.24 & 0.36 & -0.040 & 0.210 \\
\hline Root Mean Square Error & 1.70 & 1.53 & 1.447 & 1.523 \\
\hline
\end{tabular}

\subsection{Deposited Sediment Volume}

Fig.4.4 showed the simulated deposited sediment volumes obtained by using different models. According to the measurements, 176,105 cubic yards of sediment was deposited in the river during the event. The simulated results showed that none of the models can accurately predict deposited sediment volumes. All the models have under-predicted sediment depositions. Among the four models, HEC-RAS using Laursen (1958) equation predicted the closest results of 71,276 cubic yards of deposits followed by 37,576 and 36,126 cubic yards from HEC-RAS the Yang's 73 equation and HEC-6 by the Toffaleti equation. SRH-1D predicted 14,019 cubic yards of deposits. The IALLUVIAL 2 model yielded a negative sediment volume. These results suggested that HEC-RAS and HEC-6 model perform better for predicting deposited/eroded sediment volumes in ephemeral streams. Both SRH-1D and IALLUVIAL 2 have significantly under-estimated deposition.

The overall under-prediction of deposition is attributed to several limitations inherent in the models: 1) flow during the event is likely to be hyperconcentrated, but none of the models are capable of simulating sediment deposition from hyperconcentrated flow; 2) nine ungaged tributaries that could have contributed significant sediment loads were not considered; 3 ) there is a significant amount of vegetation in the channel, but none of the models addressed the effects of vegetation on sediment transport. Therefore, the overall under-predictions of deposited sediment are expected by using these sediment transport models. 


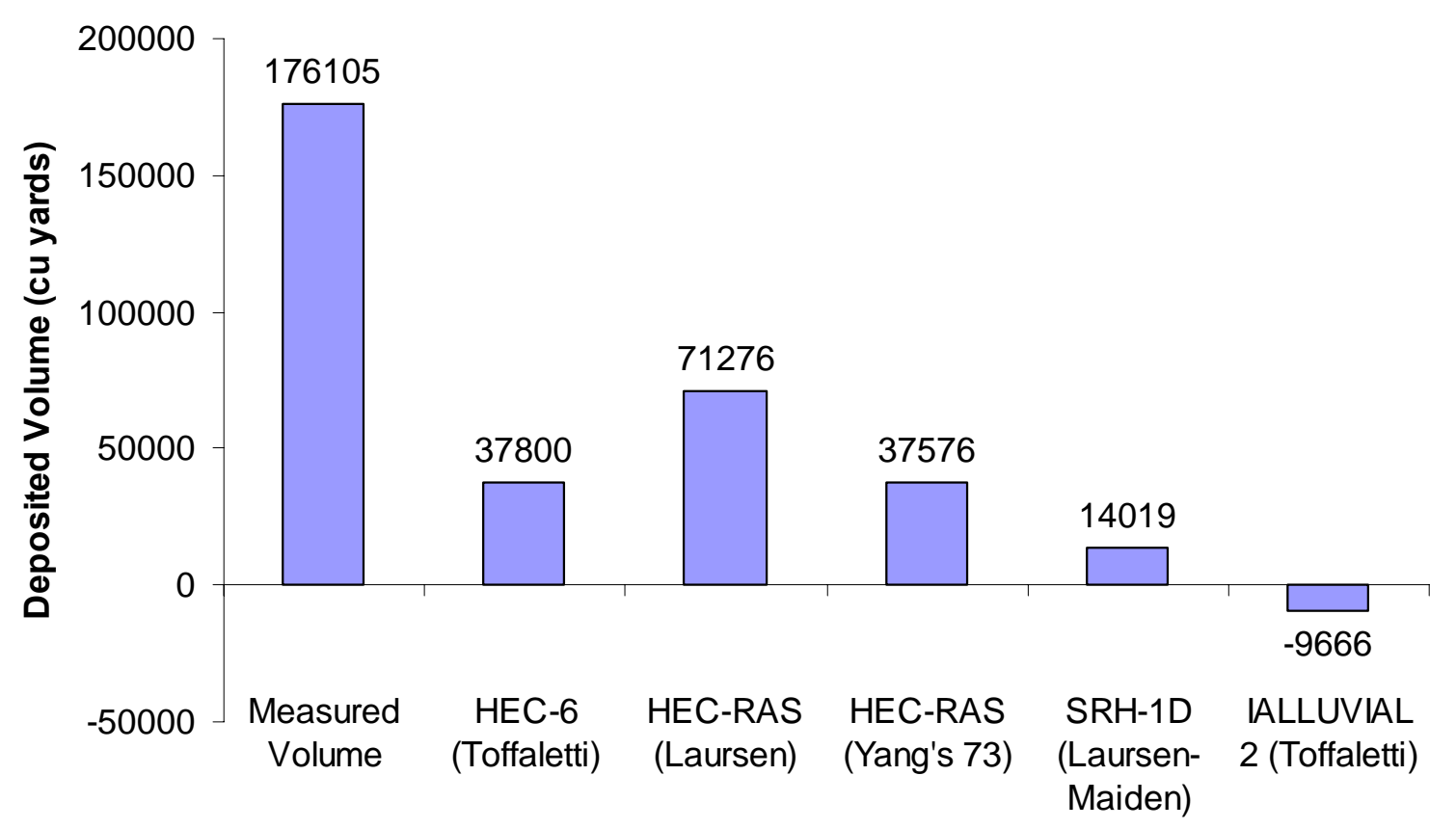

Figure 4. 4. Comparisons of simulated deposited sediment volume by using different models

Table 4. 4. Statistics of the simulated eroded/deposited sediment volume between two bridges

\begin{tabular}{|c|c|c|c|c|}
\hline $\begin{array}{c}\text { Model Performance } \\
\text { Factor for Sediment } \\
\text { Volume per Mile }\end{array}$ & $\begin{array}{c}\text { HEC-RAS } \\
\text { (Yang 73) }\end{array}$ & $\begin{array}{c}\text { HEC-6 } \\
\text { (Toffaleti) }\end{array}$ & $\begin{array}{c}\text { IALLUVIAL } \\
\text { 2 (Toffaletti) }\end{array}$ & $\begin{array}{c}\text { SRH-1D } \\
\text { (Larsen- } \\
\text { Madden) }\end{array}$ \\
\hline Mean & $-13,952.86$ & $-1,840$ & $-23,259$ & $-13,515.24$ \\
\hline $\begin{array}{c}\text { Nash-Sutcliffe } \\
\text { Efficiency }\end{array}$ & -0.84 & -1.34 & -3.417 & 0.26 \\
\hline Correlation Coefficient & -0.09 & 0.57 & -0.223 & -0.23 \\
\hline Root Mean Square & $31,814.8$ & $20,189.0$ & $12,261.0$ & $551,520.9$ \\
\hline
\end{tabular}




\section{Changes of Channel Morphology and Vegetation}

As shown before, all of the models approximately predicted accurate stage hydrographs at the La Cholla Bridge, but, none of the models perfectly predicted the average bed elevation changes and the changes at the thalweg. The poor accuracy in predicting bed morphology at large attributed to the inaccurate pre-flood geometric data, which was the surveyed channel geometry in 1998. Significant morphologic changes and vegetation growth occurred from 1998 to 2006 prior the modeled flood. The following is a visual history of the morphologic and vegetation changes in the bed of the Rillito River from 1998 to 2007 using orthophoto images from Pima County's MapGuide at the Pima County website. The scale of each set of photographs remains the same; washes are labeled in the first photo of each set only. Four sites are examined: Dodge Blvd upstream, and Oracle Blvd, La Canada and La Cholla downstream. It can be seen from these photographs that the bed from the 1998 LOMR survey is significantly different from the river bed in July of 2006 when the modeled flood even occurred. 


\subsection{Changes in Riverbed Vegetation at Dodge Blvd.}

The following five photos trace the bed vegetation history at Dodge Blvd from 1998 (Fig. 5.1.1) to March 2007 (Fig 5.1.5). Dodge Blvd is the upstream boundary for the modeling study, and also the site of the USGS gage from which discharge information was obtained. It can be seen from the photos that the river bed in 1998 was relatively free of vegetation. By 2005 (Fig. 5.1.3), there was significant vegetation growth and establishment.

Between 1998 and 2006 there were no significant flow events until July of 2006. The water table in the river bed is more shallow than in surrounding areas, and this, coupled with lack of strong flood events, allowed vegetation to take significant hold. Even after the major event of July, 2006, much of vegetation (Fig 5.1.5) remained, even though it was expected that a flood of this magnitude would scour most vegetation from the channel.

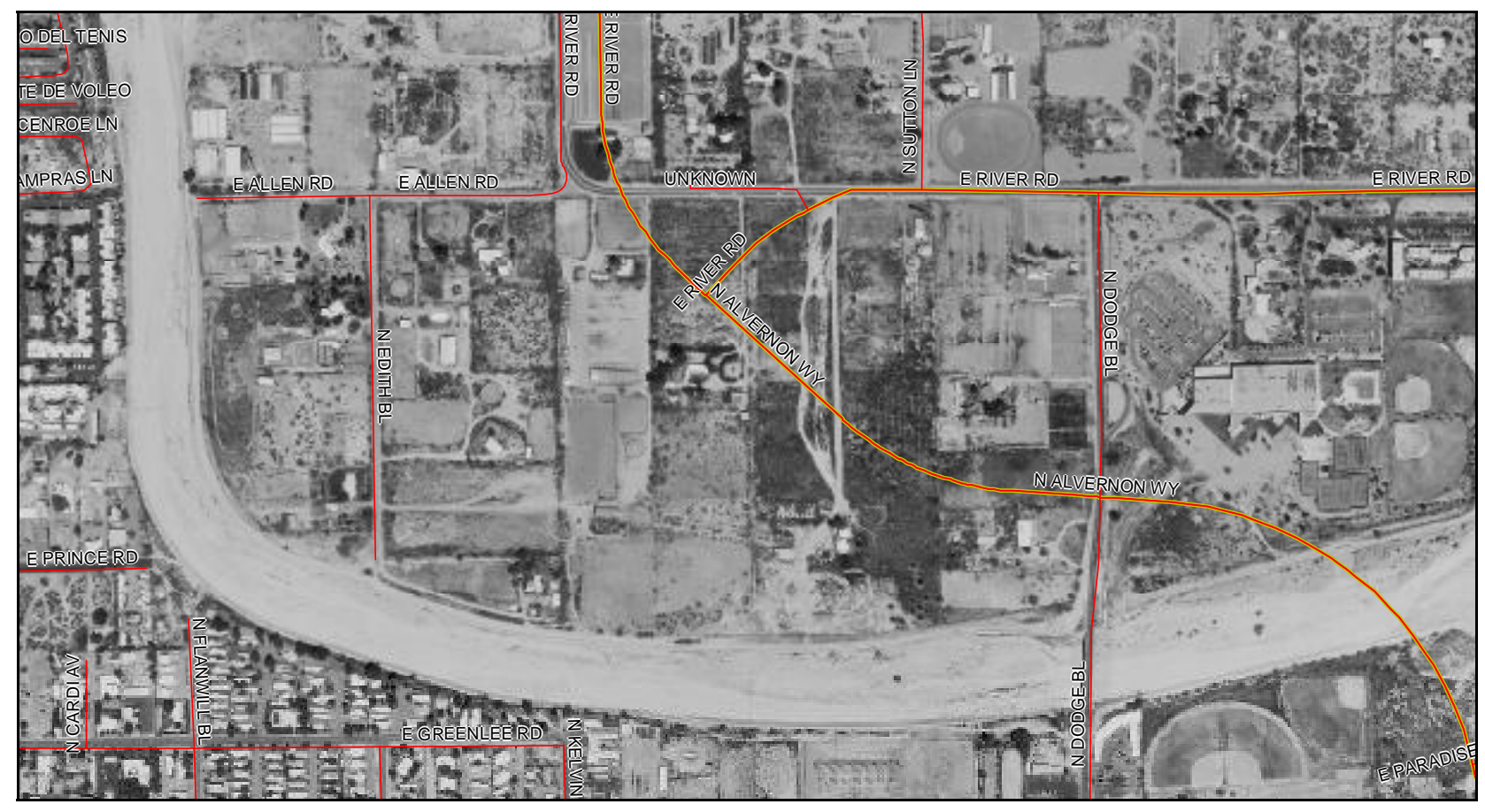

Figure 5. 1. 1. Rillito River at Dodge Blvd, 1998 


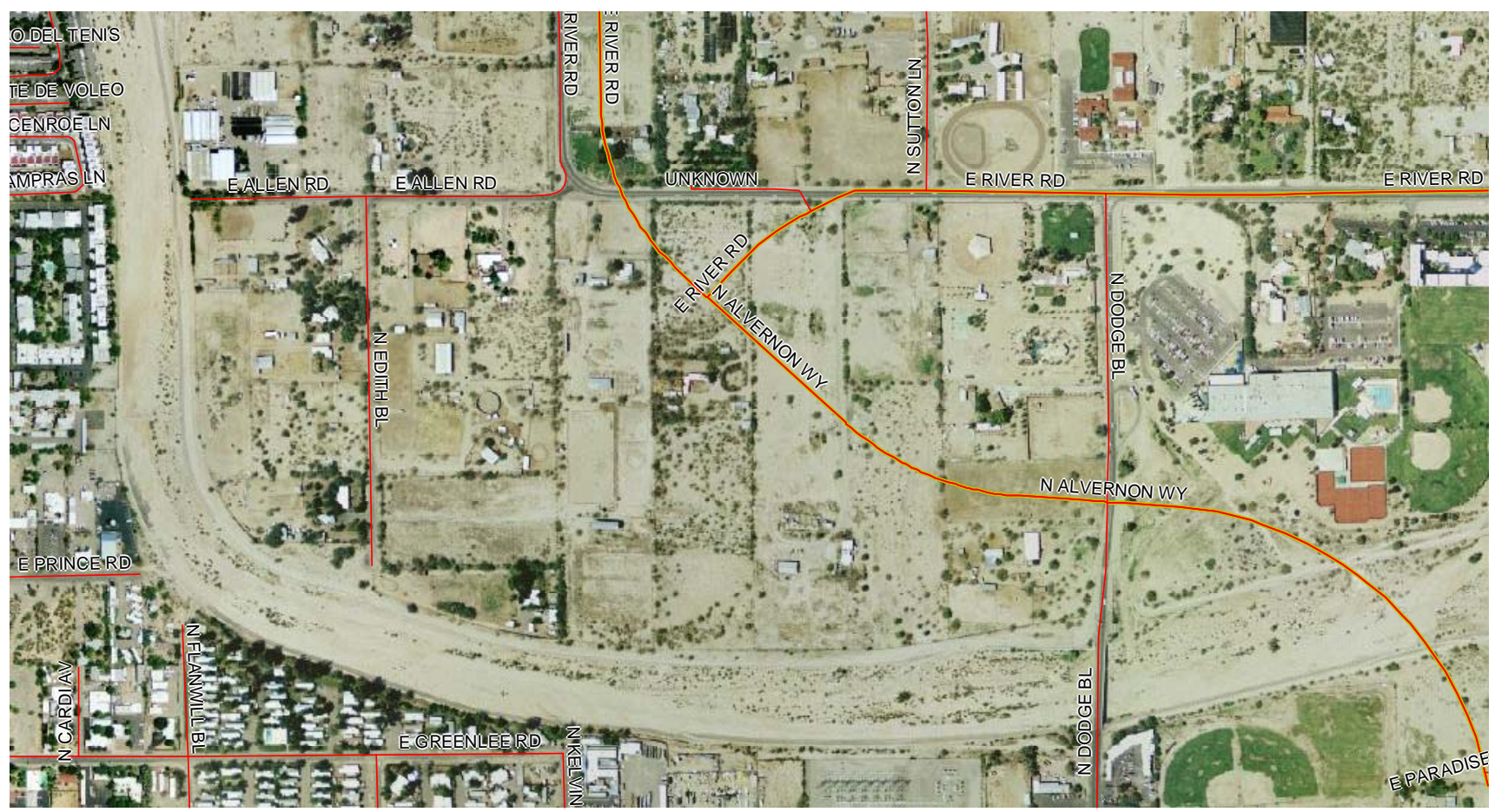

Figure 5. 1. 2. Rillito River at Dodge Blvd, 2002

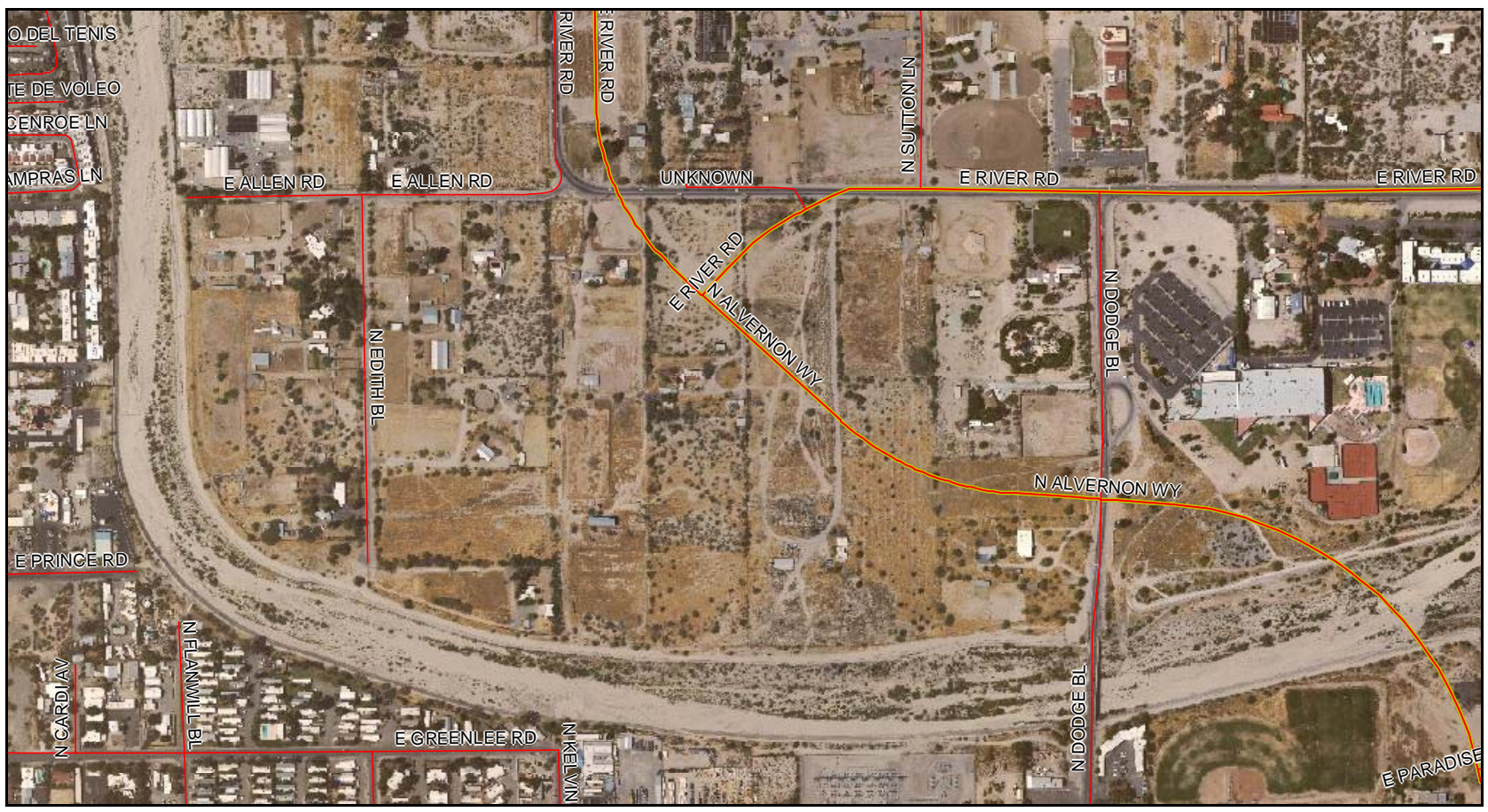

Figure 5. 1. 3 Rillito River at Dodge Blvd, 2005 


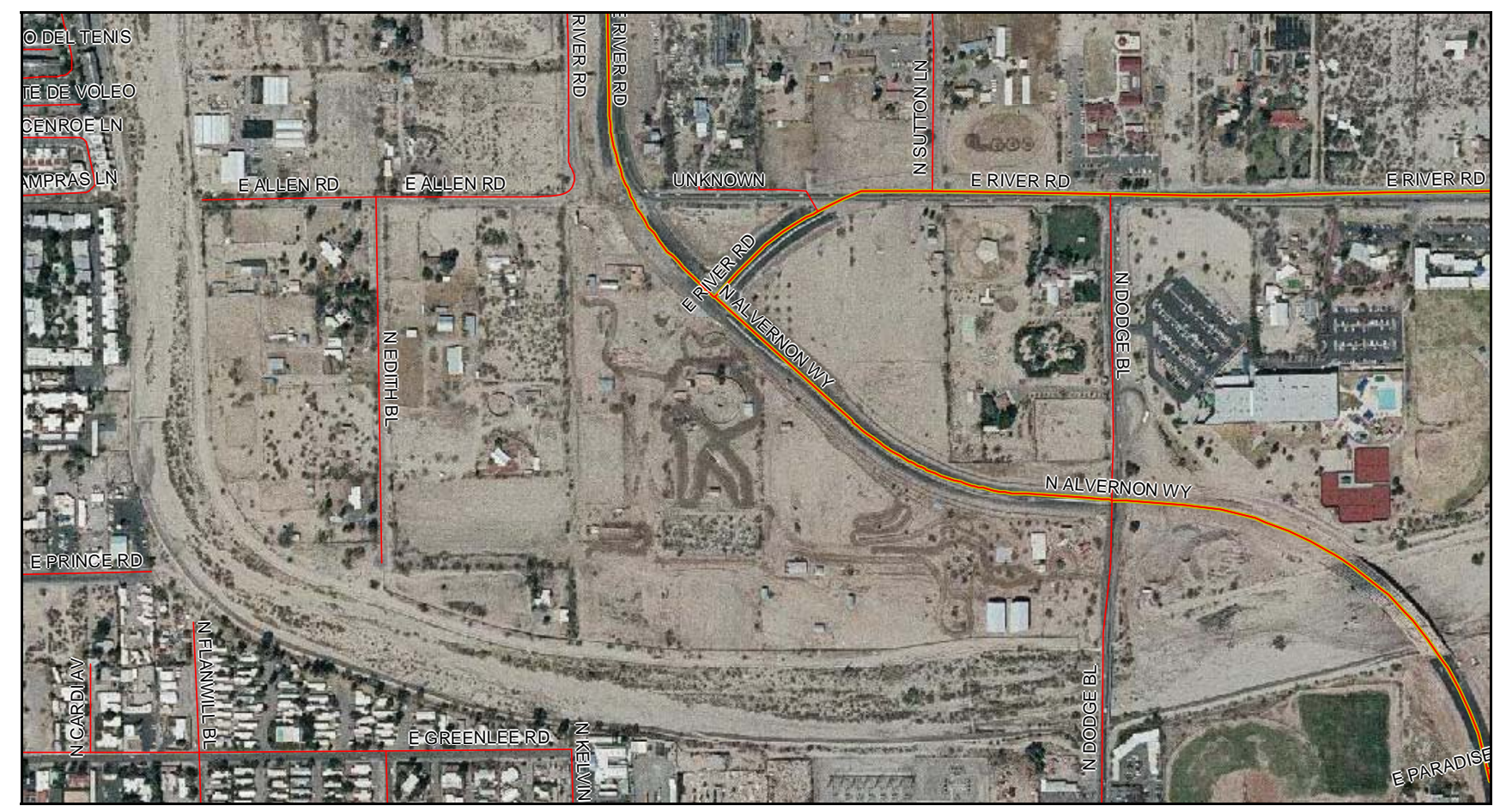

Figure 5. 1. 4. Rilltio River at Dodge Blvd, March 2006

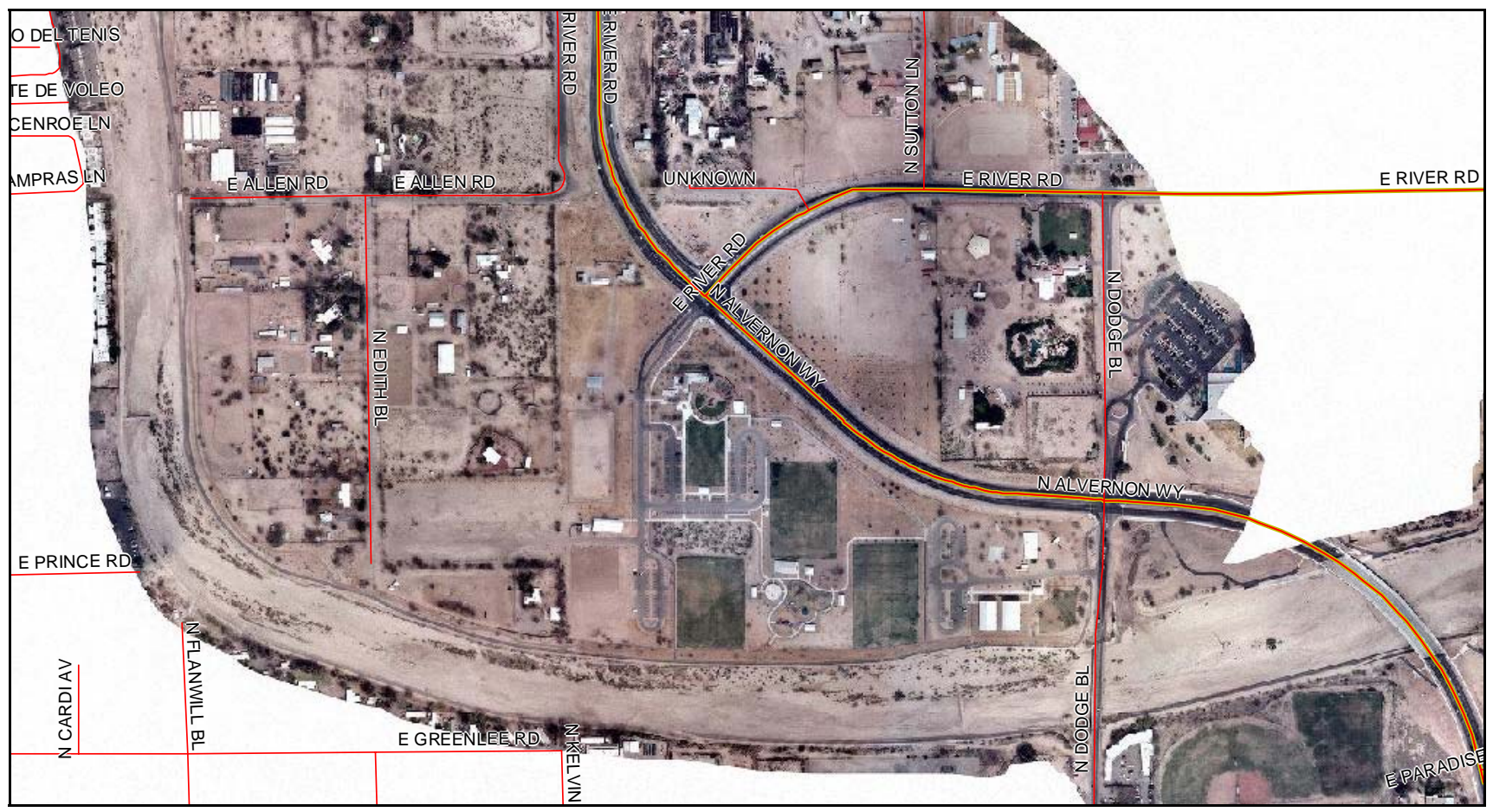

Figure 5. 1. 5. Rillito River at Dodge, March 2007 


\subsection{Changes in Riverbed Vegetation at Oracle Rd.}

The following five photos trace the bed vegetation history at Oracle Rd from 1998 (Fig. 5.2.1) to March 2007 (Fig 5.2.5). Oracle Rd is in the downstream section of the study reach and two major washes empty into the river near this location (Fig 5.2.1). Friendly Village Wash empties into the Rillito upstream of and Pima Wash empties into the Rillito downstream of the Oracle Rd. bridge. Again, it can be seen from the photos that the river bed in 1998 was relatively free of vegetation, although here there was more vegetation in the channel than was seen at Dodge. Again, as was seen at Dodge, significant establishment of vegetation is seen. After the flood, much of the vegetation remained in the channel (Fig 5.2.5).

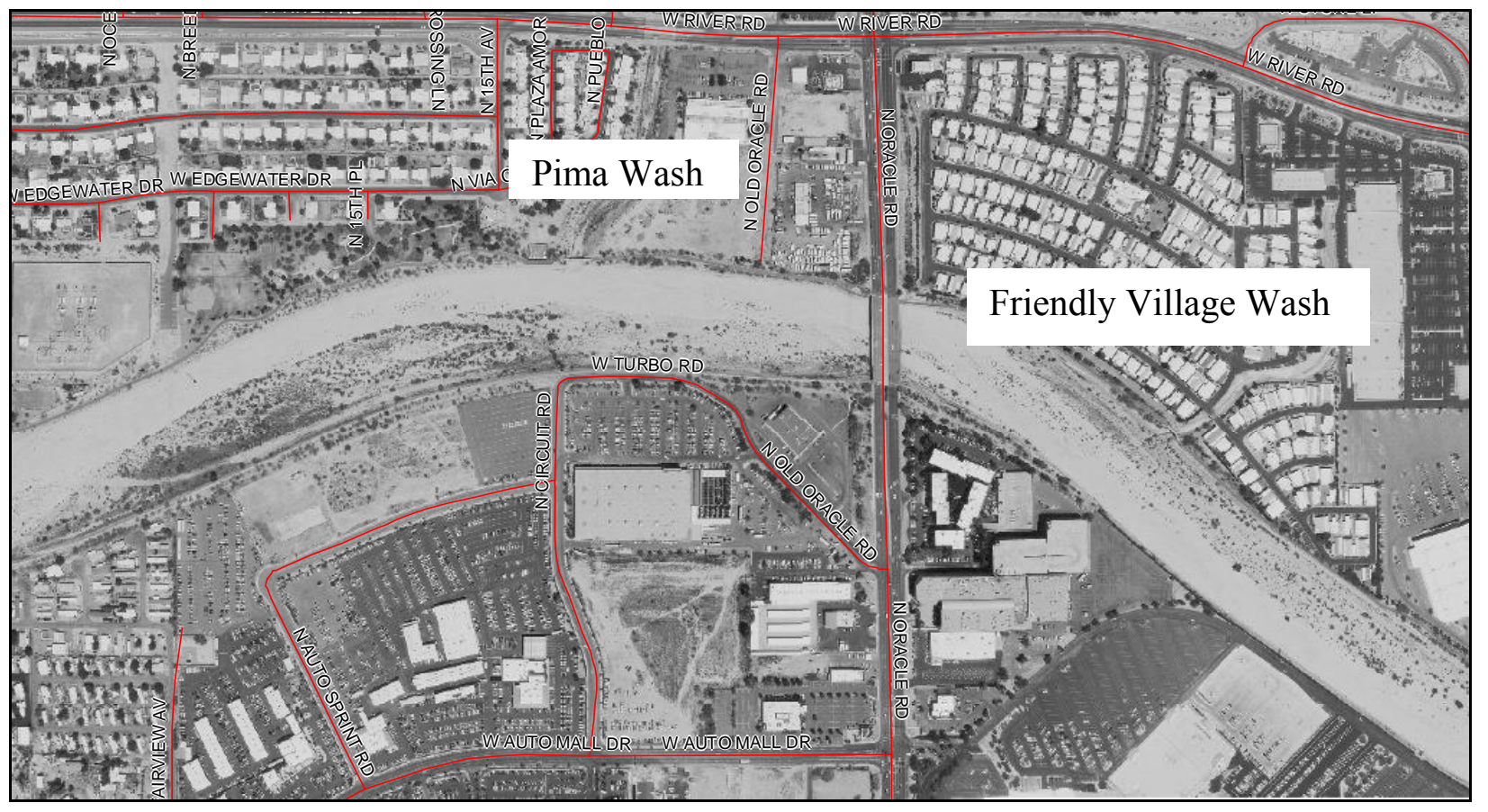

Figure 5. 2. 1. Rillito River at Oracle Rd, 1998 


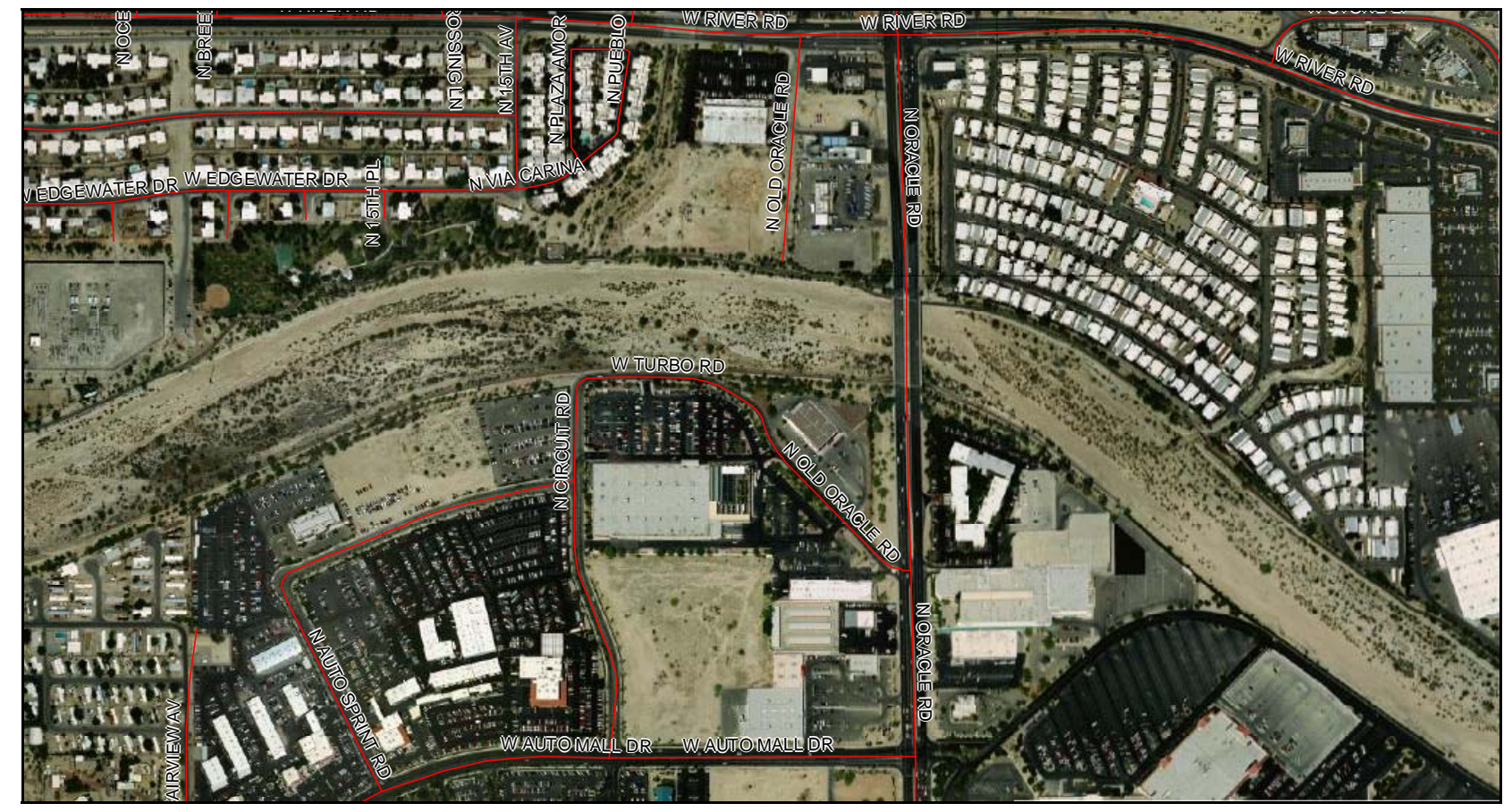

Figure 5. 2. 2. Rillito River at Oracle Rd, 2002

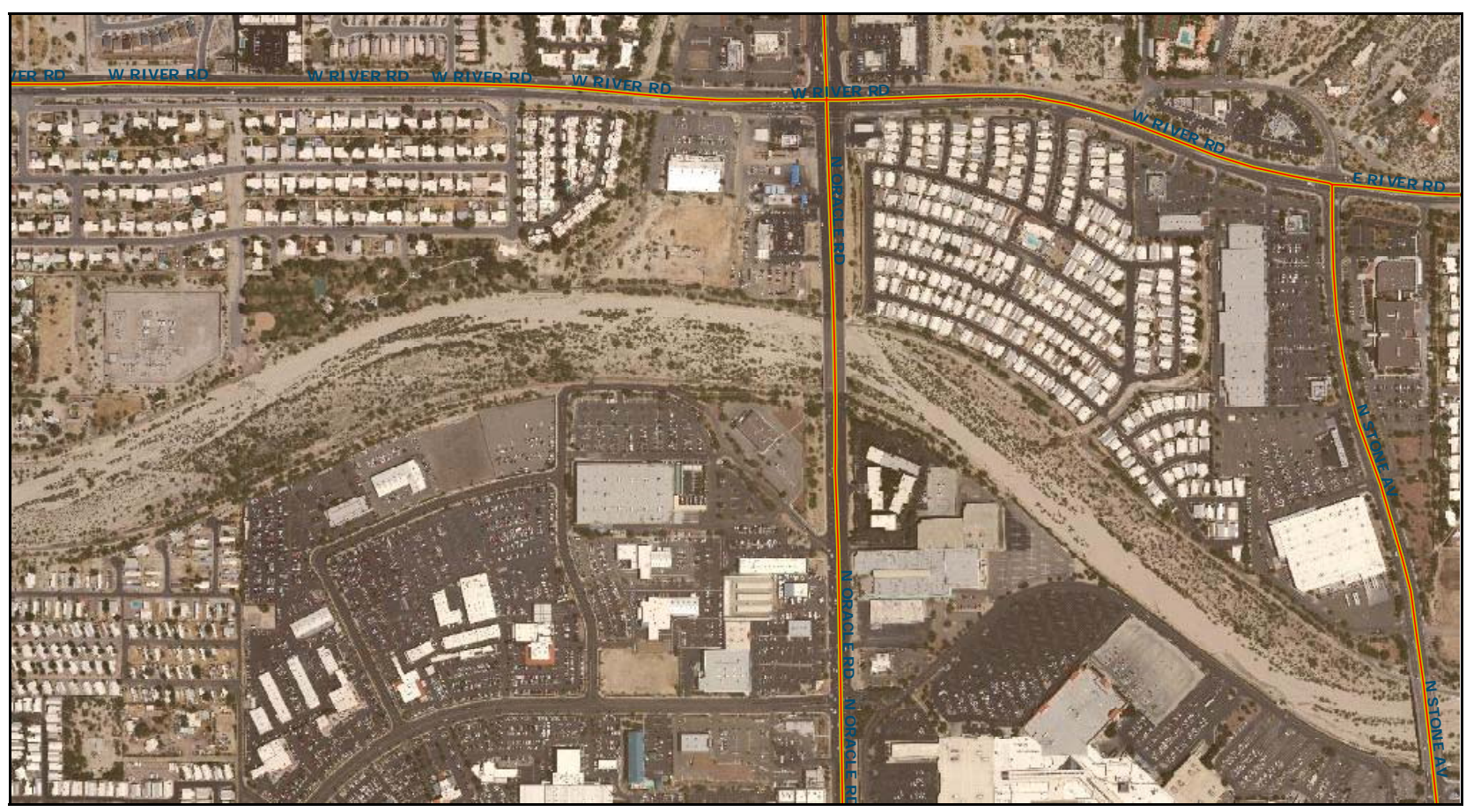

Figure 5. 2. 3 Rillito River at Oracle Rd, 2005 


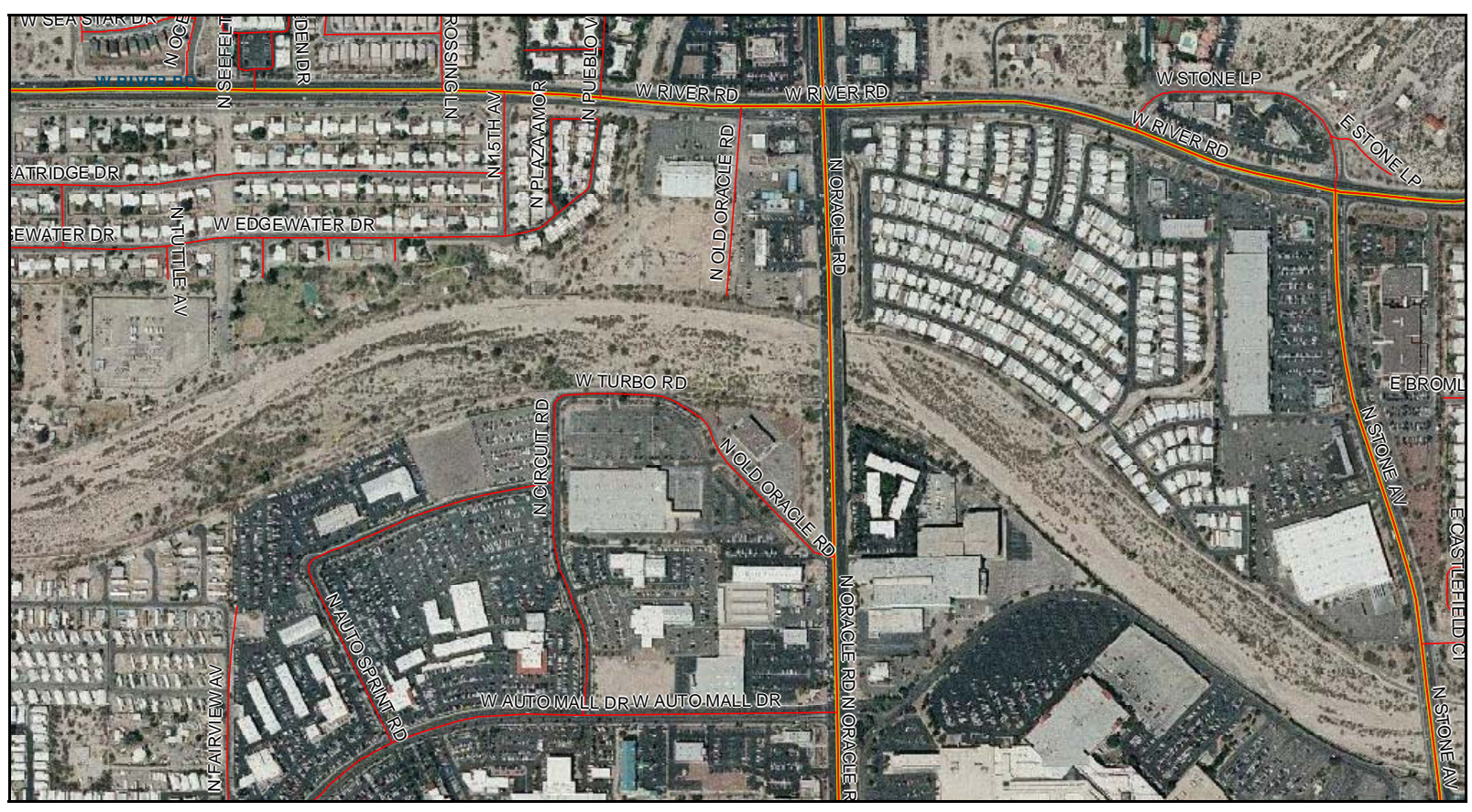

Figure 5. 2. 4 Rillito River at Oracle Rd, 2006

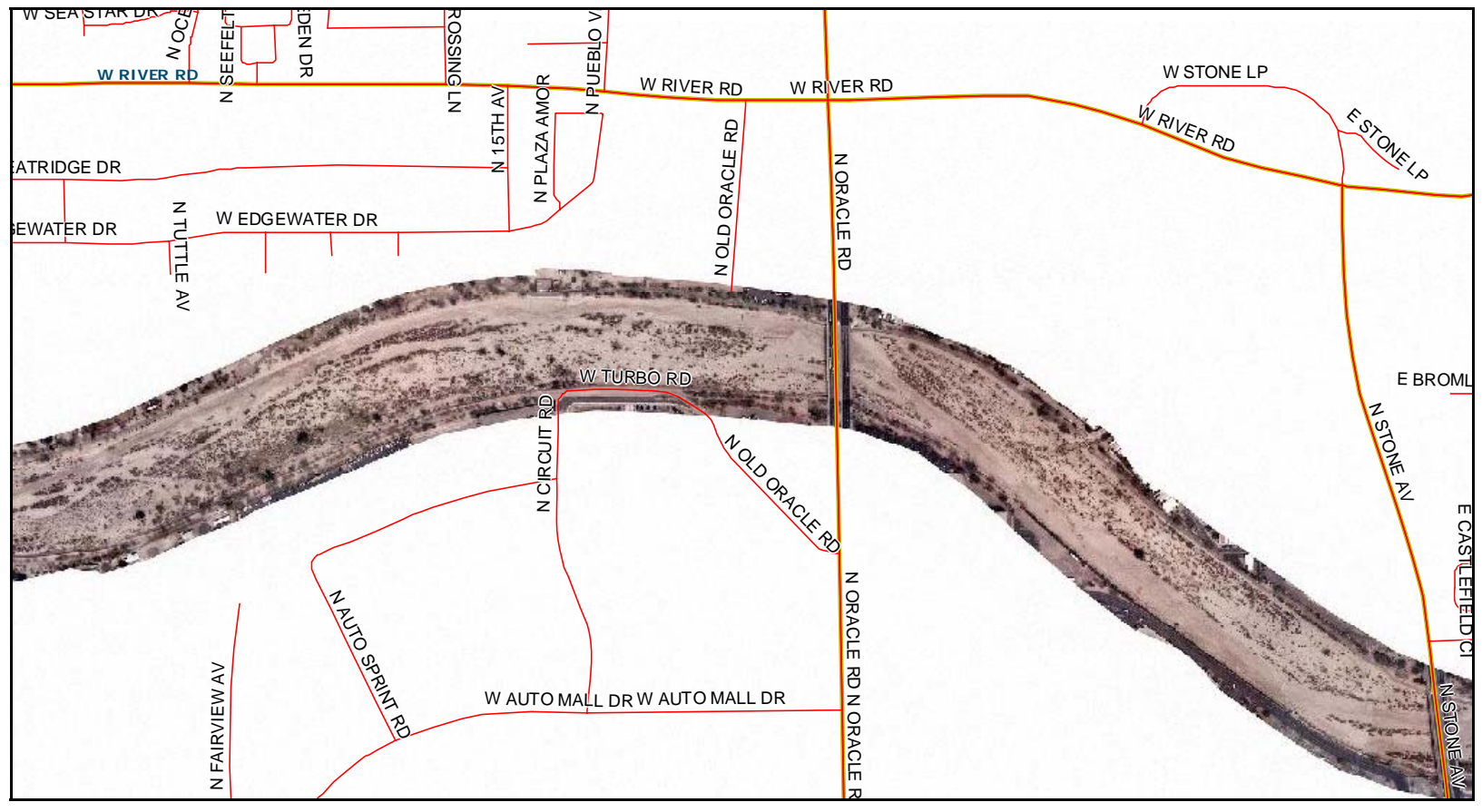

Figure 5. 2. 5 Rillito River at Oracle Rd, 2007 


\subsection{Changes in Riverbed Vegetation at La Cholla Blvd.}

The following five photos trace the bed vegetation history at La Cholla Blvd. from 1998 (Fig. 5.3.1) to March 2007 (Fig 5.3.5). La Cholla Blvd is downstream from Oracle Rd, and is the site of the second USGS gage on the Rillito River. This is the site of interest for comparisons of modeled and observed stage. Three major washes empty into the river near this location (Fig 5.3.1). Roller Coaster Wash empties into the Rillito upstream of the La Cholla Bridge, and Nanini Wash and Pegler Wash empty into the Rillito downstream of the La Cholla Blvd. bridge. As before, it can be seen from the photos that the river bed in 1998 was relatively free of vegetation, although there was a small island of vegetation in the downstream area of the photograph, where Pegler Wash joins the Rillito River. Again, as was seen at Dodge and Oracle, significant establishment of vegetation occurred. The conveyance of this particular reach of the study area was significantly reduced from 1998 to 2006 due to the presence of established islands of vegetation. After the flood, much of the channel remained significantly vegetated (Fig 5.3.5).

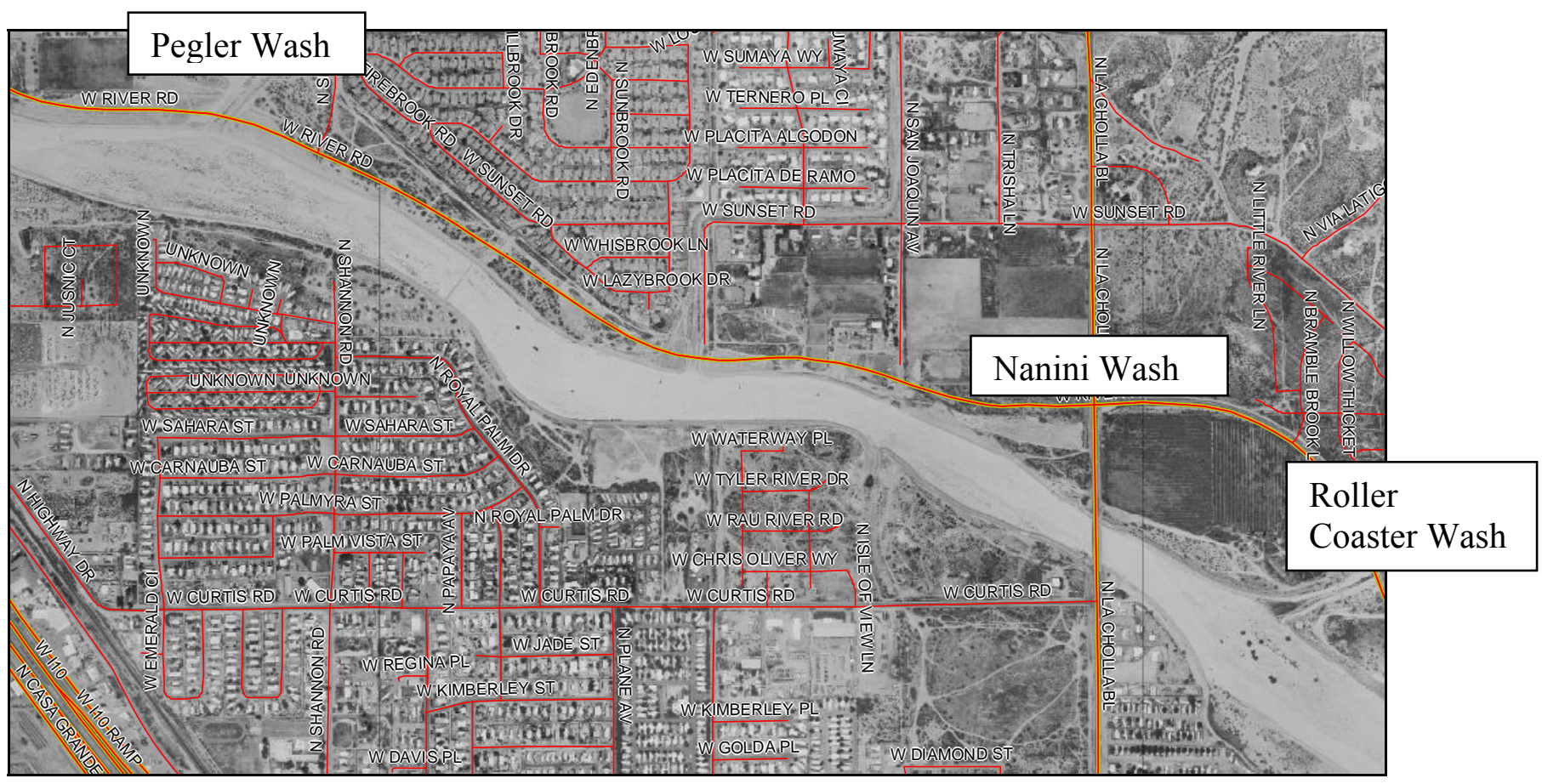

Figure 5. 3. 1. La Cholla, 1998 


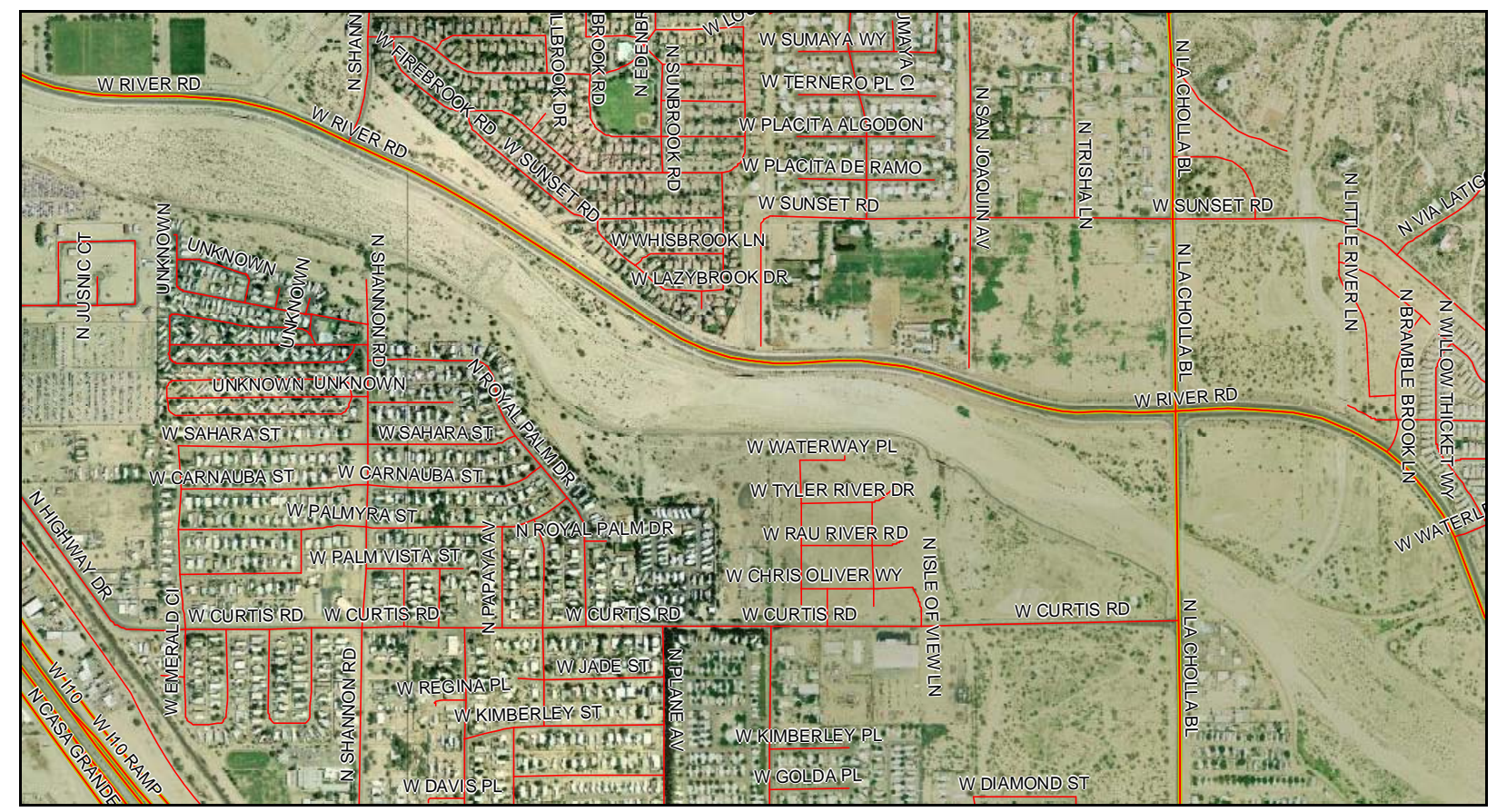

Figure 5. 3. 2 Rillito River at La Cholla, 2002

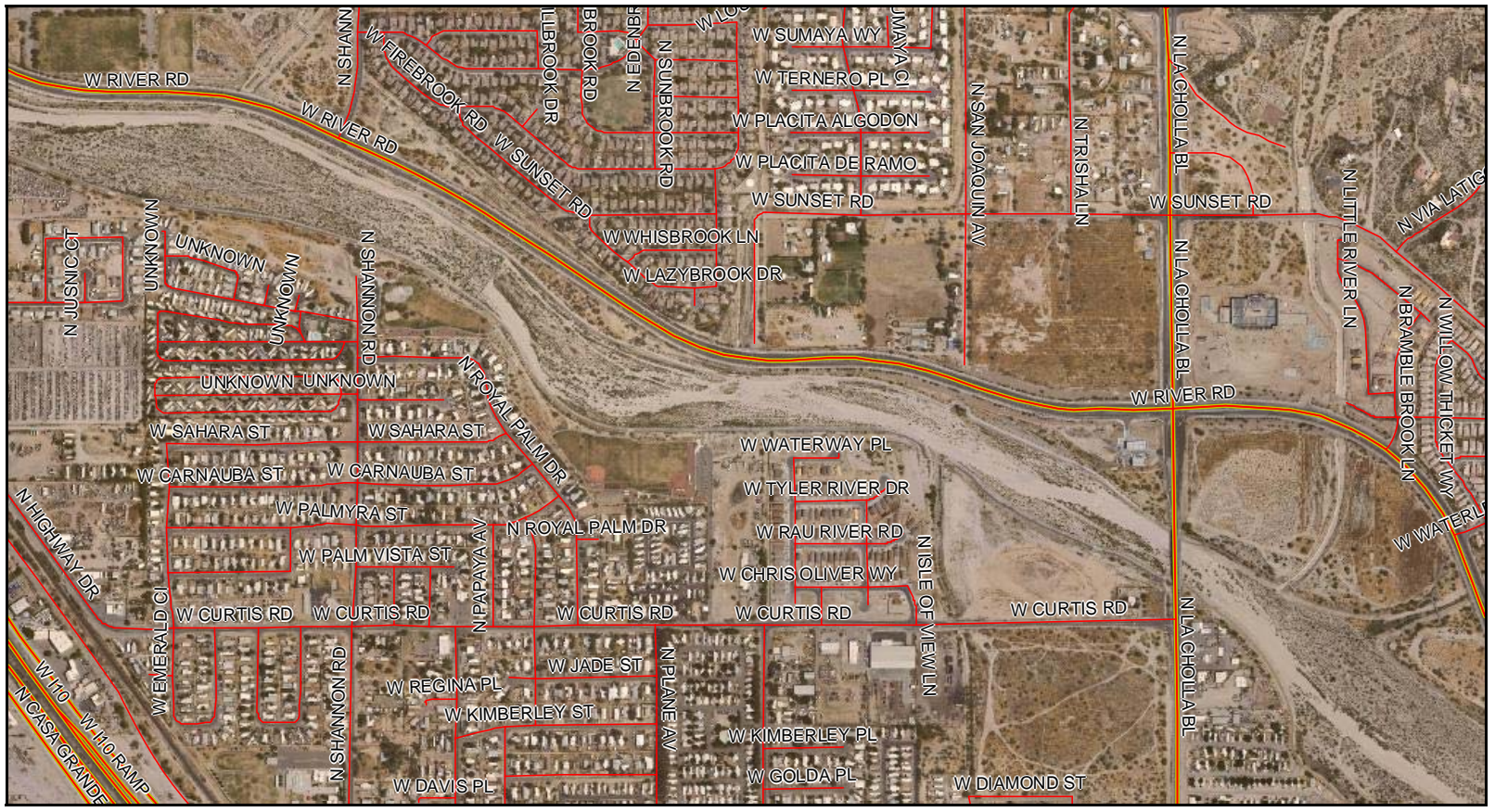

Figure 5. 3. 3. Rillito River at La Cholla, 2005. 


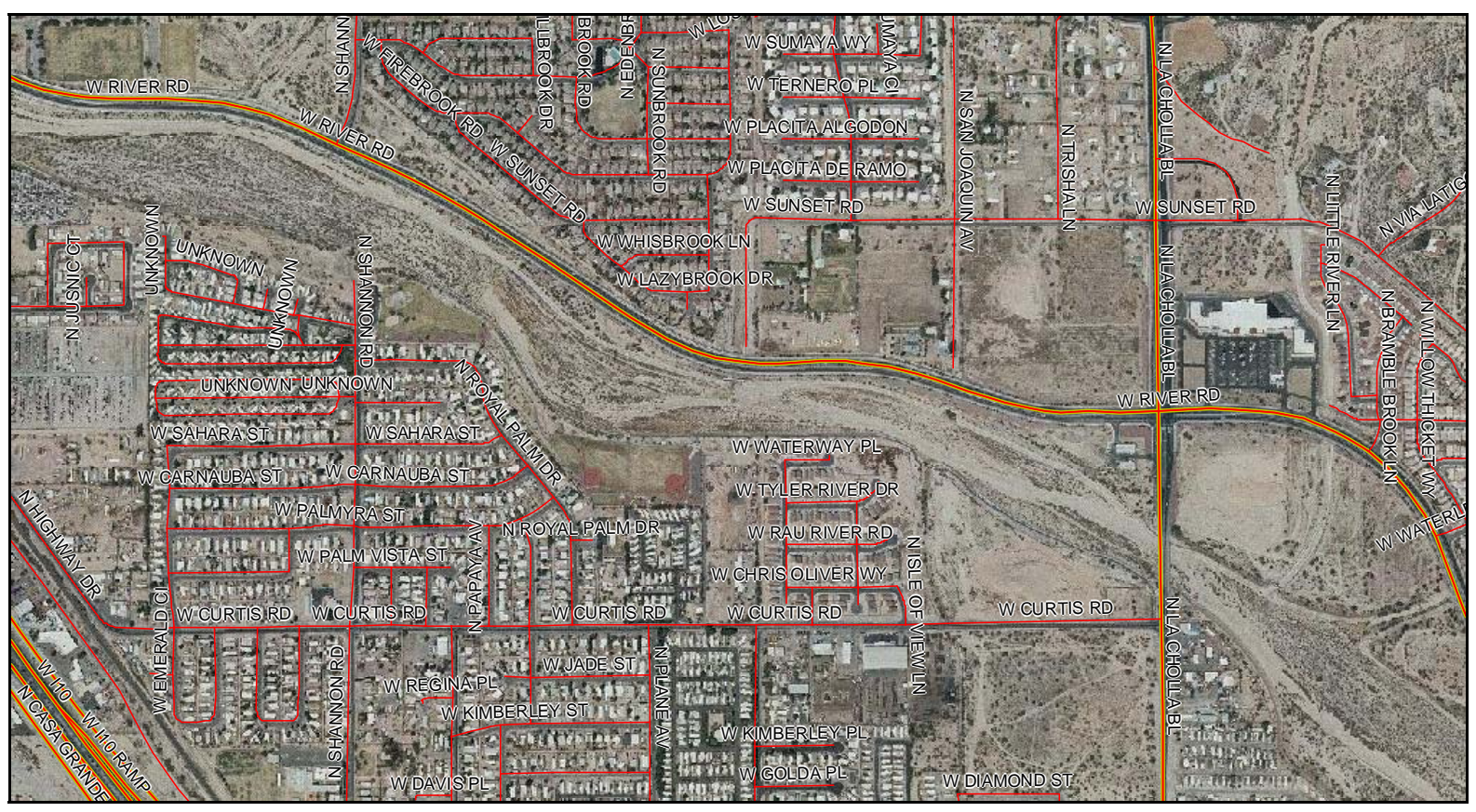

Figure 5. 3. 4. La Cholla, March 2006

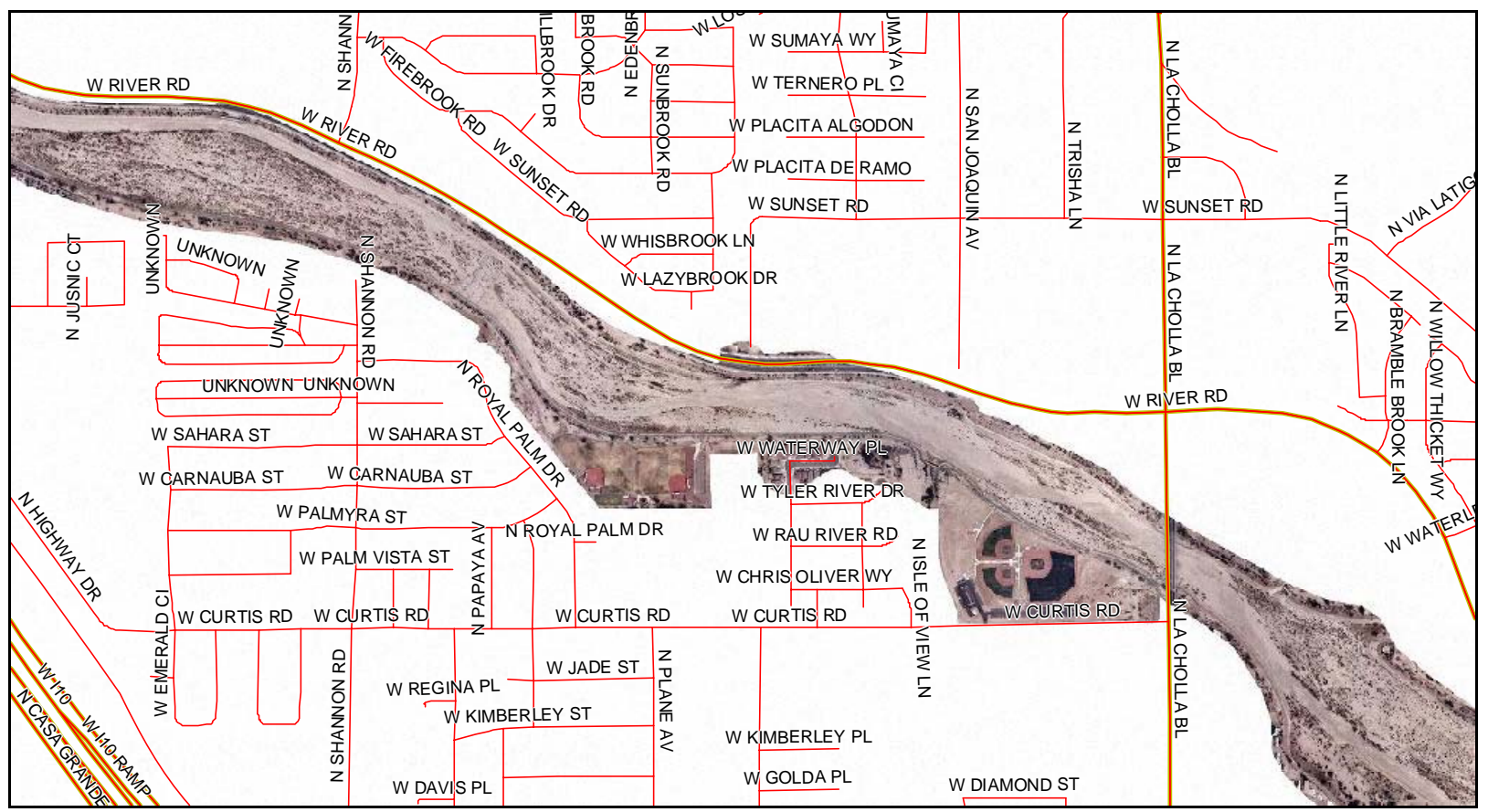

Figure 5. 3. 5. Rillito River at La Cholla, March 2007 


\subsection{Changes in Riverbed Vegetation Between La Canada Dr. and La Cholla Blvd.}

The following five photos trace the bed vegetation history at between La Canada Blvd and La Cholla Blvd. from 1998 (Fig. 5.4.1) to March 2007 (Fig 5.4.5). La Canada Dr. is downstream from Oracle Rd and upstream of La Cholla Blvd (Fig 5.3.16). Pima Wash empties into the Rillito upstream of the La Canada bridge, and Roller Coaster Wash empties into the Rillito downstream of the La Canada bridge. As in previous locations, the river bed in 1998 was relatively free of vegetation, whereas in later years again, as was seen at Dodge and Oracle road, significant establishment of vegetation occurred. As before, the channel width of this particular reach of the study area was significantly reduced from 1998 to 2006 due to the presence of established islands of vegetation. Here as well, after the flood, many of the vegetated bars and islands remain, with only a small widening seen in Fig 5.4.5.

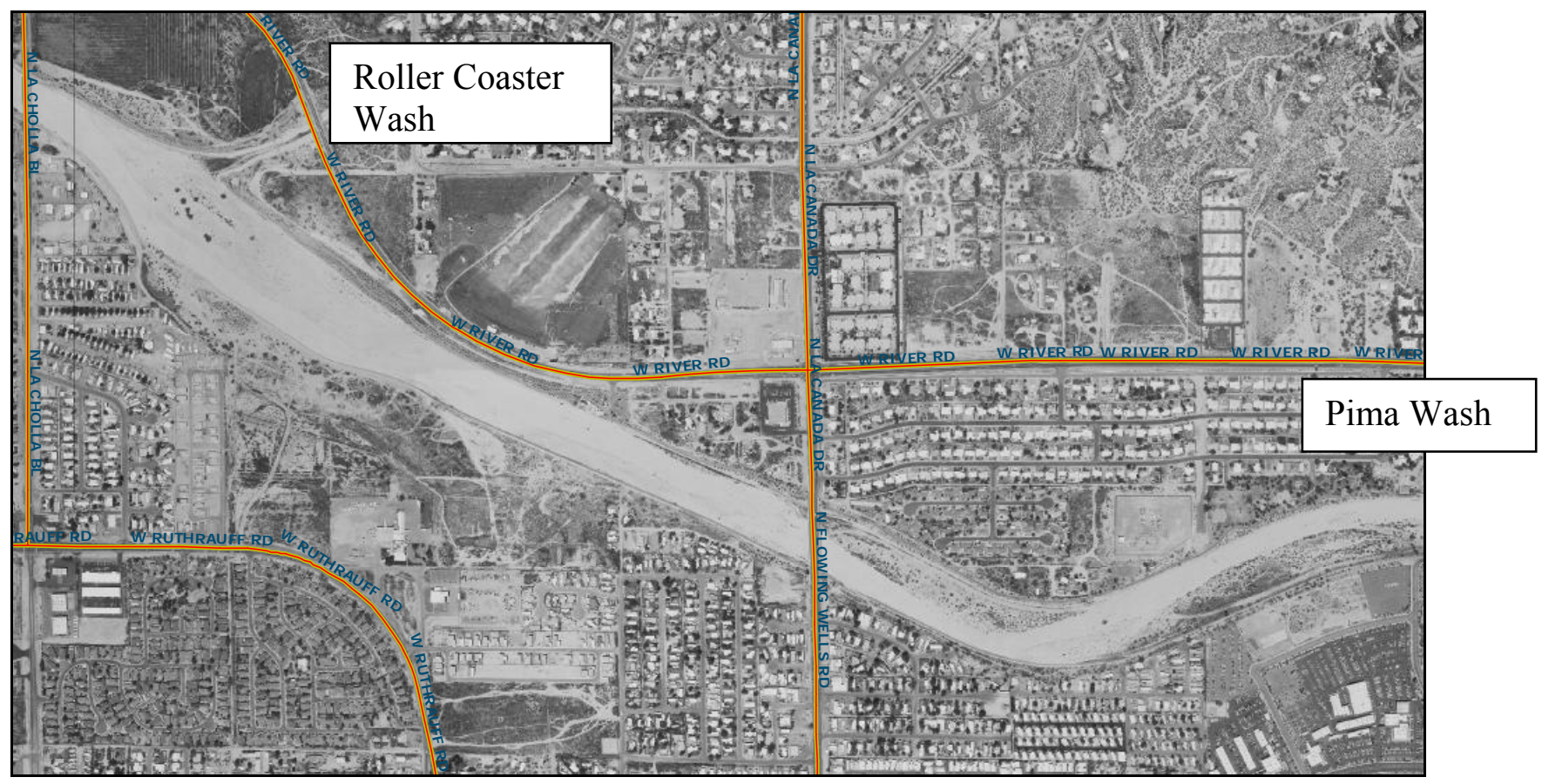

Figure 5. 4. 1. La Canada (right) and La Cholla (far left), 1998 


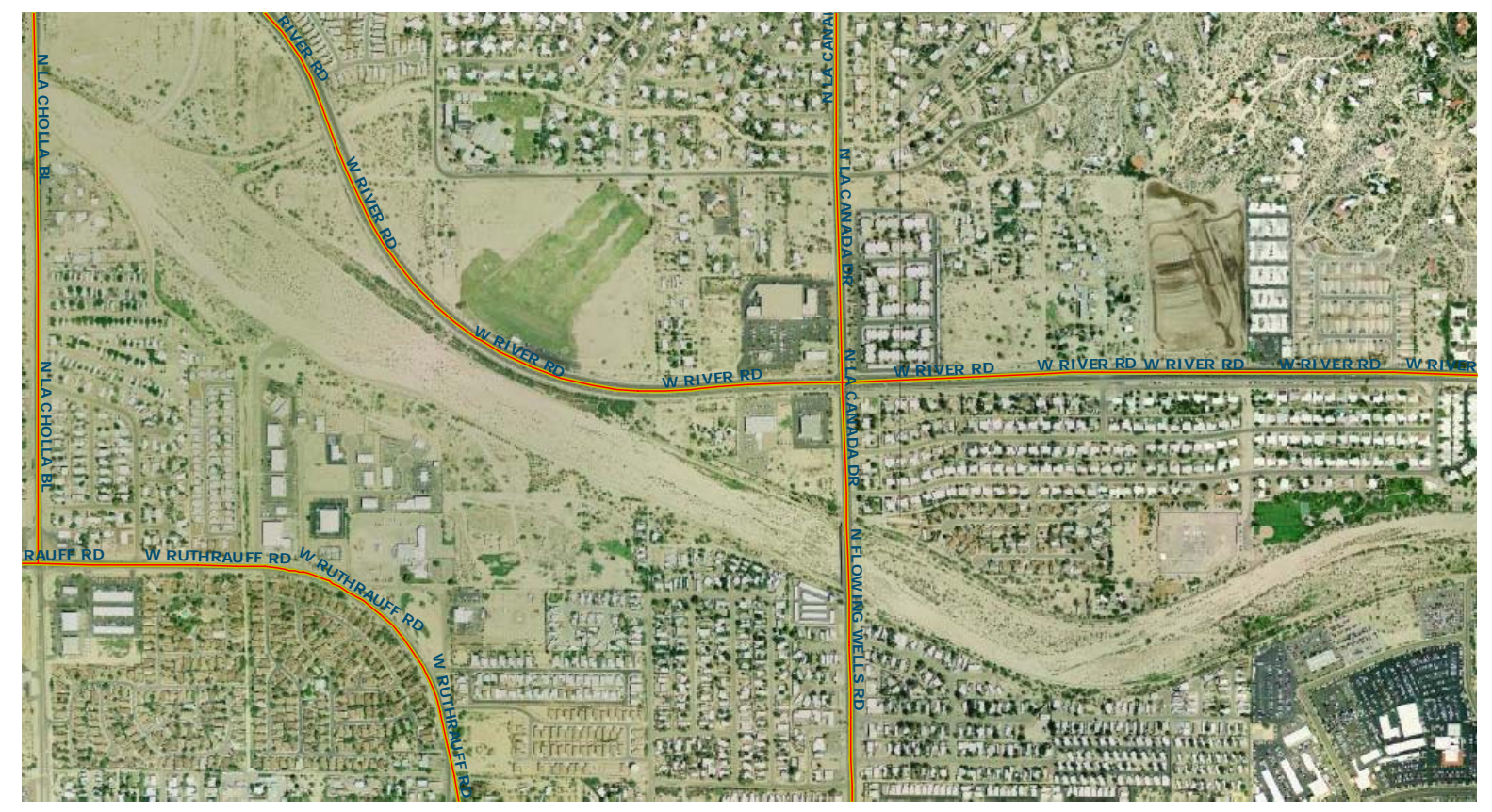

Figure 5. 4. 2. La Canada (right) and La Cholla (far left), 2002

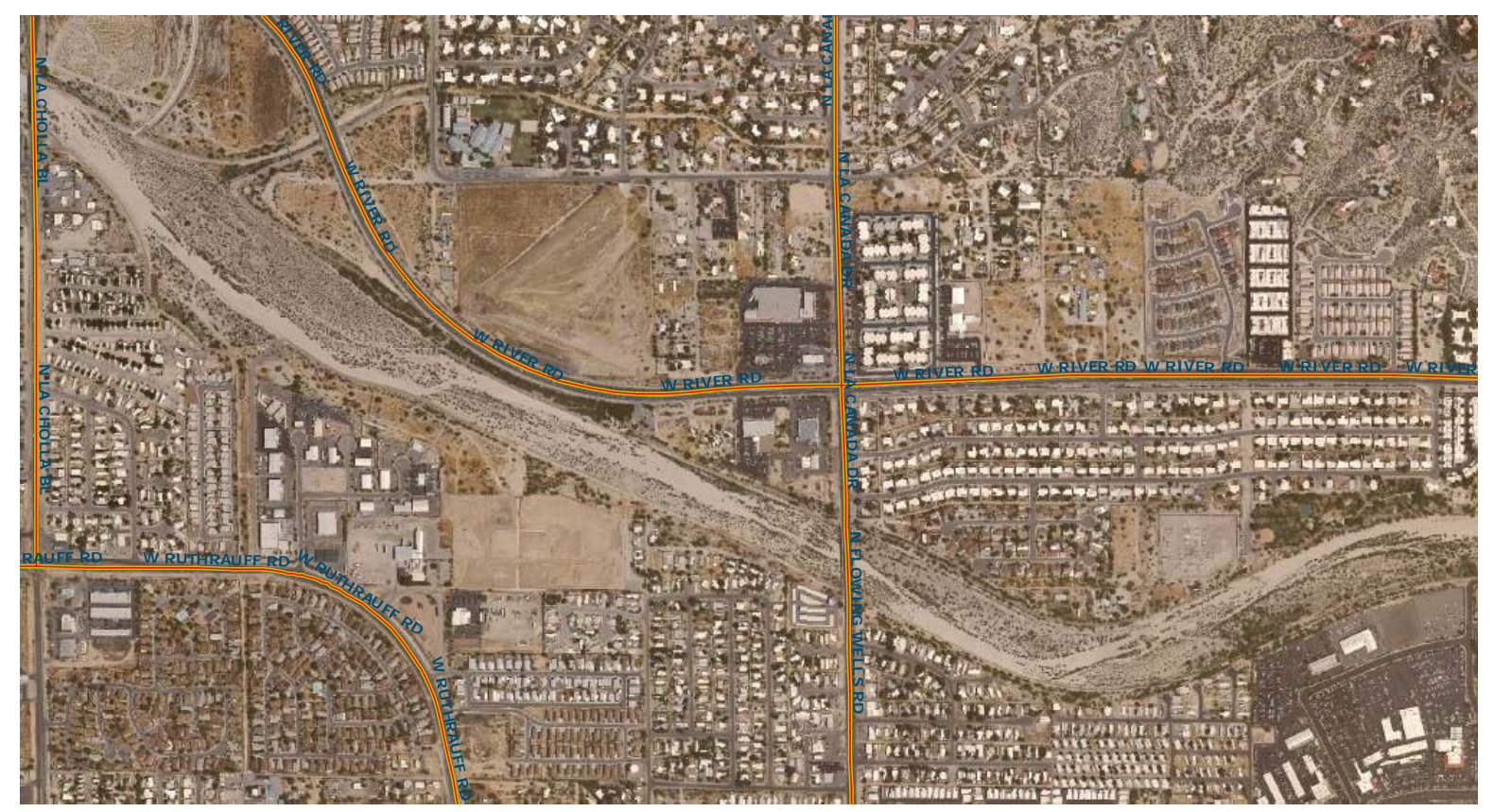

Figure 5. 4. 3. La Canada (right) and La Cholla (far left) 2005 


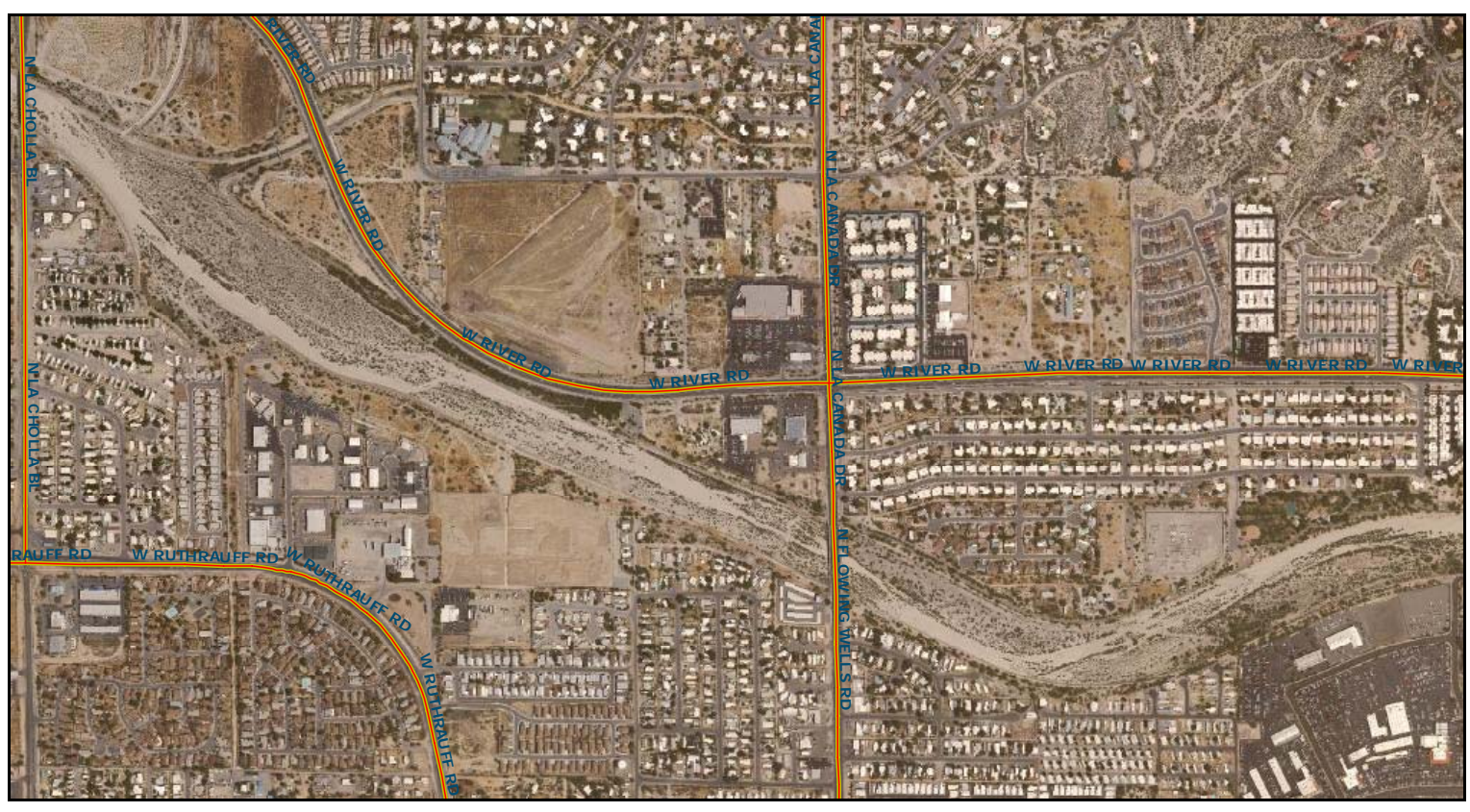

Figure 5. 4. 4. La Canada (right) and La Cholla (far left) March 2006

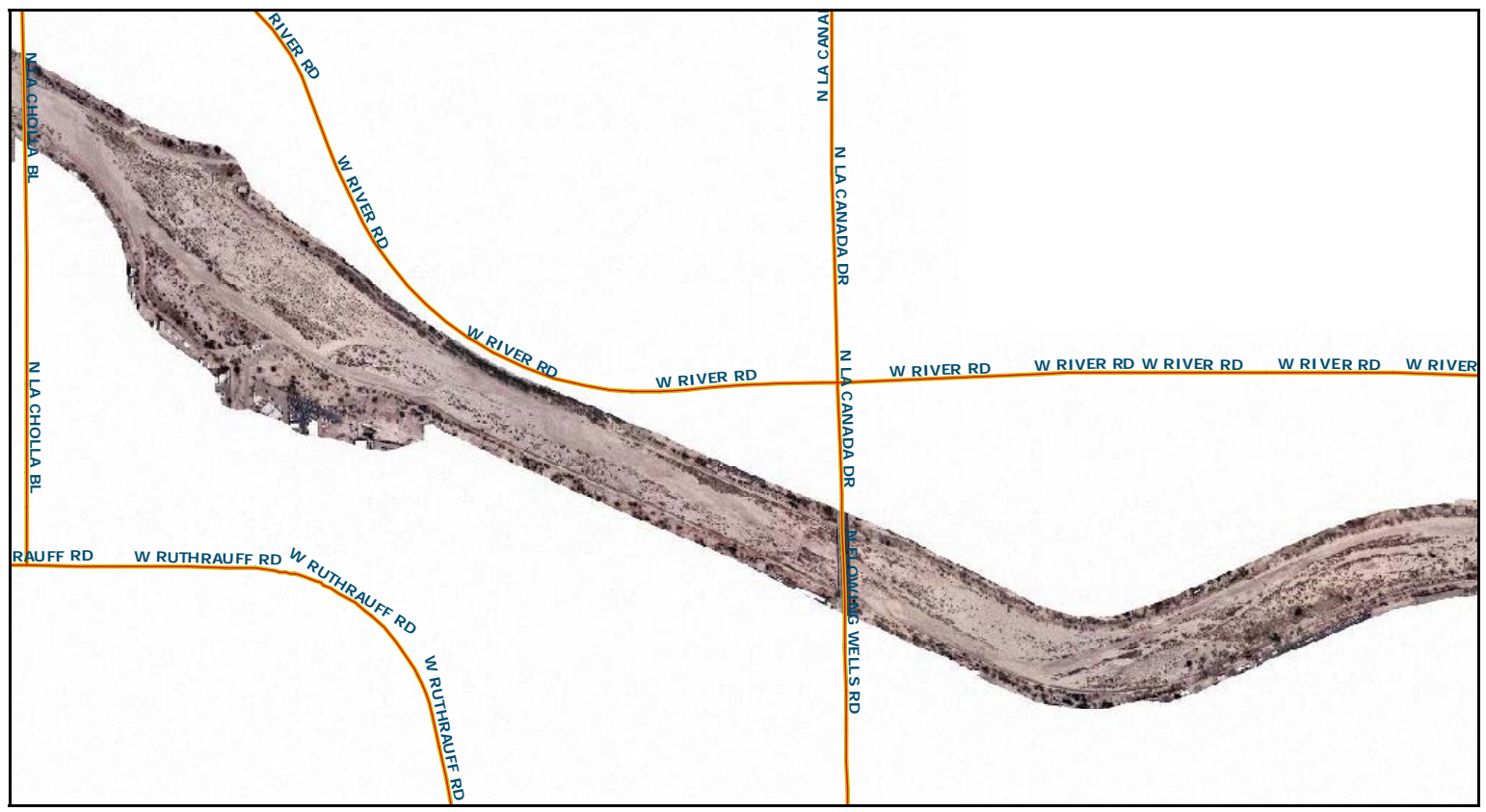

Figure 5. 4. 5. La Canada (right) and La Cholla (far left) April 2007 
These photos not only showed the sediment accumulation as the in-stream vegetation grows but also the dramatic changes in channel morphology immediately after the modeled event. Without accounting for sediment depositions prior to the modeled event, the results from all the models tend to under-predict sedimentations as showed before. As a consequence, all the models significantly under-predicted the total deposited sediment volume, which indicated that about $50 \%$ of the total deposited sediment in the study reach may come from the floods prior of the modeled event. 


\section{Conclusion}

The study examined the applicability of the four most commonly-used one-dimensional hydraulics and sediment transport models to ephemeral streams. These models are HEC-RAS 4.0 beta, HEC-6, IALLUVIAL 2, and SRH-1D. The study site is the reach of Rillito river from the Dodge Blvd. bridge to the I-10 bridges. The observed data was based on the field survey after the unpredecented event from July 16 to August $4^{\text {th }}$ with a peak discharge of $37,913.73 \mathrm{cfs}$ took place. The simulated results of stage hydrographs at La Cholla, average and at the thalweg bed elevation changes, and total deposited sediment volumes were used to evaluate the accuracy of each model.

Since the pre-flood geoemtrical data are based on a field survey in 1998. There were many flood events occurred from 1998 and 2006 prior to the modeling event as evidenced by the analysis of vegetation changes. If the changes of bed elevations from 1998 to July 2006 was insignificant, the primary findings from the comparisons are as follows:

1) As for predicting stage hydrographs, the HEC-RAS unsteady flow model can accurately predict the timing of the flood peak, while all the steady flow models including the quasiunsteady flow models are not capable of predicting the arriving time of the flood peak. The HEC-RAS unsteady flow model overpredicted the stage hydrographs, while all the steady flow models have underpredicted. The results from HEC-6, SRH1D, and IALLUVIAL 2 are very similar. Among them, IALLUVIAL 2 predicted the most closest match to the observed stages at La Cholla. The HEC-RAS quais-unsteady flow model under-estimated during low flows, but predicted an accurate peak stage.

2) As to sediment transport equations, Yang's 73 equation in HEC-RAS, Toffaleti total load equation in HEC-6 and IALLUVIAL 2, and Lausen-Madden equation in SRH-1D yielded better results than other sediment equations.

3) As for predicting bed elevation changes, none of the models are suitable for predicting the bed elevation changes at the thalweg because of the limitations of modeling methodology. HEC-6 and HEC-RAS both yielded reasonable results of averaged bed elevation changes. HEC-6 performed slightly better than the HEC-RAS model if the Nash-Sutcliffe efficiency coefficent is used as the indicator. Therefore, both the HEC-6 and HEC-RAS models are applicable.

4) As to total depsoited/eroded sediment volumes, all the models considerably under-predicted the total deposited sediment. HEC-RAS yielded the best result of 71,276 cubic yards if Laursen equation was selected, while HEC-6 calculated a result of 36,126 cubic yards. SRH- 
1D and IALLUVIAL 2 have significantly under-predicted, and are not suitable for the study site.

In summary, the modeling results recommended Yang's 73, Laursen-Madden, Laursen, and Toffalleti equations for sediment study. Both the HEC-6 and HEC-RAS models are more preferable than the IALLUVIAL 2 and SRH 1D models for predicting bed elevation changes and total sediment volume changes. The IALLUVIAL2 model is applicable to predict stage hydrographs of ephemeral rivers. 


\section{Recommendations}

Based on the modeling comparison study this section provided discussions and recommendations on the selection of several key modeling parameters including time step, distance between cross sections, boundary conditions for sediment transport analysis, and sorting method.

\subsection{Time Steps}

Both the HEC-RAS and HEC-6 sediment transport model utilized three time steps, which are flow duration and time steps for sediment and mxing layer computations, respectively. The flow duration is the length of each constant flow discharge in an unsteady flow hydrograph. For instance, if 15-mins flow hydrograph is used, the flow duration for each discharge is 15 minutes. Although flow discharge remains a constant in one flow duration, flow velocity and surface elevation are changing with changes in bed elevations. A flow duration was sliced into several smaller time steps for sediment computation, which is called the sediment time step that is used for solving the Exner equation. Flow hydraulic properties are updated after each sediment computation. Another time step is called the mixing time step required for one update of bed material gradation with newly deposited/eroded sediment matetial. Each sediment time step is further divided into several mixing time steps. The mixing time step is designed to avoid an abrupt change in bed material gradation when calculating the changes of bed elevations. The sediment time step is the one that affect the model's stability.

The HEC-RAS and HEC-6 sediment transport models as well as the IALLUVIAL 2 and SRH1D models solved the Exner equation using the explicit finite diffrence scheme. The discretisation of the first order derivatives using the forward difference scheme makes the model unstable. The Courant condition needs to be satisfied to ensure stability. The Courant condition is written as

$$
\Delta t_{\text {sed }} \leq \frac{\Delta x}{V_{\text {sed }}}
$$

where $\Delta t_{\text {sed }}$ is the sediment time step, $\Delta x$ is the distance between two cross sections; $V_{\text {sed }}$ is the sediment velocity. The sediment velocity is equal or smaller than the flow velcoity, therefore, the Courant condition can be written as

$$
\Delta t_{\text {sed }} \leq \frac{\Delta x}{V}
$$

where $\mathrm{V}$ is the flow velocity. This condition is the same as that for the flow continuity equation. If the sediment computation time step is pre-selected, the minimum distance between cross sections is $\Delta x_{\min }=V \Delta t_{\text {sed }}$. If the distances between cross sections were pre-determined, the maximum time 
step is $\left(\Delta t_{\text {sed }}\right)_{\max }=\frac{(\Delta x)_{\min }}{V_{\max }}$. In another word, the smaller the distance, the smaller the time step. To use a larger time step, the distance between two cross sections can not be too small.

\subsection{Sediment Boundray Conditions}

To calculate bed elevation changes,sediment load must be specified at both the upstream and downstream boundaries. If sediment transport at the upstream boundary is in equilibrium, the inflow sediment load equals the sediment capacity, which can be calculated by using an existing sediment transport formula. Most equations embedded in the HEC-RAS, HEC-6, IALLUVIAL 2, and SRH$1 \mathrm{D}$ models are for a single grain size that is not suitable to calculate the transport capacity of mixed grain size sediment. A non-uniform sediment transport equation is suggested for calculating the sediment transport capacity and its size gradation at the upstream boundary. The available nonuniform sediment transport equations are Parker (1990), Ackers-White (1973), Duan and Scott (2007), Wilcock and Crowe (2003). In the case of non-equilibrium sediment inflow, a field measured sediment load rating curve is needed as the inflow sediment boundary condition.

An alterantive to define the sediment rating curve and its gradations at various sediment discharges is to use the "recirculation" method as decribed in Section 3.2.5.2. This method directly utilizes HEC-6 or HEC-RAS model itself to calculate the equilibrium load based on the selected sediment transport equation. However, it may require many model runs to obtain one sediment load and the corresponding size gradation.

\subsection{Sorting Method}

Both HEC-RAS and HEC-6 models included two sediment sorting methods: one is called active layer method, and the other is the method of Exner 5. The Exner 5 method is much more sophisticated than the active layer method. The difference is that Exner 5 method considered the coarsening of surface bed material when bed surface is eroded, while the active layer only differentiates the active from the inactive bed material. Exner 5 method is generally applicable to most rivers because it computes the armoring layer if it exists. In the case of no armoring, the Exner 5 method treats the cover layer has the same composition as the substrate.

\subsection{Bed Elevation Changes at the Thalweg}

As concluded in this study, none of the models is capable of predicting bed elevation changes at the thalweg. If a project requires bed elevation changes at the thalweg, a two-dimensional modeling study is most preferable. Two-dimensional models in the public domain include TABS-MD, CASC2D, CCHE2D, ENSED2D, etc. 
TABS-MD is a two-dimensional depth-averaged model developed by Coastal and Hydraulics Laboratory (CHL), Waterways Experiment Station (WES) of the U.S. Army Corps of Engineers (USACE).

CASC2D is a two-dimensional watershed model developed by Colorado State University through a funded project with the Army Research Office (ARO) of Department of Defense (DOD).

CCHE2D is a two-dimensional depth-averaged model developed by National Center for Computational Hydrosciences and Engineering through the Cooperative Research Agreement with US Department of Agriculture.

ENSED2D is a two-dimensional depth-averaged model developed by the Desert Research Institute of University and Community College System of Nevada, and later the University of Arizona through a contract with the ARO of DOD.

A review of thes models' capability was summarized in Duan et al. (2003).

\section{Acknowledgements}

This work is a result of research sponsored by a subconstract from JE Fuller H\&G Inc. The Pima County Regional Flood Control District (PCRFCD) provided the original funding. Mr. Evan Canfield was the project manager at the PCRFD . Mr. Ian Sharp at JE Fuller H\&G Inc. helped to facilitate the execution of the subcontract. Many thanks to Evan Canfield, Fazle Karim, Ian Sharpe, and Akitsu Kimoto for providing valuable advice as the project progressed. 


\section{References}

Ackers, P., and White, W.R. (1973). Sediment Transport: New Approach and Analysis. J. of the Hydr. Div. ASCE, Vol.99, HY11.

Ariathurai, R., and R. B. Krone (1976), Finite element model for cohesive sediment transport, Journal of the Hydraulics Division, ASCE, 323-338.

Brunner G. W. and Gibson, S. (2005). Sediment Transport Modeling in HEC-RAS. Proceeding of ASCE EWRI Congress in Anchorage, Raymond Walton, editor. doi:10.1061/40792(173)442.

Colby, B. R. (1964). Practical computations of bed-material discharge, Proceedings, ASCE, Vol. 90, No. HY2.

Copeland, Ronald R., and W.A. Thomas (1989). Corte Madera Creek Sedimentation Study, Technical Report HL 89-6, USACE, Waterways Experiment Station, Vicksburg, MS.

Copeland, Ronald R. (1990). Waimea Sedimentation Study, Kauai, Hawaii, Numerical Model Investigation, Technical Report HL 90-3, USACE, Waterways Experiment Station, Vicksburg, MS.

Duan, J.G. and Chen, Li (2003) Review of Sediment Transport Models, Technical Report, Desert Research Institute, 71 pages.

Duan, J.G. (2004) Simulation of flow and pollutant dispersion in meandering channels, Journal of Hydraulic Engineering, Vol. 130, No.10, 964-976.

Duan, J.G. and Scott, S. (2007) Selective bed-load transport in Las Vegas Wash, a gravel-bed stream, Journal of Hydrology, Vol. 342, 320-330, doi: 10.1016/j.jhydrol.2007.06.001.

DuBoys, M. P. (1879). "le Rhone et les rivieres a lit affouillable," Annals de Ponts et Chaussee, 18(5), 141-195. (in French).

Engelund, F., and Hansen, E. (1972). A Monograph on Sediment Transport in Alluvial Streams. Teknish Forlag, Technical Press, Copenhagen, Denmark.

HEC (1986). U.S. Army Corps of Engineers, Hydrologic Engineering Center (HEC), Accuracy of Computed Water Surface Profiles, Research Document No. 26.

HEC (1990). U.S. Army Corps of Engineers, Hydrologic Engineering Center (HEC), Computing Water Surface Profiles with HEC-2 on a Personal Computer, Training Document No. 26.

HEC (1992). U.S. Army Corps of Engineers, Hydrologic Engineering Center (HEC), Guidelines for the Calibration and Application. 
Huang, J., and Greimann, B. (2007), User's Manual for SRH-1D V2.0. U.S. Bureau of Reclamation, Technical Service Center, Denver, Colorado.

Karim, M.F. and Kennedy, J.F. (1982). IALLUVIAL: A computer-based flow and sediment routing model for alluvial stream and its application to the Missouri River, Iowa Institute of Hydraulic Research, University of Iowa, Report N. 250.

Karim M.F. Holly, F.M., and Yang, J. C. (1987). IALLUVIAL: Numerical simulation of mobile-bed rivers, Part I, theoretical and numerical principles. Iowa Institute of Hydraulic Research, the University of Iowa. Report N. 309.

Karim M.F. Holly, F.M., Spasojerie, M., and Yang, J.C. (1987). IALLUVIAL: Numerical simulation of mobile-bed rivers, Part III, user's instructions. Iowa Institute of Hydraulic Research, the University of Iowa. Report N. 311.

Karim, M. F. and J.F. Kennedy (1990) "Menu of coupled velocity and sediment discharge relations for rivers.” J. Hydr. Engrg., ASCE 116, No. 8, pp.978-986.

Klingeman, P., C., C. J. Chaquette, and S. B. Hammond, (1979), Bed material characteristics near Oak Creek sediment transport research facilities, 1978-1979, Oak Creek Sediment Transport Report No. BM3, Water Resources Research Institute, Oregon State University, Corvallis, Oregon.

Krone, R. B. (1962). Flume Studies of the Transport of Sediment in Estuarial Shoaling Processes, Hydraulic Engineering Laboratory, University of California, Berkeley.

Laursen, E. M. (1958). The total sediment load of streams, J. of the Hydr. Div. ASCE, 84(HY1).

Limerinos, J. T. (1970). Determination of the manning coefficient from measured bed roughness in natural channels, Water Supply Paper 1898B, U.S. Geological Survey.

JE Fuller Hydrology and Geomorphology, Inc (2006). Cross Sectional Assessment of Rillito Creek, Craycroft Road to the Santa Cruz River, Pima County, Arizona, Technical Report, 38 Pages.

Madden, E. B. (1963), Channel Design for Modified Sediment Regime Conditions on the Arkansas River, Paper No. 39, Proceedings of the Federal Interagency Sedimentation Conference, Miscellaneous Publication No. 970, Agricultural Research Service, U.S. Government Printing Office, 335-352.

Magirl, C.S., Webb, R.H., Schaffner, M., Lyon, S.W., Griffiths, P.G., Shoemaker, C., Unkrich, S., Yatheendradas, S., Trock, P.A., Pytlak, E., Goodrich, D.C, Desilets, S.L.E., Youberg, A., and Pearthee, P.A. (2007). Hydrogeomorphic Response to an Extreme Precipitation Event in Southern Arizona. 
Meyer-Peter, E., and Muller, R. (1948). Formula for Bed-Load Transport, Proc. of the Int. Assoc. for Hydraulic Research, $2^{\text {nd }}$ Meeting, Stockholm.

Parker, G. (1990), Surface-based bedload transport relation for gravel rivers. Journal of Hydraulic Research 28(4), 417-436.

Toffaleti, F. B. (1966) A Procedure for computation of total river sand discharge and detailed distribution, bed to surface, Committee on Channel Stabilization, U.S. Army Corps of Engineering.

Toffaleti, F.B. (1969), Definitive computations of sand discharge in rivers, Journal of the Hydraulic Division. ASCE, Vol. 95(1), 225-246, 1969

U.S. Army Corps of Engineers (1993), HEC-6 User's Manual 1993

Vanoni, V. (ed.) (1975) Sedimentation Engineering, ASCE Manual 54, ASCE, New York.

Wu, W., S.S.Y. Wang, and Y. Jia (2000), Nonuniform sediment transport in alluvial rivers, Journal of Hydraulic Research, Vol. 38(6):427-434.

Yang, C.T. (1996) Sediment Transport: Theory and Practice. McGraw-Hill Companies, Inc., New York, NY.

Yang, C.T. (1973). Incipient Motion and Sediment Transport, J. of the Hydr. Div. ASCE, 99 (HY10).

Yang, C.T. (1984), Unit Stream Power Equation for Gravel, J. of the Hydr. Div. ASCE, 110 (HY12).

Yang, C.T. and Simoes, F. J. M. (2000). User's Manual for GSTARS 2.1, Technical Report, US Department of the Interior, Bureau of Reclamation, Denver, Colorado.

Yang, C.T., and Simões, F.J.M. (2002), User's manual for GSTAR3 (Generalized Stream Tube model for Alluvial River Simulation version 3.0). U.S. Bureau of Reclamation, Technical Service Center, Denver, Colorado 


\section{Appendix A. HEC-RAS Model}

HEC-RAS is a one-dimensional, steady and unsteady flow, sediment transport/mobile bed computational modeling software package. The Hydrologic Engineering Center (HEC) of US Army Corps of Engineers (USACE) developed the original version released in 1995. The main purpose of HEC-RAS is to analyze the hydraulics of flow through natural and engineered channels. HEC-RAS has undergone several revisions over the past 13 years, and has become a widely-used software program utilized by both government agencies and private firms. The most recent version of HECRAS 4.0 was used during this project.

HEC-RAS 4.0 is an integrated system of software that is designed for interactive use in a multitasking environment. It is applicable for simulating flow hydrodynamics as well as alluvial channel morphodynamic processes. HEC-RAS 4.0 is comprised of a graphical user interface and reporting facilities with the ability to calculate steady and unsteady flow water surface profiles and compute sediment transport. HEC-RAS 4.0 has incorporated sediment transport analysis module that can be used to evaluate the sediment deposition in reservoirs, design channel contractions required to maintain navigation depths or decrease the volume of maintenance dredging, predict the influence of dredging on the rate of deposition, estimate possible maximum scour during large flood events, and evaluate sedimentation in fixed channels.

\section{A.1. HEC-RAS Steady Flow Model - Flow Hydrodynamics}

\section{A.1.1. Governing Equations}

The governing equation for the one-dimensional, steady-state, open channel flow calculation is the energy equation,

$$
Y_{2}+Z_{2}+\beta_{2} \frac{V_{2}^{2}}{2 g}=Y_{1}+Z_{1}+\beta_{1} \frac{V_{1}^{2}}{2 g}+h_{e}
$$

where:

$g=$ acceleration due to gravity

$h_{e}=$ energy head loss of flow between cross section 1 (upstream) and 2 (downstream)

$V_{1}, V_{2}=$ cross section average velocities at both ends of a reach

$Y_{1}, Y_{2}=$ depth of water at cross sections

$Z_{1}, Z_{2}=$ elevation of the main channel inverts

$\beta_{1}, \beta_{2}=$ velocity distribution coefficients for flow at the ends of a reach.

The equations are solved by the Standard Step method. These governing equations also hold for quasi-unsteady flow. Water surface profiles are calculated for each flow after the energy losses are determined. 


\section{A.1.2 Hydraulic Losses}

The hydraulic loss is composed of friction loss, $h_{e}$, and, contraction or expansion losses, $h_{c}$.

$$
h_{e}=h_{f}+h c
$$

Friction loss is calculated by three equations

$$
\begin{gathered}
h_{f a}=\sqrt{S_{f 1} S_{f 2}}\left(x_{2}-x_{1}\right) \\
h_{f b}=\left[\frac{2 Q}{\left(K_{1}+K_{2}\right)}\right]\left(x_{2}-x_{1}\right) \\
h_{f}=\min \left(h_{f a}, h_{f b}\right)
\end{gathered}
$$

where:

$S_{f 1}, S_{f 2} \quad=$ Representative friction slope for cross section 1 and 2

$x_{1}, x_{2}=$ length of the strip between cross section 1 and 2

$Q \quad=$ water discharge

$K_{1}, K_{2} \quad=$ subsection conveyance.

Each cross section is characterized by a number of nodes along the transverse direction of the streambed. The cross sections are divided into subsections of trapezoidal shapes, usually consisting of a main channel and left and right overbanks. Only contraction and expansion losses are considered as form loss, and calculated as

$$
h_{c}=C_{c}\left|\beta_{1} \frac{V_{1}^{2}}{2 g}-\beta_{2} \frac{V_{2}^{2}}{2 g}\right|
$$

where $C_{c}$ is loss coefficient for expansion or contraction. If the quantity within the absolute value notation is negative, flow is contraction and $C_{c}$ is the coefficient of contraction; if it is positive, flow is expanding and $C_{c}$ is the coefficient of expansion. The Manning's coefficient in the main channel is determined by dividing it into $\mathrm{N}$ parts, each with a known wetted perimeter $\mathrm{P}_{\mathrm{i}}$ and roughness coefficient $\mathrm{n}_{\mathrm{i}}$.

$$
n_{c}=\left[\frac{\left.\sum_{i=1}^{N}\left(P_{i} n_{i}{ }^{1.5}\right)\right)}{P}\right]^{2 / 3}
$$

where:

$$
\begin{aligned}
& \mathrm{n}_{\mathrm{c}}=\text { composite or equivalent coefficient of roughness } \\
& \mathrm{P}=\text { wetted perimeter of entire main channel }
\end{aligned}
$$


$\mathrm{P}_{\mathrm{i}}=$ wetted perimeter of subdivision 1

$\mathrm{n}_{\mathrm{i}}=$ coefficient of roughness for subdivision

The model can process supercritical flow as well as subcritical flow. However, it does not account for the head loss caused by a hydraulic jump or fall, and therefore cannot handle the subcritical to supercritical flow transition.

\section{A.1.3 Velocity Distribution Factor}

The velocity distribution factor, $\alpha$, in the energy equation, is determined in terms of conveyance and area in the three flow elements: left overbank, right overbank, and channel as

$$
\alpha=\frac{\left(A_{t}\right)^{2}\left[\frac{K_{l o b}^{3}}{A_{l o b}^{2}}+\frac{K_{c h}^{3}}{A^{2}{ }_{c h}}+\frac{K_{r o b}^{3}}{A^{2}{ }_{r o b}}\right]}{K_{t}^{3}}
$$

where:

$A_{t=}$ total flow area of cross section

$\mathrm{A}_{\mathrm{lob}}, \mathrm{A}_{\mathrm{ch}}, \mathrm{A}_{\mathrm{rob}}=$ flow areas of left overbank, main channel and right overbank, respectively

$\mathrm{K}_{\mathrm{t}}=$ total conveyance of cross section

$\mathrm{K}_{\mathrm{lob}}, \mathrm{K}_{\mathrm{ch}}, \mathrm{K}_{\mathrm{rob}}=$ conveyances of left overbank, main channel and right overbank, respectively in which $K$ is computed by

$$
K_{t}=\frac{1}{n} A_{t} R^{2 / 3}
$$

where $A_{t}$ and $K_{t}$ are

$$
A_{t}=\sum_{j=1}^{N S S} A_{j}, \quad K_{t}=\sum_{j=1}^{N S S} K_{j}
$$

$N S S=$ total number of subsections across each cross section

$n$ = Manning's roughness coefficient

The friction slope at each cross section is calculated from Manning's equation as follows:

$$
S_{f}=\left[\frac{Q}{K}\right]^{2}
$$

\section{A.1.4 Critical Section Factor, Effective Depth and Effective Width}

HEC-RAS Beta 4 uses the Froude number to examine if the flow regime is subcritical or supercritical. It is expressed as

$$
F r=\frac{v}{\sqrt{g D}}
$$

Froude number is calculated and if it is less than 1, the flow is subcritical. If it is greater than 1 , the flow is supercritical. If it is equal to 1 , it is critical flow. 
The critical water depth is the depth for which the total energy head is a minimum (the minimum specific energy for the cross section). The critical depth is determined with an iterative procedure whereby values of WS are assumed and corresponding values of $\mathrm{H}$ are determined from total head energy equation until a minimum value for $\mathrm{H}$ is reached.

$$
H=W S+\frac{\alpha V^{2}}{2 g}
$$

where

$$
\begin{aligned}
& \mathrm{H}=\text { total energy head } \\
& \mathrm{WS}=\text { water surface elevation } \\
& \frac{\alpha V^{2}}{2 g}=\text { velocity head }
\end{aligned}
$$

\section{A.1.5 Numerical Solution}

Once the downstream water surface elevation is assigned (or water surface elevation at the upstream cross section in case of a supercritical flow), the corresponding total conveyance and velocity head is determined. Friction slope is computed and the energy equation is solved for the total energy loss; the water surface profile computation progresses upstream for subcritical flow based on the energy equation. New to HEC-RAS 4.0 is a trial or relaxation iterative method. The first-step iteration uses an assumed value, and the iteration is continued until the values agree to within .01 feet $(.003 \mathrm{~m})$, or a user-defined tolerance.

\section{A.2 HEC-RAS Unsteady Flow Model - Flow Hydrodynamics}

\section{A.2.1 Governing Equations}

The governing equations in the unsteady flow model are the continuity equation and the momentum equation.

The continuity equation is given by:

$$
\frac{\partial A}{\partial t}+\frac{\partial Q}{\partial x}=q_{l}
$$

The continuity equation by adding a storage term becomes

$$
\frac{\partial A}{\partial t}+\frac{\partial S}{\partial t}+\frac{\partial Q}{\partial x}=q_{l}
$$

where:

$$
\begin{aligned}
& \mathrm{q}_{1}=\text { lateral inflow per unit length } \\
& \mathrm{x}=\text { distance along the channel } \\
& \mathrm{t}=\text { time } \\
& \mathrm{Q}=\text { flow }
\end{aligned}
$$




$$
\begin{aligned}
& \mathrm{A}=\text { cross sectional area } \\
& \mathrm{S}=\text { storage from non conveying portions of cross section }
\end{aligned}
$$

Water in the channel flows along the main channel and can be considered as 1D flow; water in the floodplain exchanges with the main channel through lateral inflow and outflow. Both the continuity and momentum equations should be solved separately in the main channel and floodplain. Then, for main channel and floodplain separately,

$$
\frac{\partial A_{c}}{\partial t}+\frac{\partial Q_{c}}{\partial x}=q_{f}
$$

and:

$$
\frac{\partial A_{f}}{\partial t}+\frac{\partial S}{\partial t}+\frac{\partial Q_{f}}{\partial x_{f}}=q_{c}+q_{l}
$$

where the subscripts $\mathrm{c}$ and $\mathrm{f}$ refer to the channel and floodplain respectively, and $\mathrm{q}_{\mathrm{c}}$ and $\mathrm{q}_{\mathrm{f}}$ are the exchanges of water between the channel and the flood plain.

The discrete continuity equation,

$$
\begin{gathered}
\frac{\Delta A_{c}}{\Delta t}+\frac{\Delta Q_{c}}{\Delta x}=\overline{q_{f}} \\
\frac{\Delta A_{f}}{\Delta t}+\frac{\Delta S}{\Delta t}+\frac{\Delta Q_{f}}{\Delta x_{f}}=\overline{q_{c}}+\overline{q_{l}}
\end{gathered}
$$

The exchange between main channel and floodplain is equal, $\Delta x_{c} q_{c}=-q_{f} \Delta x_{f}$, then equations combine into

$$
\Delta Q+\frac{\Delta A_{c}}{\Delta t} \Delta x_{c}+\frac{\Delta A_{f}}{\Delta t} \Delta x_{f}+\frac{\Delta S}{\Delta t} \Delta x_{f}-\overline{Q_{l}}=0
$$

The momentum equation is given by:

$$
\frac{\partial Q}{\partial t}+\frac{\partial(V Q)}{\partial x}+g A\left(\frac{\partial z}{\partial x}+S_{f}\right)=0
$$

where:

$$
\begin{aligned}
& g=\text { acceleration of gravity } \\
& X=\text { distance along the channel } \\
& V=\text { velocity } \\
& Q=\text { flow } \\
& A=\text { cross sectional area } \\
& S_{f}=\text { friction slope }
\end{aligned}
$$


Separate momentum equations for the channel and floodplain are given by:

$$
\begin{gathered}
\frac{\partial Q_{c}}{\partial t}+\frac{\partial\left(V_{c} Q_{c}\right)}{\partial x_{c}}+g A_{c}\left(\frac{\partial z}{\partial x_{c}}+S_{f c}\right)=M_{f} \\
\frac{\partial Q_{f}}{\partial t}+\frac{\partial\left(V_{f} Q_{f}\right)}{\partial x_{f}}+g A_{f}\left(\frac{\partial z}{\partial x_{f}}+S_{f f}\right)=M_{c}
\end{gathered}
$$

The discrete forms of these equations are:

$$
\begin{gathered}
\frac{\Delta Q_{c}}{\Delta t}+\frac{\Delta\left(V_{c} Q_{c}\right)}{\Delta x_{c}}+g \overline{A_{c}}\left(\frac{\Delta z}{\Delta x_{c}}+\overline{S_{f c}}\right)=M_{f} \\
\frac{\Delta Q_{f}}{\Delta t}+\frac{\Delta\left(V_{f} Q_{f}\right)}{\Delta x_{f}}+g \overline{A_{f}}\left(\frac{\Delta z}{\Delta x_{f}}+\overline{S_{f f}}\right)=M_{c}
\end{gathered}
$$

Using $\Delta x_{c} M_{c}=-M_{f} \Delta x_{f}$ and adding, then rearranging all the terms, the equations become:

$$
\frac{\Delta\left(\Delta Q_{c} \Delta x_{c}+\Delta Q_{f} \Delta x_{f}\right)}{\Delta t}+\Delta\left(V_{c} Q_{c}\right)+\Delta\left(V_{f} Q_{f}\right)+g\left(\overline{A_{c}}+\overline{A_{f}}\right) \Delta z+g \overline{A_{c} S_{f c}} \Delta x_{c}+g \overline{A_{f} S_{f f}} \Delta x_{f}=0
$$

After consolidating some terms, and divided by $\Delta \mathrm{x}_{\mathrm{e}}$, the momentum equation for the floodplain and the main channel becomes:

$$
\frac{\Delta\left(\Delta Q_{c} \Delta x_{c}+\Delta Q_{f} \Delta x_{f}\right)}{\Delta t \Delta x_{e}}+\frac{\Delta(\beta V Q)}{\Delta x_{e}}+g \bar{A}\left(\frac{\Delta z}{\Delta x_{e}}+\overline{S_{f}}\right)=0
$$

where

$$
\begin{aligned}
& \Delta \mathrm{x}_{\mathrm{e}}=\text { equivalent flow path } \\
& \mathrm{S}_{\mathrm{f}}=\text { friction slope for the entire cross section } \\
& \mathrm{V}=\text { velocity } \\
& \mathrm{Q}=\text { flow } \\
& \mathrm{A}=\text { cross sectional area }\left(\overline{A_{c}}+\overline{A_{f}}\right) \\
& \beta=\text { Velocity distribution factor }
\end{aligned}
$$

where the subscripts $\mathrm{c}$ and $\mathrm{f}$ refer to the channel and floodplain respectively.

\section{A.2.2. Hydraulic Losses}

The hydraulic loss is given by: 


$$
h_{l}=C \frac{V^{2}}{2 g}
$$

where:

$$
\begin{aligned}
\mathrm{h}_{1} & =\text { head loss } \\
\mathrm{C} & =\text { Coefficient }
\end{aligned}
$$

The velocity head is evaluated at the tailwater for subcritical flow and at the headwater for supercritical flow in the contraction. The rate of energy loss can be expressed as a local slope:

$$
\mathrm{S}_{\mathrm{h}}=\frac{d h_{l}}{d x}
$$

where $\mathrm{dh}_{1}=$ swell head.

\section{A.2.3. Velocity Distribution Factor}

The velocity distribution factor, $\beta$, in the momentum equation, is determined in terms of velocity, flow and area in the flood plain and main channel as

$$
\beta=\frac{V_{c}^{2} A_{c}+V_{f}^{2} A_{f}}{V^{2} A}=\frac{\Delta\left(Q_{c} V_{c}+Q_{f} V_{f}\right)}{Q V}
$$

where the subscripts $\mathrm{c}$ and f refer to the channel and floodplain respectively, and

$$
\begin{aligned}
& \mathrm{V}=\text { velocity } \\
& \mathrm{Q}=\text { flow } \\
& \mathrm{A}=\text { cross sectional area }\left(\overline{A_{c}}+\overline{A_{f}}\right) \\
& \beta=\text { velocity distribution factor. }
\end{aligned}
$$

The discrete form can be written as:

$$
\Delta(\beta Q V)=\Delta\left(Q_{c} V_{c}+Q_{f} V_{f}\right)
$$

\section{A.2.4. Critical Section Factor, Effective Depth and Effective Width}

HEC-RAS 4.0 calculates the Froude number to examine whether the flow regime is subcritical or supercritical. The Froude number is expressed as

$$
F r=\frac{v}{\sqrt{g D}}
$$

If the Froude number is less than 1, the flow is subcritical; if it is greater than 1, the flow is supercritical; and if it is equal to 1 , the flow is critical. The critical water depth is is the depth for which the total energy head is a minimum (the minimum specific energy for the cross section). The critical depth is determined with an iterative procedure whereby the water surface elevations are assumed and corresponding values of flow depth are determined from the total head energy equation until a minimum value for flow depth is reached. The total head energy equation is given as 


$$
H=W S+\frac{\alpha V^{2}}{2 g}
$$

where

$\mathrm{H}=$ total energy head

WS $=$ water surface elevation

$\frac{\alpha V^{2}}{2 g}=$ velocity head

\section{A.2.5. Numerical Solution}

The unsteady flow equations are non-linear. The Newton -Raphson technique can be used to solve these equations but the process is rather slow. To avoid the non-linear solution, the Preissmann Implicit Finite Difference scheme is used for the solution .

\section{A.3. HEC-RAS Quasi-unsteady Flow Model - Sediment Transport}

\section{A.3.1. Governing Equation}

Different sediment transport functions are available in HEC-RAS. They are:

- Ackers and White (1973)

- Engelund and Hansen (1972)

- Copeland's form of Laursen (1990)

- Meyer - Peter and Muller (1948)

- Toffaleti

- Yang (both sand and gravel Equations.)

- Wilcock

These functions are selected on the basis of their validity and collective range of applicability. For the given initial condition and transport parameters, the Ackers \& White, Laursen (Copeland) and Yang equations were selected as the transport functions most relevant to the Rillito River.

The Ackers \& White method is a total load transport relation developed under the assumption that fine sediment transport is best related to the turbulent fluctuations in the water column and coarse sediment is best related to the net grain shear with the mean velocity used as the representative variable. The transport function was developed in terms of particle size, mobility and transport. This method is applicable only to non-cohesive sands greater than $0.04 \mathrm{~mm}$, so only transition and coarse sediments apply. In the case of the Rillito River, the sediments are all larger than $0.04 \mathrm{~mm}$ with one exception, so this equation is applicable. The Ackers \& White equation is as follows: 


$$
X=\frac{G_{g r}(S G) d_{s}}{D\left(\frac{u_{*}}{V}\right)^{n}}
$$

where $\mathrm{X}=$ sediment concentration

$$
\begin{gathered}
G_{g r}=C\left(\frac{F_{g r}}{A}-1\right) \\
F_{g r}=\left(\frac{u_{*}{ }^{n}}{\sqrt{\frac{\rho_{s}-\rho}{\rho} g d_{s}}}\right)\left[\frac{U}{\sqrt{32} \ln \frac{a D}{d_{s}}}\right]
\end{gathered}
$$

The Laursen method is a total sediment load predictor, derived from a combination of qualitative analysis, original experiments, and supplementary data. The contributions extend to the gravel sized sediment and the applicability ranges from 0.011 to $29 \mathrm{~mm}$, median particle diameter. The general transport equation for the Laursen (Copeland) function for a single grain size is represented by:

$$
C_{m}=0.01 \gamma\left(\frac{d_{S}}{D}\right)^{7 / 6}\left(\frac{\tau_{o}^{\prime}}{\tau_{c}}-1\right) f\left(\frac{u_{o}}{\omega}\right)
$$

Yang's method (1973) was developed under the premise that unit stream power is the dominant factor in the determination of total sediment concentration. Yang (1984) expanded the applicability of his function to include the gravel-sized sediments. The general transport equation for sand and gravel using the Yang function for a single grain size is represented by

$$
\log C_{t}=5.435-0.286 \log \frac{w d}{v}-0.457 \log \frac{U_{*}}{w}+\left(1.799-0.409 \log \frac{w d}{v}-0.314 \frac{U_{*}}{w}\right) \log \left(\frac{V S}{w}-\frac{V_{c r} S}{w}\right)
$$

in which $C_{t}=$ total sand concentration by weight in $p p m=10^{6} \times \gamma_{s} q_{t} / \gamma q$, and the dimensionless critical velocity is defined by:

$$
\begin{gathered}
\frac{V_{c}}{w_{f}}=\frac{2.5}{\log \left(\frac{u_{*} d_{50}}{v}\right)-0.06}+0.66 \text { for } 1.2<\frac{u_{*} d_{50}}{v}<70 \\
\frac{V_{c}}{w_{f}}=2.05 \text { for } \frac{u_{*} d_{50}}{v} \geq 70
\end{gathered}
$$

\section{A.3.2. Selection of Fall Velocity Method}


Within HEC-RAS, there are four methods available for computing the fall velocity. The four methods are Toffaleti (1968), van Rijn (1993), Ruby (1933) and Report 12. Report 12 is the default method in HEC6 and is recommended by the American Society of Civil Engineers (ASCE).

The Ruby Method was used for computing the fall velocity during completion of this project. The fall velocity is based on a combination of Stoke's law and (for fine particles subject only to viscous resistance) an impact formula (for large particles outside of the Stoke's region). This equation has been shown to be adequate for silt, sand and gravel grains. Ruby suggested that particles of the shape of crushed quartz grains, with a specific gravity of approximately 2.65 are the most applicable for his equation. Ruby's equation is given as:

$$
\omega=F_{1} \sqrt{(s-1) g d_{S}}
$$

in which

$$
F_{1}=\sqrt{\frac{2}{3}+\frac{36 v^{2}}{g d^{3}(s-1)}}-\sqrt{\frac{36 v^{2}}{g d^{3}(s-1)}}
$$

\section{A.3.3. Equilibrium Depth}

Sediment control volume is from midway from the next cross section upstream and ends midway to the next cross section downstream. The vertical thickness of the sediment control volume can be specified by maximum depth or minimum elevation. Maximum depth is used to specify the vertical thickness of the sediment control volume. It allows setting the control volume depth as a distance below the original invert of the channel. When the maximum depth is entered, HEC-RAS computes the minimum erodible elevation as the original channel invert elevation minus the maximum depth. Essentially, maximum depth indicates the maximum allowable depth of erosion at any particular cross section.

Since the bed material of the Rillito River is sand and there are no bedrock outcroppings, there will be indefinite erosion in the case of the Rillito River. As a result, the model was run for 10 feet maximum erodible depth for all three of the chosen transport equations.

\section{A.3.4. Hydraulic Sorting of Bed Material}

Two sorting methods are available in HEC-RAS 4.0: the Exner 5 method and the active layer method. Exner 5 is a three-layer active bed model that includes the capability of forming a coarse surface layer that will limit erosion of deeper material, thereby simulating bed armoring, and is the default method in HEC-RAS 4.0. The Exner equation is given as:

$$
B\left(1-p_{o}\right) \frac{\partial z_{b}}{\partial t}+\frac{\partial Q_{t}}{\partial x}=0
$$

where

$$
\begin{aligned}
& p_{0}=\text { porosity } \\
& \mathrm{Z}_{\mathrm{b}}=\text { bed elevation }
\end{aligned}
$$


$\mathrm{Q}_{\mathrm{t}}=$ volumetric sediment transport rate

$\mathrm{x}=$ longitudinal distance.

The active layer method is a two layer active bed approach and is only valid for sandy bed materials when bed armoring does not exist. For the Rillito river, the Exner 5 method was used because the amount of gravels in the bed material may form an armoring preventing fine material from transport.

\section{A.3.5. Network Model}

A "network model" is the looped system where river reaches (segments) split apart and then come back together. HEC-RAS beta is capable of simulating hydraulics and sediment transport in the river network system. HEC-RAS computes the water surface elevations at all locations for either a given set of flow data or by routing hydrographs through the system. HEC-RAS defines the network with segments and control points. A segment is a part of a river system that gathers data both upstream (water and sediment) and downstream at a control point. Also, additional data upstream is gathered in order to evaluate any upstream impacts due to construction alternatives that are being evaluated within the segment. Different control points are in the network system where water and sediment flow from a high level tributary to a low level one. Different segments and control points are connected and are named or numbered to describe the sequence of the network easily.

The connectivity of the segments is very important in order to understand how the computation should proceed from one segment to the other. The control point is the downstream when the flow is subcritical whereas the control point is the upstream when the flow is supercritical. The computation sequence of the water surface profile is from downstream to upstream for the subcritical case. Each profile is calculated first from the downstream boundary to the upstream end of the main stem, and then the model comes back to each control point and goes up along every tributary. The sediment computations are carried out in the reverse sequence. The model calculates the most remote tributary first to determine its contribution to the next segment. After all sediment computations for the tributary are completed, computations proceed to the next segment, with the main stem last. The current version of the HEC-RAS does not determine the amount of flow going to each segment at a flow split. After the simulation is made, the flow should be adjusted in each segment in order to obtain a balance in energy around the junction of a flow split.

\section{A.4. Summary}

HEC-RAS has been extensively applied worldwide to perform one-dimensional steady and unsteady flow river hydraulic calculations. Its capability for sediment simulation is also developed and is able to perform sediment transport and mobile bed computations, along with the water quality analysis. The model is applicable to supercritical, subcritical, and mixed flow conditions. All four components of the model share common geometric data and common routines for geometric and hydraulic computations. The full network of natural and constructed channels can be simulated with 
this model. HEC-RAS is designed to perform the one dimensional hydraulic calculation in the channel.

The first component, steady flow water surface profiles, is intended for calculating water surface profiles for steady gradually varied flow. A single river reach, a dendritic system, or a full network of channels can be simulated by this model. The model solves the one-dimensional energy equation to obtain the hydraulics of the channel system. The momentum equation is also utilized for the rapidly varied case. The second component, unsteady flow simulation, is intended for simulating one dimensional unsteady flow through a full network of open channels. The hydraulic calculation for the steady flow component is incorporated into the unsteady flow module. The unsteady flow equation solver is adapted from the UNET model. It has the ability to model storage areas and hydraulic connections between storage areas, as well as between stream reaches. The third component, sediment transport and mobile bed computations, is intended for the simulation of onedimensional sediment transport calculations resulting from the scour and deposition over a period of time. The model is designed to evaluate the volume as well as the location of deposition in reservoirs, simulate channel scour and armoring processes, provide guidance for various channel, levee, and encroachment alternatives, dredging activity and channel contraction design for navigation, estimate maximum possible scour during large flood events, and evaluate sedimentation in fixed channels. The sediment transport is uncoupled from the hydraulics and calculated by solving the sediment continuity equation. Different sediment transport functions are used for this purpose. The fourth component, water quality analyses, is intended to perform the water quality analyses.

In this model, the channel consists of a main channel and overbanks. Users can designate the movable and immovable parts in a cross section. Manning's roughness and the expansion/ contraction coefficients are utilized in the model. Water surfaces of different discharges inundate different nodes with different elevations along the cross section, and therefore can result in different deposition or scour at one cross section.. Contraction and expansion is counted in the model by considering the energy loss induced by channel width variation.

The sediment transport module can simulate non-cohesive bed material load with the default sediment transport functions, whereas for cohesive bed material load, either standard transport equations or the Krone and Partheniades approach is necessary. HEC-RAS does not treat the bed load and suspended load separately but solves as the total bed load. The model presents Active layer and Exner 5 as the two sorting methods to simulate the streambed armoring process. Four different types of fall velocity methods are also available, among which Report 12 is recommended by the ASCE.

HEC-RAS Beta is a user friendly software which is comprised of a graphical user interface, separate analysis components, data storage, and management capabilities, with both graphical and tabular reporting facilities. However, the sediment transport function is being modified in the later versions and expected to improve significantly in the new software. 


\section{Appendix B. HEC-6 Model}

HEC-6 is a one-dimensional numerical model for steady open channel flow designed to calculate changes in river bed profiles resulting from scour or deposition. The HEC of the Institute for Water Resources (IWR) of the USACE developed the original version. This model can be used to evaluate the sediment deposition in reservoirs, design channel contractions required to maintain navigation depths or decrease the volume of maintenance dredging, predict the influence of dredging on the rate of deposition, estimate possible maximum scour during large flood events, and evaluate sedimentation in fixed channels.

In HEC-6, flow hydraulics and sediment transport simulations are decoupled. A continuous flow hydrograph is approximated with a series of steady flows of variable discharges and durations. For each flow, it employs the one-dimensional energy equation to compute the water surface profile and thereby provides velocity, energy slope, depth, etc., at each cross section. Equilibrium sediment transport processes are then computed at each section. Sediment transport rates are calculated by size fractions, thereby allowing the simulation of hydraulic sorting and armoring.

Development of HEC-6 began in the 1970's; the latest version of HEC-6, Version 4.1, was released in 1993. It runs on a DOS or Windows platform in a command line manner. There has been no further development since version 4.1. New generations of HEC software packages are under development at present, in which HEC-RAS will be enhanced with the functionality of HEC-6. In contrast to HEC-6, HEC-RAS software has many advantages not only in the easy-to-use graphic interface which could perform the data input, model run, and results analysis, but also in modeling capabilities such as the unsteady flow simulation. The sediment transport has been weak in HECRAS until now, but improvements are expected in the near future.

\section{B.1. Flow Hydrodynamics}

\section{B.1.1. Governing Equations}

The governing equation for the one-dimensional, steady-state, open channel flow calculation is the energy equation,

$$
W S_{2}+\frac{\alpha_{2} V_{2}^{2}}{2 g}=W S_{1}+\frac{\alpha_{1} V_{1}^{2}}{2 g}+h_{e}
$$

where

$g=$ acceleration of gravity

$h_{e}=$ energy loss of flow between cross section 1 and 2

$V_{1}, V_{2}=$ cross section average velocities at both ends of a reach

$W S_{1}, W S_{2}=$ water surface elevations at the ends of a reach

$\alpha_{1}, \alpha_{2}=$ velocity distribution coefficients for flow at the ends of a reach. 
The water discharge hydrograph is approximated by a sequence of steady flow discharges, each of which continues for a specified period of time. Water surface profiles are calculated for each flow after the energy losses are determined.

The downstream water surface elevation must be specified as the boundary condition for subcritical flow. In the case of a reservoir, the operating rule may be applied. A boundary condition or operating rule may be used at any location along the main stream or tributaries of the study domain.

\section{B.1.2. Hydraulic Losses}

The hydraulic loss is composed of friction loss, $h_{e}$, and, form losses, $h_{o}$.

$$
h_{e}=h_{f}+h_{o}
$$

Friction loss is calculated by Manning's equation

$$
h_{f}=\left[\frac{Q}{K_{t}^{\prime}}\right]^{2}
$$

in which

$$
K_{t}^{\prime}=\sum_{j=1}^{N S S}\left[\frac{1}{n_{j}}\right] \frac{\frac{\left(A_{2}+A_{1}\right)_{j}}{2}\left[\frac{R_{2}+R_{1}}{2}\right]_{j}^{2 / 3}}{L_{j}^{1 / 2}}
$$

where:

$A_{1}, A_{2}=$ downstream denoted " 1 " and upstream denoted " 2 " wetted areas of the cross sections

NSS $=$ total number of subsections across each cross section

$L_{j}=$ length of the jth strip between subsections

$n=$ Manning's roughness coefficient

$Q=$ water discharge

$R_{1}, R_{2}=$ downstream and upstream hydraulic radius, respectively

$K_{t}^{\prime}=$ length-weighted subsection conveyance

Each cross section is characterized by a number of nodes along the transverse direction of the streambed. It is also divided into subsections of trapezoidal shapes, usually consisting of a main channel and left and right overbanks. In each time step, the area of each cross section is computed by summing the areas of each subsection below the water level. 
Only contraction and expansion losses are considered as form loss, and calculated as

$$
h_{o}=C_{L}\left|\frac{\alpha_{2} V_{2}^{2}}{2 g}-\frac{\alpha_{1} V_{1}^{2}}{2 g}\right|
$$

where $C_{L}$ is loss coefficient for expansion or contraction. If the quantity within the absolute value notation is negative, flow is contracting and $C_{L}$ is the coefficient of contraction; if it is positive, flow is expanding and $C_{L}$ is the coefficient of expansion.

The Manning's coefficient is determined by the Strickler's equation

$$
n=\frac{d^{1 / 6}}{24}
$$

where $d$ is the grain size.

For bed material mixture, the Manning's coefficient is based upon bed gradation is calculated by Limerino's (1970) relationship

$$
n=\frac{0.076 R^{1 / 6}}{1.16+2.0 \log _{10}\left(\frac{R}{d_{84}}\right)}
$$

The model can process supercritical flow as well as subcritical flow. However, it does not account for the head loss caused by the hydraulic jump or fall, and therefore cannot handle the subcritical to supercritical flow transition.

\section{B.1.3. Velocity Distribution Factor}

The velocity distribution factor, $\alpha$, in the energy equation, is determined as

$$
\alpha=\frac{\sum_{j=1}^{N S S}\left|\frac{K_{j}^{3}}{A_{j}^{2}}\right|}{\left|\frac{K_{t}^{3}}{A_{t}^{2}}\right|}
$$

in which $K_{j}$ is computed for each subsection $j$ by

$$
K_{j}=\frac{1}{n_{j}} A_{j} R_{j}^{2 / 3}
$$

where $A_{j}$ is the area of the $j$ th subsection and $A_{t}$ and $K_{t}$ are 


$$
A_{t}=\sum_{j=1}^{N S S} A_{j}, \quad K_{t}=\sum_{j=1}^{N S S} K_{j}
$$

\section{B.1.4. Critical Section Factor, Effective Depth and Effective Width}

HEC-6 uses the critical section factor, $C R T$, to examine whether the flow regime is subcritical or supercritical. It is expressed as

$$
C R T=\frac{Q}{\left(\frac{g}{\alpha}\right)^{1 / 2}}
$$

$C R T$ is compared with the computed section factor $Z S Q$. If $C R T$ is less than $Z S Q$, the flow is subcritical. Otherwise the flow is supercritical. $Z S Q$ is calculated as

$$
Z S Q=A_{t}\left(\frac{A_{t}}{W_{t}}\right)
$$

where $W_{t}$ is the width of water surface. If supercritical flow exists, the model approximates the channel geometry using the effective depth, EFD, and width, EFW, and determines the water surface elevation based upon the supercritical normal depth. EFD and $E F W$ are

$$
\begin{aligned}
& E F D=\frac{\sum_{i=1}^{i_{t}} D_{a v g} \cdot a_{j} \cdot D_{a v g}^{2 / 3}}{\sum_{i=1}^{i_{t}} a_{j} \cdot D_{a v g}^{2 / 3}} \\
& E F W=\frac{\sum_{i=1}^{i_{t}} a_{j} \cdot D_{\text {avg }}^{2 / 3}}{E F D^{5 / 3}}
\end{aligned}
$$

where

$$
\begin{aligned}
& a_{i}=\text { flow area of each trapezoidal element } \\
& D_{a v g}=\text { average water depth of each trapezoidal element } \\
& i_{t}=\text { the total number of trapezoidal elements in a subsection. }
\end{aligned}
$$

$E F D$ and $E F W$ are also used in the sediment transport calculation. The sediment transport capacity for non-rectangular sections is calculated by $E F D$ and $E F W$.

\section{B.1.5. Numerical Solution}

Once the downstream water level is assigned, the water surface profile computation progresses upstream based on the energy equation. A trial, or relaxation iterative, method is adopted in HEC-6 to implement this calculation. The first-step iteration uses a relaxation factor of 0.9 , and in the later steps this factor changes according to the computational values and assumed values in the last two steps. 


\section{B.2. Sediment Transport}

\section{B.2.1. Governing Equation}

In HEC-6, the bed elevation change is obtained by solving the Exner sediment continuity equation

$$
\frac{\partial G}{\partial x}+B_{o} \cdot \frac{\partial Y_{s}}{\partial t}=0
$$

where

$B_{o}=$ width of movable bed, specified by the user for each cross section

$G=$ average sediment discharge during time step $\Delta t$

$Y_{s}=$ depth of sediment in control volume.

Unlike the flow energy equation that is written between cross sections, the sediment continuity equation is written for a control volume. Each control volume is surrounded by cross sections. The width of the control volume is usually equal to the width of movable bed and its depth extends from the water surface to the top of non-erodible bed layer. The upstream and downstream interfaces of the control volume are at the midpoints of the upstream and downstream reaches around the cross section, respectively. The amount of sediment and flow in a control volume are

$$
V_{\text {sed }}=B_{o} \cdot Y_{s} \cdot \frac{L_{u}+L_{d}}{2}, \quad V_{f}=B_{o} \cdot D \cdot \frac{L_{u}+L_{d}}{2}
$$

where

$$
\begin{aligned}
& L_{u}, L_{d}=\text { length of the upstream and downstream reach } \\
& V_{\text {sed }}, V_{f}=\text { volume of sediment and fluid in control volume. }
\end{aligned}
$$

The discretized form of the sediment continuity equation is

$$
\frac{G_{d}-G_{u}}{0.5\left(L_{d}+L_{u}\right)}+\frac{B_{s p}\left(Y_{s p}^{\prime}-Y_{s p}\right)}{\Delta t}=0
$$

where

$B_{s p} \quad=$ width of movable bed at the cross section in the control volume

$G_{u}, G_{d} \quad=$ sediment load at the upstream and downstream cross section

$Y_{s p}^{\prime}, Y_{s p}=$ depth of sediment at the cross section before and after the time step.

HEC-6 adopts the equilibrium transport mode. It assumes that the transport capacity can be satisfied within each time step for each control volume as long as the sediment is available. HEC-6 provides thirteen sediment transport functions for bed material load including

a. Toffaleti's (1966) transport function 

b. Madden's (1963) modification of Laursen's (1958) relationship
c. $\quad$ Yang's (1973) stream power for sands
d. DuBoys' transport function (Vanoni 1975)
e. Ackers-White (1973) transport function
f. Colby (1964) transport function
g. Toffaleti (1966) and Schoklitsch (1930) combination
h. Meyer-Peter and Müller (1948)
i. $\quad$ Toffaleti and Meyer-Peter and Müller combination
j. $\quad$ Madden's (1985, unpublished) modification of Laursen's (1958) relationship
k. Modification by Ariathurai and Krone (1976) of Parthenaides' (1965) method for scour and Krone's (1962) method for deposition of cohesive sediments
1. Copeland's (1990) modification of Laursen's relationship (Copeland and Thomas 1989)

User specification of transport coefficients is based upon observed data. These functions are applied to each individual grain size. For mixture, the transport rate is the weighted average of all size classes with the weighting coefficients equal to the fraction of each size class.

\section{B.2.2. Equilibrium Depth}

Equilibrium depth is the minimum depth of a grain size of which the sediment transport is negligible under the given unit discharge. It is determined from Einstein's equation,

$$
\psi=\frac{\rho_{s}-\rho_{f}}{\rho_{f}} \cdot \frac{d}{D S_{f}}
$$

and Manning's equation,

$$
V=\frac{1}{n} D^{2 / 3} S_{f}^{1 / 2}
$$

where $\psi$ is transport intensity from Einstein's bed load function, and $q$ is the unit discharge. For bed load transport is negligible, $\psi$ equals 30 or larger.

\section{B.2.3. Hydraulic Sorting of Bed Material}

Two methods are provided in HEC-6 for bed material sorting calculation. Method 1 divides the streambed into an active layer and the underlying inactive layer. The active layer can exchange with the flow and inactive layer. Method 1 first evaluates the stability of the active layer in the bed. The bed stability coefficient is 


$$
B S F=\frac{\sum_{i=1}^{N G S} P R O B \cdot P R O B \cdot P I_{i} \cdot d_{m i}}{\sum_{i=1}^{N G S} P R O B \cdot P I_{i} \cdot d_{m i}}
$$

where

$d_{m i} \quad=$ median grain diameter for grain size class $i$

$N G S=$ number of grain sizes present

$P I_{i} \quad=$ fraction of bed composed of grain size class $i$

$P R O B=$ probability that grains will stay in the bed

A stability factor equal to or greater than 0.65 indicates a stable armor layer and the bed material is taken from the active layer until enough stable grains are left to cover the bed to the depth of one stable grain size. For each size class, this method calculates an equilibrium depth. The smallest size, $d_{a}$, which corresponds to an equilibrium depth greater than the flow depth, is defined as the smallest stable grain size. The model then calculates the depth of bed material that must be removed to reach equilibrium in a time step with consideration of $d_{a}$. This depth is used to calculate an equilibrium depth for the mixture of multiple grain sizes. HEC- 6 designates the zone of material between the bed surface and equilibrium depth as the active layer and the zone from equilibrium depth to the model bottom as the inactive layer. After the depth of the active layer has been calculated, Method 1 completes the bed change calculation for that cross section.

Method 2 is an algorithm based on the concept that exchange of sediment particles occurs within a thin "cover layer" of bed material at the bed surface. The active layer is divided into two layers: a cover layer that is retained from the previous time step, and a sub-surface layer that is created at the beginning of the time step from the inactive layer. The thickness of the subsurface layer is based on the equilibrium depth. In each time step, deposited material is placed in the cover layer. Eroded material is removed from the cover layer first. If there is an insufficient amount of a specific size class present in the cover layer to meet the sediment transport capacity, material may be withdrawn from the subsurface layer. However, if there is enough volume of coarser-sized particles in the cover layer to cover the bed to a thickness of one grain diameter, the subsurface layer cannot provide the fine material in this case. At the end of every time step, subsurface layer is mixed with the inactive layer and the new cover layer, sub-surface layer and inactive layer will be set again.

The concept of an entrainment coefficient is introduced in HEC-6. This coefficient is used to determine what percentage of the equilibrium concentration could be achieved in that reach. It is determined as

$$
E T C O N=1.368-e^{-E N T R L R}
$$

where ENTRLR is the entrainment ratio associated with the rate at which the flow approaches its equilibrium load and is calculated as

$$
E N T R L R=\frac{R E A C H \text { LENGTH }}{30 \cdot D E P T H}
$$


in which the 30 times flow depth is similar to the adaptation length for the unsaturated sedimentladen flow.

When deposition occurs, the model calculates the deposition by size fractions and introduces a coefficient for sediment deposition rate as

$$
D E C A Y(i)=\frac{V_{s}(i) \Delta t}{D_{s}(i)}
$$

where

$D_{s}(i)=$ effective depth occupied by sediment size $i$

$V_{s}(i)=$ settling velocity.

For cohesive sediment deposition, the Krone (1962) equation is used

$$
\frac{C}{C_{0}}=\exp \left(-k^{\prime} t\right)
$$

where $C_{o}, C=$ concentration at the beginning and end of each time period

$K^{\prime}=V_{s} P_{r} / 2.3 D$

$D$ = water depth

$P_{r}=$ probability that a floc will stick to bed $\left(1-T_{b} / T_{d}\right)$

$t=$ reach length/flow velocity

$T_{b}=$ bed shear stress

$T_{d}=$ critical bed shear stress for deposition.

For cohesive sediment scour, the Parthenaides (1965) equation adapted by Ariathurai and Krone (1976) is employed

$$
C=\frac{M_{1} S_{a}}{Q \gamma}\left[\frac{T_{b}}{T_{s}}-1\right]+C_{0}
$$

The consolidation is accounted for the consolidated unit weight

$$
\gamma=\gamma_{1}+B \cdot \log _{10} T
$$

where $B=$ coefficient of consolidation for silts or clay

$T=$ accumulated time in years

$\gamma_{1}=$ initial unit weight of the sediment deposit, usually after one year of consolidation 


\section{B.2.4. Network Model}

HEC-6 is capable of simulating hydraulics and sediment transport in the river network system. HEC-6 defines the network with segments and control points. A segment is a part of a river system that has upstream water and sediment inflow and downstream termination at a control point. The network is connected by the control points at which water and sediment flow from a high level tributary into a low-level one. Segments and control points are numbered so that the structure and the sequence of the network can be described by the numbers.

The computation sequence of the water surface profile is from downstream to upstream and from main stem to tributaries. Each profile is calculated first from the downstream boundary to the upstream end of the main stem, and then the model comes back to each control point and goes up along every tributary. The sediment computations are carried out in the reverse sequence. The model calculates the most remote tributary first to determine its contribution to the next segment. After all sediment computations for the tributary are completed, computations proceed to the next segment, with the main stem last.

\section{B.3. Conclusion}

For decades, HEC-6 has been extensively applied worldwide. Its capability for sediment simulation is widely accepted. HEC-6 is capable of modeling one-dimensional, steady-state open channel flow, nonuniform equilibrium sediment transport, and streambed morphological processes. The model is applicable to supercritical as well as subcritical flow conditions, except for the subcritical to supercritical transition. A stream network system can be simulated with this model. HEC-6 is designed to simulate long-term trends of scour or deposition in the channel. It can be used to evaluate the volume as well as the location of deposition in reservoirs, simulate channel scour and armoring processes, provide guidance for dredging activity and channel contraction design for navigation, and estimate large flood scour events, among others. When applying the model to simulate a single flood event, the accuracy will be significantly reduced because of the simlifications in flow hydraulic model and the uncertainties in sediment transport rate.

The model solves the one-dimensional energy equation to obtain the hydraulics of the channel system. The sediment transport is uncoupled from the hydraulics and calculated by solving the sediment continuity equation.

In this model, the channel is divided into strips along the transversal direction and consists of a main channel and overbanks. Users can designate the movable and immovable parts in a cross section. Water surfaces of different discharges inundate different nodes with different elevations along the cross section, and therefore can result in different deposition or scour at one cross section. To a certain degree, it exhibits the two-dimensional effect in the channel. However, the eroded bed material was evenly distributed along the wetted perimeter after each computation of bed elevation change.

The energy equation properly describes the steady-state hydraulics. The algebraic form avoids

the trouble of solving the differential equations. Contraction and expansion are accounted for in the model by considering the energy loss induced by channel width variation. 
The sediment transport module can simulate the non-cohesive and cohesive bed material load as the total load; it does not treat the bed load and suspended load separately. The model presents two methods to simulate the streambed armoring process. The concepts of the active layer and the inactive layer in the bed are introduced in these methods for the computation of sediment exchange between flow and bed. In method 2, the active layer is further divided into a cover layer and subsurface layer. Method 2 is more accurate than method 1 since it partially avoids the over-mixing in the whole bed layer of sediment and the process is more close to nature. It considers the mechanism of non-equilibrium sediment transport, but that is quite limited. The sediment transportation equation is not included in this method, nor in method 1. The expression of entrainment ratio is highly empirical and does not account for the effect of sediment concentration in the flow. The mixing mechanism between the layers in the bed is also based on modeling rules, and therefore, is different from the real process.

Since the model is for sediment transport computation of steady-state flow, the discharges for each time-step are the same everywhere along the main channel. Thus the model cannot be applied to a long reach of the channel in which the unsteady characteristics of flow are not negligible.

The equilibrium sediment transport modeling method determines that the time step of sediment computing cannot be too small to result in instabilty. Otherwise the sediment-laden flow may approach equilibrium in a short time. The same is for the armoring process of the streambed. Cohesive sediment deposition, scour and consolidation could be simulated in this model. Bank stability and erosion are not considered.

HEC-6 is now available on DOS and Windows platforms. A graphical user interface is not included in HEC-6, but is provided in the new generation of HEC software. The sediment transport function is expected to improve significantly in the new software as well. 


\section{Appendix C. IALLUVIAL2 Model}

IALLUVIAL2 is a quasi-unsteady, one-dimensional water and sediment routing model for short- or long-term simulation of water surface and bed evolution of alluvial channels. IALLUVIAL2 has adopted convenient data input and output to facilitate applications in professional engineering practice as well as in numerical experimentation and research for alluvial channel flows. The computer program IALLUVIAL2 is the successor to the program IALLUVIAL developed at the Iowa Institute of Hydraulic Research (IIHR), University of Iowa. IALLUVIAL was conceived and initially developed in 1982 by Professor John F. Kennedy and Dr. Fazle Karim at IIHR.

\section{C.1. Flow Hydrodynamics}

\section{C.1.1. Governing Equations}

The governing flow equation for steady-state, one-dimensional open channel flow is the energy equation in the form

$$
\frac{d}{d x}\left(z+d+\frac{Q^{2}}{2 g A^{2}}\right)=S_{f}
$$

where

$$
\begin{aligned}
& \mathrm{z}=\text { bed elevation } \\
& \mathrm{d}=\text { water depth } \\
& \mathrm{Q}=\text { water discharge } \\
& \mathrm{A}=\text { cross sectional area } \\
& \mathrm{S}_{\mathrm{f}}=\text { energy slope }
\end{aligned}
$$

Eq. (C.1) is the differential form of energy equation, and its integration gives the usual form as in Eq.A.1. The initial and boundary conditions that are necessary for a solution are: intial $\mathrm{z}$ and sediment size distribution at all computational points, known water and sediment discharge hydrographs at the upstream boundary, and a known stage hydrograph or rating curve at the downstream end. IALLUVIAL 2 provides two options for the downstream boundary; in the case that a downstream water surface elevation is known, the rating curve or a known water surface elevation can be directly imposed. In most cases in natural rivers, this is not known, and the model will calculate the downstream water surface elevation based on known values of $\mathrm{Q}$ and $\mathrm{d}_{50}$, as well as bed slope at the downstream end. For quasi-steady state analysis the flow discharge hydrograph is divided into discrete time intervals, with each interval having a steady discharge.

\section{C.1.2. Hydraulic Losses}

Hydraulic losses are computed as the sume of boundary friction loss and form loss. Friction loss is obtained from Manning's equation or other friction factor formulations. Form loss is estimated from contraction and expansion losses and calculated using equation (B.5). 


\section{C.1.3. Numerical Solution}

The defualt option for numerical solution in IALLUVIAL 2 is an uncoupled approach, in which energy equation is first solved to obain water surface elevations and other hydraulic variables, from downstream to upstream for subcritical flow or upstream to downstream for supercritical flow. Sediment continuity, sorting, and armoring equations are then applied upstream to downstream to calculate changes in bed elevations and sediment characteristics. In addition to this uncoupled approach, an option is provied in the program, in which an iterative coupling strategy is used to solve the energy, sediment, friction, and channel geometry equations simultaneously. The river reach is divided into subreaches, and the computations for each are performed for successive, discrete time intervals. At each time step, the governing equations are solved first in a backwater, upstream sweep, as outlined below, then the sediment continuity equation is solved. The computation of the water surface profile proceeds from the downstream boundary to the upstream. Since the solution to the energy equation is here not assumed to change with time, at each time step the following iterations take place:

1. load imposed boundary conditions: both mainstem and tributary water and sediment inflows, downstream water surface elevation.

2. using the latest estimate of $\mathrm{z}$ as a fixed bed elevation and using latest estimates of $\mathrm{d}_{50}$ and armoring factor, the depth, cross sectional area, energy slope, water surface width, and sediment discharge are computed at each point by simultaneous solution of all equations mentioned above.

3. Using the values of sediment discharge and water surface width computed in step 2, a new estimate of bed elevation $\mathrm{z}^{\mathrm{n}+1}$ is calculated using a Preissman finite-difference approximation.

4. using this new bed elevation estimate, new estimates for armoring factor and $\mathrm{d}_{50}$ are computed.

Steps 2 through 4 are repeated until successive estimates of $z^{n+1}$ no longer change significantly. At this point convergence is assumed to be reached.

This computational procedure for sediment discharge, friction factor, and water surface profile is applied at all cross sections and nodes.

\section{C.2. Sediment Transport}

\section{C.2.1. Governing Equation}

IALLUVIAL 2 solves the sediment continuity equation,

$$
(1-p) B \frac{\partial z}{\partial t}+\frac{\partial Q_{s}}{\partial x}=0
$$

where 


$$
\begin{aligned}
& \mathrm{p}=\text { sediment porosity } \\
& \mathrm{x}=\text { longitudinal coordinate } \\
& \mathrm{Qs}=\text { sediment discharge } \\
& \mathrm{B}=\text { water surface width }
\end{aligned}
$$

Channel geometry is represented as:

$$
\begin{aligned}
& \mathrm{A}=\mathrm{A}(\mathrm{d}, \mathrm{x}) \\
& \mathrm{B}=\mathrm{B}(\mathrm{d}, \mathrm{x})
\end{aligned}
$$

IALLUVIAL 2 treats open channel flow as one-dimensional and quasi-steady state. At each time step the equations of fluid motion and continuity, friction-factor, and sediment discharge and continuity are solved. After the first computational stage, the backwater sweep is completed, then the sediment continuity equation is solved for each sub-reach to yield aggradation or degradation depths and changes in bed armoring.

The Total-Load Transport Model (TLTM) developed by Karim and Kennedy is used for the sediment and friction-factor predictors. Since friction factors of alluvial streams are dependent on their sediment discharges, the model does not specify a fixed hydraulic roughness unless the Manning's equation is used. Instead, the sediment-discharge and friction factor predictors are used in an iterative scheme.

The sediment discharge predictor

$$
\log \left(\frac{g_{s}}{\sqrt{g(s-1) d_{50}^{3}}}\right)=-2.2786+2.9719 \log V_{1}+1.06 \log V_{1} \log V_{3}+0.2989 \log V_{2} \log V_{3}
$$

where $V_{1}=v / \sqrt{g(s-1) D_{50}} ; V_{2}=d / D_{50} ; V_{3}=\left(u_{*}-u_{*}\right) / \sqrt{g(s-1) D_{50}}$

and the friction-factor predictor

$$
\log \left(\frac{U}{\sqrt{g(s-1) d_{50}}}\right)=-0.4812+0.3761 \log V_{4}+0.3106 \log V_{5}
$$

where $V_{4}=q / \sqrt{g(s-1) D_{50}^{3}} ; \quad V_{5}=S \cdot 10^{3}$

are the model's version of the Karim-Kennedy relation. Variables used in this form of the KarimKennedy equation are defined as

$q_{s}=$ sediment discharge $\left(f t^{3} / \mathrm{sec} / f t\right)$

$\mathrm{U}=$ averaged velocity $(\mathrm{ft} / \mathrm{s})$ 
$\mathrm{g}=$ gravitational acceleration

$\mathrm{s}=$ specific gravity of sediment

$D_{50}=$ median sediment size $(\mathrm{ft})$

$\mathrm{D}=$ hydraulic depth (ft)

$u_{*}=$ shear velocity $(\mathrm{ft} / \mathrm{s})$

$u_{*_{c}}=$ critical shear velocity $(\mathrm{ft} / \mathrm{s})$

$\mathrm{Q}=$ unit water discharge

$\mathrm{S}=$ energy slope $(\mathrm{ft} / \mathrm{ft})$

These interdependent relations are solved iteratively and simultaneously.

The sediment continuity equation (C.3) is discretized to calculate total degradation, where $\left[\left(\mathrm{q}_{\mathrm{s}}\right)_{\mathrm{i}}>\left(\mathrm{q}_{\mathrm{s}}\right)_{\mathrm{i}+1}\right]$, or total aggradation, where $\left[\left(\mathrm{q}_{\mathrm{s}}\right)_{\mathrm{i}}<\left(\mathrm{q}_{\mathrm{s}}\right)_{\mathrm{i}+1}\right]$ in reach $\mathrm{i}$. The form then becomes

$$
d_{s i}=\frac{\left(q_{s}\right)_{i}-\left(q_{s}\right)_{i+1}}{1-p} \frac{\Delta t}{\Delta x}
$$

or

$$
d_{a i}=\frac{\left(q_{s}\right)_{i+1}-\left(q_{s}\right)_{i}}{1-p} \frac{\Delta t}{\Delta x}
$$

where $\Delta \mathrm{x}=$ subreach length and $\Delta \mathrm{t}=$ time interval. The total degradation $\mathrm{d}_{\mathrm{si}}$ in subreach $\mathrm{i}$ is distributed among the different sediment size fractions in proportion to the fraction of transported sediment in that size fraction according to the relation

$$
\left(\delta_{\mathrm{i}, \mathrm{k}}\right)_{\mathrm{t}}=\mathrm{d}_{\mathrm{si}} \mathrm{p}_{\mathrm{di}, \mathrm{k}}
$$

where $p_{\mathrm{di}, \mathrm{k}}=$ fraction of sediment discharge in size interval $\mathrm{k}$ and reach $\mathrm{i}$, and is calculated from the the Karim-Kennedy relation (1981)

$$
p_{d i, k}=\frac{p_{i, k}\left(\frac{D_{50 i}}{D_{k}}\right)^{x}}{\sum_{k=1}^{m} p_{i, k}\left(\frac{D_{50 i}}{D_{k}}\right)^{x}}
$$

where

$P_{i, k}=$ fraction of bed material in the kth fraction in subreach $\mathrm{i}$

$\mathrm{D}_{50 \mathrm{i}}=$ median bed-material size in subreach $\mathrm{i}$

$\mathrm{D}_{\mathrm{k}}=$ geometric mean size of fraction $\mathrm{k}$ 
$\mathrm{m}=$ total number of sediment-size intervals

and $\mathrm{x}$ is given by

$$
x=0.0316\left(\frac{d}{D_{50 i}}\right)^{0.50}
$$

where $d=$ average flow depth in reach $i$. The depth of deposited materials in each size fraction during aggradation is calculated from

$$
\left(\delta_{\mathrm{i}, \mathrm{k}}\right)_{\mathrm{t}}=\mathrm{d}_{\mathrm{ai}} \mathrm{p}_{\mathrm{di}, \mathrm{k}}
$$

in which it is again assumed that each sediment size fraction is deposited in proportion to its representation in the bed sediment size distribution. Thus the change in bed elevation $\Delta z$ in a subreach with length $\Delta \mathrm{x}$ at each time step is calculated by the sediment continuity equation (C.3). The solution is reached by discretizing the equation and finding $\mathrm{q}_{\mathrm{s}}$ at the upstream $\left(\mathrm{q}_{\mathrm{si}}\right)$ and downstream $\left(\mathrm{q}_{\mathrm{si}+1}\right)$ ends of the subreach at successive times. IALLUVIAL2 does not use stability or weighting factors in these calculations. When a deficit exists between the downstream and upstream stations of the subreach, $\Delta \mathrm{z}$ is positive, indicating degradation.

For IALLUVIAL 2, the values of subreach length $(\Delta x)$ and time step $(\Delta t)$ should not be arbitrary, as such a selection will lead to misleading values of depth of degradation $\left(\mathrm{d}_{\mathrm{si}}\right)$ or depth of aggradation $\left(\mathrm{d}_{\mathrm{ai}}\right)$. The depth of degradation or aggradation at a time interval is directly proportional to $\alpha=\Delta \mathrm{t} / \Delta \mathrm{x}$. The calculation of $\mathrm{d}_{\mathrm{si}}$ and $\mathrm{d}_{\mathrm{ai}}$ is greatly influenced by the choices of reach length and time interval. Since no relation exists to calculate $\alpha_{\max }$ for a given system, one must follow certain guidelines in choosing the model time step and reach lengths. If the primary interest is estimating the average bed elevation changes due to degradation or aggradation, the following guidelines are deemed reasonable. For a given data set, reach lengths $(\Delta x)$ are generally given. Select the number of cross sections such that $\Delta x$ is nearly uniform or does not vary significantly and eliminate short reach lengths compared to averaged reach lengths. As for $\Delta t$, start with an initial value and change it either way in eth successive simulations until the results give best match with the observed volume, or results do not change significantly from one simulation to the other.

\section{C.2.2. Hydraulic Sorting of Bed Material}

The hydraulic bed material sorting relation below symbolizes the accounting operations which simulate the sorting at successive points in time.

$$
d_{50}^{n} \rightarrow d_{50}^{n+1}
$$

This is used in conjunctgion with a bed armoring relation below, which symbolizes additional accounting procedures to simulate development of a stable armor layer..

$$
A C F^{n} \rightarrow A C F^{n+1}
$$


In a river, when the bed degrades, finer sediment particles are preferentially transported which results in coarsening of the bed surface. If these coraser sediments are sufficiently large, they will not be transported in the flow, and will thus slowly accumulate on the bed surface, resulting in an "armor" layer. The fraction of bed surface covered by these coarse, immobile particles, $\mathrm{A}_{\mathrm{f}}$, is calculated in the following equation,

$$
A_{f}(t)=C_{1}(1-p) d_{s}(t) \sum_{k=\ell}^{m} \frac{P_{k}}{D_{k}}
$$

where

$$
\begin{aligned}
& p=\text { porosity } \\
& d_{s}(t)=\text { depth of degradation at time } t \\
& P_{k}=\text { fraction of bed material with size } D_{k} \\
& m=\text { total number of size intervals } \\
& l=\text { the finest size interval which remains immobile on the bed } \\
& C_{1}=\text { a constant }
\end{aligned}
$$

\section{C.2.3. Network Model}

IALLUVIAL2 has the capability to model tributaries of the main reach. Locations and water and sediment inputs from these tributaries need to be specified. The model computes the additional tributaries without uncoupling the sediment-discharge/ friction-factor which is the main feature of the IALLUVIAL2 model.

\section{C.3. Conclusion}

IALLUVIAL2 was recently upgraded to a newer version which incorporates 24 sediment transport relations, in addition to the Karim-Kennedy equation used in the original model; new equations are: Yang (sand), Einstein-Brown, Meyer-Peter-Muller, Karim $\left(\mathrm{D}_{50}\right)$, Engelund-Hansen, Ackers-White, Karim (size fraction), Schoklitsch, Laursen, Toffaleti, Parker (gravel bed), Van Rijn (bed load), Van Rijn (bed and suspended load), Shen-Hung, Shields, Bagnold (bed load), Bagnold (total load), Inglis-Lacey, Graf, Garde-Dattatri, Vittal-Raju-Garde, Yang (sand \& gravel), KarimKennedy II, and a user-supplied function. In addition to these sediment transport equations, IALLUVIAL 2 also includes 5 new friction-factor relations, in addition to the Karim-Kennedy equation used in the original model. New relations are: Einstein-Barbarossa, Engelund, Karim, Manning equation and Brownlie. Both Brownlie and the Karim and Karim-Kennedy friction relations allow for a variable roughness with variable $Q$. This is a unique feature in the IALLUVIAL 2 model. 
IALLUVIAL 2 simulates sediment sorting and bed armoring appropriate for both sand and gravel bed streams. Vertical heterogeneity in size distribution of different subsurface layers of bed sediments (below initial channel bed) are accounted for in the sediment sorting procedure, and the effects of bed armoring on sediment discharge and friction factor are included. The model is also capable of utilizing contributions from tributaries and from bank erosion. In addition, there is an option for adjustment in flow parameters for compound channels, due to momentum exchange at the interface between the main channel and overbank flows. The model can also compute additional scour at bends due to secondary currents; this option uses Falcon-Kennedy and Odgaard methods to estimate bend scour at a selected time step. Bed elevation changes across cross-sections are estimated using shear stress distribution over channel widths, making the model quasi-2D in sediment continuity. There is also an option for global iteration (at each time step) coupling governing equations for flow continuity, sediment continuity and related processes (sorting, armoring, etc). IALLUVIAL2 is capable of modeling sub-critical or super-critical flow regimes, or allowed to choose the regime based on internal calculations.

Since the model provides an option for computation of sediment discharges by 24 different relations mentioned before, a comparison can be made of computed and observed values (where available) of sediment discharges for given flow variables. This allows the user to evaluate comparative values in order to select an appropriate relation to be used in simulation. IALLUVIAL2 can also be run both coupled and decoupled, depending on the needs of the user and the nature of the simulation. 


\section{Appendix D. SRH-1D Model}

One dimensional sedimentation and river hydraulics model (SRH-1D) is a numerical model for simulating flow and sediment transport in alluvial rivers (Yang and Simoes 2000). It can be used to compute flow hydraulics (e.g. water surface profiles, velocity) for open channel flow, to simulate the hydraulic and sediment variations in both the longitudinal and the transverse directions and the change of alluvial channel profile and cross sectional geometry accounting for site specific conditions such as channel bank stability and erosion limits. Many sediment transport equations (Duboys 1978, Meyer-Peter and Muller 1948, Laursen 1958, Toffaleti 1969, Engelund and Hansen 1972, Ackers and White 1973, Yang 1973, Yang 1984, Parker 1990, Yang 1996) were implemented.

\section{D.1. Flow Hydrodynamics}

\section{D.1.1. Governing Equations}

\section{Steady flow}

The energy equation for steady gradually varied flow between downstream cross section 1 and upstream cross section 2 is expressed as:

$$
Z_{2}+\beta_{2} \frac{V_{2}^{2}}{2 g}-Z_{1}-\beta_{1} \frac{V_{1}^{2}}{2 g}=h_{f}+h_{e}
$$

where:

$Z_{1}, Z_{2}=$ water surface elevations at cross sections 1 and 2, respectively;

$V_{1}, V_{2}=$ average velocities at cross sections 1 and 2, respectively;

$\beta_{1}, \beta_{2}=$ velocity distribution coefficients at cross sections 1 and 2, respectively;

$g=$ gravitational acceleration;

$h_{\mathrm{f}}=$ friction loss between cross sections 1 and 2 , and

$h_{\mathrm{c}}=$ contraction or expansion losses between cross sections 1 and 2 .

\section{Unsteady flow}

One-dimensional river flows are described by the conservation of mass equation,

$$
\frac{\partial\left(A+A_{d}\right)}{\partial t}+\frac{\partial Q}{\partial x}=q_{\text {lat }}
$$

and the momentum equation written in divergent form,

where:

$$
\frac{\partial Q}{\partial t}+\frac{\partial\left(\beta Q^{2} / A\right)}{\partial x}+g A \frac{\partial Z}{\partial x}=-g A S_{f}
$$

$Q=$ discharge $\left(\mathrm{m}^{3} / \mathrm{s}\right)$,

$A=$ cross section area $\left(\mathrm{m}^{2}\right)$,

$A d=$ ineffective cross section area $\left(\mathrm{m}^{2}\right)$,

qlat $=$ lateral inflow per unit length of channel $\left(\mathrm{m}^{2} / \mathrm{s}\right)$,

$t=$ time independent variable (s), 
$x=$ spatial independent variable $(\mathrm{m})$,

$g=$ gravity acceleration $\left(\mathrm{m} / \mathrm{s}^{2}\right)$,

$\beta=$ velocity distribution coefficients,

$Z=$ water surface elevation $(\mathrm{m})$,

$S_{f}=$ energy slope $\left(=\frac{Q|Q|}{K^{2}}\right)$, and

$K=$ conveyance $\left(\mathrm{m}^{3} / \mathrm{s}\right)$.

\section{D.1.2. Hydraulic Losses}

The equation for friction loss in steady flow may be calculated in two ways as:

$$
\begin{aligned}
& h_{f a}=\sqrt{S_{f_{1}} S_{f_{2}}}\left(x_{2}-x_{1}\right) \\
& h_{f b}=\left[\frac{2 Q}{K_{1}+K_{2}}\right]^{2}\left(x_{2}-x_{1}\right)
\end{aligned}
$$

where:

$S_{f_{1}}, S_{f_{2}}=$ friction slopes at cross sections 1 and 2, respectively;

$x_{1}, x_{2}=$ streamwise coordinates of cross sections 1 and 2, respectively;

$Q=$ flow rate; and

$K_{1}, K_{2}=$ conveyance at cross sections 1 and 2 , respectively.

The actual friction loss $h_{\mathrm{f}}$ used is the minimum of $\mathrm{h}_{\mathrm{fa}}$ and $\mathrm{h}_{\mathrm{fb}}$.

For a specific discharge, the conveyance, $K$, is used to determine the friction slope $S_{f}$ :

$$
S_{f}=\left(\frac{Q}{K}\right)^{2}
$$

where $K$ is computed from the Manning's equation:

where:

$$
Q=K S_{f}^{1 / 2}=\frac{C_{m}}{n} A R^{2 / 3} S_{f}^{1 / 2}
$$

$$
\begin{aligned}
& n=\text { Manning's coefficient; } \\
& A=\text { cross-sectional area; } \\
& R=\text { hydraulic radius }(A / P) \\
& P=\text { wetted perimeter; and } \\
& C_{m}=1.486 \text { for English units or } 1.0 \text { for SI units. }
\end{aligned}
$$

The equation for contraction or expansion losses is expressed as:

$$
h_{c}=C_{c}\left|\frac{\beta_{1} V_{1}^{2}}{2 g}-\frac{\beta_{2} V_{2}^{2}}{2 g}\right|
$$


where: $C_{c}=$ a user defined contraction or expansion coefficient. The expansion coefficient is used when the velocity head at the downstream section 1 is less than that at the upstream section 2 . Conversely, the contraction coefficient is used when the velocity head at the downstream section 1 is greater than that at the upstream section 2. This is similar to the way HEC-RAS treats energy loss.

The friction loss in unsteady flow is represented by the energy slope $S$, which can be calculated by $S_{f}=\frac{Q|Q|}{K^{2}}$, with Q and K having the same meanings above.

\section{D.1.3. Velocity Distribution Factor}

Not clearly defined in SRH-1D.

\section{D.1.4. Critical Section Factor, Effective Depth and Effective Width}

SRH-1D uses the standard step method to solve the energy equation for steady gradually varied flows. Presently, only subcritical and critical flow profiles are calculated when the steady flow option is used.

\section{D.1.5. Numerical Solution}

SRH-1D uses different numerical schemes for steady and unsteady flow simulation: For steady flow, the standard step method is applied; for unsteady flow, an implicit Preissmann Scheme is adopted while certain modifications are needed for the simulation of supercritical flow.

\section{Steady flow}

The standard step method is used to solve the governing equations for steady flow, which can be expressed as:

$$
f\left(Z_{2}\right)=Z_{2}+\beta_{2} \frac{V_{2}^{2}}{2 g}-Z_{1}-\beta_{1} \frac{V_{1}^{2}}{2 g}-h_{f}-h_{c}=0
$$

This nonlinear algebraic equation can be solved by the Newton-Raphson iterative method (Jain, 2000). Let $Z_{2}^{*}$ be an estimate of $Z_{2}$, the Newton-Raphson method gives a better estimate of $Z_{2}$ using the following:

$$
Z_{2}^{\prime}=Z_{2}^{*}-\frac{f\left(Z_{2}^{*}\right)}{f^{\prime}\left(Z_{2}^{*}\right)}
$$

where

$$
f^{\prime}\left(Z_{2}^{*}\right)=1-\beta_{2} \frac{V_{2}^{2}}{g R}-\frac{\partial h_{f}}{\partial Z_{2}}
$$

\section{Unsteady flow}

The numerical scheme used in SRH-1D scheme uses a staggered grid. The scheme also uses a nonconservative form of the momentum equation. The scheme is similar to Kutija and Newett (2002), 
but the position of $A$ and $Q$ points are reversed. In SRH-1D, $A$ points are located at the cross section and $Q$ points are located at the center of two cross sections.

The discretization of the continuity equation is made with one $A$-point and two $Q$ points giving the difference equation:

$$
A_{i}^{n}+A_{d i}^{n}-A_{i}^{n-1}-A_{d i}^{n-1}=-\frac{\Delta t}{\Delta x_{i}}\left(\overline{Q_{i+1}}-\overline{Q_{i}}\right)
$$

where the overbar signifies a time weighted averaged value with a weighting factor $\theta$ in the time dimension. The time weighted discharge, $Q_{i}$, can be written as:

$$
\overline{Q_{i}}=\theta Q_{i}^{n}+(1-\theta) Q_{i}^{n-1}
$$

and Eq. (D.11) can be written in an iteration form, with $m$ signifying the iteration number;

$$
\Delta A_{i}^{m}=\alpha_{i} \Delta Q_{i}^{m}+\delta_{i} \Delta Q_{i+1}^{m}+\gamma_{i}
$$

where the coefficients are:

$$
\begin{aligned}
& \alpha_{i}=\frac{\theta \Delta t}{\Delta x_{i}} \\
& \delta_{i}=-\frac{\theta \Delta t}{\Delta x_{i}} \\
& \gamma_{i}=-A_{i}^{n}-A_{d i}^{n}+A_{i}^{n-1}+A_{d i}^{n-1}+\left(\overline{Q_{i}}-\overline{Q_{i+1}}\right) \frac{\Delta t}{\Delta x_{i}}
\end{aligned}
$$

The discrete form of the momentum equation is made with two $A$-points and three $Q$-points with a weighting factor $\theta$ in the time dimension giving the difference equation:

$$
Q_{i}^{n}-Q_{i}^{n-1}+\frac{\Delta t}{\Delta s_{i}}\left(\overline{F_{e}}-\overline{F_{w}}\right)=\Delta \operatorname{tg} \frac{\overline{A_{i}}+\overline{A_{i-1}}}{2}\left(\frac{\overline{Z_{i}}+\overline{Z_{i-1}}}{\Delta s_{i}}-\overline{S_{f i}}\right)
$$

where:

$$
\begin{aligned}
& \overline{F_{e}}=\beta \frac{\left(\overline{Q_{i}}+\overline{Q_{i+1}}\right)^{2}}{4 \overline{A_{i}}} \\
& \overline{F_{w}}=\beta \frac{\left(\overline{Q_{i}}+\overline{Q_{i+1}}\right)^{2}}{4 \overline{A_{i-1}}} \\
& S_{f i}=\frac{4 \overline{Q_{i}}\left|\overline{Q_{i}}\right|}{\left(\overline{K_{i}}+\overline{K_{i+1}}\right)^{2}}
\end{aligned}
$$

An important difference between the scheme in SRH-1D and Kutija and Newett (2002) is the treatment of the flux terms $\left(F_{e}\right.$ and $\left.F_{w}\right)$. SRH-1D uses the conservative form while Kutija and Newett do not. Using a weighting factor $\theta$ in the time dimension, Eq. (D.11) can be written in iteration form as: 


$$
\begin{aligned}
& \Delta Q_{i}^{m}+\theta \frac{\Delta t}{\Delta x_{i}}\left(\frac{\partial \overline{F_{e}}}{\partial Q_{i}^{n}} \Delta Q_{i}^{m}+\frac{\partial \overline{F_{e}}}{\partial Q_{i+1}^{n}} \Delta Q_{i+1}^{m}+\frac{\partial \overline{F_{e}}}{\partial A_{i}^{n}} \Delta A_{i}^{m}-\frac{\partial \overline{F_{w}}}{\partial Q_{i}^{n}} \Delta Q_{i}^{m}-\frac{\partial \overline{F_{w}}}{\partial Q_{i-1}^{n}} \Delta Q_{i-1}^{m}-\frac{\partial \overline{F_{w}}}{\partial A_{i-1}^{n}} \Delta A_{i-1}^{m}\right) \\
& -\theta \Delta \operatorname{tg} \frac{\Delta A_{i}^{m}+\Delta A_{i-1}^{m}}{2}\left(\frac{Z_{i-1}^{n+1}-Z_{i}^{n+1}}{\Delta S_{i}}-S_{f i}^{n+1}\right)-\theta \Delta \operatorname{tg} \frac{\Delta A_{i}^{m}+\Delta A_{i-1}^{m}}{2}\left(\begin{array}{c}
\frac{\Delta A_{i-1}^{m}}{T_{i-1}^{n+1} \Delta S_{i}}-\frac{\Delta A_{i}^{m}}{T_{i}^{n+1} \Delta S_{i}}-\frac{\partial \overline{S_{f i}}}{\partial A_{i}^{n}} \Delta A_{i}^{m} \\
-\frac{\partial S_{f i}}{\partial A_{i-1}^{n}} \Delta A_{i-1}^{m}-\frac{\partial S_{f i}}{\partial Q_{i}^{n}} \Delta Q_{i}^{m}
\end{array}\right) \\
& =-Q_{i}^{n}+Q_{i}^{n-1}-\frac{\Delta t}{\Delta x_{i}}\left(\overline{F_{e}}-\overline{F_{w}}\right)+\Delta \operatorname{tg} \frac{\Delta A_{i}^{m}+\Delta A_{i-1}^{m}}{2}\left(\frac{Z_{i-1}-Z_{i}}{\Delta S_{i}}-S_{f i}\right)
\end{aligned}
$$

\section{D.2. Sediment Transport}

\section{D.2.1. Governing Equation}

The Exner equation (Exner, 1920; 1925) was derived assuming that changes to the volume of sediment in suspension are much smaller than the changes to the volume of sediment in the bed, which is generally true for long-term simulations where steady flow is being simulated. The mass conservation equation for sediment reduces to

where

$$
\frac{\partial Q_{s}}{\partial x}+\varepsilon \frac{\partial A_{d}}{\partial t}-q_{s}=0
$$

$\varepsilon=$ volume of sediment in a unit bed layer volume (one minus porosity);

$A_{d}=$ volume of bed sediment per unit length; $Q_{s}=$ volumetric sediment discharge;

$q_{s}=$ lateral sediment inflow per unit length.

Integrating (c) over a control volume centered on each cross section gives an equation for the deposition depth $\left(\Delta Z_{b}\right)$ for a single sediment size fraction at a particular cross section, $i$ :

$$
\varepsilon_{i} W_{i} \Delta x_{i} \Delta Z_{b, j}=q_{s, i} \Delta x_{i} \Delta t+\left(Q_{s, i-1}-Q_{s, i}\right) \Delta t
$$

SRH-1D employs many transport functions for non-cohesive material, as listed below. Usually, each transport function was developed for a certain range of sediment size and flow conditions. Computed results based on different transport functions can differ significantly from each other and from measurements. No universal function exists which can be applied with accuracy to all sediment and flow conditions. Yang(1996) published a more detailed description of some of these functions including comprehensive comparisons and evaluations.

Many transport formula were developed assuming uniform size gradations. In these cases, the transport capacity is modified by the fraction of the size class in the active layer according to the following equation,

$$
Q_{i}^{*}=p_{i} Q_{i}^{T}
$$


where $p_{i}$ is the mass fraction of that size class in the active layer and $Q_{i}^{T}$ is the transport capacity predicted by the formula assuming uniform size.

\section{D2.2. Sediment Transport Formulas}

Sediment transport functions available in SRH-1D and its type (B = bed load; BM = bedmaterial total load).

1. Meyer-Peter and Müller (1948) - modified by Wong and Parker (2006) B

2. Laursen (1958)

3. Modified Laursen's Formula (Madden, 1993)

4. Engelund and Hansen (1972)

$\mathrm{BM}$

$\mathrm{BM}$

$\mathrm{BM}$

$\mathrm{BM}$

5. Ackers and White (1973)

6. Ackers and White (HR Wallingford, 1990)

7. Yang (1973) + Yang (1984)

8. Yang (1979) + Yang (1984)

9. Brownlie (1981)

10. Yang et al. (1996)

11. Parker (1990)

12. Wilcock and Crowe (2003)

13. $\mathrm{Wu}(2004)$
$\mathrm{BM}$

$\mathrm{BM}$

$\mathrm{BM}$

$\mathrm{BM}$

$\mathrm{BM}$

$\mathrm{B}$

B

$\mathrm{BM}$

Among 13 sediment transport formulas available in SRH-1D model. Only seven yielded a successful simulation for this study case. These widely used and working formulas are from Laursen (1958), Madden and Laursen (1993), Yang (1973), Engelund (1967), Yang (1979), Ackers-White (1973), and Wu and Wang (2002).

The Laursen (1958) formula in the dimensionally homogeneous form recommended by the American Society of Civil Engineers Task Committee (1971)can be written as

$$
C_{t}=0.01 \gamma \sum_{i} p_{i}\left(\frac{d_{i}}{D}\right)^{7 / 6}\left(\frac{\tau^{\prime}}{\tau_{c i}}-1\right) f\left(\frac{U_{*}}{\omega_{i}}\right)
$$

where

$C_{t}=$ sediment concentration by weight per unit volume

$U_{*}=\sqrt{g D S}$

$p_{i}=$ percentage of material of $i^{\text {th }}$ sized particles

$\omega_{f i}=$ fall velocity of mean sized particles $d_{i}$ in water

$D=$ average flow depth

$\tau_{c i}=$ critical tractive force for $\mathrm{i}^{\text {th }}$ sized sediment as given by the Shields diagram

Laursen's bed shear stress, $\tau^{\prime}$, is the grain resistance obtained from the Manning equation,

$$
\tau^{\prime}=\frac{\rho V^{2}}{58}\left(\frac{d_{50}}{D}\right) 1 / 3
$$


In the equation, the shear stress parameter $\left(\tau^{\prime} / \tau_{c i}-1\right)$ is important for determining bed load, and the parameter $\frac{U_{*}}{\omega_{i}}$ relates to suspended load. The functional relation $f\left(\frac{U_{*}}{\omega_{i}}\right)$ is given by Laursen (1958)in a graphical form. Madden (1993) revised the Laursen (1958) relation in order to match the sediment load vs discharge rating curve in the lower Arkansas River. The consequence was to increase the predictions for very large sediment load. Both the Laursen (1958) equation and the revised one by Madden and Laursen (1993) are included in SRH-1D and applied in this study.

Yang (1979) proposed a sand transport formula for flow conditions well exceeding those required for incipient motion. In this case, the dimensionless critical unit stream power required at incipient motion can be neglected. Yang's 1979 sand transport formula for sediment concentration greater than 100 parts per million by weight is written as follows,

$$
\log C_{t s}=5.165-0.153 \log \frac{w_{f} d}{v}-0.297 \log \frac{U_{*}}{w_{f}}+\left(1.78-0.36 \log \frac{w_{f} d}{v}-0.48 \log \frac{U_{*}}{w_{f}}\right) \log \frac{V S}{w_{f}}
$$

The coefficients in this equation were determined from 452 sets of laboratory flume data.

The Wu and Wang (2000) formula computes the suspended and bed load separately, and then adds them together to obtain the total bed material load:

$$
q_{t}=q_{b}+q_{s}
$$

The bed load is computed from the equation below,

$$
\frac{q_{b i}}{p_{i} \sqrt{g(s-1) d_{i}^{3}}}=0.0053\left[\left(\frac{n^{\prime}}{n}\right)^{1.5} \frac{\tau_{b}}{\tau_{c i}}-1\right]^{2.2}
$$

where $n^{\prime}=0.05 d_{50}^{1 / 6}$ and $n$ is total Manning's roughness coefficient for the bed.

The critical shear stress is calculated as:

$$
\tau_{c i}=\theta_{c}(s-1)=d_{i} \xi_{i}
$$

where the exposure factor, $\xi i$, is calculated as:

$$
\xi_{i}=\left(\frac{p_{h i}}{p_{e i}}\right) \alpha
$$

where $\alpha=0.6$, which can be modified by the user. The probability of hiding and exposure, $p_{h i}$ and $p_{e i}$ respectively, are calculated as:

$$
p_{h i}=\sum_{j=1}^{N} \frac{p_{j} d_{j}}{\left(d_{i}+d_{j}\right)}, p_{e i}=\sum_{j=1}^{N} \frac{p_{j} d_{i}}{\left(d_{i}+d_{j}\right)}
$$

The critical shear stress, $\theta c$, recommended is 0.03 ; however, the user can modify this if necessary. The suspended load is determined as:

$$
\frac{q_{s i}}{p_{i} \sqrt{g(s-1) d_{i}^{3}}}=0.0053\left[\left(\frac{U}{w_{f i}}\right)^{1.5} \frac{\tau_{b}}{\tau_{c i}}-1\right]^{1.74}
$$


The Ackers-White (1973) formula for predicting the total bed material load is written as

$$
\begin{aligned}
& X=\frac{G_{g r} d \gamma_{s} / \gamma}{D}\left(\frac{U_{*}}{U}\right)^{n} \\
& G_{g r}=C\left(\frac{F_{g r}}{A}-1\right)^{m} \\
& F_{g r}=\frac{U_{*}^{n}}{\sqrt{\frac{\rho_{s}-\rho}{\rho} g d}}\left[\frac{U}{\sqrt{32} \lg (\alpha h / d)}\right]^{1-n} \\
& d_{g r}=d\left[\frac{\frac{\rho_{s}-\rho}{\rho} g}{v^{2}}\right]^{1 / 3} \\
& \text { if } 1<d_{g r} \leq 60 \\
& n=1.00-0.56 \log d_{g r} \\
& A=0.23 d_{g r}^{-\frac{1}{2}}+0.14 \\
& m=\frac{9.66}{d_{g r}}+1.34 \\
& \log C=2.86 \log d_{g r}-\left(\log d_{g r}\right)^{2}-3.53 \\
& \text { if } d_{g r}>60 \\
& n=0.00 \\
& A=0.17 \\
& m=1.50 \\
& C=0.025
\end{aligned}
$$

where

$X=\quad$ rate of sediment transport in terms of mass flow per unit mass flow rate, i.e., concentration by weight of fluid flux

$G_{g r}=\quad$ a dimensionless sediment transport rate

$F_{g r}=\quad$ mobility number for sediment

$d_{g r}=\quad$ dimensionless grain diameter

$U_{*}=\quad$ shear velocity

$U=$ depth averaged flow velocity

$D=\quad$ flow depth 


$$
\alpha=\quad \text { coefficient in rough turbulent equation }(=10)
$$

$A, n, m, C=$ transition coefficients

\section{D.2.3. Equilibrium Depth}

Not clearly defined in SRH-1D.

\section{D.2.4. Hydraulic Sorting of Bed Material}

A user-defined number of size fractions will be used to represent the sediment size distributions. The bed profile is composed of a number of layers of various thicknesses and bulk densities. Each individual layer is assumed to have the same size distribution and bulk density throughout its depth. In each layer, bulk density of the cohesive sediment increases with time due to consolidation. The bulk density of the non-cohesive sediment remains constant. During consolidation, the bed thickness decreases but no mixing occurs between layers.

The active layer is defined as a thin upper zone of constant thickness that is proportional to the geometric mean of the largest size class. The constant of proportionality is user defined. The thickness of the active layer can control the rate at which the bed armors. The active layer methodology assumes that all sediment particles of a given size class inside the active layer are equally exposed to the flow.

For more details please refer to SRH-1D user manual at the site http://www.usbr.gov/pmts/sediment/model/srh1d/index.html.

\section{D.2.5.Network Model}

SRH-1D provides solutions to both dendritic networks and looped networks. The method used by SRH-1D for such networks is similar to that found in Chaudhry (1993). However, some modifications were made to handle large numbers of connections within a river network.

The following strategy is used to record the network connection information. River numbering is in ascending order from upstream to downstream. The boundary condition for each river entering a junction is the ID numbers of the other rivers entering that junction. If the flow is into the junction, the ID number is positive and if the flow is out of the junction the ID number is negative. In a looped network where the flow direction is unknown before the numerical simulation, the input flow direction can be assumed by the user. A calculated positive discharge means that the assumed flow direction is correct. A negative discharge indicates a flow direction opposite of that initially assumed.

A numerical solution of flow in a network requires the calculation of both the energy equation and the continuity equation. At each cross section, the flow depth and flow discharge are initially unknown. The energy equation and the continuity equation are written for each cross section as: 


$$
\begin{aligned}
& F_{i}=Z_{i+1}-Z_{i}+\frac{1}{2 g}\left(\frac{\beta_{i+1} Q_{i+1}\left|Q_{i+1}\right|}{A_{i+1}^{2}}-\frac{\beta_{1} Q_{i}\left|Q_{i}\right|}{A_{i}^{2}}\right)+h_{f}+\frac{C_{e}}{4 g}\left(\frac{Q_{i+1}\left|Q_{i+1}\right|}{A_{i+1}^{2}}+\frac{Q_{i}\left|Q_{i}\right|}{A_{i}^{2}}\right)=0 \\
& G_{i}=Q_{i+1}-Q_{i}-Q_{\text {Lati }}=0
\end{aligned}
$$

where $Q_{\text {Lat }}=$ the lateral inflow at the reach between cross sections $i$ and $i+1$. Since $A$ and $R$ are functions of only water surface elevation $Z$, the unknowns are water surface elevation and discharge. For a river with $N+1$ cross-sections, there are $2(N+1)$ unknowns, but only $2 N$ equations for $N$ river reaches. Therefore, two boundary conditions are required for a unique solution of the system and these can be written in a general form as:

$$
\begin{aligned}
& B U=f\left(Q_{1}, Z_{1}\right) \\
& B D=f\left(Q_{N+1}, Z_{N+1}\right)
\end{aligned}
$$

where $f$ and $f^{\prime}$ are functions defined by the boundary conditions and $B U$ and $B D$ signify the upstream and downstream boundary conditions, respectively.

\section{D.3. Conclusion}

SRH-1D is a one-dimensional hydraulic and sediment transport model for use in natural rivers and manmade canals with EPA (Environmental Protection Agency) and Reclamation (Bureau of Reclamation) as its funding partners. SRH-1D was originally named GSTAR-1D (Yang et al., 2007; Huang and Greimann, 2007). In June 2007, the model name was changed to SRH-1D. It is a mobile boundary model with the ability to simulate steady or unsteady flows, internal boundary conditions, looped river networks, cohesive and non-cohesive sediment transport, and lateral inflows.

SRH-1D uses the standard step method to solve the energy equation for steady gradually varied flows. Presently, only subcritical and critical flow profiles are calculated when the steady flow option is used. For unsteady flow simulation, SRH-1D solves the Saint-Venant Equation. The numerical scheme used in SRH-1D scheme uses a staggered grid. The scheme also uses a nonconservative form of the momentum equation.

SRH-1D defines the geometry of the channel much in the same way as HEC-RAS. A translator of geometry from HEC-RAS geometry file to SRH-1D input file is provided to facilitate the construction of geometry data in SRH-1D input. However, the internal boundary data need to be added into the file manually.

SRH-1D simulates the physical processes important to both cohesive and non-cohesive sediment transport. There are two types of sediment routing available in SRH-1D: unsteady sediment routing and Exner equation routing. The unsteady sediment routing computes the changes to the suspended sediment concentration with time. The Exner equation routing ignores changes to the suspended sediment concentration over time. Bed material mixing processes include bed material sorting and armoring. Consolidation is compaction of cohesive sediment over time. 
SRH-1D reads a single input file that contains all the necessary information to perform a simulation. An input file is organized in sequential records, and the data are prepared in ASCII files. After preparing the input data file, SRH-1D can be executed within windows by double-clicking the filename in Windows Explorer. SRH-1D can also be used from the command line interface. However, a graphical user interface is not provided and all edits of input need to be done within a plain text file editor. If the simulation is properly performed, a series of output files will be generated, also in the format of ASCII files. 


\section{Appendix E: Bed Material Size Distributions}

Table E. 1. Sediment Size Gradations From Craycroft Roadto I-10 Bridge

\begin{tabular}{|c|c|c|c|c|c|c|c|}
\hline \multicolumn{5}{|c|}{ Craycroft Confluence Bridge } & \multirow{2}{*}{\multicolumn{3}{|c|}{$\begin{array}{c}\text { Swan Road Bridge } \\
\text { Site: Upstream Center }\end{array}$}} \\
\hline \multicolumn{3}{|c|}{ Site: Upstream Right } & \multicolumn{2}{|c|}{ Site: Upstream Left } & & & \\
\hline & Surface & substrate & Surface & Substrate & & Surface & Substrate \\
\hline & $\begin{array}{c}\text { Percent } \\
\text { finer }(\%)\end{array}$ & $\begin{array}{c}\text { Percent } \\
\text { finer }(\%)\end{array}$ & $\begin{array}{c}\text { Percent } \\
\text { finer }(\%)\end{array}$ & $\begin{array}{c}\text { Percent } \\
\text { finer }(\%)\end{array}$ & $\begin{array}{l}\text { Sieve size } \\
\quad(\mathrm{mm})\end{array}$ & $\begin{array}{c}\text { Percent } \\
\text { finer }(\%)\end{array}$ & $\begin{array}{c}\text { Percent } \\
\text { finer }(\%)\end{array}$ \\
\hline 6.350 & 84.786 & 90.780 & 86.250 & 96.830 & 6.350 & 83.460 & 82.740 \\
\hline 4.760 & 78.466 & 86.639 & 80.061 & 94.186 & 4.760 & 76.485 & 77.807 \\
\hline 2.380 & 58.945 & 68.765 & 59.452 & 72.781 & 2.380 & 50.529 & 58.764 \\
\hline 2.000 & 54.085 & 62.936 & 53.741 & 64.457 & 2.000 & 43.275 & 52.233 \\
\hline 1.180 & 40.441 & 43.195 & 37.537 & 37.758 & 1.180 & 24.337 & 32.440 \\
\hline 1.000 & 36.803 & 37.168 & 33.204 & 30.177 & 1.000 & 19.808 & 26.726 \\
\hline 0.850 & 33.861 & 32.194 & 29.844 & 24.462 & 0.850 & 16.160 & 22.405 \\
\hline 0.500 & 22.995 & 14.926 & 18.898 & 9.003 & 0.500 & 8.591 & 9.585 \\
\hline 0.300 & 13.262 & 4.756 & 11.918 & 3.662 & 0.300 & 6.508 & 5.093 \\
\hline 0.250 & 9.706 & 2.318 & 9.724 & 2.599 & 0.250 & 5.580 & 3.792 \\
\hline 0.150 & 4.232 & 0.380 & 5.004 & 1.167 & 0.150 & 3.194 & 1.571 \\
\hline 0.075 & 1.331 & 0.073 & 1.915 & 0.430 & 0.075 & 1.677 & 0.693 \\
\hline Pan & 0.000 & 0.002 & 0.000 & -0.003 & Pan & -0.005 & 0.003 \\
\hline \multicolumn{3}{|c|}{ Dodge Boulevard Bridge } & \multicolumn{5}{|c|}{ Country Club Pedestrian Bridge } \\
\hline \multicolumn{3}{|c|}{ Site: Upstream Center } & \multicolumn{3}{|c|}{ Site: Upstream Right } & \multicolumn{2}{|c|}{ Site: Upstream Left } \\
\hline & Surface & Substrate & & Surface & Substrate & Surface & Substrate \\
\hline $\begin{array}{l}\text { Sieve size } \\
(\mathrm{mm})\end{array}$ & $\begin{array}{c}\text { Percent } \\
\text { finer }(\%)\end{array}$ & $\begin{array}{c}\text { Percent } \\
\text { finer }(\%)\end{array}$ & $\begin{array}{l}\text { Sieve size } \\
(\mathrm{mm})\end{array}$ & $\begin{array}{c}\text { Percent } \\
\text { finer }(\%)\end{array}$ & $\begin{array}{c}\text { Percent } \\
\text { finer }(\%)\end{array}$ & $\begin{array}{c}\text { Percent } \\
\text { finer }(\%)\end{array}$ & $\begin{array}{c}\text { Percent } \\
\text { finer }(\%)\end{array}$ \\
\hline 6.350 & 82.650 & 76.730 & 6.350 & 70.560 & 67.460 & 99.050 & 76.100 \\
\hline 4.760 & 77.813 & 71.631 & 4.760 & 66.261 & 63.655 & 98.817 & 71.489 \\
\hline 2.380 & 60.589 & 52.003 & 2.380 & 51.206 & 48.524 & 96.782 & 53.991 \\
\hline 2.000 & 55.687 & 45.899 & 2.000 & 45.835 & 43.425 & 95.111 & 48.216 \\
\hline 1.180 & 41.943 & 29.382 & 1.180 & 28.857 & 28.469 & 86.185 & 31.512 \\
\hline 1.000 & 38.041 & 25.265 & 1.000 & 23.699 & 24.297 & 82.440 & 27.121 \\
\hline 0.850 & 34.619 & 21.751 & 0.850 & 19.592 & 20.528 & 78.074 & 23.065 \\
\hline 0.500 & 21.471 & 11.203 & 0.500 & 7.483 & 9.329 & 62.187 & 11.754 \\
\hline 0.300 & 9.423 & 4.450 & 0.300 & 2.531 & 3.856 & 37.241 & 6.492 \\
\hline 0.250 & 6.870 & 2.959 & 0.250 & 1.535 & 2.628 & 25.573 & 4.944 \\
\hline 0.150 & 3.420 & 1.310 & 0.150 & 0.533 & 1.201 & 5.048 & 2.518 \\
\hline 0.075 & 1.278 & 0.580 & 0.075 & 0.272 & 0.557 & 1.536 & 1.162 \\
\hline Pan & -0.001 & 0.001 & Pan & -0.003 & 0.003 & -0.002 & 0.004 \\
\hline
\end{tabular}




\begin{tabular}{|c|c|c|c|c|c|c|c|c|c|}
\hline \multicolumn{5}{|c|}{ Campbell Avenue Bridge } & \multicolumn{5}{|c|}{ Mountain Avenue Bridge } \\
\hline \multicolumn{3}{|c|}{ Upstream Left } & \multicolumn{2}{|c|}{ Upstream Right } & \multicolumn{3}{|c|}{ Upstream Right } & \multicolumn{2}{|c|}{ Upstream Left } \\
\hline & Surface & Substrate & Surface & Substrate & & Surface & Substrate & Surface & Substrate \\
\hline $\begin{array}{l}\text { Sieve } \\
\text { size } \\
(\mathrm{mm})\end{array}$ & $\begin{array}{c}\text { Percent } \\
\text { finer } \\
(\%)\end{array}$ & $\begin{array}{c}\text { Percent } \\
\text { finer }(\%)\end{array}$ & $\begin{array}{c}\text { Percent } \\
\text { finer } \\
(\%)\end{array}$ & $\begin{array}{c}\text { Percent } \\
\text { finer }(\%)\end{array}$ & $\begin{array}{c}\text { Sieve } \\
\text { size } \\
(\mathrm{mm})\end{array}$ & $\begin{array}{c}\text { Percent } \\
\text { finer } \\
(\%)\end{array}$ & $\begin{array}{c}\text { Percent } \\
\text { finer }(\%)\end{array}$ & $\begin{array}{c}\text { Percent } \\
\text { finer } \\
(\%)\end{array}$ & $\begin{array}{c}\text { Percent } \\
\text { finer }(\%)\end{array}$ \\
\hline 6.350 & 95.920 & 58.200 & 98.330 & 94.570 & 6.350 & 99.320 & 80.260 & 83.380 & 93.950 \\
\hline 4.760 & 92.869 & 53.425 & 96.597 & 87.364 & 4.760 & 98.839 & 74.761 & 79.562 & 88.174 \\
\hline 2.380 & 70.207 & 37.115 & 85.467 & 70.937 & 2.380 & 94.256 & 54.504 & 66.082 & 86.054 \\
\hline 2.000 & 60.550 & 32.617 & 80.551 & 61.785 & 2.000 & 91.196 & 48.051 & 61.826 & 74.029 \\
\hline 1.180 & 29.809 & 20.078 & 61.864 & 35.217 & 1.180 & 74.530 & 27.749 & 49.216 & 51.592 \\
\hline 1.000 & 26.365 & 16.915 & 54.616 & 29.085 & 1.000 & 67.744 & 22.734 & 45.310 & 45.174 \\
\hline 0.850 & 21.648 & 14.374 & 48.094 & 24.266 & 0.850 & 60.573 & 18.369 & 42.041 & 39.474 \\
\hline 0.500 & 11.687 & 6.450 & 20.645 & 11.028 & 0.500 & 29.029 & 7.272 & 27.206 & 21.716 \\
\hline 0.300 & 8.999 & 5.570 & 4.662 & 4.093 & 0.300 & 6.243 & 2.537 & 10.877 & 8.238 \\
\hline 0.250 & 8.376 & 4.192 & 1.995 & 2.448 & 0.250 & 2.509 & 1.501 & 6.846 & 4.472 \\
\hline 0.150 & 4.851 & 1.989 & 0.507 & 0.617 & 0.150 & 0.273 & 0.396 & 2.390 & 1.128 \\
\hline 0.075 & 1.541 & 0.648 & 0.235 & 0.038 & 0.075 & 0.105 & 0.154 & 0.990 & 0.343 \\
\hline Pan & 0.001 & 0.002 & -0.001 & -0.248 & Pan & 0.001 & -0.005 & 0.003 & -0.004 \\
\hline \multicolumn{5}{|c|}{ First Avenue Bridge } & \multicolumn{3}{|c|}{ Stone Avenue Bridge } & & \\
\hline \multicolumn{3}{|c|}{ Upstream Left } & \multicolumn{2}{|c|}{ Upstream Right } & \multicolumn{3}{|c|}{ Upstream Center } & & \\
\hline & Surface & Substrate & Surface & Substrate & & Surface & Substrate & & \\
\hline $\begin{array}{l}\text { Sieve } \\
\text { size } \\
(\mathrm{mm})\end{array}$ & $\begin{array}{c}\text { Percent } \\
\text { finer } \\
(\%)\end{array}$ & $\begin{array}{c}\text { Percent } \\
\text { finer }(\%)\end{array}$ & $\begin{array}{c}\text { Percent } \\
\text { finer } \\
(\%)\end{array}$ & $\begin{array}{c}\text { Percent } \\
\text { finer }(\%)\end{array}$ & $\begin{array}{c}\text { Sieve } \\
\text { size } \\
(\mathrm{mm})\end{array}$ & $\begin{array}{c}\text { Percent } \\
\text { finer } \\
(\%)\end{array}$ & $\begin{array}{c}\text { Percent } \\
\text { finer }(\%)\end{array}$ & & \\
\hline 6.350 & 83.650 & 92.620 & 98.900 & 99.230 & 6.350 & 91.980 & 64.530 & & \\
\hline 4.760 & 77.085 & 89.334 & 98.272 & 98.110 & 4.760 & 87.364 & 61.335 & & \\
\hline 2.380 & 56.556 & 72.519 & 94.572 & 92.760 & 2.380 & 72.279 & 48.193 & & \\
\hline 2.000 & 50.844 & 66.251 & 92.077 & 90.597 & 2.000 & 67.451 & 43.642 & & \\
\hline 1.180 & 34.335 & 44.229 & 79.233 & 79.768 & 1.180 & 52.655 & 29.631 & & \\
\hline 1.000 & 30.192 & 36.984 & 73.318 & 74.693 & 1.000 & 48.217 & 25.579 & & \\
\hline 0.850 & 26.221 & 31.297 & 67.803 & 70.833 & 0.850 & 44.075 & 22.237 & & \\
\hline 0.500 & 14.026 & 12.814 & 46.880 & 55.472 & 0.500 & 28.908 & 10.399 & & \\
\hline 0.300 & 7.275 & 4.069 & 28.287 & 46.917 & 0.300 & 18.914 & 3.569 & & \\
\hline 0.250 & 5.472 & 2.401 & 21.647 & 43.169 & 0.250 & 5.072 & 2.160 & & \\
\hline 0.150 & 3.339 & 0.724 & 10.129 & 31.400 & 0.150 & 2.737 & 0.715 & & \\
\hline 0.075 & 2.107 & 0.177 & 3.350 & 20.415 & 0.075 & 2.098 & 0.257 & & \\
\hline Pan & 0.001 & 0.000 & -0.001 & -0.003 & Pan & -0.004 & 0.005 & & \\
\hline
\end{tabular}




\begin{tabular}{|c|c|c|c|c|c|c|c|c|c|}
\hline \multicolumn{5}{|c|}{ Oracle Road Bridge } & \multicolumn{5}{|c|}{ La Canada Road Bridge } \\
\hline \multicolumn{3}{|c|}{ Site: Upstream Right } & \multicolumn{2}{|c|}{ Site: Upstream Left } & \multicolumn{3}{|c|}{ Site: Upstream Center } & \multicolumn{2}{|c|}{ Site: Upstream Left } \\
\hline & Surface & Substrate & Surface & Substrate & & Surface & Substrate & Surface & Substrate \\
\hline $\begin{array}{l}\text { Sieve } \\
\text { size } \\
(\mathrm{mm})\end{array}$ & $\begin{array}{c}\text { Percent } \\
\text { finer } \\
(\%)\end{array}$ & $\begin{array}{c}\text { Percent } \\
\text { finer }(\%)\end{array}$ & $\begin{array}{c}\text { Percent } \\
\text { finer } \\
(\%)\end{array}$ & $\begin{array}{l}\text { Percent } \\
\text { finer }(\%)\end{array}$ & $\begin{array}{l}\text { Sieve } \\
\text { size } \\
(\mathrm{mm})\end{array}$ & $\begin{array}{l}\text { Percent } \\
\text { finer } \\
(\%)\end{array}$ & $\begin{array}{c}\text { Percent } \\
\text { finer }(\%)\end{array}$ & $\begin{array}{c}\text { Percent } \\
\text { finer }(\%)\end{array}$ & $\begin{array}{c}\text { Percent } \\
\text { finer }(\%)\end{array}$ \\
\hline 6.350 & 85.090 & 98.430 & 83.420 & 91.230 & 6.350 & 99.020 & 91.620 & 99.750 & 98.190 \\
\hline 4.760 & 81.491 & 96.694 & 79.704 & 87.735 & 4.760 & 98.299 & 86.584 & 99.647 & 95.230 \\
\hline 2.380 & 68.767 & 86.791 & 66.964 & 68.770 & 2.380 & 93.681 & 61.296 & 98.947 & 72.008 \\
\hline 2.000 & 63.826 & 81.663 & 62.876 & 61.366 & 2.000 & 90.946 & 53.115 & 98.537 & 63.005 \\
\hline 1.180 & 46.718 & 56.561 & 49.608 & 36.448 & 1.180 & 78.284 & 34.102 & 96.418 & 40.969 \\
\hline 1.000 & 40.601 & 47.332 & 44.884 & 29.562 & 1.000 & 72.612 & 28.588 & 95.512 & 35.707 \\
\hline 0.850 & 35.962 & 38.209 & 40.153 & 24.674 & 0.850 & 67.203 & 24.525 & 94.523 & 31.593 \\
\hline 0.500 & 18.959 & 14.010 & 21.686 & 10.669 & 0.500 & 41.228 & 12.084 & 87.522 & 18.467 \\
\hline 0.300 & 9.687 & 5.259 & 9.685 & 4.794 & 0.300 & 16.703 & 4.907 & 65.325 & 9.456 \\
\hline 0.250 & 6.554 & 3.266 & 7.092 & 3.439 & 0.250 & 9.822 & 3.323 & 53.937 & 6.705 \\
\hline 0.150 & 2.577 & 0.813 & 3.213 & 1.740 & 0.150 & 1.686 & 1.401 & 13.696 & 2.490 \\
\hline 0.075 & 1.383 & 0.166 & 1.430 & 0.703 & 0.075 & 0.477 & 0.429 & 3.026 & 0.631 \\
\hline Pan & 0.000 & -0.002 & 0.002 & 0.003 & Pan & -0.004 & -0.003 & 0.002 & -0.005 \\
\hline \multicolumn{3}{|c|}{ La Cholla Road Bridge } & \multicolumn{5}{|c|}{ Union Pacific Rail Road Bridge } & & \\
\hline \multicolumn{3}{|c|}{ Site: Upstream Center } & \multicolumn{3}{|c|}{ Upstream Left Center } & \multicolumn{2}{|c|}{ Upstream Right } & & \\
\hline & Surface & Substrate & & Surface & Substrate & Surface & Substrate & & \\
\hline $\begin{array}{l}\text { Sieve } \\
\text { size } \\
(\mathrm{mm})\end{array}$ & $\begin{array}{c}\text { Percent } \\
\text { finer } \\
(\%)\end{array}$ & $\begin{array}{c}\text { Percent } \\
\text { finer }(\%)\end{array}$ & $\begin{array}{l}\text { Sieve } \\
\text { size } \\
(\mathrm{mm})\end{array}$ & $\begin{array}{l}\text { Percent } \\
\text { finer }(\%)\end{array}$ & $\begin{array}{l}\text { Percent } \\
\text { finer }(\%)\end{array}$ & $\begin{array}{c}\text { Percent } \\
\text { finer } \\
(\%)\end{array}$ & $\begin{array}{c}\text { Percent } \\
\text { finer }(\%)\end{array}$ & & \\
\hline 6.350 & 94.810 & 86.480 & 6.350 & 92.710 & 98.160 & 99.260 & 91.760 & & \\
\hline 4.760 & 92.105 & 81.352 & 4.760 & 88.758 & 96.906 & 98.774 & 89.960 & & \\
\hline 2.380 & 74.881 & 63.251 & 2.380 & 69.562 & 86.462 & 95.511 & 76.288 & & \\
\hline 2.000 & 67.287 & 57.252 & 2.000 & 62.445 & 80.114 & 93.584 & 70.352 & & \\
\hline 1.180 & 41.102 & 38.824 & 1.180 & 43.084 & 55.189 & 86.998 & 49.453 & & \\
\hline 1.000 & 33.570 & 33.369 & 1.000 & 38.093 & 47.489 & 84.064 & 43.357 & & \\
\hline 0.850 & 27.229 & 28.872 & 0.850 & 34.394 & 41.601 & 81.617 & 38.081 & & \\
\hline 0.500 & 10.251 & 14.150 & 0.500 & 23.373 & 22.467 & 66.638 & 20.074 & & \\
\hline 0.300 & 4.394 & 5.715 & 0.300 & 21.723 & 9.143 & 47.381 & 8.240 & & \\
\hline 0.250 & 3.518 & 3.742 & 0.250 & 19.014 & 6.066 & 40.239 & 5.328 & & \\
\hline 0.150 & 1.858 & 1.465 & 0.150 & 12.120 & 2.177 & 14.065 & 1.823 & & \\
\hline 0.075 & 0.705 & 0.539 & 0.075 & 6.575 & 0.609 & 4.372 & 0.325 & & \\
\hline Pan & -0.002 & -0.005 & Pan & 0.002 & 0.002 & -0.002 & 0.005 & & \\
\hline
\end{tabular}




\begin{tabular}{|c|c|c|c|c|c|}
\hline \multicolumn{3}{|c|}{ I-10 Westbound Frontage Road Bridge } & \multicolumn{3}{c|}{ I-10 Eastbound Frontage Road Bridge } \\
\hline \multicolumn{2}{|c|}{ Site: Upstream Center } & \multicolumn{3}{c|}{ Site: Upstream Center } \\
\hline $\begin{array}{c}\text { Sieve } \\
\text { size } \\
(\mathrm{mm})\end{array}$ & $\begin{array}{c}\text { Purface } \\
\text { finer (\%) }\end{array}$ & $\begin{array}{c}\text { Substrate } \\
(\%)\end{array}$ & $\begin{array}{c}\text { Percent finer } \\
\text { size } \\
(\mathrm{mm})\end{array}$ & $\begin{array}{c}\text { Percent } \\
\text { finer (\%) }\end{array}$ & $\begin{array}{c}\text { Percent finer } \\
(\%)\end{array}$ \\
\hline 6.350 & 93.260 & 95.060 & 6.350 & 100.000 & 100.000 \\
\hline 4.760 & 91.279 & 93.963 & 4.760 & 100.000 & 99.970 \\
\hline 2.380 & 80.361 & 89.187 & 2.380 & 99.994 & 99.930 \\
\hline 2.000 & 76.033 & 87.054 & 2.000 & 99.988 & 99.900 \\
\hline 1.180 & 61.050 & 77.692 & 1.180 & 99.895 & 99.670 \\
\hline 1.000 & 56.214 & 73.936 & 1.000 & 99.852 & 99.519 \\
\hline 0.850 & 51.771 & 70.326 & 0.850 & 99.815 & 99.299 \\
\hline 0.500 & 36.498 & 41.092 & 0.500 & 98.968 & 96.366 \\
\hline 0.300 & 17.786 & 18.732 & 0.300 & 82.863 & 79.457 \\
\hline 0.250 & 13.542 & 11.167 & 0.250 & 74.544 & 67.835 \\
\hline 0.150 & 6.333 & 2.366 & 0.150 & 18.534 & 25.288 \\
\hline 0.075 & 2.886 & 0.466 & 0.075 & 5.383 & 4.765 \\
\hline Pan & -0.001 & 0.000 & Pan & 0.000 & 0.000 \\
\hline
\end{tabular}


Appendix F. Locations of Cross Sections

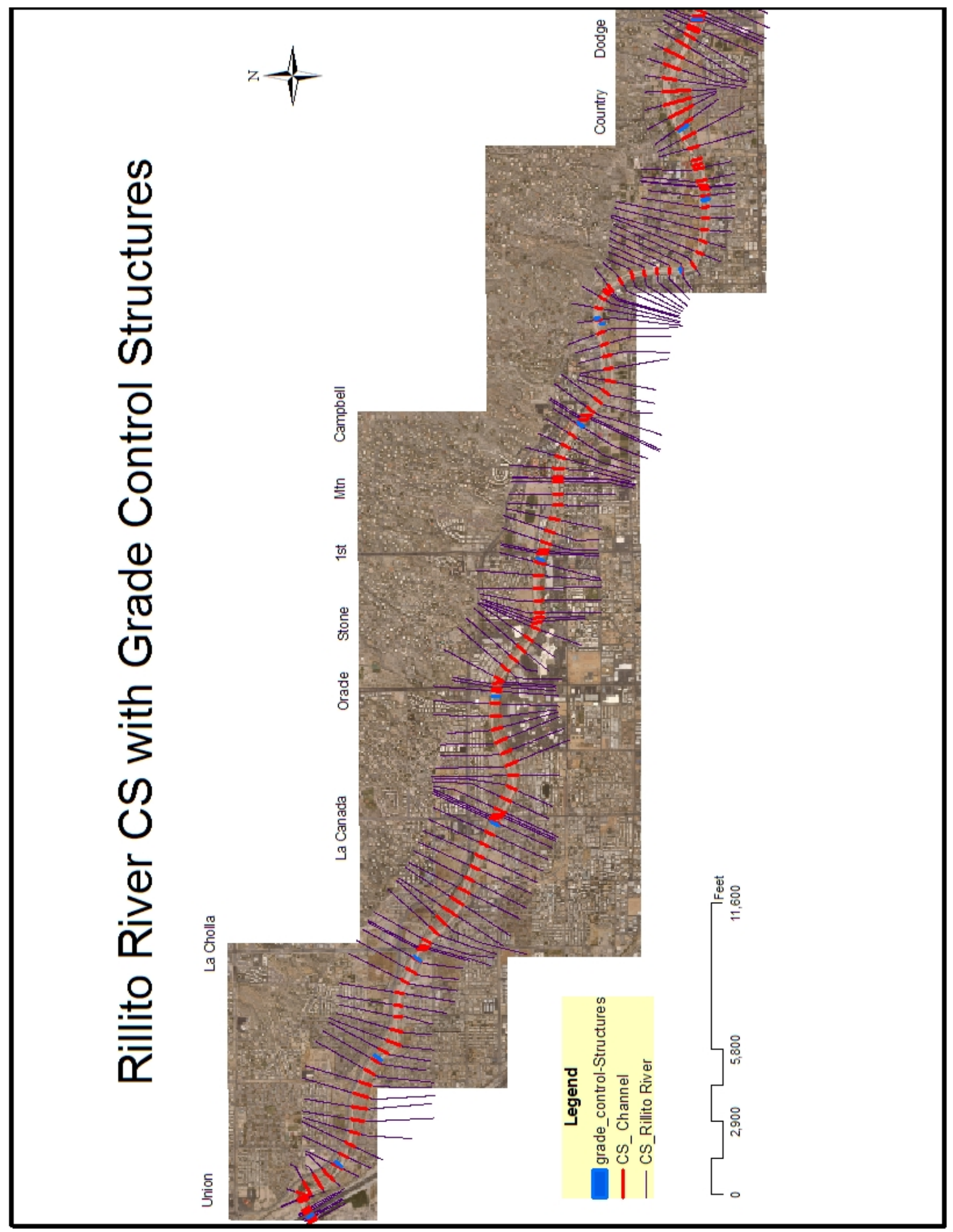




\section{Appendix G. Changes in Cross Sections}
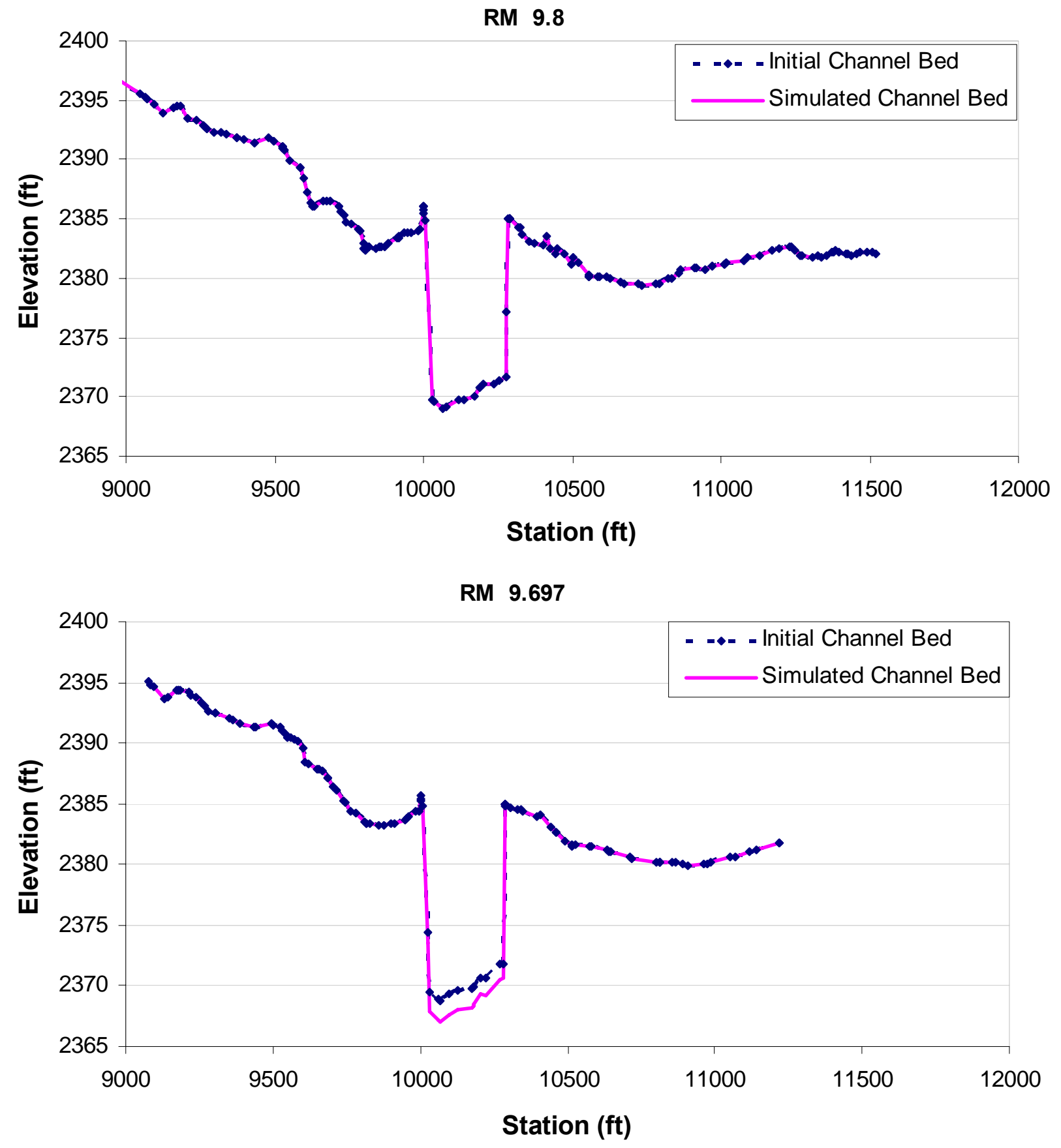

Figure G. 1. Changes of cross sections at River Mile 9.8 and 9.697 

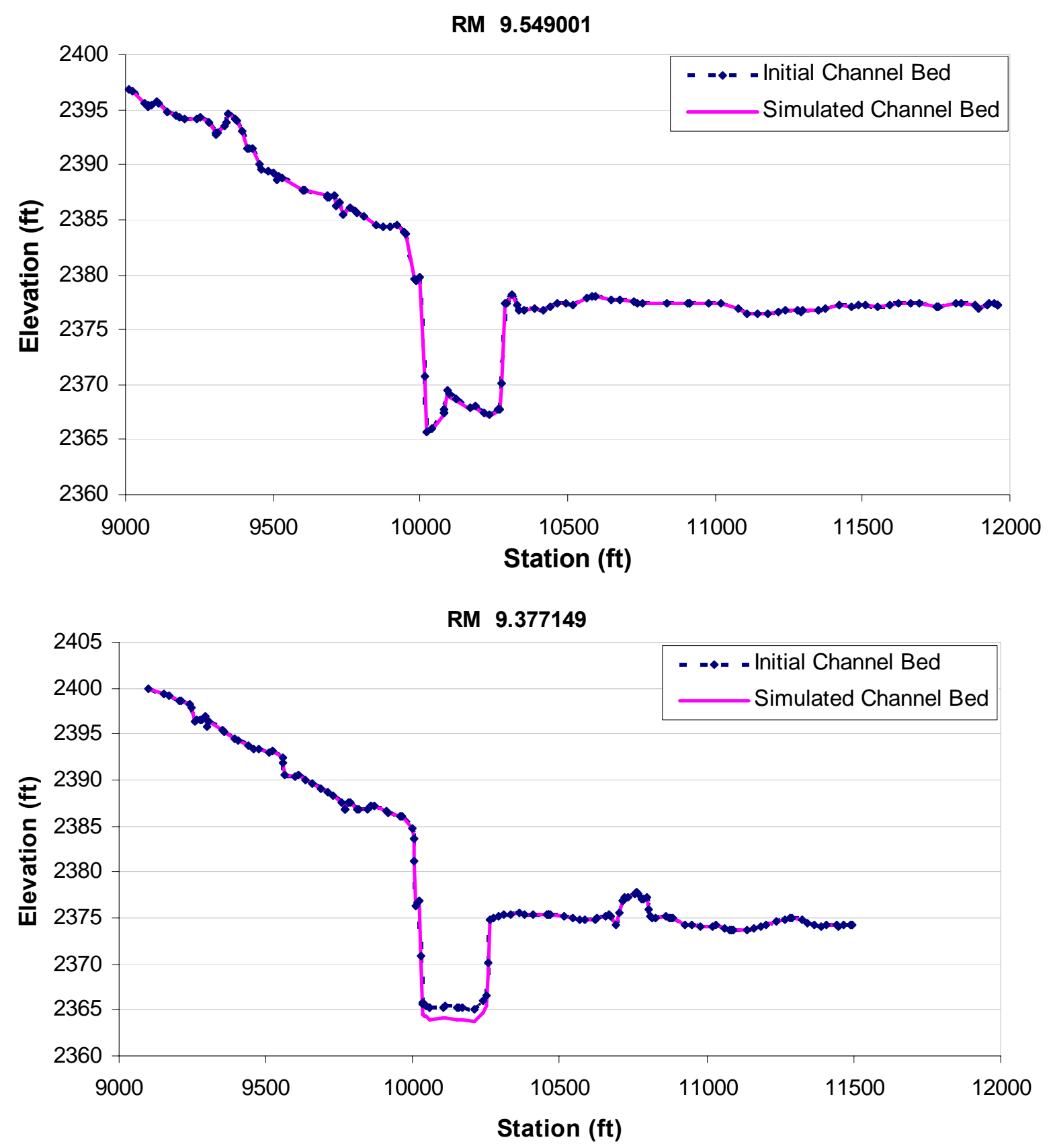

Figure G. 2. Changes of cross sections at River Mile 9.549 and 9.377 
RM 9.197274
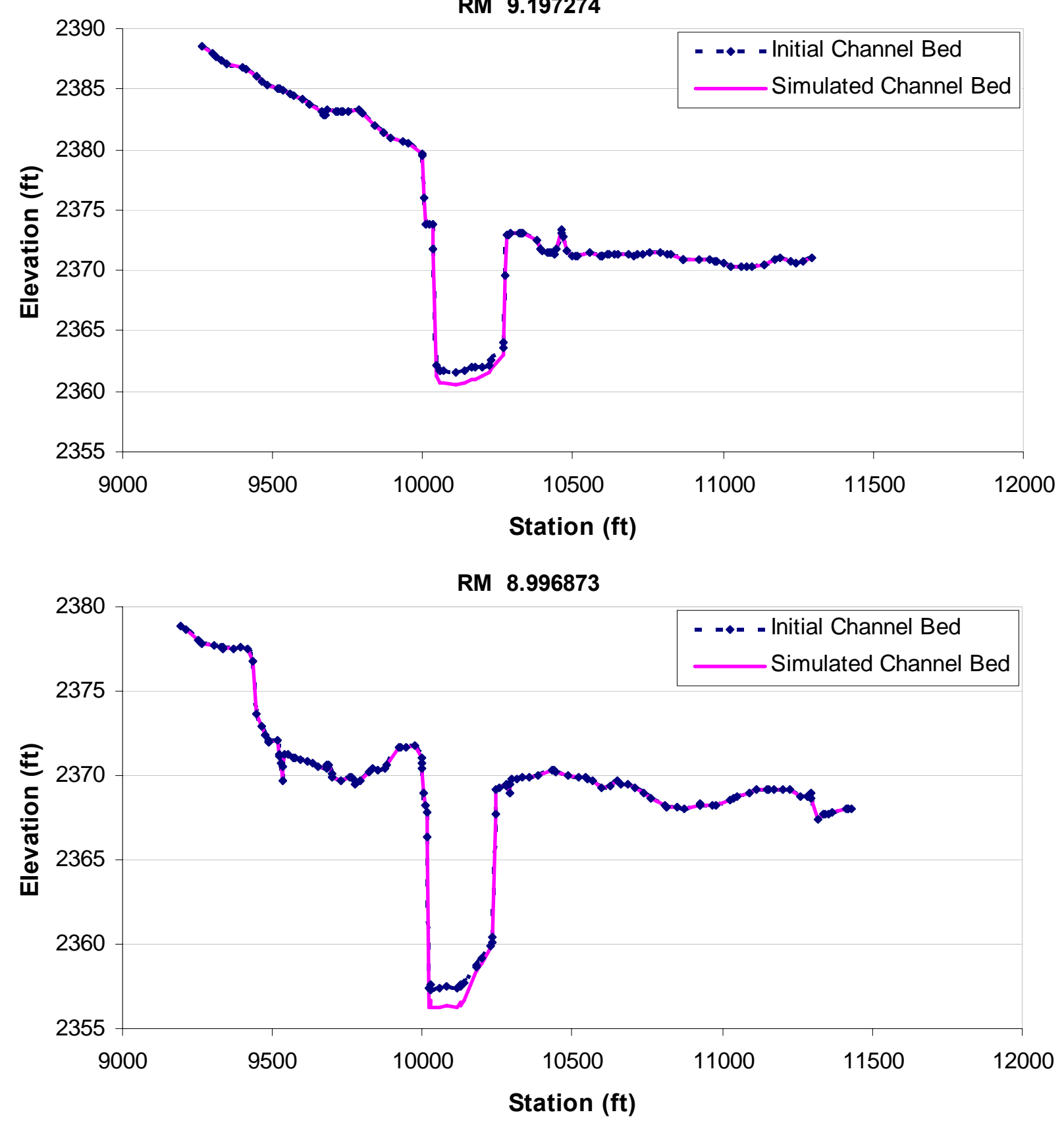

Figure G. 3. Changes of cross sections at River Mile 9.197 and 8.997 
RM 8.80764

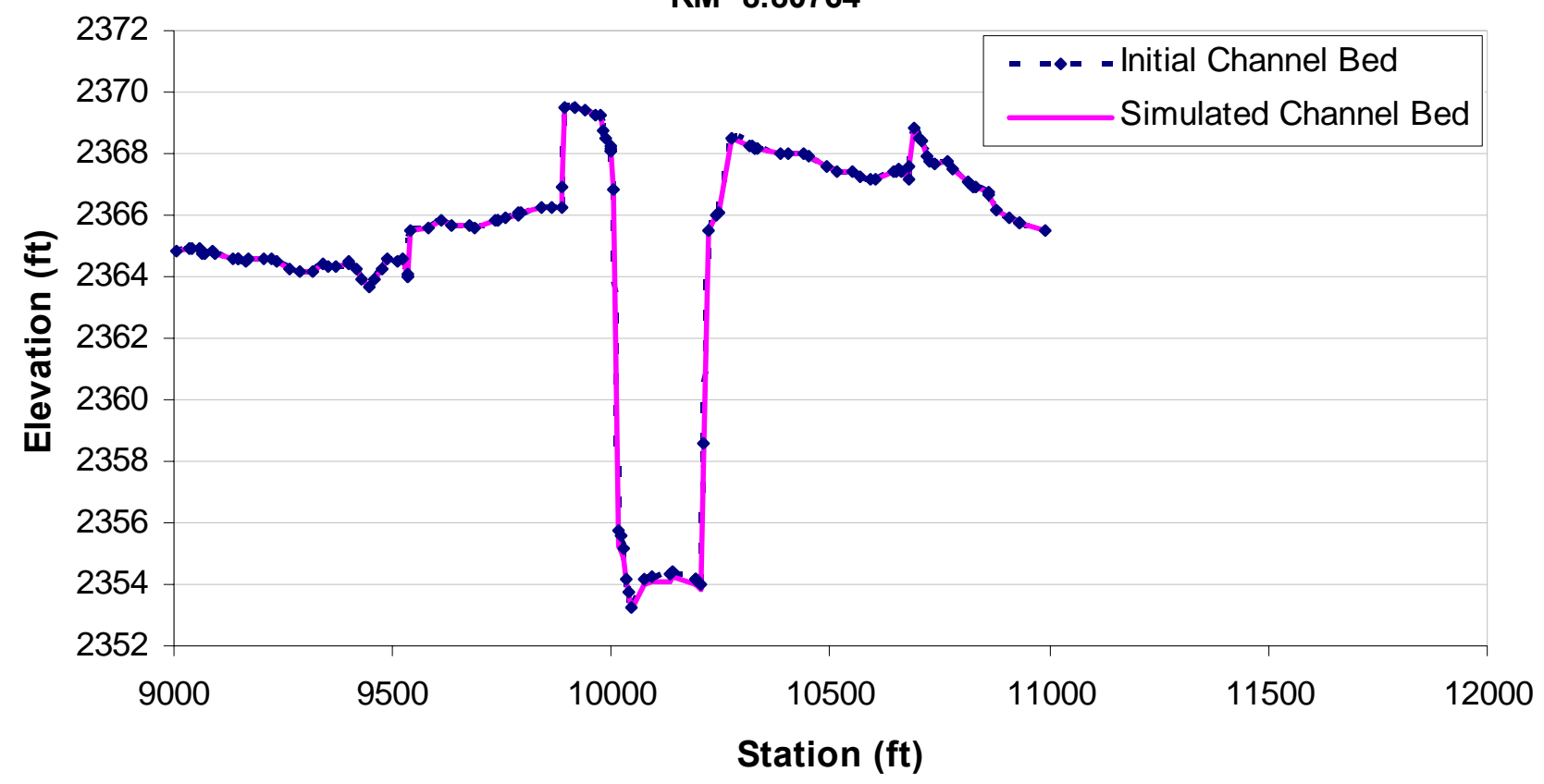

RM 8.617916

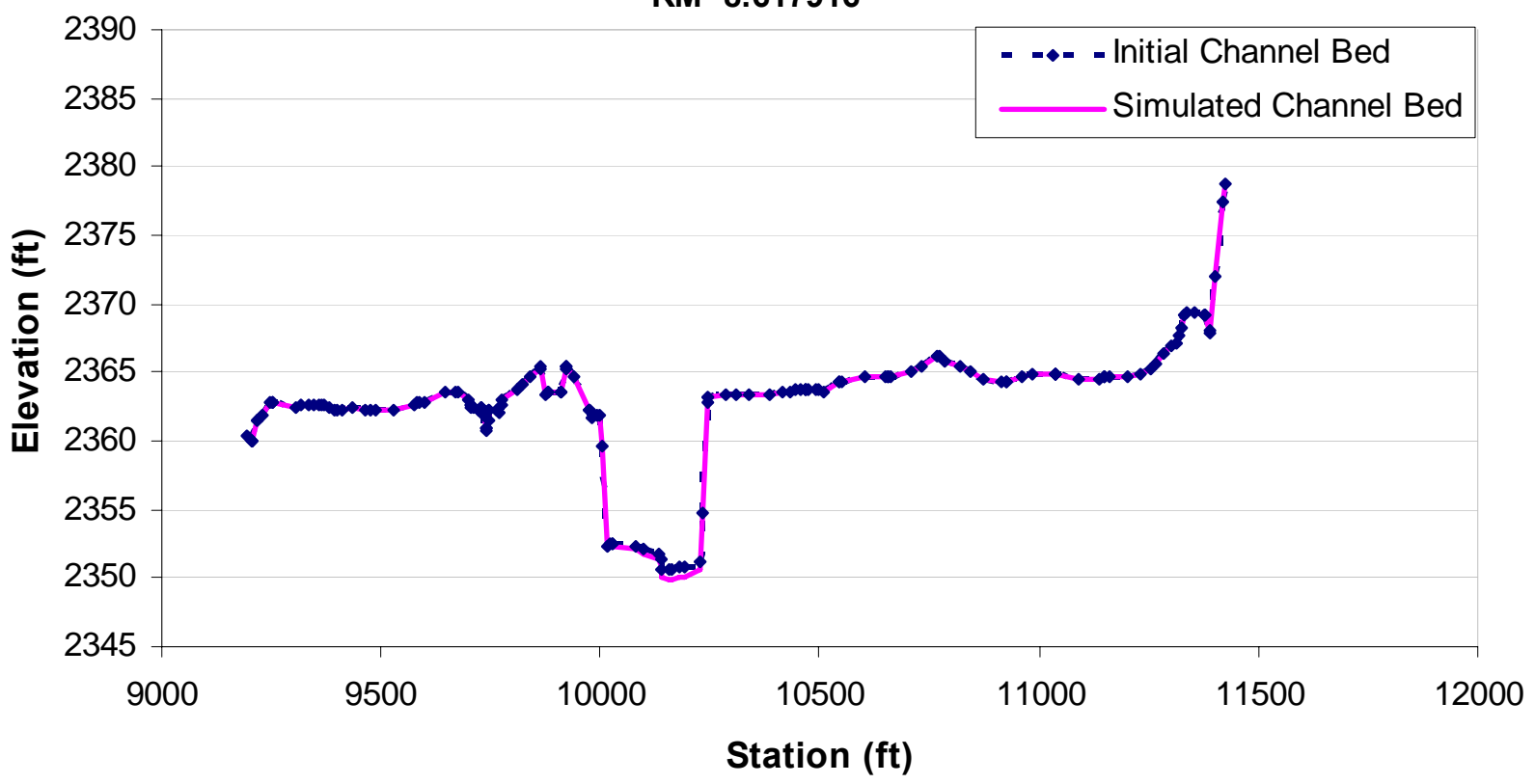

Figure G. 4 Changes of cross sections at River Mile 8.807 and 8.618 

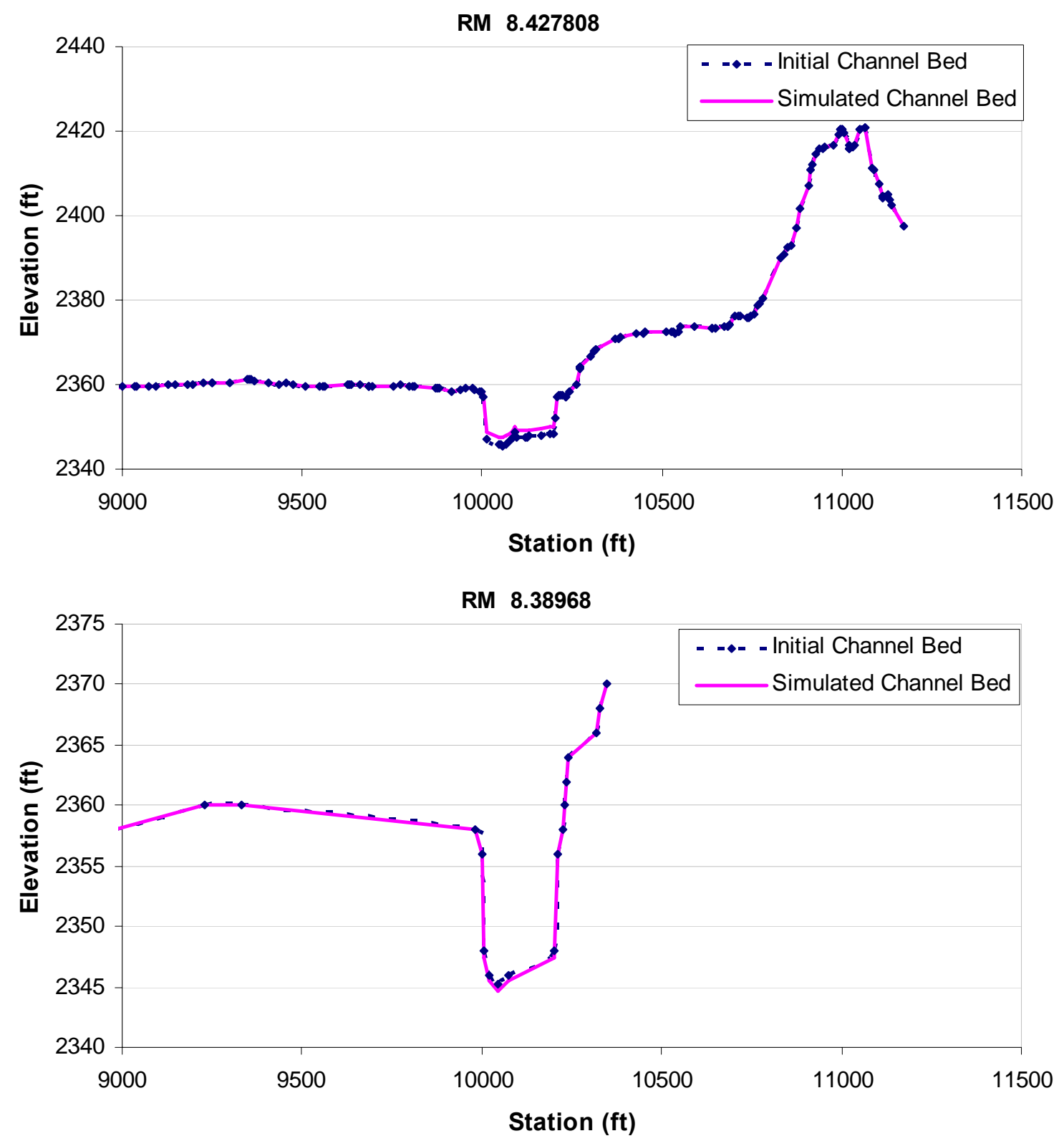

Figure G. 5. Changes of cross sections at River Mile 8.428 and 8.390 

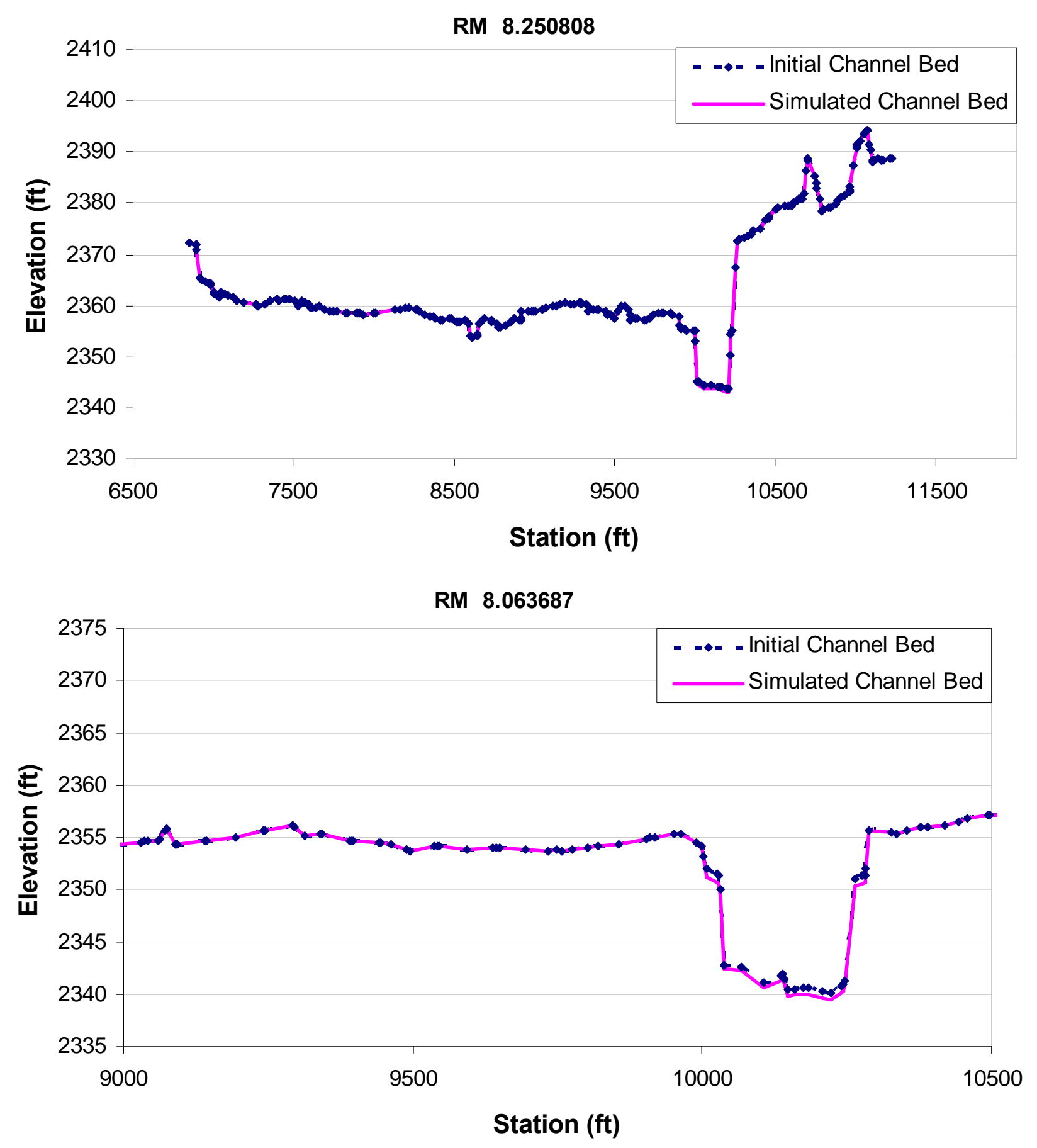

Figure G. 6. Changes of cross sections at River Mile 8.251 and 8.064 
RM 7.880875

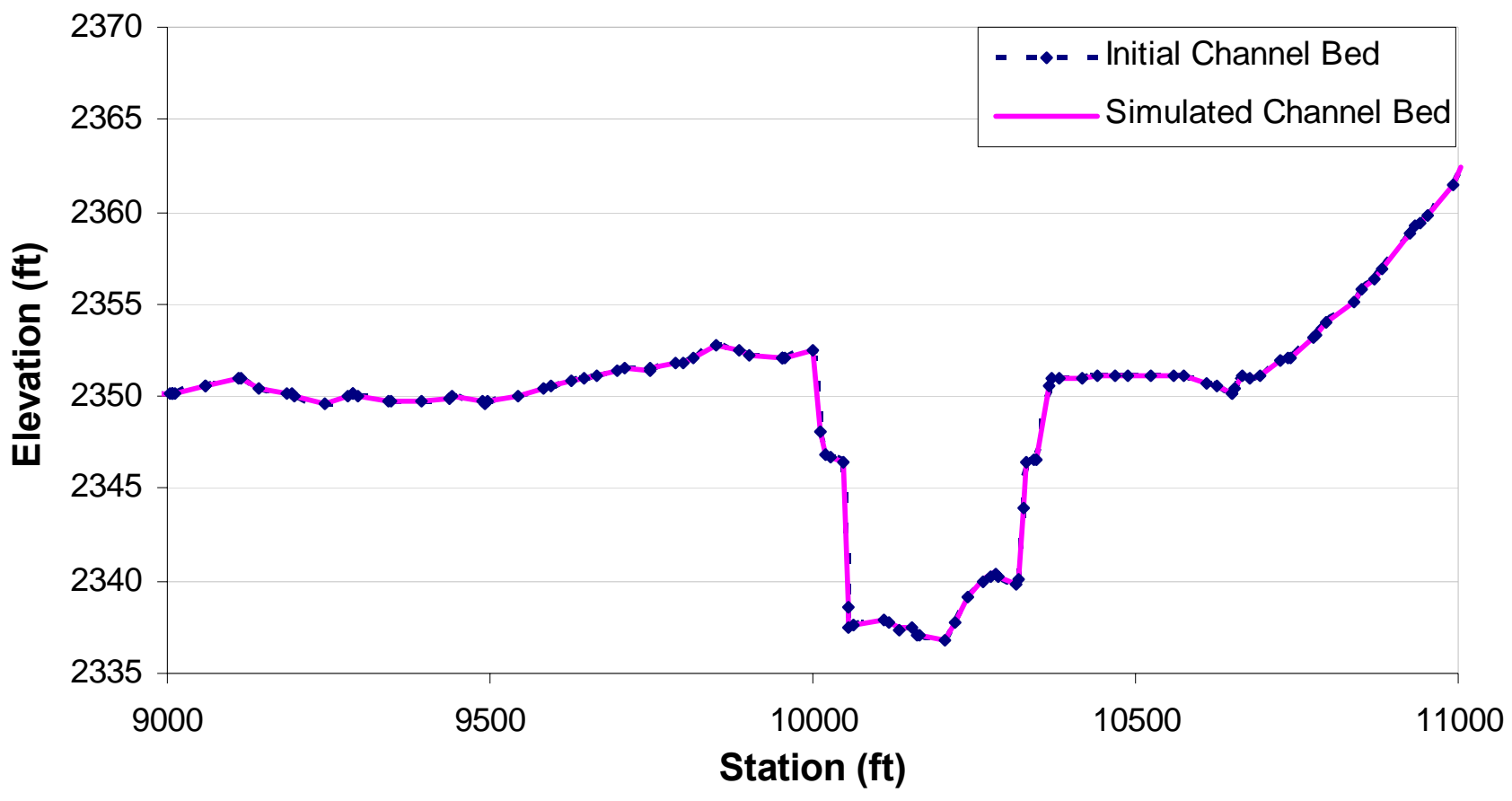

RM 7.689414

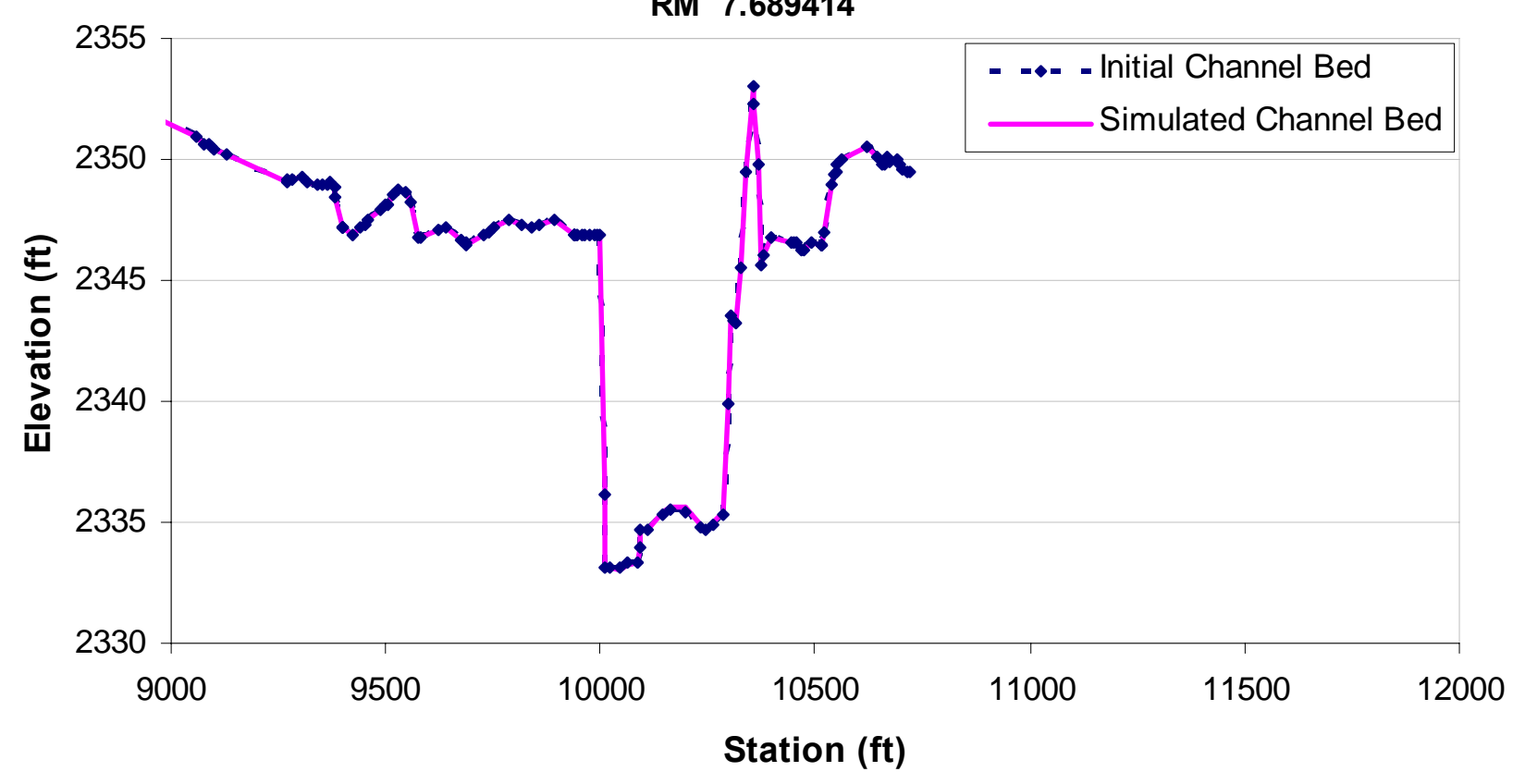

Figure G. 7. Changes of cross sections at River Mile 7.881 and 7.690 

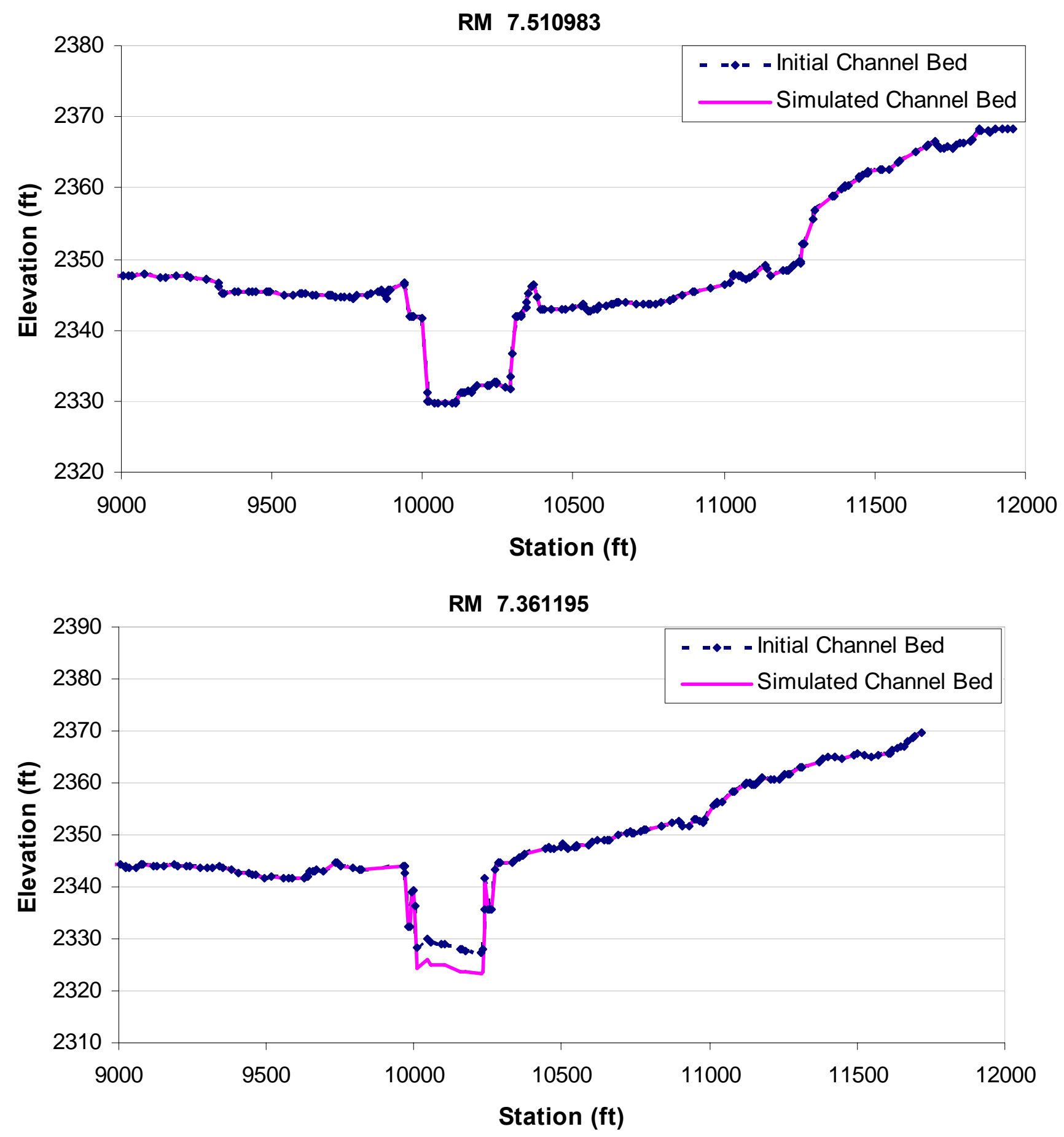

Figure G. 8. Changes of cross sections at River Mile 7.511 and 7.361 
RM 7.281818
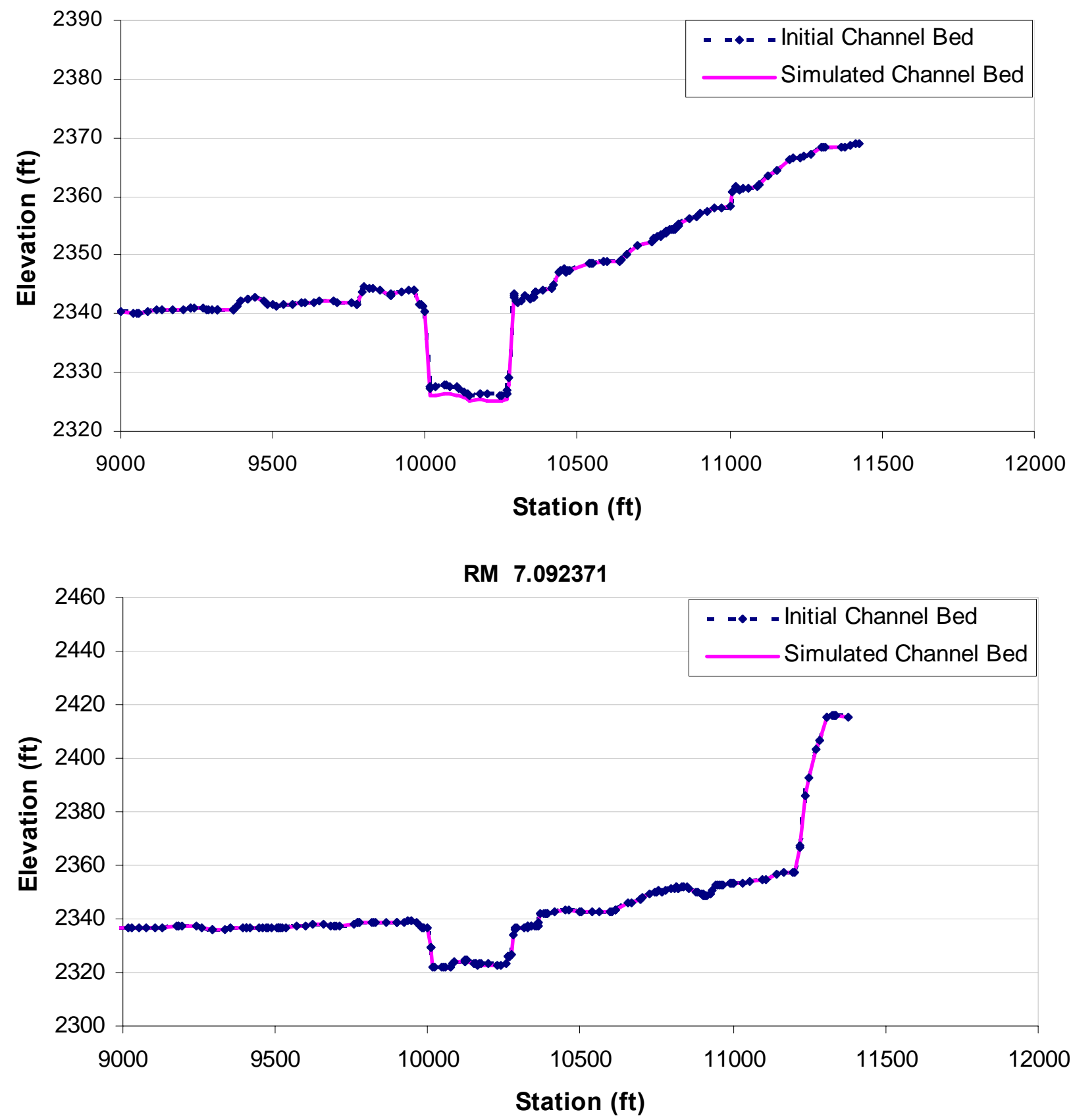

Figure G. 9. Changes of cross sections at River Mile 7.282 and 7.092 

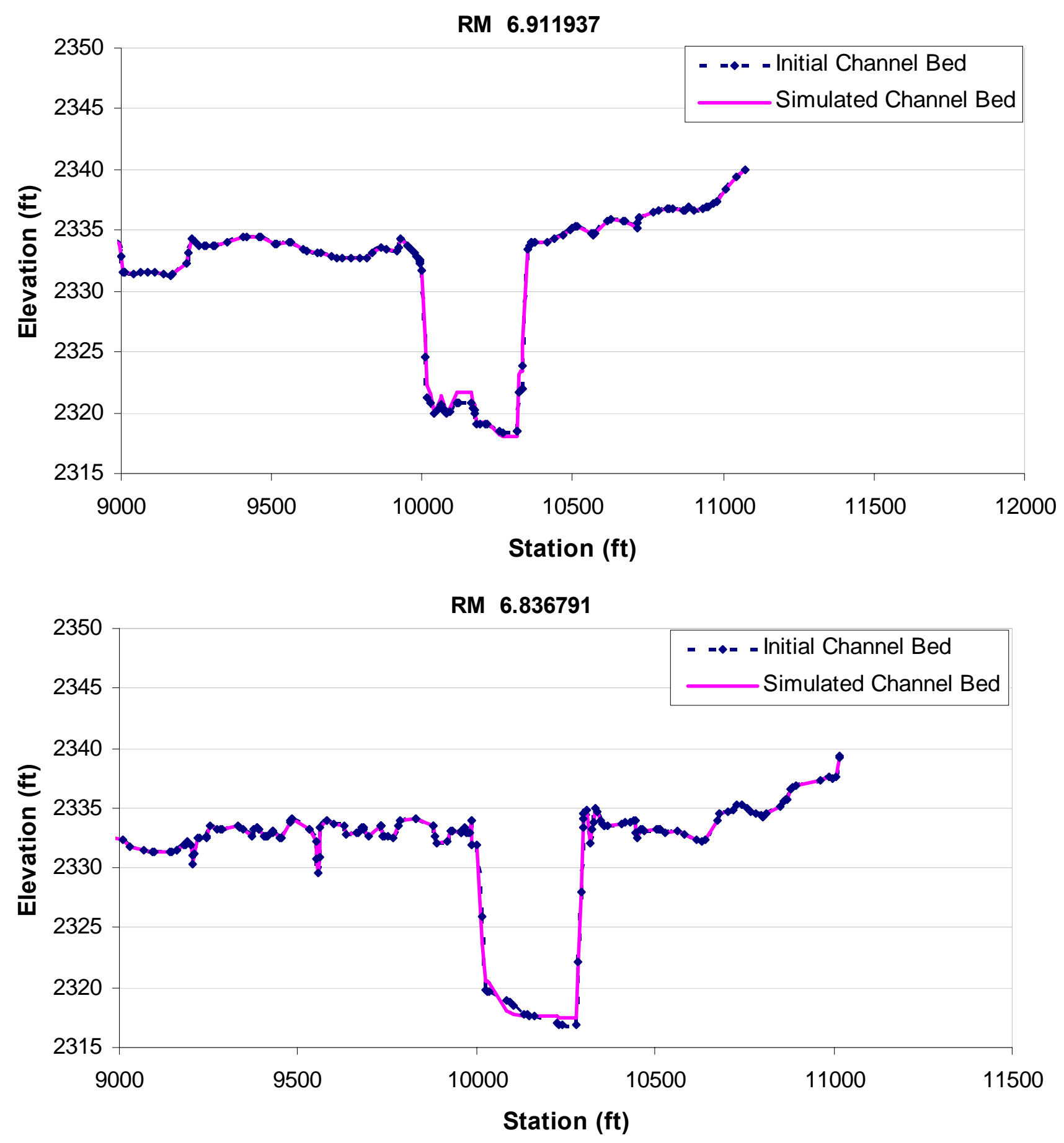

Figure G. 10. Changes of cross sections at River Mile 6.912 and 6.837 

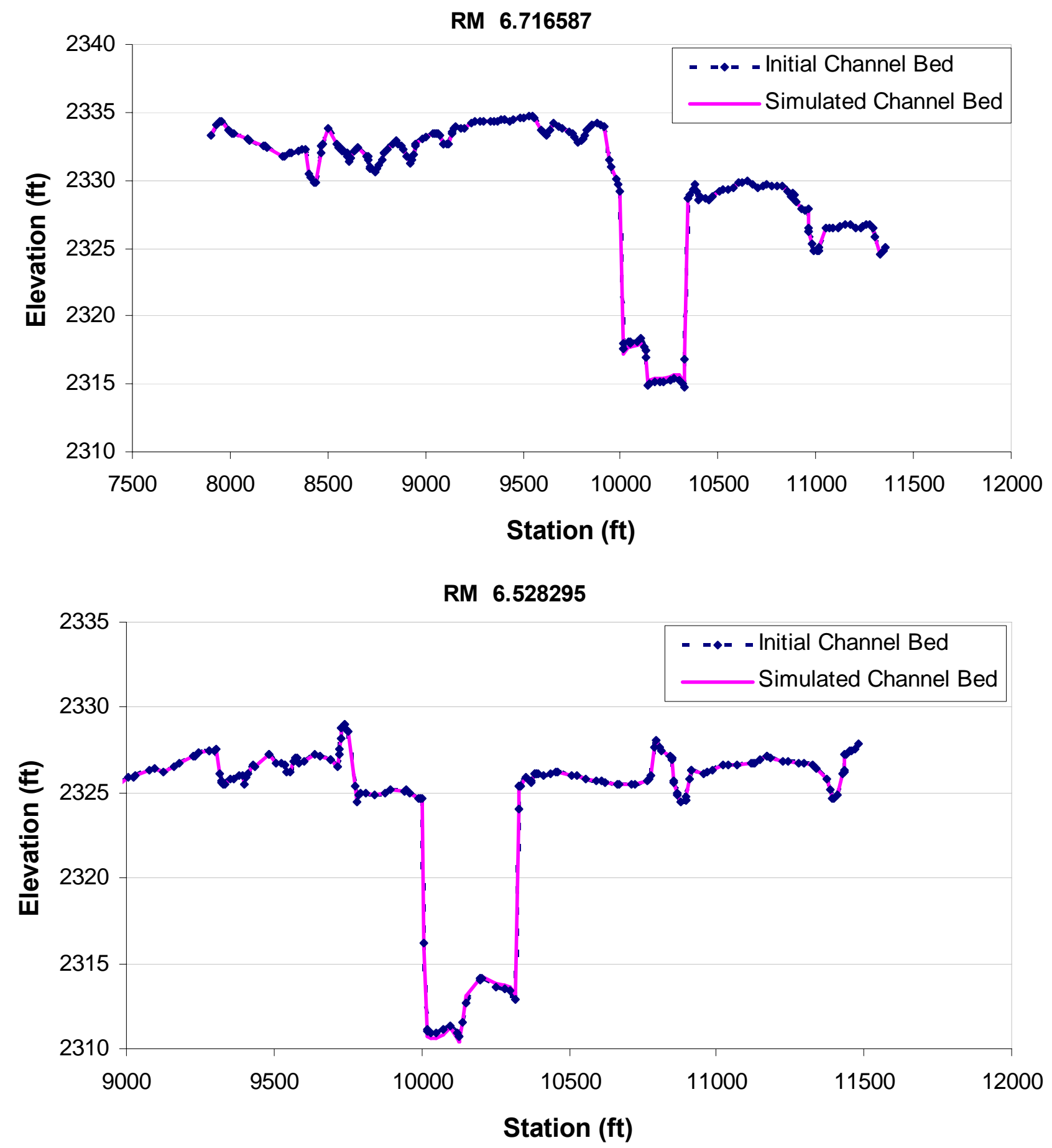

Figure G. 11. Changes of cross sections at River Mile 6.717 and 6.528 
RM 6.339111
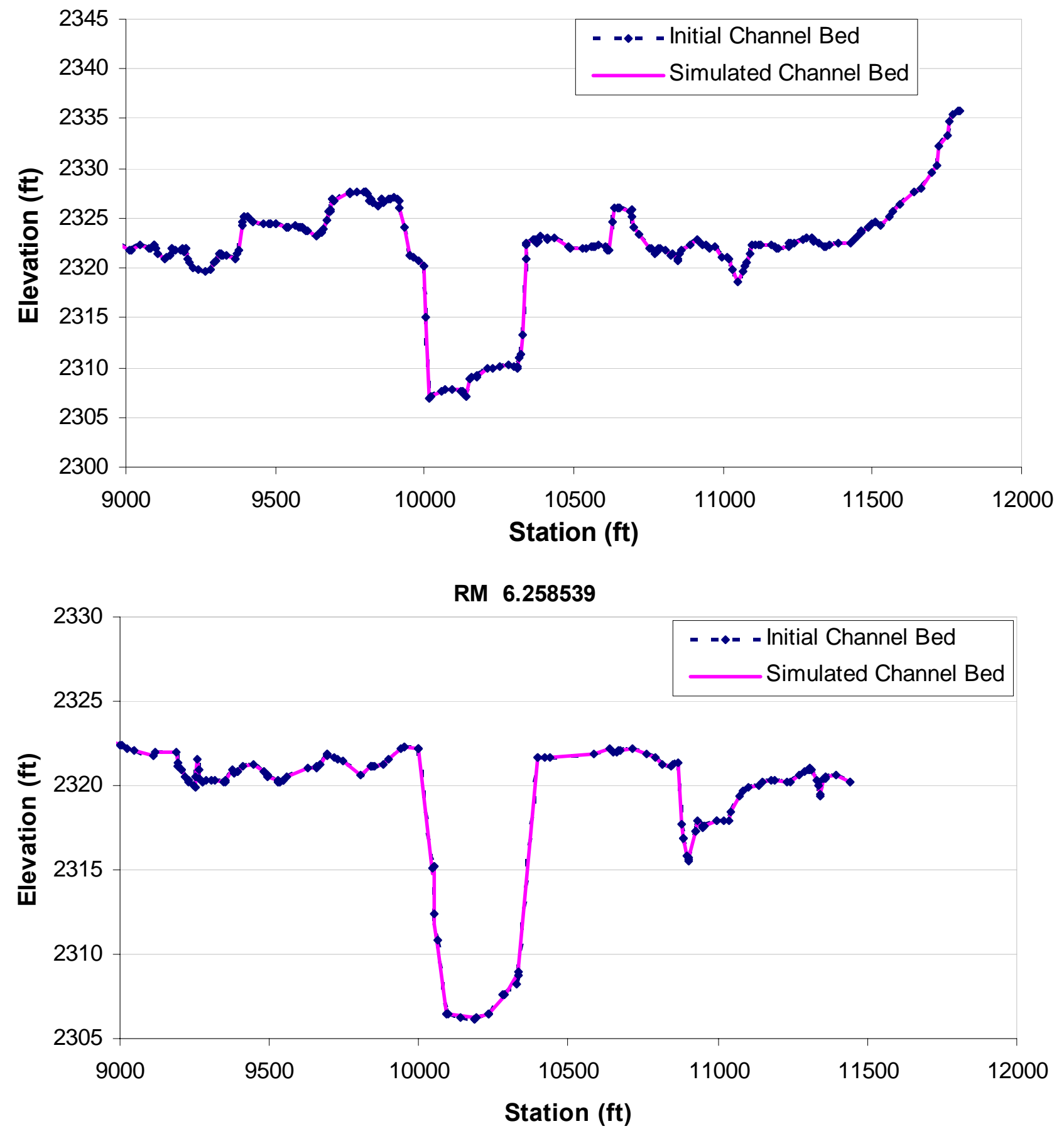

Figure G. 12. Changes of cross sections at River Mile 6.339 and 6.259 

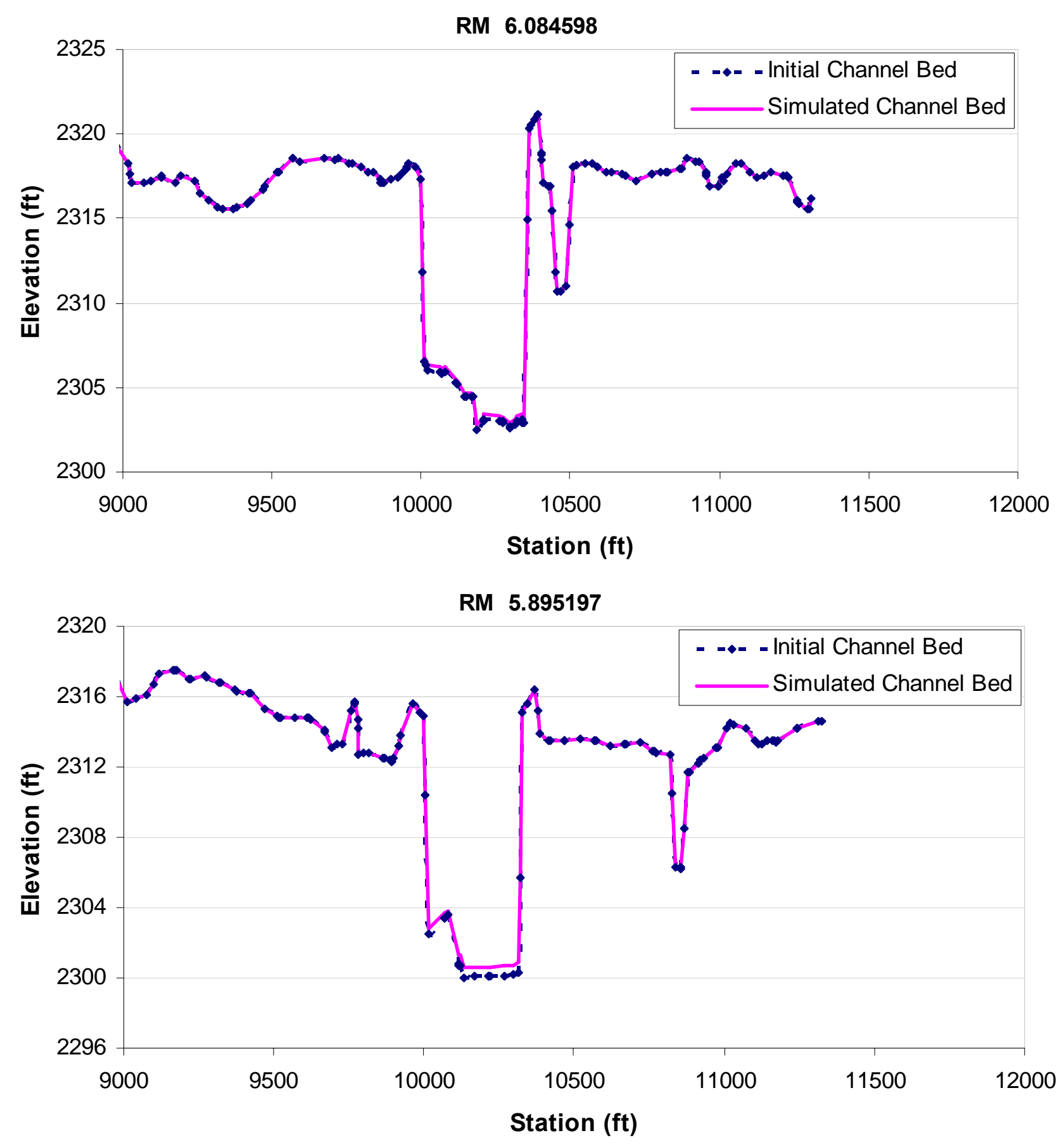

Figure G. 13. Changes of cross sections at River Mile 6.085 and 5.895 
RM 5.756926
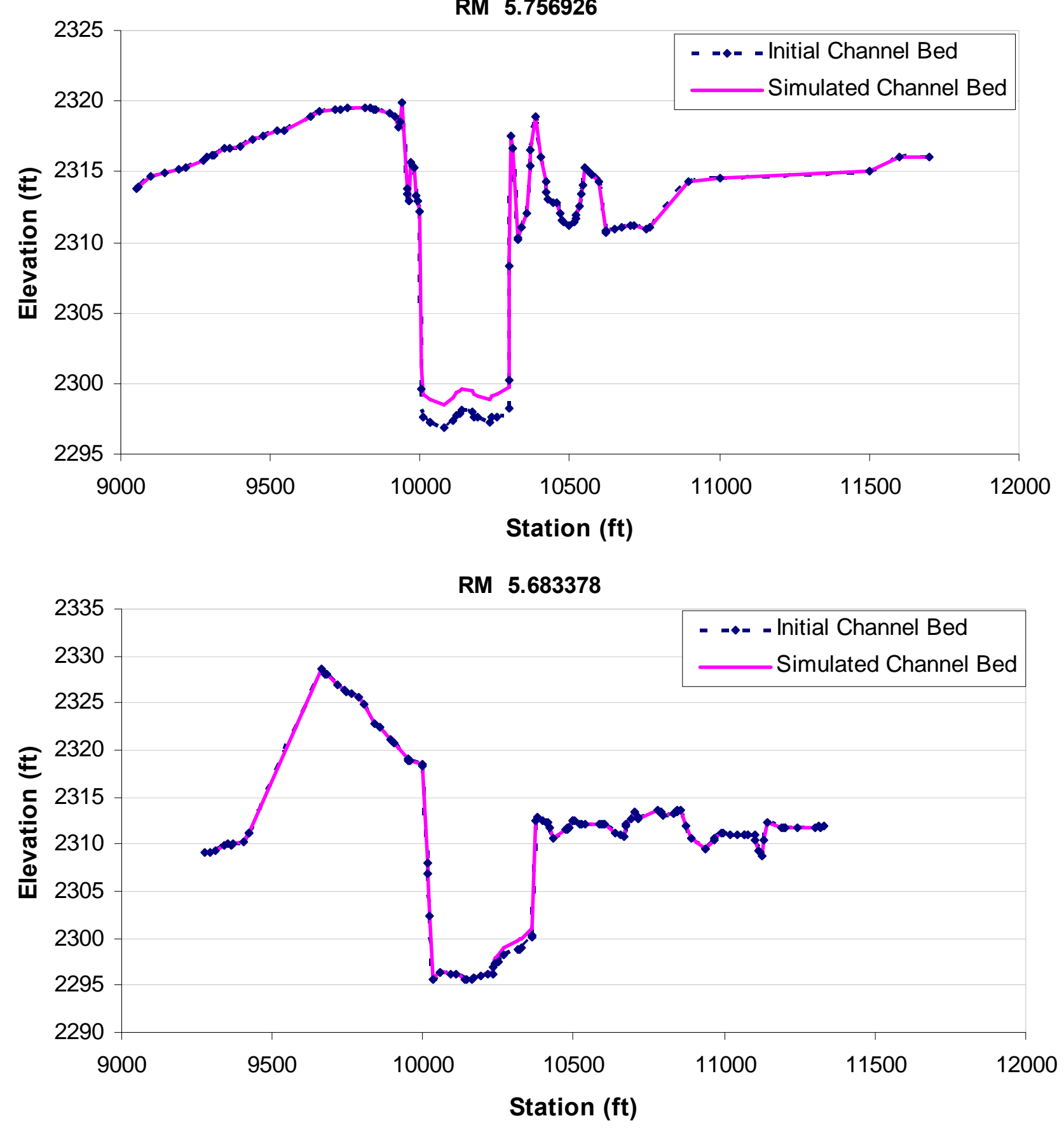

Figure G. 14. Changes of cross sections at River Mile 5.757 and 5.683 

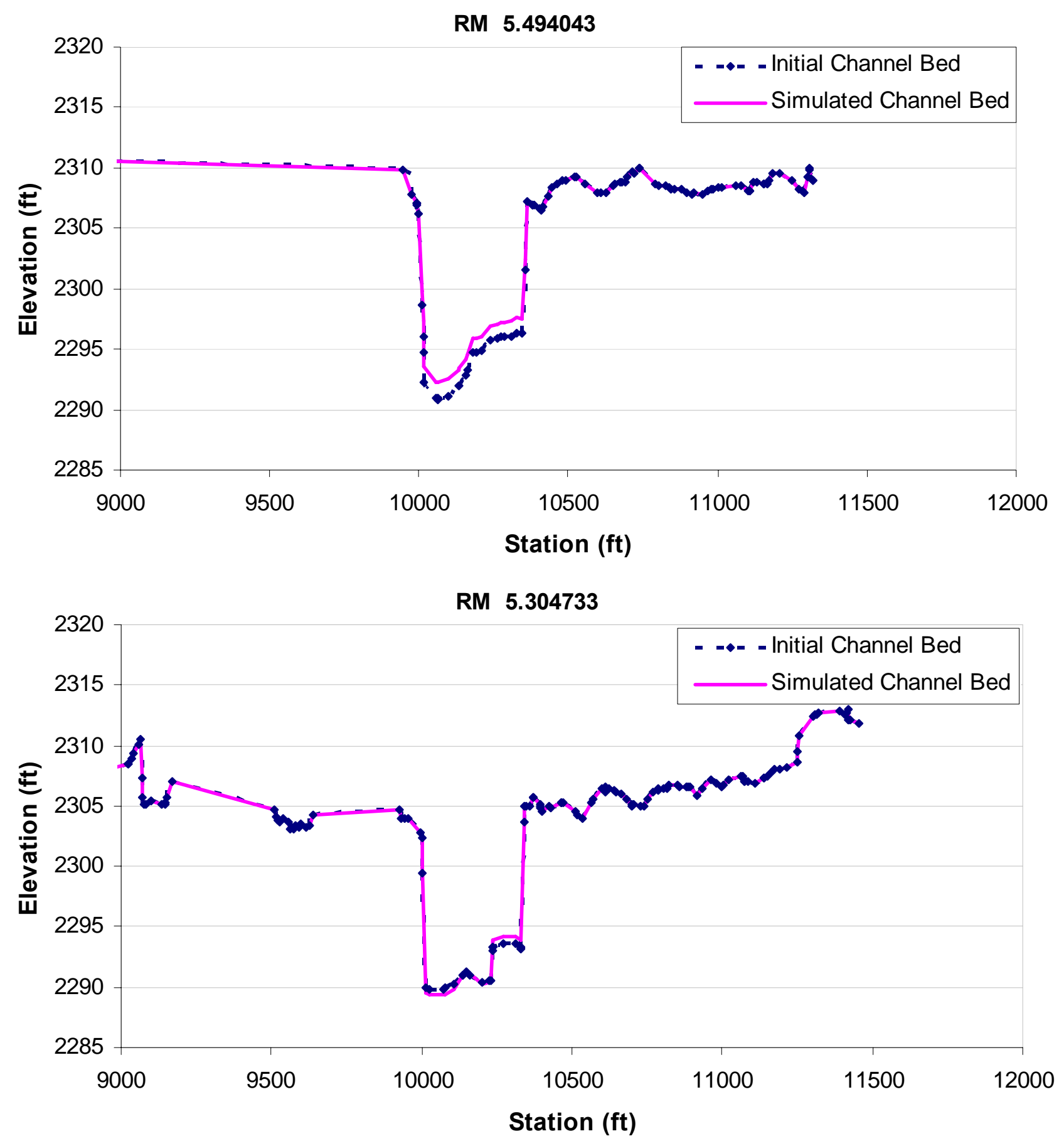

Figure G. 15. Changes of cross sections at River Mile 5.494 and 5.305 

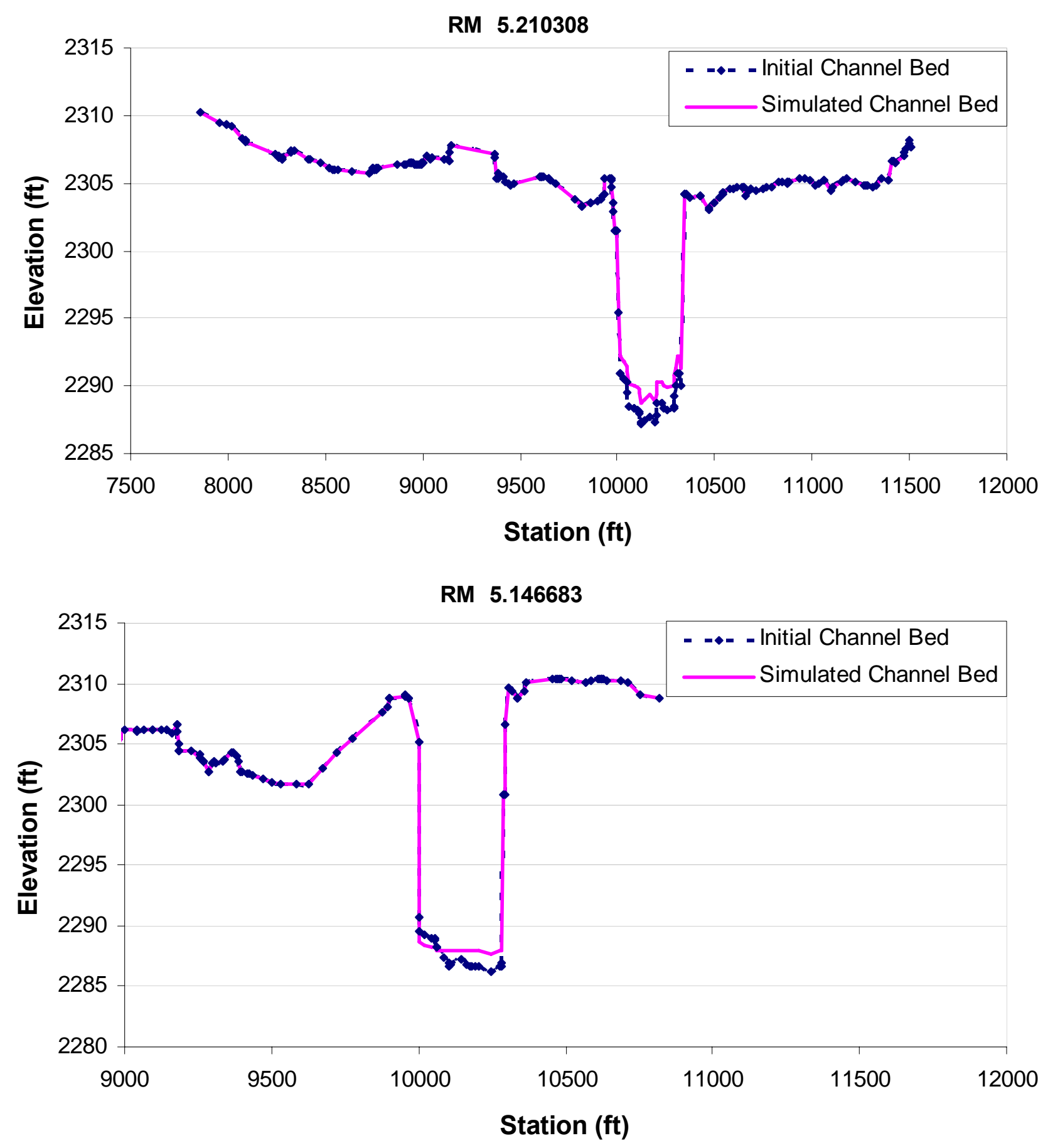

Figure G. 16. Changes of cross sections at River Mile 5.210 and 5.147 
RM $\mathbf{5 . 0 2 0 8 4 4}$
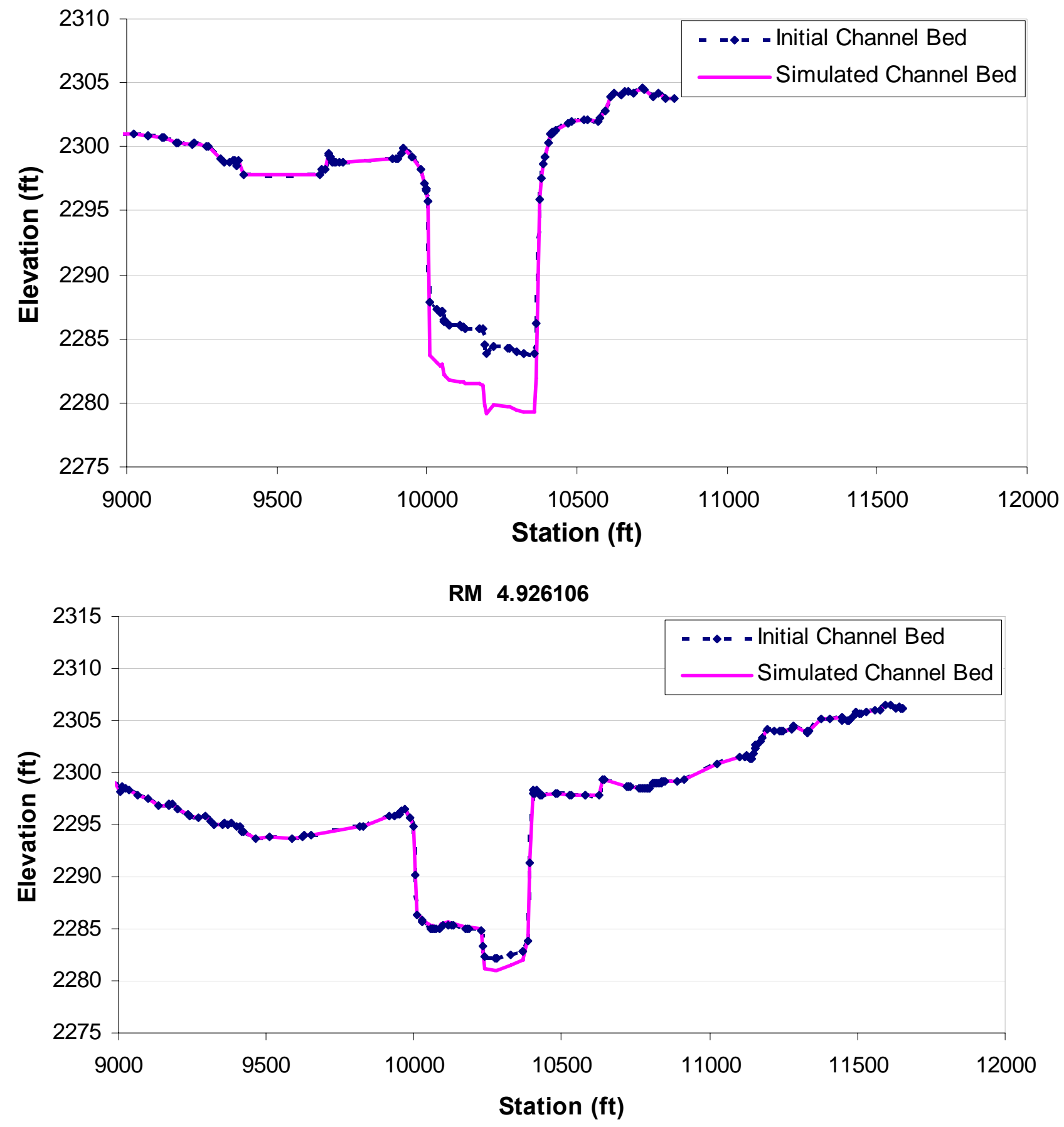

Figure G. 17. Changes of cross sections at River Mile 5.021 and 4.926 

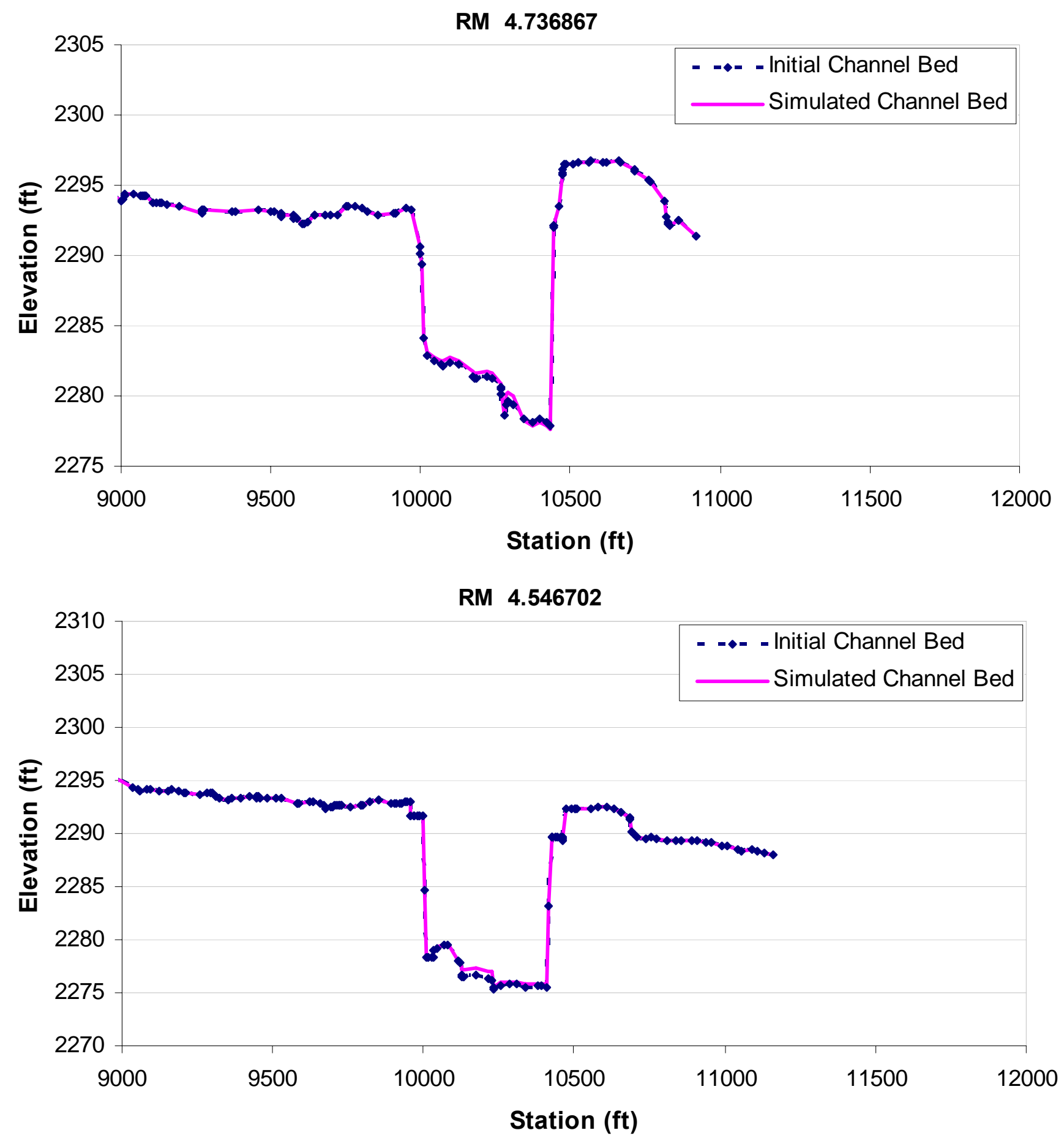

Figure G. 18. Changes of cross sections at River Mile 4.737 and 4.547 

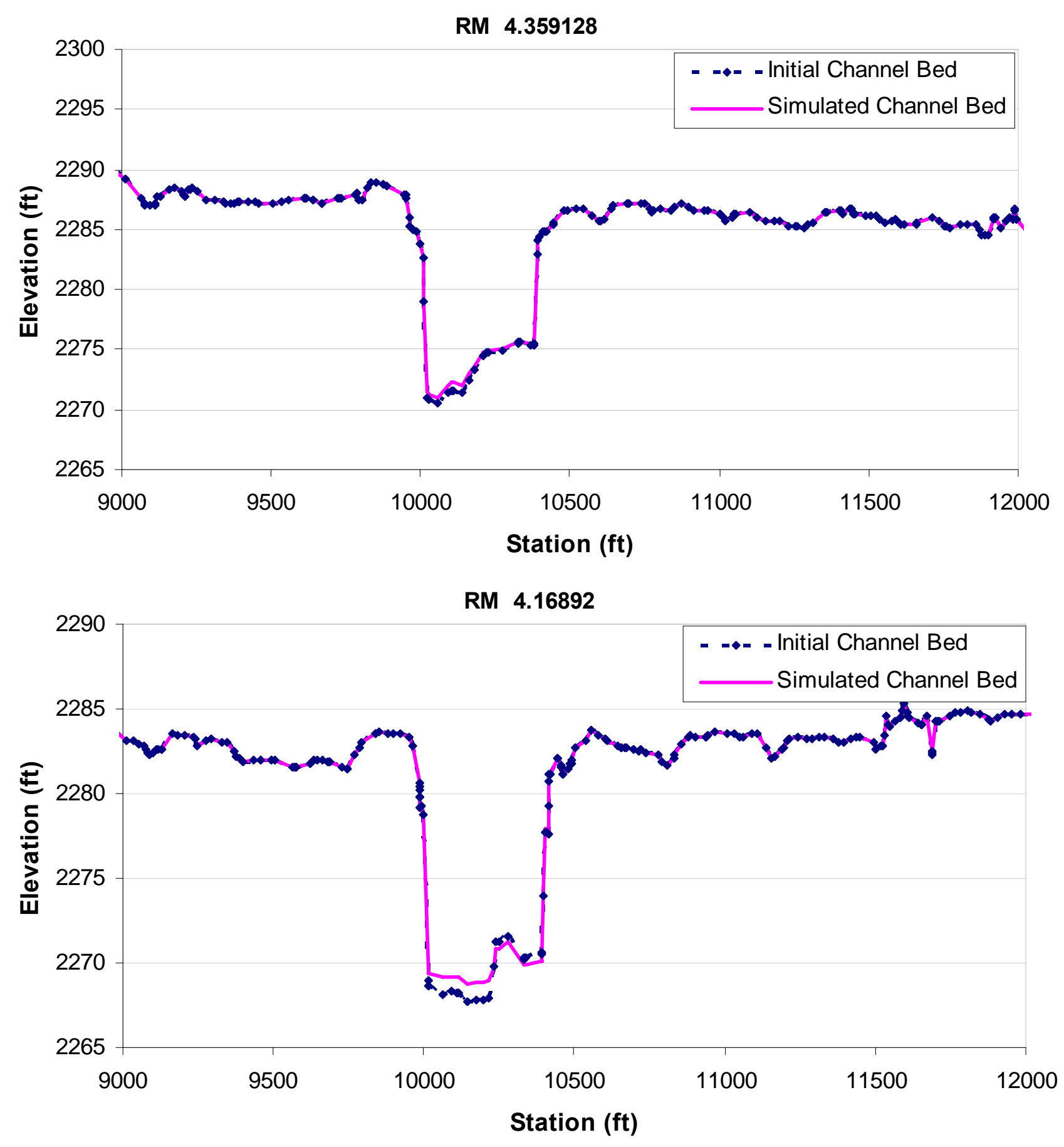

Figure G. 19. Changes of cross sections at River Mile 4.359 and 4.169 
RM 4.112

- -•- - Initial Channel Bed Simulated Channel Bed

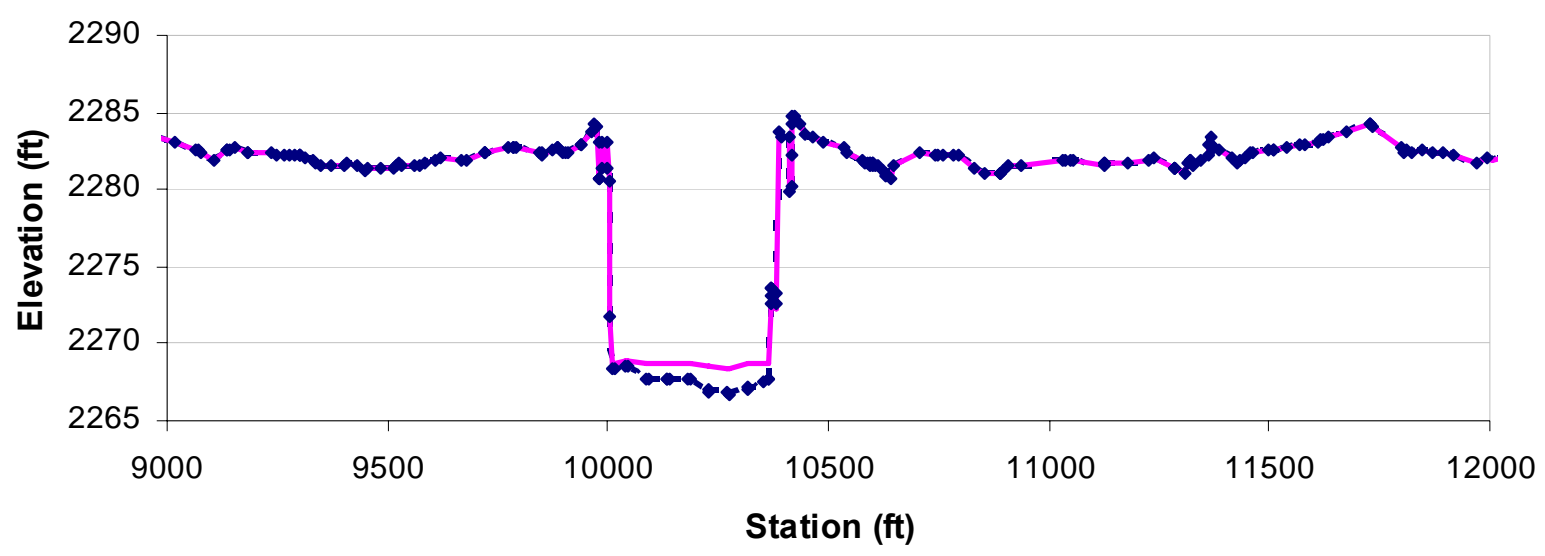

RM 4.073878

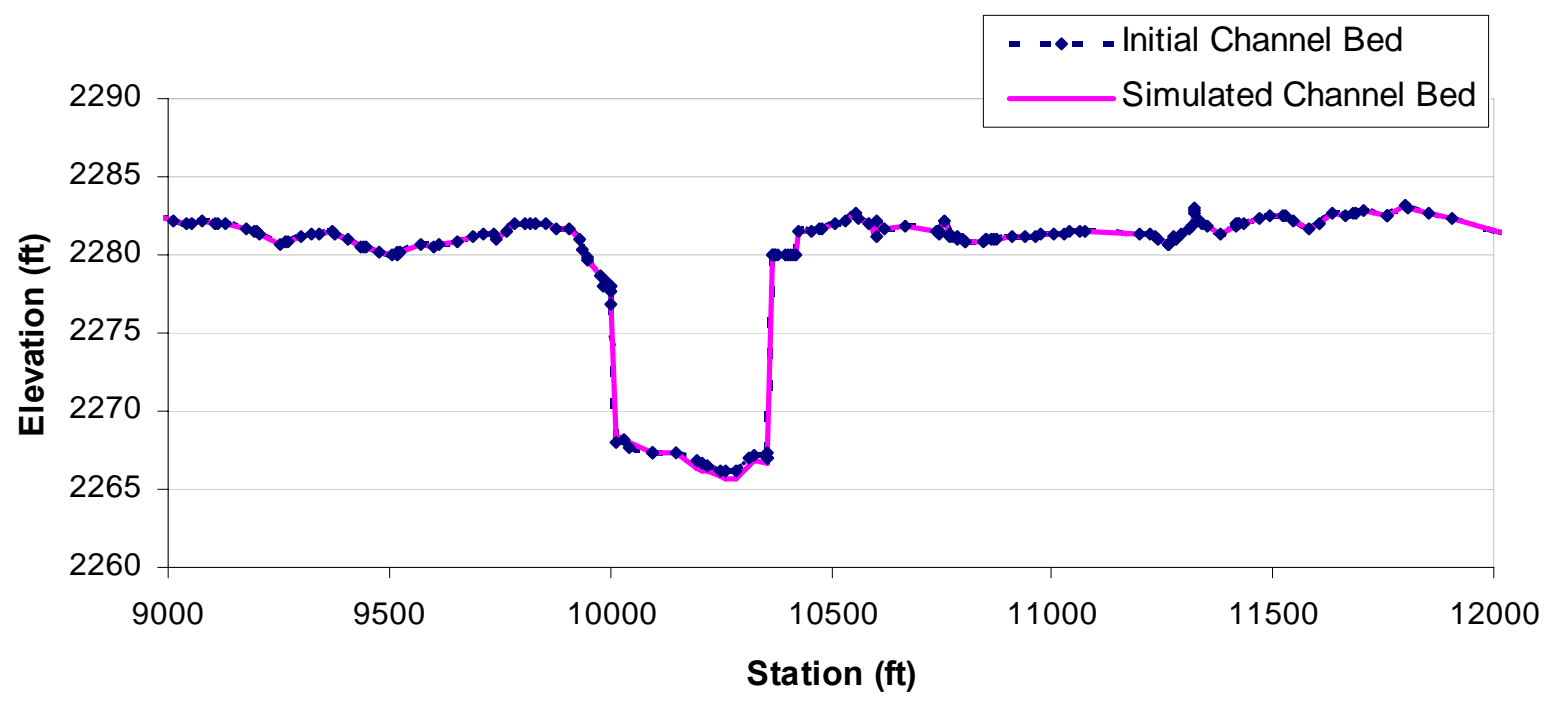

Figure G. 20. Changes of cross sections at River Mile 4.112 and 4.074 
RM 3.884592
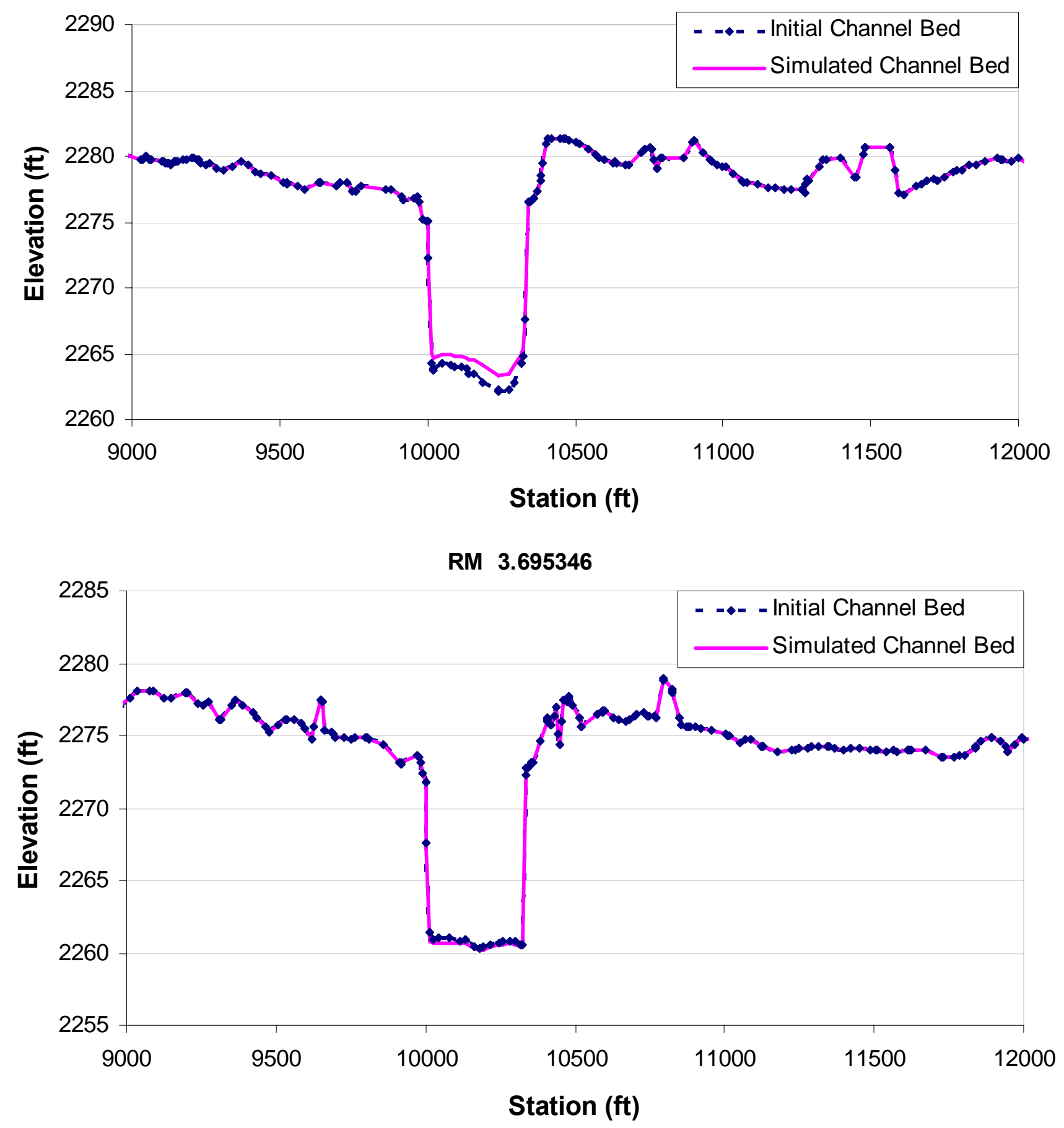

Figure G. 21. Changes of cross sections at River Mile 3.885 and 3.695 
RM 3.506066
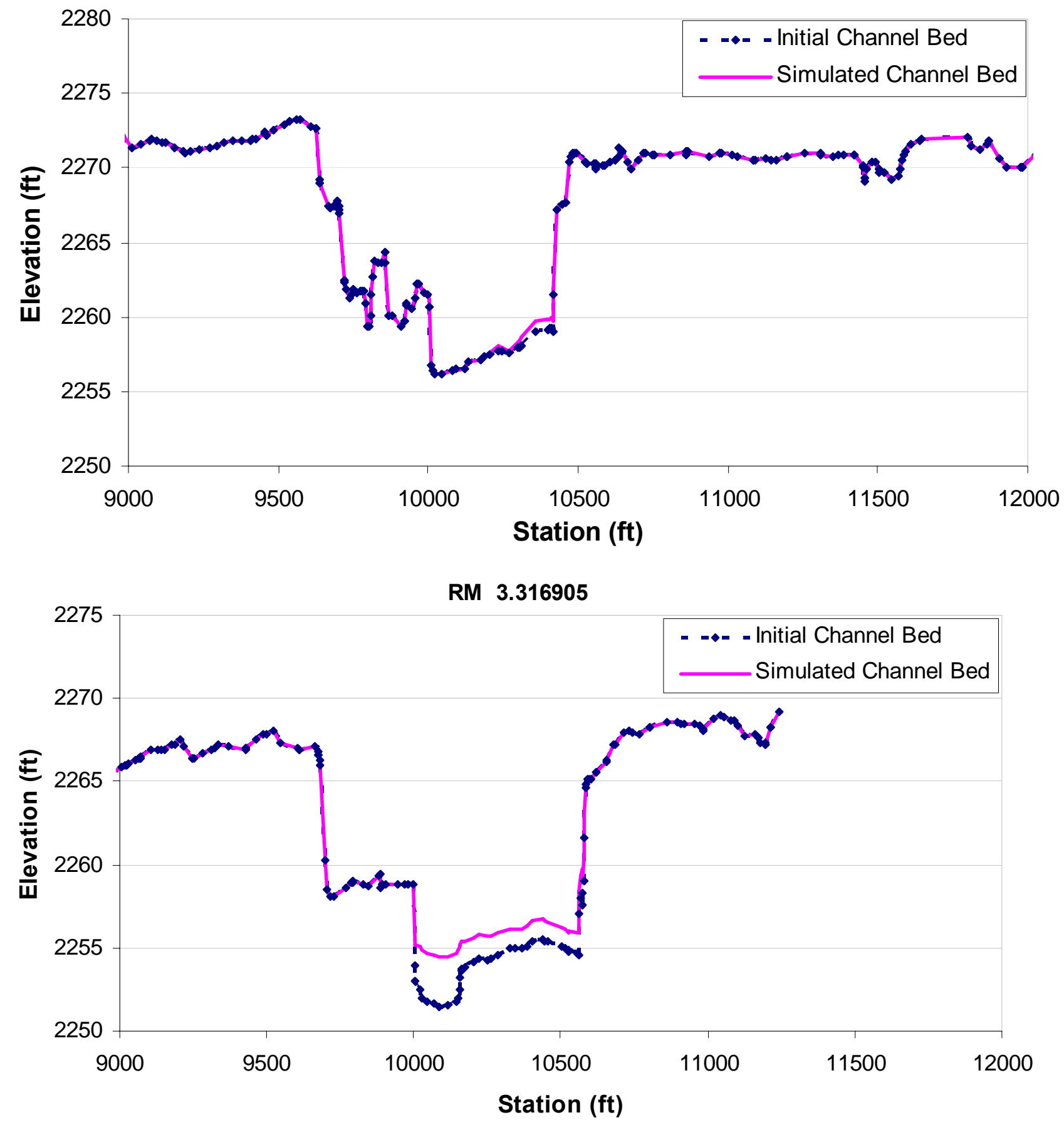

Figure G. 22. Changes of cross sections at River Mile 3.507 and 3.317 

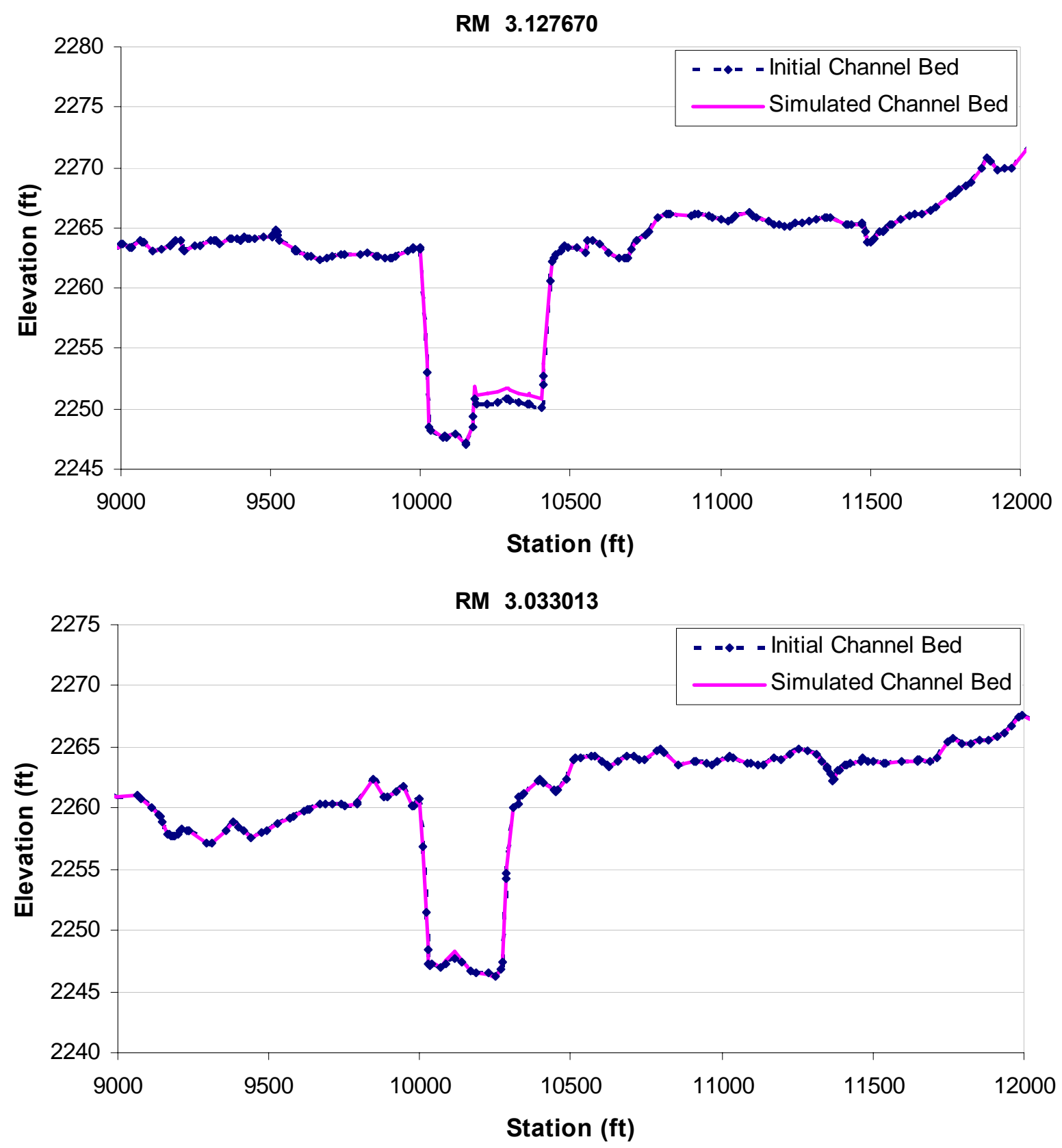

Figure G. 23. Changes of cross sections at River Mile 3.128 and 3.033 

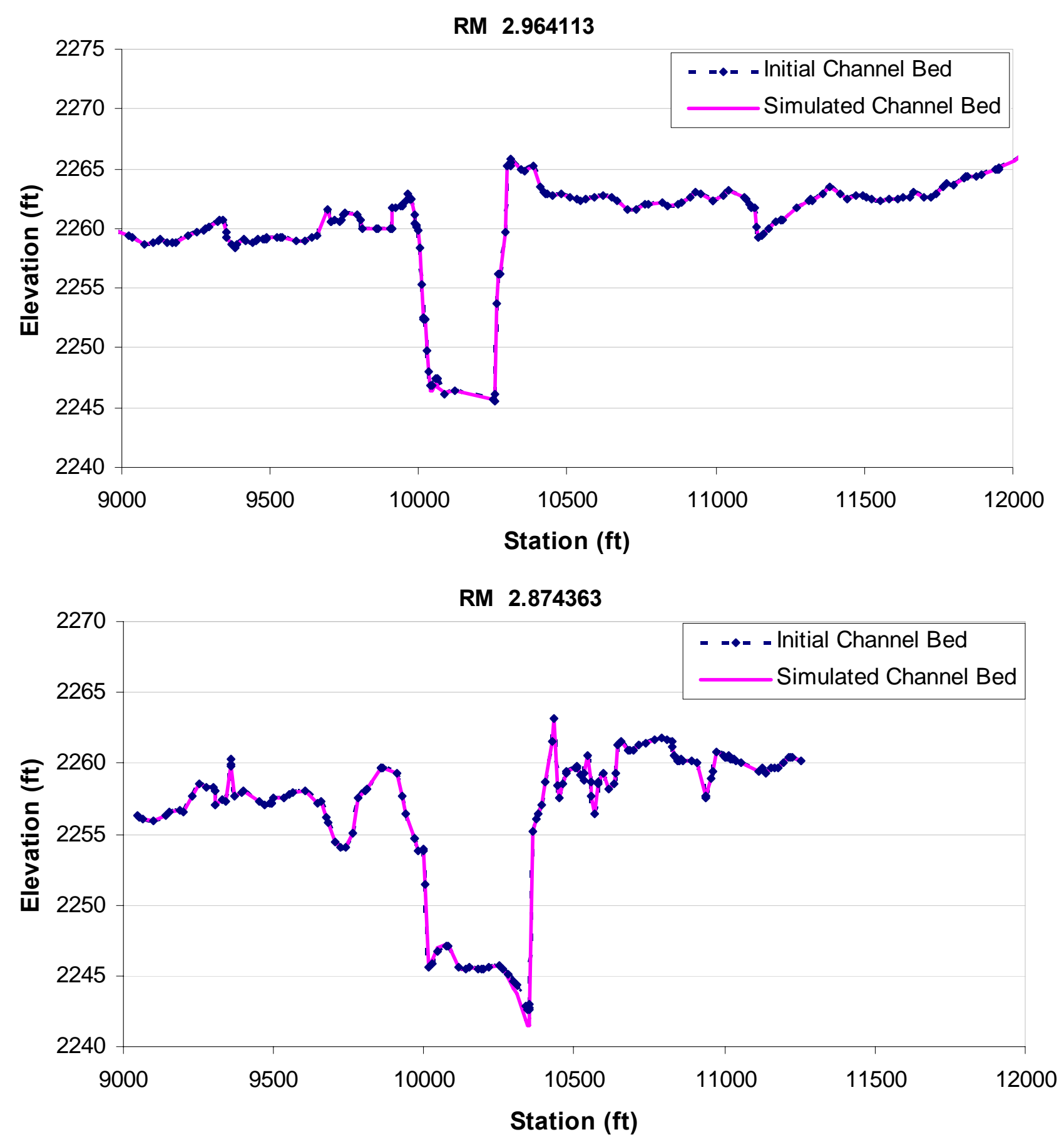

Figure G. 24. Changes of cross sections at River Mile 2.964 and 2.874 

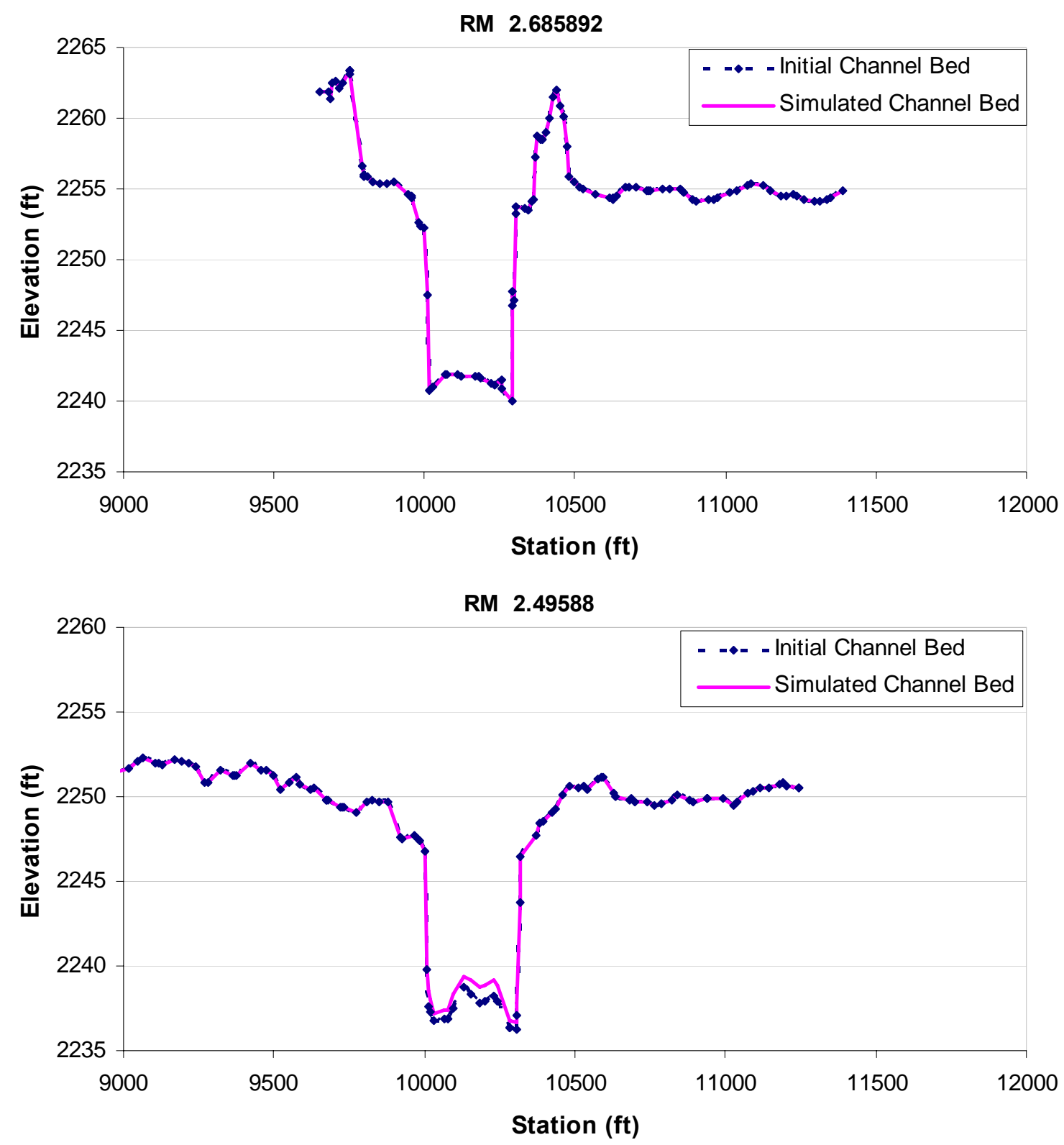

Figure G. 25. Changes of cross sections at River Mile 2.686 and 2.496 
RM 2.306653
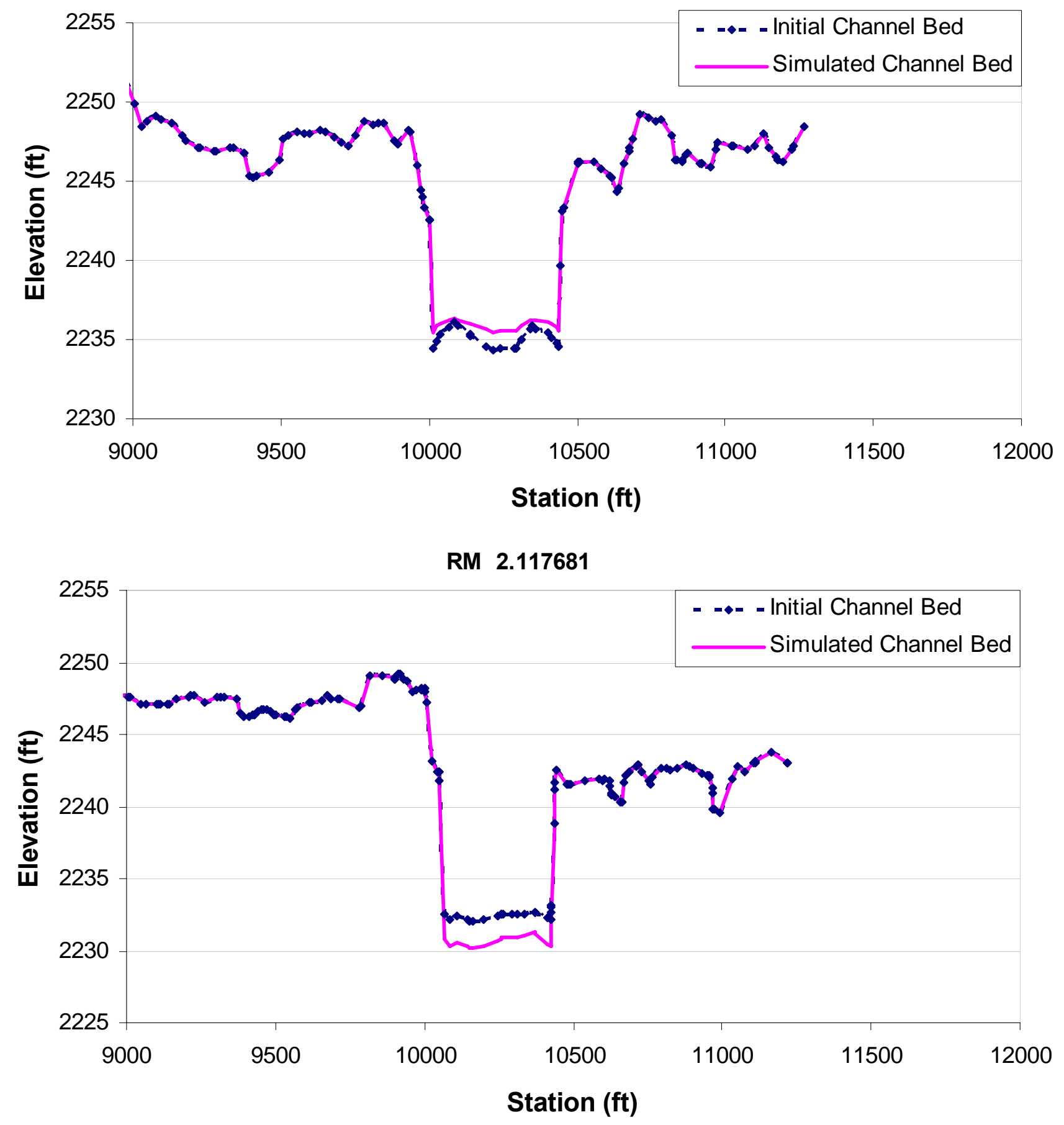

Figure G. 26. Changes of cross sections at River Mile 2.307 and 2.118 

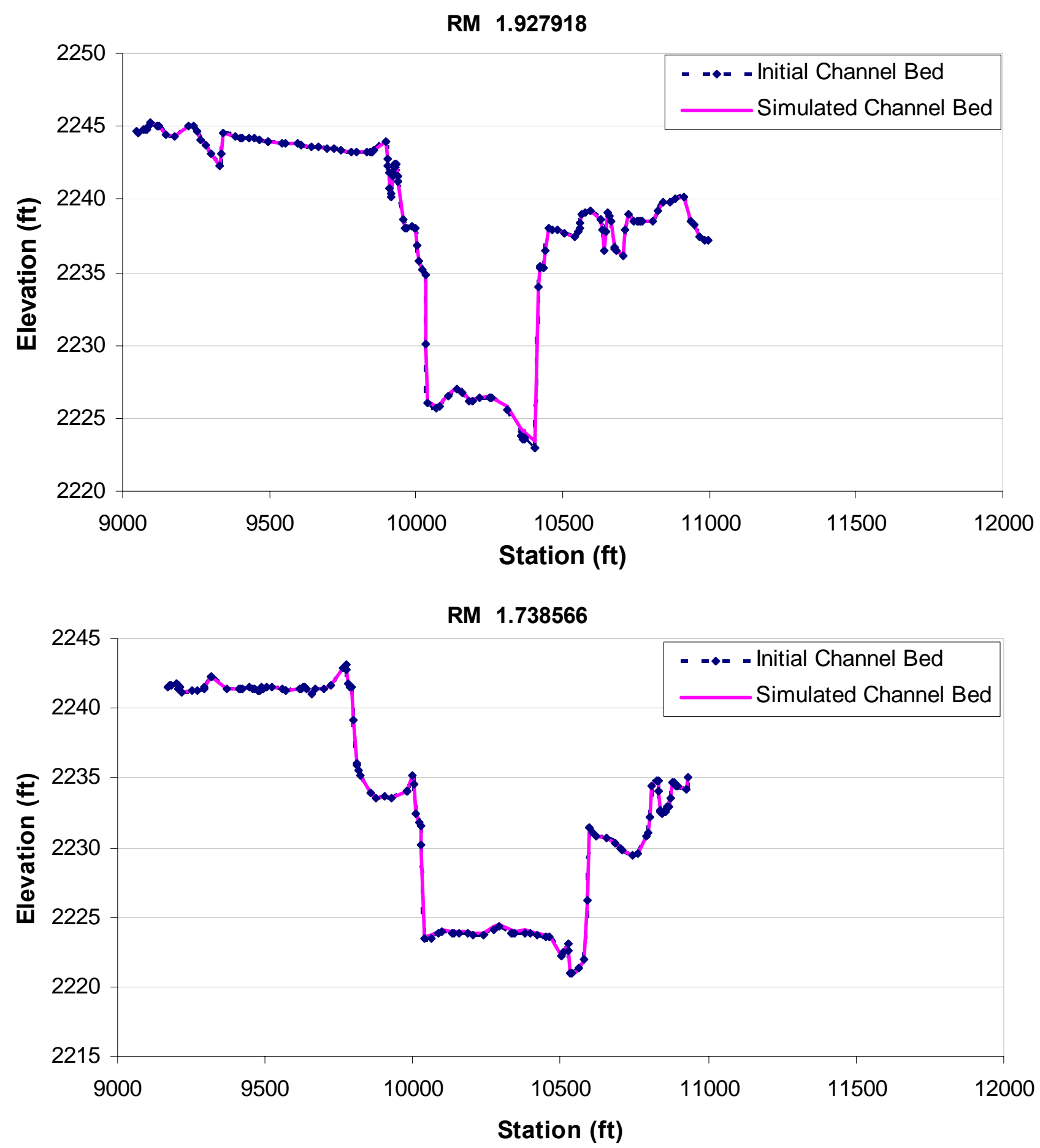

Figure G. 27. Changes of cross sections at River Mile 1.928 and 1.739 

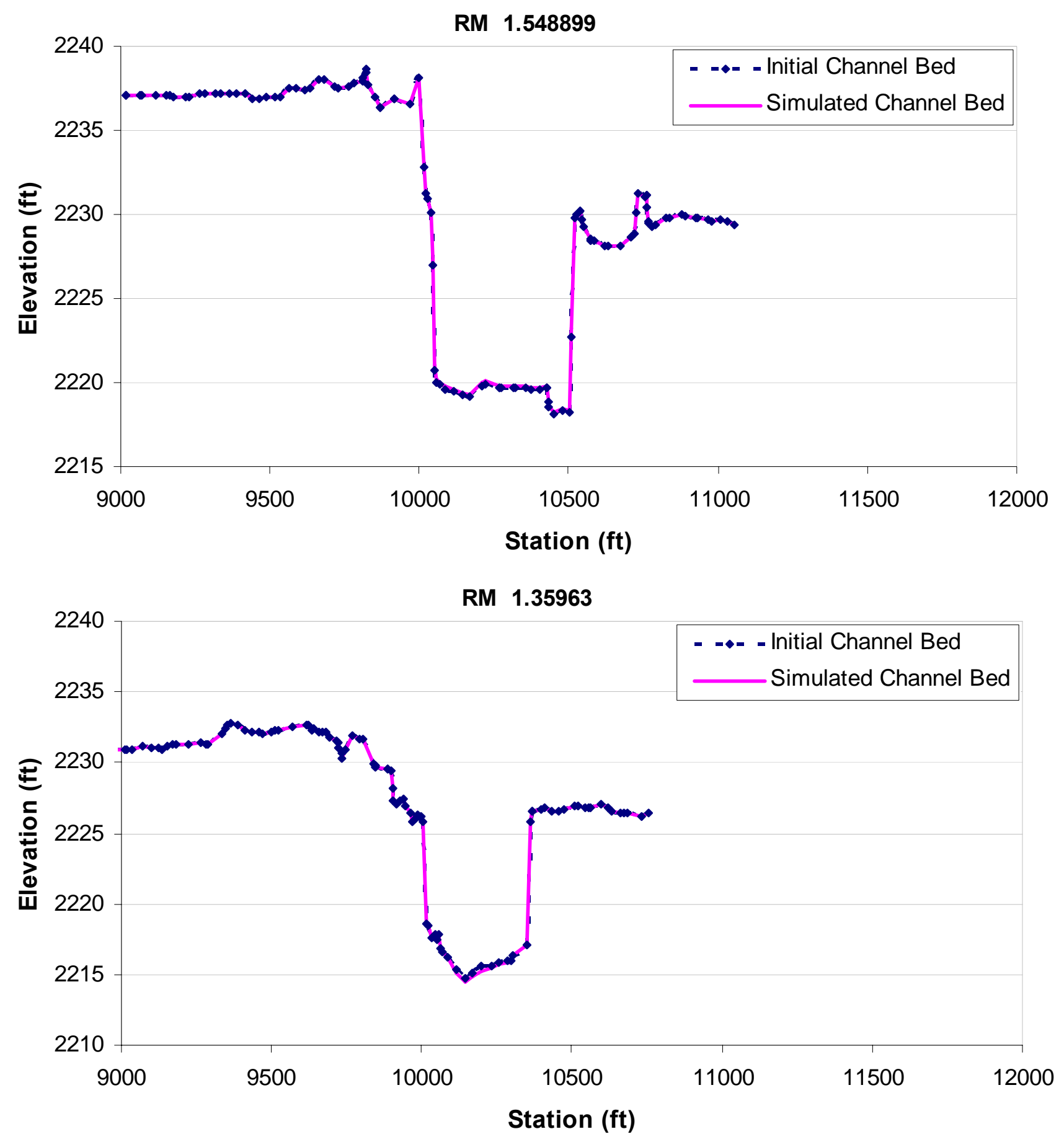

Figure G. 28. Changes of cross sections at River Mile 1.549 and 1.360 

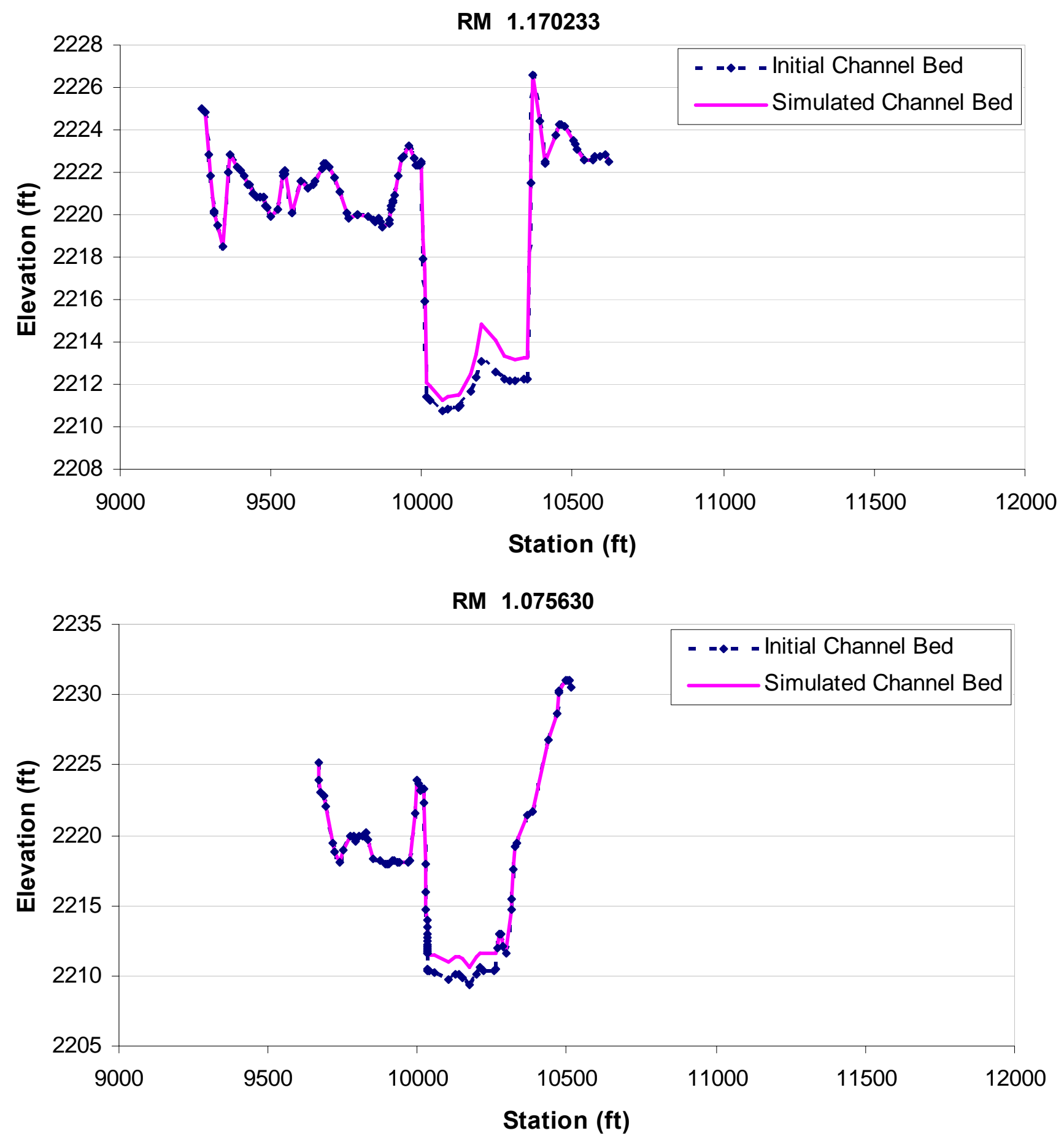

Figure G. 29. Changes of cross sections at River Mile 1.170 and 1.076 

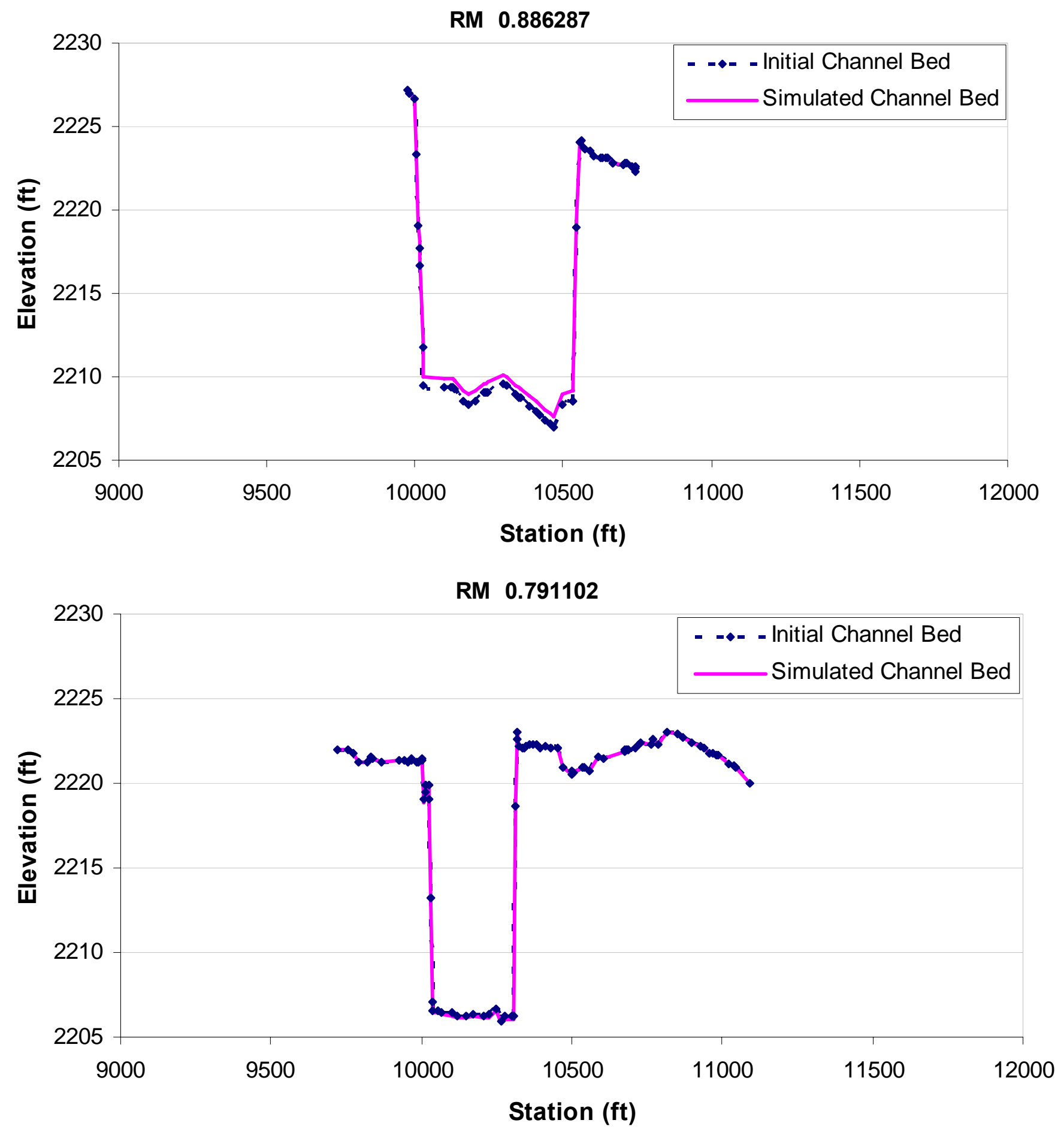

Figure G. 30. Changes of cross sections at River Mile 0.886 and 0.791 
RM 0.785054
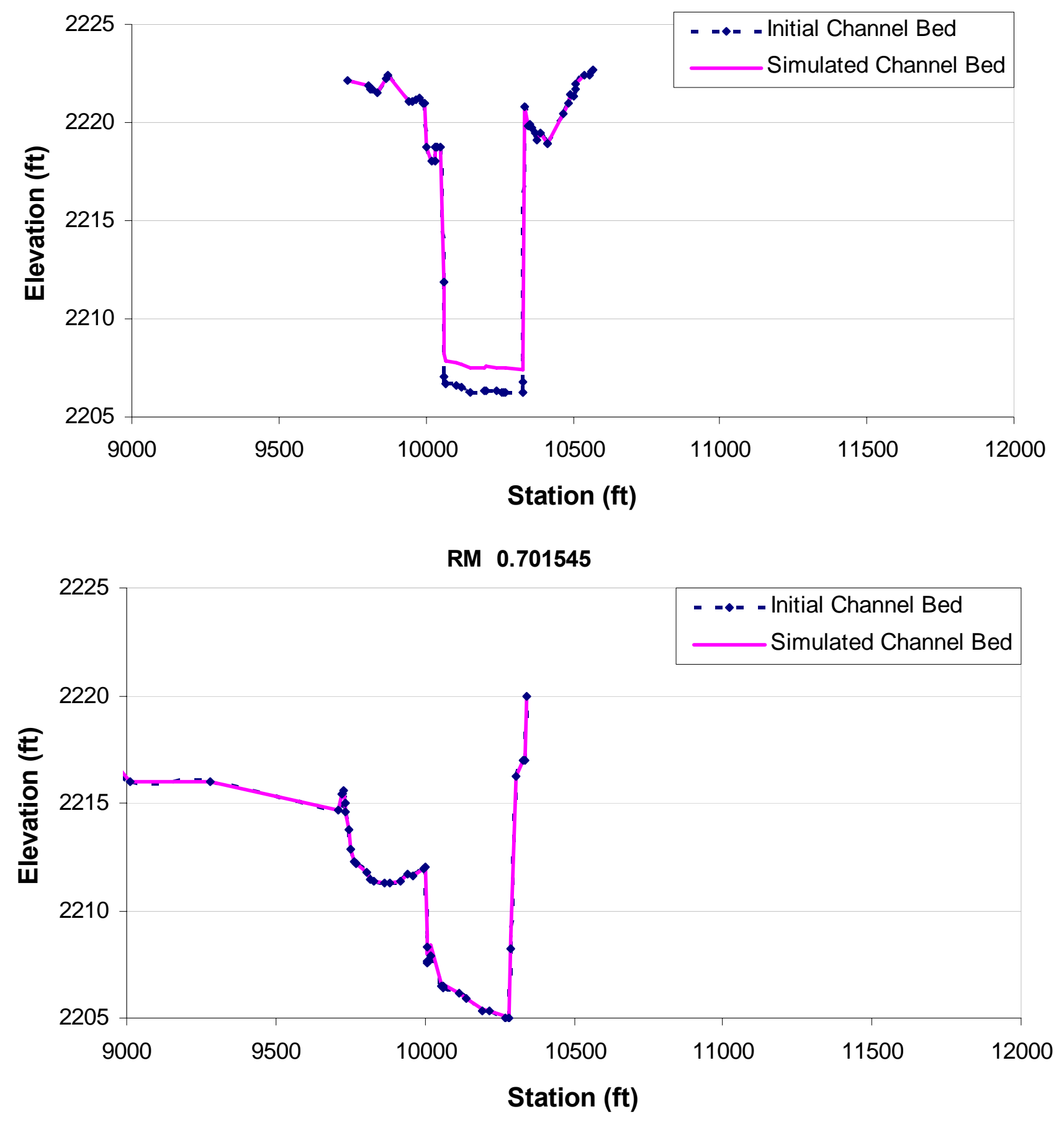

Figure G. 31. Changes of cross sections at River Mile 0.785 and 0.701 

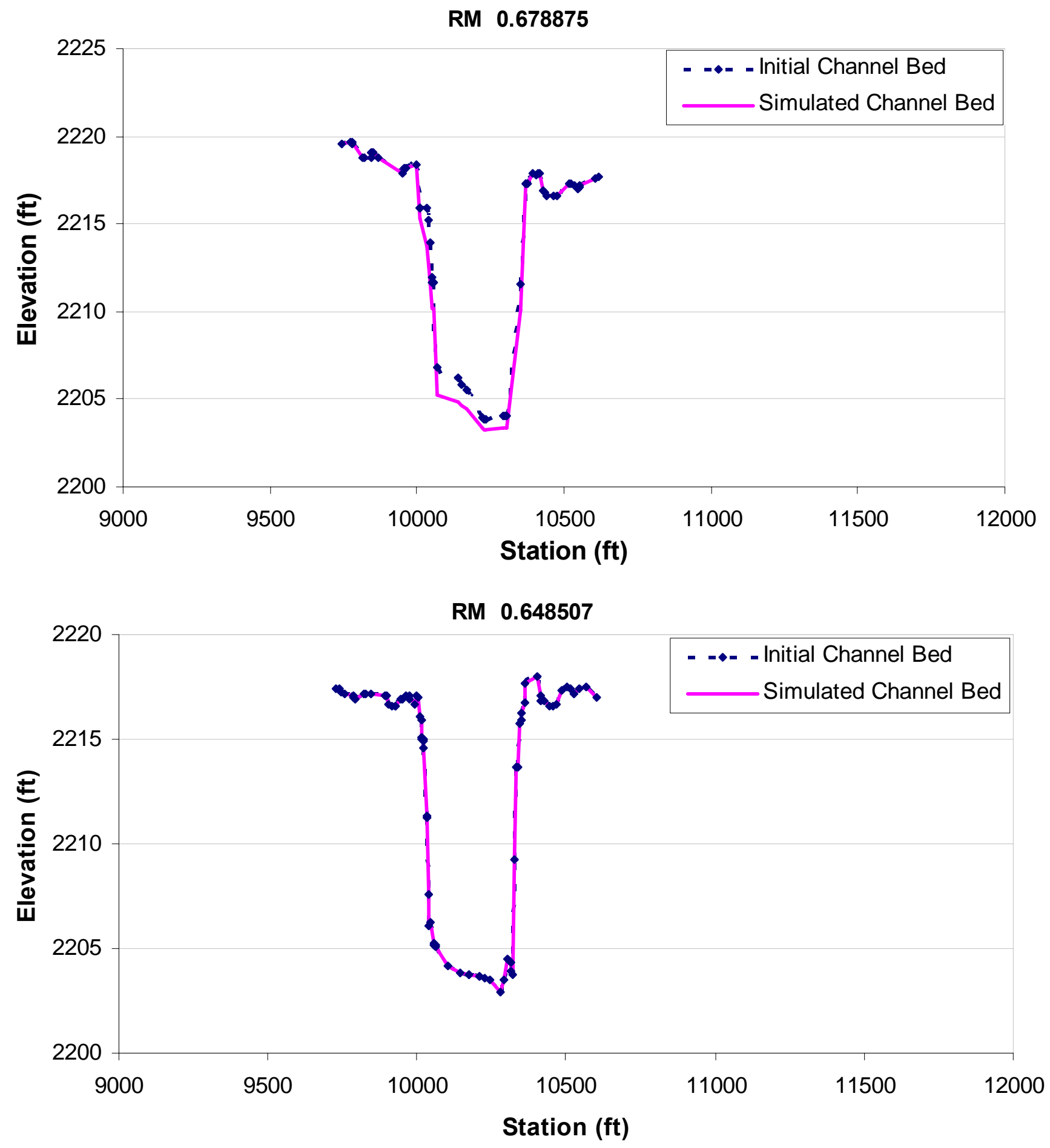

Figure G. 32. Changes of cross sections at River Mile 0.679 and 0.649 